Erster Beratungsgegenstand:

\title{
Erziehungsauftrag und Erziehungsmaßstab der Schule im freiheitlichen Verfassungsstaat
}

1. Bericht von Prof. Dr. Michael Bothe, Frankfurt/Main

\section{Inhalt}

Seite

1. Einführung: Vom Sinn des Themas $\ldots \ldots \ldots \ldots \ldots \ldots . . .8$

2. Gesellschaftliche Herausforderungen an das Erziehungs-

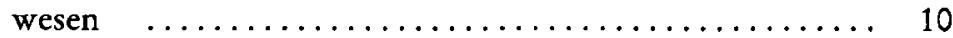

2.1 Die gesellschaftliche Binnenproblematik ....... 10

2.2 Die Außenproblematik ............... 16

3. Der staatliche Erziehungsauftrag $\ldots \ldots \ldots \ldots \ldots \ldots \ldots \ldots 17$

4. Erziehungsmaßstäbe $\ldots \ldots \ldots \ldots \ldots \ldots \ldots \ldots \ldots \ldots \ldots \ldots$

4.1 Sinn und Unsinn rechtlich festgelegter Erziehungsmaßstäbe und -ziele ................... 22

$4.2 \quad$ Erziehungsziele im pluralistischen Staat . . . . . . . 29

$4.3 \quad$ Einzelne Erziehungsziele $\ldots \ldots \ldots \ldots \ldots \ldots \ldots \ldots$

4.3.1 Erziehungsziel: kritische, verantwortliche und gemeinschaftsorientierte Selbstverwirklichung ... 32

4.3.2 Erziehungsziel: moderne Industrie- und Informationsgesellschaft .............. 35

4.3.3 Erziehung in der multikulturellen Gesellschaft .... 36 4.3.3.1 Multikulturalität in der Erziehung . ..... 36

4.3.3.2 Multikulturalität als Erziehungsziel ...... 40

4.3.4 Erziehungsmaßstab Europa ............ 40

4.3.5 Erziehung zu Frieden und Völkerverständigung ... 41

4.4 Zur Bedeutung von Erziehungszielen - eine Schlußbetrachtung $\ldots \ldots \ldots \ldots \ldots \ldots \ldots \ldots \ldots 41$ 


\section{Einführung: Vom Sinn des Themas}

Selten ist es dem Vorstand unserer Vereinigung gelungen, ein Thema so zeitgenau zu plazieren: Heute ist, von der UNESCO proklamiert, der Internationale Tag des Lehrers' ${ }^{1}$.

Besteht kraft Verfassung ein staatlicher Erziehungsauftrag? Die bejahende Antwort auf diese Frage ist weitgehendes Allgemeingut der Verfassungsinterpreten.

Schwieriger ist die Frage nach den Erziehungsmaßstäben zu beantworten, da eine inhaltliche Festsetzung solcher Maßstäbe sich an dem Gebot der Ermöglichung von Pluralismus und an der weltanschaulichen Neutralität des Staates zu stoßen scheint. Dies ist in der Vergangenheit hitzig und ausgiebig, unter Beteiligung vieler prominenter Mitglieder unserer Vereinigung diskutiert worden². Was kann uns veranlassen, diese beiden Fragen gerade heute wieder aufzunehmen? Ist es ein archäologisches Interesse, wichtige Debatten nicht in Vergessenheit geraten zu lassen?

Ein derartiges Interesse ist jedenfalls nicht allein geeignet, die Beschäftigung unserer Vereinigung mit diesem Gegenstand zu rechtfertigen. Es ist vielmehr die Tatsache, daß die Erziehung in der "social fabric" eine Schlüsselrolle einnimmt, wie auch immer man die Anforderungen der Gesellschaft und des politischen Systems an die Schule definiert ${ }^{3}$. „Was Hänschen nicht lernt, lernt Hans nimmer mehr“. Oder: „Wer die Schule hat, hat die Zukunft" ${ }^{\text {" }}$. Das bedeutet zweierlei: Die Frage nach der Rolle der Schule in der Gesellschaft ist eine politische Frage, die mit Mitteln des Rechts zu definieren und zu steuern der Rechtstaat in Anspruch nehmen muß. Zum zweiten ist diese Rolle und sind damit Inhalte schulischer Bil-

1 Vereinte Nationen 42 (1994), S. 162.

2 Vgl. zusammenfassend Peter Häberle, Erziehungsziele und Orientierungswerte im Verfassungsstaat, 1981. Aus der kaum überschaubaren Literatur der 70er Jahre seien insbes. genannt: Hans Ulrich Evers, Die Befugnis des Staates zur Festlegung von Erziehungszielen in der pluralistischen Gesellschaft, 1979; Thomas Oppermann, Nach welchen rechtlichen Grundsätzen sind das öffentliche Schulwesen und die Stellung der an ihm Beteiligten zu ordnen? Gutachten C für den 51. Deutschen Juristentag, 1976; Kommission Schulrecht des Deutschen Juristentages, Schule im Rechtsstaat, Bd. 1: Entwurf für ein Landesschulgesetz, 1981.

${ }^{3}$ Dazu eingehend Günter Frankenberg, Verrechtlichung schulischer Bildung. Elemente einer Kritik und Theorie des Schulrechts, Diss. München 1978, S. 96 ff.; vgl. auch Peter Huber, Erziehungsauftrag und Erziehungsmaßstab der Schule im freiheitlichen Verfassungsstaat, BayVBl. 1994, S. 545.

4 Vgl. etwa Adolf Arndt, Aufgaben und Grenzen der Staatsgewalt im Bereich der Schulbildung, in: ders. (Hrsg.), Politische Reden und Schriften, 1976, S. 203 ff., 208; skeptisch dazu Ingo Richter, Sitzungsbericht M zum 51. DJT 1976, M 26; Evers, a. a. O. (Fn. 2), S. 92 m. w. N. 
dung und Ausbildung historisch bedingt oder historisch gefordert. "Vitae discimus" heißt Lernen für ein prognostiziertes, nicht für ein abstraktes Leben.

Schule soll und will befähigen zur Bewährung im persönlichen, gesellschaftlichen, politischen und beruflichen Leben in ihrer Zeit. Im Erziehungswesen ist die Debatte um Reformen stets geführt worden im Hinblick auf die sich wandelnden Anforderungen der Gesellschaft an das Erziehungssystem ${ }^{5}$.

Folglich ist die Frage nach dem Erziehungsauftrag und noch mehr die nach Erziehungsmaßstäben eine Frage danach, ob und wie die Schulen den Herausforderungen gerecht werden, die die gesellschaftlichen Probleme in einer bestimmten historischen Situation erzeugen. Das heißt, daß sie sich wandeln. Also: "schola semper reformanda"? Es wird manche reformgeplagte Eltern schaudern lassen, aber in Abständen muß das schon sein. In der Tat haben sich seit den heftigen Debatten der 70er Jahre um rechtliche Vorgaben des Erziehungswesens einige wesentliche gesellschaftliche Rahmenbedigungen gewandelt ${ }^{6}$.

Wenn wir also nach dem Wandel des verfassungsrechtlich verankerten Erziehungsauftrages und der aus dem Grundgesetz ableitbaren Erziehungsmaßstäbe fragen, so bedeutet das zugleich die Frage danach, ob und wie denn die Verfassung einen solchen fordern, wie weit sie ihn gar bewirken kann. Also nicht nur Wandel der Verfassung, auch Wandel durch Verfassung ist gefragt. Auch damit sind wir bei einer alten Streitfrage ${ }^{7}$.

Damit ergibt sich der Gang unserer Überlegungen. Wir müssen zunächst einen Blick auf die soziale Wirklichkeit werfen und uns fragen, welche Probleme einer Lösung harren, die, jedenfalls auch, eine Herausforderung an das Erziehungssystem darstellen. Es sind gesellschaftliche Krisenphänomene, die unsere heutige Beschäftigung mit dem Thema erfordern. Ein Blick auf diese Krisenphänomene und Zukunftsprobleme ist darum der erste Schritt unserer Überlegungen. Im Anschluß daran ist der Normbestand, der den Rahmen des Erziehungswesens darstellt, darauf zu überprüfen, ob er Direktiven bereithält oder bereithalten könnte, die zur Bewältigung jener Herausforderungen beitragen könnten, und welchen Grenzen solche Direktiven unterliegen. Da es sich zum großen Teil

5 Vgl. OECD, The Curriculum Redefined: Schooling for the 21st century, 1994, insbes. S. 9 ff., 20 ff., 29, 41 ff.; Lutz-Rainer Reuter, Bildung zwischen Politik und Recht, in: Rüdiger Voigt (Hrsg.), Verrechtlichung, 1980, S. $116 \mathrm{ff.}, 118$.

6 Dazu sogleich unter 2.1, vgl. insbes. die Nachw. Fn. 11-15.

7 Die Frage, ob sich durch einen stillen Verfassungswandel oder eher durch einen Wandel der Verfassungsinterpretation die verfassungsrechtlichen Vorgaben des Bildungswesens geändert hatten, war in den 70er Jahren umstritten, vgl. dazu Oppermann, DJT 51 (1976), C 18. 
um Strukturprobleme handelt, die den Gesellschaften der entwickelten Industriestaaten gemeinsam sind, wird es dabei auch rechtsvergleichende Ausblicke geben müssen. Ebenso sind Direktiven nicht nur im nationalen Recht, sondern auch im Europa- und Völkerrecht zu suchen. Bei alledem ist nicht nur nach dem Inhalt solcher Direktiven zu fragen, sondern auch ihre Brauchbarkeit als gesellschaftliches Steuerungsmittel kritisch zu beleuchten.

\section{Gesellschaftliche Herausforderungen an das Erziehungswesen}

Es gibt viele große und kleine Herausforderungen, denen wir die uns folgende Generation ausgesetzt sehen und für die darum die Schule vorbereiten sollte. Lassen Sie mich davon nur einige wenige herausgreifen, deren zentrale Bedeutung wohl niemand bestreiten wird, bei allen Kontroversen, die über die Bewertung im einzelnen bestehen. Der erste Problemkomplex betrifft den Wandel gsellschaftlicher Strukturen in den westlichen Industriestaaten (innere Problematik), der zweite die Stellung Deutschlands und Europas in der Welt (äußere Problematik).

\subsection{Die gesellschaftliche Binnenproblematik}

Die innergesellschaftliche Problematik sei mit drei Stichworten schlaglichtartig beleuchtet: Deutschland - ein Land von Singles, von Konsumenten und ein Altenheim. Man kann auch die ersten beiden Stichworte zusammenfassen: ein Land von Selbstverwirklichern. Das dritte Element der gesellschaftlichen Entwicklung ist nicht nur eine Folge des Fortschritts der Medizin, sondern auch eine solche der beiden ersten, welche das Reproduktionsverhalten unserer Gesellschaft nachhaltig beeinflußt haben.

Zur Verdeutlichung der Stichworte: Die gesellschaftliche Entwicklung der westlichen Industriestaaten ist in diesem Jahrhundert sehr stark von Enttraditionalisierung und Individualisierung, von dem Prinzip persönlicher Autonomie geprägt ${ }^{8}$. Die weit zurückreichenden historischen und geistesgeschichtlichen Wurzeln dieser Entwicklung sind hier nicht dar-

${ }^{8}$ Helmut Klages, Traditionsbruch als Herausforderung. Perspektiven der Wertewandelgesellschaft, 1993, insbes. S. 9 ff., 253 ff.; Wolfgang Brezinka, Erziehungsziele heute - Problematik und Leitlinien, Pädagogische Rundschau 45 (1991), S. 561, 573; zur Geschichte und Problematik der Individualisierung vgl. Ulrich Beck, Risikogesellschaft - Auf dem Weg in eine andere Moderne, 1986, S. $130 \mathrm{ff}$., $157 \mathrm{ff}$.; vgl. ferner Norbert Elias, Die Gesellschaft der Individuen, 1987, insbes. S. $207 \mathrm{ff}$. 
zustellen'. Die empirische Sozialforschung weist in den 60er Jahren einen deutlichen Schub dieser Entwicklung nach, weg von Pflicht- und Akzeptanzwerten, hin zu Selbstentfaltungswerten. Dieser Trend ist ungebrochen, aber es sind seit den 60er Jahren Ändergunen eingetreten. Die Propagierung der Selbstentfaltungswerte in den 60er und 70er Jahren war sehr stark durch reformerischen Schwung, durch Utopien gekennzeichnet. Deshalb wurde sie auch als politischer Konfessionalismus kritisiert ${ }^{10}$. Die konservative Kritik betonte demgegenüber jedenfalls im Streit um Bildungsreformen ${ }^{11}$ den Pluralismus, während sie in anderen Bereichen stärker wertbezogen argumentierte ${ }^{12}$. Dieser Elan hat jedoch nachgelassen, es wird die "Erschöpfung utopischer Energien" konstatiert ${ }^{13}$, eine Pluralisierung der Selbstentfaltungswerte ${ }^{14}$ mit stärkerer Betonung hedonistischer Elemente, eine verbreitete Orientierungslosigkeit sind festzustellen. Die genaue Tragweite dieses Befundes und seine Bezeichnung als Postmoderne sind umstritten ${ }^{15}$. Neokonservative Ansätze betonen in dieser Situation nicht Pluralismus, sondern Besinnung auf historische Werte ${ }^{16}$.

9 Eine summarische Übersicht bei $H$. Klages, a. a. O. (Fn. 8), S. $253 \mathrm{ff.}$

10 Vgl. die Nachweise bei Martin Stock, Die pädagogische Freiheit des Lehrers im Lichte des schulischen Bildungsauftrags, RdJb 1986, S. $212 \mathrm{ff}$., 217; gegen eine solche Charakterisierung nachdrücklich Lutz Dietze, Die Reform der Lehrinhalte als Verfassungsproblem, 1976, insbes. S. $183 \mathrm{f}$.

11 Oppermann, a. a. O. (Fn. 2), insbes. S. 94 ff.; Günter Püttner, Toleranz als Verfassungsprinzip, 1977, S. 50; ders., Toleranz und Lehrpläne für Schulen, DÖV 1974, S. $656 \mathrm{ff}$;; eher an der Erhaltung traditioneller Werte orientiert ist der Ansatz von Wolfgang Brezinka, Die Pädagogik der Neuen Linken, 6. Aufl. 1981, insbes. S. 222 ff.; zur Kritik am konservativen Pluralismus-Ansatz, Friedhelm Hase / Karl-Heinz Ladeur, Verfassungsfragen der Curriculum-Revision - Zur juristischen Sanktionierung einer harmonisierenden Pädagogik, KJ 1976, S. 19 ff.; insbes. S. 25 ff.; Lutz Dietze, Verfassungsfragen lernzielorientierter Curricula, DVBl. 90 (1975), S. 389 ff., $401 \mathrm{ff.}$

12 Vgl. vor allem konservative Positionen in der sog. Grundwerte-Diskussion, vgl. Helmut Kobl, Freiheit, Solidarität, Gerechtigkeit, in: Günter Gorschenek (Hrsg.), Grundwerte in Staat und Gesellschaft, 1977, S. 52 ff.; Hans Maier, Zur Diskussion über die Grundwerte, ebd. S. 172 ff.; A. v. Campenbausen, Grundwerte in Staat und Gesellschaft, ebd. S. $190 \mathrm{ff}$. Dies gilt insbes. für den Streit um das Abtreibungsrecht.

${ }^{13}$ Jürgen Habermas, Die neue Unübersichtlichkeit, 1985, S. 141 ff., ebenso Beck, a. a. O. (Fn. 8), S. 309.

${ }^{14}$ H. Klages, a. a. O., S. 31 ff.; Thomas Gensicke, Wertewandel und Familie. Auf dem Weg zu "egoistischem" oder "kooperativem" Individualismus?, Aus Politik und Zeitgeschichte B 29-30/94, S. $36 \mathrm{ff}$.

15 Wolfgang Welsch, Unsere postmoderne Moderne, 3. Aufl. 1991, S. 79 ff., 149 ff., $162 \mathrm{ff}$;; skeptisch gegenüber der These von der Postmoderne Habermas, a. a. O. (Fn. 13), S. 145; ablehnend H. Klages, a. a. O. (Fn. 8), S. 9 ff., 262.

${ }^{16}$ Habermas, a. a. O. (Fn. 13), S. $39 \mathrm{ff}$. 
Für das Erziehungswesen ist zunächst von Bedeutung, wie sich die stärkere Betonung von Selbstentfaltungswerten auf die elterliche Erziehung auswirkt. In ihrer persönlichen Autonomie sind Mann und Frau gleich. Traditionelle Rollenverteilung in der Familie ist mit diesem Prinzip unvereinbar. Gebundenheit und Geborgenheit in vorgefundenen gesellschaftlichen Gruppen (Ehe, Familie, Großfamilie), in die man hineingeboren wird oder hineinheiratet, werden als Bedrohung der persönlichen Autonomie, als Gefahr für die Selbstverwirklichung empfunden. Als Folge dieser Entwicklung ist das Ende der Familie oder der familiären Bindung konstatiert oder prognostiziert worden. Das war wohl nicht ganz richtig ${ }^{17}$. Sicher ist der Verzicht auf familiäre Bindung eine verbreitete Option (Singles), die übrigens nicht notwendig den Verzicht auf Kinder bedeutet. Die familiäre oder familienähnliche Bindung bleibt aber erwünscht, sie verändert sich jedoch. Statt der Exklusivität der Familie mit etablierter Rollenverteilung finden wir eine breite Variationsbreite von Verbindungsformen eigener Wahl - Wahlverwandtschaften als postfamiliale Familie ${ }^{18}$. Die unterschiedlichen Formen der Liquidation der zahlreichen gescheiterten Ehen und anderen Lebensgemeinschaften verstärken die Buntheit des Bildes.

Für den Juristen hat diese Entwicklung allerlei Probleme mit sich gebracht, die bekannt und hier nicht auszubreiten sind. Auch die Verfassungsgebung hat darauf reagiert, so etwa die neue Verfassung des Landes Brandenburg à la carte:

„Art. 26 (Ehe, Familie und Lebensgemeinschaften):

(1) Ehe und Familie sind durch das Gemeinwesen zu schützen und zu fördern. Besondere Fürsorge wird Müttern, Alleinerziehenden und kinderreichen Familien sowie Familien mit behinderten Angehörigen zuteil.

(2) Die Schutzbedürftigkeit anderer auf Dauer angelegter Lebensgemeinschaften wird anerkannt ${ }^{19}$.

Für das Erziehungswesen hat diese Entwicklung zwei ganz wesentliche Konsequenzen. Zum ersten stellt sich die Frage nach dem Träger des

\footnotetext{
17 Hans Bertram, Die Stadt, das Individuum und das Verschwinden der Familie, Aus Politik und Zeitgeschichte B 29-30/94, S. $15 \mathrm{ff}$.

${ }^{18}$ Beck, a. a. O. (Fn. 8), S. 189 ff.; Elisabeth Beck-Gernsheim, Auf dem Weg in die postfamiliale Familie. Von der Notgemeinschaft zur Wahlverwandtschaft, Aus Politik und Zeitgeschichte B 29-30/94, S. 3 ff.; dies., Arbeitsteilung, Selbstbild und Lebensentwurf, Neue Konfliktlagen in der Familie, Kölner Zeitschrift für Soziologie und Sozialpsychologie 44 (1992), S. $273 \mathrm{ff}$.

19 Hervorhebung vom Verf. Ob der Ausschluß des Vaters von der besonderen Fürsorge verfassungsgemäß ist, kann hier nicht diskutiert werden.
} 
Elternrechts ander ${ }^{20}$ als in einer Zeit mit klarer familiärer Rollenverteilung. Zum zweiten - und hier wird es noch problematischer - ist nach den Konsequenzen dieser Entwicklung für das Verhältnis zwischen Elternrecht und staatlichem Erziehungsauftrag zu fragen. Setzt die prinzipielle Gleichordnung von staatlicher Schulhoheit und Elternrecht ${ }^{21}$ eine hinreichend leistungsfähige Familie voraus und trifft, so könnte man fragen, diese Voraussetzung für die postfamiliale Familie zu? Oder geht mit dem Anspruch auf den Kindergartenplatz der Verzicht auf den elterlichen Erziehungsvorrang einher? Entsteht gar durch die Schwäche der postfamilialen Familie ein erzieherisches Vakuum, in das der Staat eintreten muß? Hier kann man nur davor warnen, das Kind mit dem Bade auszuschütten. Die geschilderte Entwicklung darf nicht zu einem Eindringen des Staates in den Privatbereich der elterlichen Erziehung führen.

Fragen wir weiter nach den inhaltlichen Anforderungen, die der Trend zu Selbstentfaltungswerten für die schulische Erziehung zur Folge haben könnte, gilt es die Probleme zu erfassen, die der Trend für die Gesellschaft und für die zu Erziehenden mit sich bringt. Drei Problembereiche sind vor allem zu nennen: Gemeinsinndefizit, Verlust an Urteilsfähigkeit und Reaktion auf frustrierte Selbstentfaltung.

Zum ersten: Selbstentfaltung ist ein relativ offenes, wertneutrales Konzept $^{22}$. Wo sie aber ausgeübt wird im Sinne von Konsum und Anspruchsdenken, bleibt Gemeinsinn auf der Strecke. Eben dies ist ein wesentliches Problem der postmodernen Gesellschaft. „Wir amüsieren uns $\mathrm{zu}$ Tode ${ }^{\text {“23 }}$, lautet ein bezeichnender Buchtitel. So ist denn bedauernd festgestellt worden, der beschriebene Wertewandel habe zu einem dramatischen Rückgang von Hinnahme- und Folgenbereitschaft geführt, der das Mindestmaß an Gemeinschaftsethos aufzulösen drohe, das den Staat bislang zusammengehalten habe ${ }^{24}$.

Diese Aussage ist zu undifferenziert. Es gibt Selbstverwirklichung im Dienste der Gemeinschaft. Zum anderen muß natürlich gefragt werden, welches Maß an Gemeinsinn für eine pluralistische Gesellschaft wirklich

${ }^{20}$ Vgl. dazu Hans-Walter Schlie, Elterliches Erziehungsrecht und staatliche Schulaufsicht im Grundgesetz, 1986, S. 15 ff.: verheiratete Eltern, geschiedene Eltern, nichtehelicher Vater.

${ }^{21}$ S. u. 3., insbes. die Nachw. Fn. 61.

22 Klages, a. a. O. (Fn. 8), S. 31.

${ }^{23}$ Neil Postman, Amusing Ourselves to Death, Public Discourse in the Age of Show Business, 1985; deutsche Übersetzung: Wir amüsieren uns zu Tode, Urteilsbildung im Zeitalter der Unterhaltungsindustrie, 1992.

${ }^{24}$ Brezinka, a. a. O. (Fn. 8), S. 574. 
unverzichtbar ist ${ }^{25}$. Ein gewisses Maß an Konflikt, d. h. Dissens braucht diese Gesellschaft, daraus schöpft sie ihre Entwicklungsmöglichkeiten. Sie ist aber auf die Einhaltung von Spielregeln einer Konfliktkultur und auf das „Mitmachen“, d. h. auf Partizipation angewiesen, genauso wie der Markt seine wohlstandsstiftende Funktion für alle nur erfüllen kann, wenn genügend Marktteilnehmer mitspielen und sich dabei an gewisse Regeln halten. Eine Selbstentfaltung, die sich der Gemeinschaft verweigert, die Freiheit ohne Verantwortung will, ist ein wesentliches Problem unserer Gesellschaft.

Zum zweiten: Eine wesentliche Voraussetzung der Partizipation ist Information und ihre Verarbeitung. Die moderne Informationsgesellschaft könnte wie nie zuvor Chancen für den umfassend informierten, und deshalb kritisch partizipierenden Bürger bieten. Doch das Gegenteil ist der Fall. Auch Information wird konsumiert, Information ist Unterhaltung (und was für eine: Stichwort Reality TV), Unterhaltung ist Kommerz ${ }^{26}$. Die Rolle der audiovisuellen Medien führt zu einem starken Verlust an Urteilskraft, zu Unmündigkeit und Passivität ${ }^{27}$. Die kritische Auswahl und Verarbeitung von Information ist ein wesentliches Problem unserer Gesellschaft ${ }^{28}$.

Zum dritten: Enttraditionalisierung, das Verneinen von traditionellen Bindungen und das Schwinden von Sicherheit, die durch traditionelle Rollenverteilung vermittelt wurde, führen zu einer kühlen Gesellschaft, $\mathrm{zu}$ Vereinsamungsphänomenen und Beziehungslosigkeit. Auch die Betonung von Selbstentfaltungswerten führt zu Frustrationen, wo in der gesellschaftlichen Wirklichkeit Selbstentfaltung an Grenzen stößt ${ }^{29}$. All dies erzeugt neurotische Reaktionen. Gewalt ${ }^{30}$, Rechtsextremismus und Drogensucht oder Flucht in neue, falsche Geborgenheit (Stichwort: „Jugendsekten") sind die Folge.

Was folgt aus alledem für die schulische Erziehung? Zunächst: es kann nicht ihre Aufgabe sein, den Großtrend zu Selbstentfaltungswerten auf-

${ }^{25}$ Vgl. dazu Albert O. Hirschmann, Wieviel Gemeinsinn braucht die liberale Gesellschaft?, Leviathan 1994, H. 2, S. 293 (gekürzter Abdruck FR vom 25. 6. 1994, S. ZB 3).

${ }^{26} \mathrm{~J}$. Becker, Die Einfalt in der Vielfalt - Standardisierte Massenkommunikation als Problem der politischen Kultur, Aus Politik und Zeitgeschichte B 39/94, S. 21 ff.; Habermas, a. a. O. (Fn. 13), S. 36.

${ }^{27}$ Postman, a. a. O., zusammenfassend S. $189 \mathrm{ff}$.

28 Vgl. auch Postman, a. a. O., S. $197 \mathrm{f}$.

${ }^{29}$ Klages, a. a. O. (Fn. 8), S. 39 f.

${ }^{30}$ Heidrun Bründel/ Klaus Hurrelmann, Gewalt macht Schule. Wie gehen wir mit aggressiven Kindern um?, 1994; dies., Zunehmende Gewaltbereitschaft von Kindern und Jugendlichen, Aus Politik und Zeitgeschichte B 38/94, S. 3 ff. 
zuhalten oder gar umzukehren und statt dessen Traditionen von Gemeinschaftsdisziplin zu neuem Leben zu erwecken. Es kann und darf nicht das Ziel sein, etwa durch „Rückbesinnung auf traditionelle Werte“ den Versuch zu unternehmen, den Gewinn an persönlicher Autonomie, der in den geschilderten Entwicklungen liegt, wieder zurückzunehmen, sozusagen die gute alte Zeit wiederherzustellen. Weder Schule noch Gesellschaftspolitik dürfen den Trend zur Individualisierung in einen solchen zu Kollektivierung (die ja sehr unterschiedlich ideologisch verbrämt sein kann) wandeln. Es wurde aber gezeigt, daß in Selbstentfaltungswerten unterschiedliche Entwicklungsmöglichkeiten angelegt sind. Hier ist die Schule gefordert ${ }^{31}$. Es ist eine Aufgabe und Herausforderung für das staatliche Erziehungswesen, den Gefahren, die unseren Gesellschaften aus diesen Entwicklungen drohen, entgegenzuwirken. Es soll auch die einzelnen zu Erziehenden in die Lage versetzten, mit den Problemen fertig zu werden, die diese Entwicklungen für die individuelle Existenz mit sich bringen. $\mathrm{Ob}$ und inwieweit dies möglich ist, muß mit einem Fragezeichen versehen werden. Sicher sind auch andere Bereiche der Gesellschaftspolitik gefragt. Aber ohne Erfolge im Erziehungswesen ist eine Bekämpfung der Funktionsstörungen, die aus den geschilderten Entwicklungen für unsere Gesellschaft drohen, kaum möglich. Je mehr das Kind bei seinen Eltern als Vorbild die ungezügelte Selbstverwirklichung sieht, desto mehr wird es Aufgabe der staatlichen Erziehung, Gemeinschaftswerte zu vermitteln. Dies ist kein Hinweggehen des Staates über einen elterlichen Erziehungsplan, sondern eine inhaltliche Herausforderung an das staatliche Schulwesen. Die Schule kann nicht die Geborgenheit eines Elternhauses ersetzen. Wo aber Fernsehen und Video an die Stelle elterlicher Erziehung getreten sind, kann sie allein noch kritischen Umgang mit Unterhaltungsangebot vermitteln und sinnstiftend wirken. $\mathrm{Daß}$ in der Schule Lesen und Schreiben gelernt wird, hat im Zeitalter des Fernsehens eine größere kultur- und gesellschaftspolitische Bedeutung als früher ${ }^{32}$.

Sie kann und muß aber zu einem verantwortlichen Umgang mit der Individualisierung anleiten. Gefordert ist $\mathrm{m}$. a. W. eine Erziehung, die zu kritischer, verantwortlicher und gemeinschaftsorientierter Selbstverwirklichung befähigt. „Für den auf die Freiheit und Selbstverwirklichung des einzelnen orientierten Staat hat (das staatliche Bildungskonzept) seinen tragenden Bezugspunkt in der Herausbildung und Weckung des spezifischen Humanum, der zum eigenen Urteil und zur vernunftgeleiteten

31 Postman, a. a. O. (Fn. 23), S. 197 f.

32 Postman, a. a. O., S. 197 f. 
Selbstverwirklichung befähigten Person, die in Auseinandersetzung mit der geistigen und sozialen Umwelt ebenso ihre Individualität entfaltet

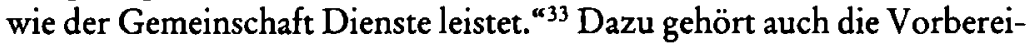
tung auf neue Rollenverteilung in der Familie und die Entwicklung der Fähigkeit, in einer enttraditionalisierten Gesellschaft einen sinnvollen Lebensentwurf selbständig zu finden.

\subsection{Die Außenproblematik}

Auch die-Außenproblematik sei mit drei Stichworten schlaglichtartig beleuchtet: Deutschland als Ein- (und auch Aus-)wanderungsland, als Wirtschaftsstandort und als Weltmacht.

$\mathrm{Da}$ eine gute Bildungs- und Ausbildungsinfrastruktur Voraussetzung eines erfolgreichen wettbewerbsfähigen Wirtschaftsstandorts ist, ist $\mathrm{Ge}-$ meingut. Das gilt nicht nur für den tertiären, sondern auch für den primären und sekundären Ausbildungsbereich, auf dem der tertiäre letzten Endes aufbaut. Dazu gehört auch, daß der Jugendliche in der Schule lernt, mit den Bedingungen der industriell-technischen Welt und der Informationsgesellschaft zurechtzukommen ${ }^{34}$. Umweltbewußtes Handeln ist ein Teilaspekt dieser Fähigkeit ${ }^{35}$. Die staatliche Schule sollte ihre Absolventen befähigen, im Berufsleben ihren Mann/Frau zu stehen. Dazu gehört auch die Fähigkeit, auf einem internationalen Arbeitsmarkt zu konkurrieren oder für deutsche Unternehmen im Ausland zu arbeiten. Insofern muß Deutschland auch Auswanderungsland sein. Sein Erziehungswesen muß die Internationalisierung der Lebenszusammenhänge reflektieren ${ }^{36}$.

Größere Probleme bereitet wohl die Tatsache, daß Deutschland wie alle westlichen Industriestaaten ein Einwanderungsland ist ${ }^{37}$. Daß dies so ist, kann niemand leugnen, der mit offenen Augen durch eine deutsche Stadt geht. Ob das so bleiben kann und soll, ist freilich Gegenstand des

${ }^{33}$ Ermst-Wolfgang Böckenförde, Der Staat als sittlicher Staat, 1978, S. 33.

${ }^{34}$ Daher die Forderung der WRV nach Arbeitskunde als Unterrichtsfach.

${ }^{35}$ Vgl. Art. 7 Abs. 2 Verf. NRW: Erziehung nzur Verantwortung für die Erhaltung der natürlichen Lebensgrundlagen".

${ }^{36}$ Für andere Industrieländer vgl. Sir Claus Moser, Ends and Means in Curriculum Reform, in: OECD, a. a. O. (Fn. 5), S. 49; Takashi Yamagiwa, Curriculum Reform and its Implementation, New Trends in the Revised Curricula in Japan, ebd. S. 70 ff.

37 Vgl. Daniel Cohn-Bendit / Thomas Schmid, Heimat Babylon. Das Wagnis der multikulturellen Demokratie, 1992, S. 26 ff.; Ame Gieseck / Ulrich Heilemann / Hans Dietrich v. Loeffelbolz, Wirtschafts- und sozialpolitische Aspekte der Zuwanderung in die Bundesrepublik, Aus Politik und Zeitgeschichte B 7/93, S. 29 ff., zu den Konsequenzen für das Bildungswesen S. 38. 
Streits. Das kann hier nicht ausdiskutiert werden. Ich vermag freilich nicht zu sehen, wie denn der Migrationsdruck ${ }^{38}$, der durch das Wohlstandsgefälle zwischen Nord und Süd, West und Ost erzeugt wird, aufgehalten werden kann. Zwar haben die Staaten Westeuropas und Nordamerikas in schöner oder unschöner Eintracht die Zäune an ihren Grenzen erhöht. Aber dies kann nur eng begrenzte Wirkung haben, von Erfolg möchte ich nicht sprechen. Deshalb muß unser Erziehungssystem der Herausforderung gerecht werden, daß wir eine multikulturelle Gesellschaft sind und bleiben werden. Es muß Kinder aus anderen Kulturen aufnehmen und erziehen. Es muß Kinder aus unserer Kulturtradition darauf vorbereiten, mit Menschen aus anderen Kulturen verträglich umzugehen.

Zum dritten Stichwort: Deutschland ist in der Weltpolitik ein nicht nur wirtschaftlicher Machtfaktor geworden, sondern auch ein politischer und militärischer, womit wir manchmal noch etwas Schwierigkeiten haben. Um so mehr braucht unser Land Menschen, die bereit und in der Lage sind, mit dieser Situation Deutschlands verantwortlich umzugehen. An Gelegenheiten, wo solche Tugenden gefordert sind, fehlt es nicht; dies ist nicht nur eine Sache politischer Entscheidungsträger. Das bedeutet nicht nur eine Bejahung von und ein Eintreten für Frieden und Völkerverständigung. Es bedeutet auch, daß Gemeinsinn grenzüberschreitend zu verstehen ist, als Verpflichtung in Europa und in der Welt, als Bereitschaft zu internationaler Solidarität.

Damit ist nun ein gesellschaftlich-politischer Rahmen skizziert, in dem der staatliche Erziehungsauftrag zu verorten ist.

\section{Der staatliche Erziehungsauftrag}

Der staatliche Erziehungsauftrag verstanden als die Verpflichtung des Staates, ein leistungsfähiges öffentliches Schulsystem vorzuhalten ${ }^{39}$, ist

${ }^{38}$ Yabn Moulier Boutang / Demetrios Papademetriou, Typology, Evolution and Performance of Main Migration Systems, in: OECD, Migration and Development. New Partnership for Cooperation, 1994, S. 19 ff.; Albert Müblum, Armutswanderung, Asyl und Abwehrverhalten - Globale und nationale Dilemmata, Aus Politik und Zeitgeschichte B 7/93, S. 3 ff.; Jochen Blaschke, Internationale Migration: ein Problemaufriß, in: Manfred Knapp (Hrsg.), Migration im neuen Europa, 1994, S. 23 ff.; Jürgen Filjakowski, Die Bundesrepublik und das Migrationsproblem: historische Erfahrungen und aktuelle Herausforderungen, ebd. S. $113 \mathrm{ff}$.

${ }^{39}$ Die inhaltliche Gestaltung dieses Auftrags wird allein unten unter den Erziehungsmaßstäben behandelt. In der Literatur finden sich verschieden stark inhaltlich angereicherte Konzepte des Erziehungsauftrages, vgl. etwa Kommission Schulrecht des DJT, Schule im Rechtsstaat Bd. I, Entwurf für ein Landesschulgesetz, S. 64 f. 
aus dem Sozialstaatsprinzip in Verbindung mit Art. 7 Abs. 1 GG abzuleiten ${ }^{40}$. Die Schule ist Bestandteil der vom Staat für das Funktionieren der Gesellschaft zur Verfügung gestellten Infrastruktur. Diese Funktion ist im Sozialstaatsprinzip angelegt. Neben Art. 7 kommen weitere grundrechtliche Aspekte hinzu: Staatliches Schulehalten ist auch Erfüllung staatlicher Schutz- und Förderungspflichten für das Recht auf freie Entfaltung der Persönlichkeit ${ }^{41}$ und die Ausbildungsfreiheit (Art. 12). Eine weitere, z. T. auch deutlichere Grundlage sind die entsprechenden Bestimmungen der Länderverfassungen ${ }^{42}$. Ein neuerer, etwas exzentrischer Kritiker ${ }^{43}$ leugnet dies: Staatliches Schulehalten sei weder erforderlich noch verhältnismäßig. Demgegenüber ist daran festzuhalten, daß ein Verfassungsgebot der grundsätzlichen Staatlichkeit des Schulwesens besteht ${ }^{44}$. Wo so grundlegende Lebenschancen vergeben werden wie im Schulwesen ${ }^{45}$, ist der Staat selbst gefordert. Dies entspricht einer gemeineuropäischen Verfassungspraxis ${ }^{46}$.

40 Grundlegend Oppermann, Nach welchen Grundsätzen sind das Öffentliche Schulwesen und die Stellung der an ihm Beteiligten zu ordnen? Gutachten C für den 51. Deutschen Juristentag, 1976, S. C 19 ff.; Bodo Pieroth, Erziehungsauftrag und Erziehungsmaßstab der Schule im freiheitlichen Verfassungsstaat, DVBl. 1994, S. 949 ff., 951.

${ }^{41}$ P. M. Huber, a. a. O. (Fn. 3), S. 547.

42 LV Brandenburg, Art. 29 Abs. 2 und 30 Abs. 5.

${ }^{43}$ Erich Bärmeier, Über die Legitimität staatlichen Handelns unter dem Grundgesetz der BRD. Die Unvereinbarkeit staatlichen Schulehaltens mit den Verfassungsprinzipien der "Staatsfreiheit " und der Verhältnismäßigkeit, 1992; ders., Das Verfassungsprinzip der Verhältnismäßigkeit und die Unverhältnismäßigkeit staatlichen Schulehaltens, RdJB 1993, S. 80 ff.

${ }^{4}$ Peter Glotz / Klaus Faber, Richtlinien und Grenzen des Grundgesetzes für das Bildungssystem, in: Ernst Benda / Werner Maihofer / Hans-Jochen Vogel (Hrsg.), Handbuch des Verfassungsrechts der Bundesrepublik Deutschland, 1983, S. 999 ff., 1012; A. v. Campenhausen, Erziehungsauftrag und staatliche Schulträgerschaft, 1967, S. $19 \mathrm{f}$.

${ }^{45}$ Vgl. Frankenberg, a. a. O. (Fn. 3), S. 114.

${ }^{46}$ Alle neueren europäischen Verfassungen sehen Schulehalten als Aufgabe des Staates bzw. staatlicher Untergliederungen. Sie unterscheiden sich lediglich in der Frage, ob und inwieweit dieser Bereich privater Aktivität geöffnet ist. Mit weitgehender Öffnung für private Schulen z. B. Art. 23 Abs. 4 und 5 der niederländischen Verfassung (mit Finanzierungspflicht des Staates), Art. 27 Abs. 6 der spanischen Verfassung und Art. 75 der portugiesischen Verfassung. Restriktiv dagegen Art. 16 Abs. 3 und 8 der griechischen Verfassung. In diesem Zusammenhang spielt auch das unterschiedliche Verhältnis von Staat und Kirche eine Rolle. Dies hat insbesondere in Portugal Schwierigkeiten bereitet, vgl. Victor Silva Lopes, Constuição da República portuguesa 1976 (anotada), 1976, S. 139 f. 
Die allgemeine Privatisierungsdebatte, in die auch der zweite Beratungsgegenstand dieser Tagung einzuordnen ist, sollte darum den Schulbereich aussparen. Die Effizienzsteigerung durch privates Management und Konkurrenz, eine der wesentlichen Leitideen der Privatisierung ${ }^{47}$, hat im Schulwesen keinen Platz. Schule ist nicht Post oder Bahn. Als warnendes Beispiel diene die problematische Entwicklung, ja der Verfall des öffentlichen Schulwesens in den Vereinigten Staaten, der durch eine unzureichende Finanzbasis bedingt ist. Das „zwang“ die reichen Eltern dazu, ihre Kinder in Privatschulen zu schicken. Ein Versuch, den Gleichheitssatz der Verfassungen des Bundes und der Gliedstaaten zur Remedur einzusetzen, hatte nur Teilerfolge auf der Ebene der Staaten ${ }^{48}$.

Solange nicht eine unverantwortliche staatliche Haushaltspolitik die Leistungsfähigkeit der öffentlichen Schulen untergräbt, was gegenwärtig leider nicht völlig selbstverständlich ist, können die Privatschulen auf ihre gegenwärtige komplettierende und eher marginale Rolle verwiesen bleiben $^{49}$. Ihre ratio essendi ist (noch?) nicht die Erhöhung der Effizienz des Schulwesens insgesamt, etwa im Sinne leistungsfördernder Konkurrenz, sondern sie ist historischer und grundrechtlicher Natur. Historisch ermöglichte die Zulassung von Privatschulen u. a. die Fortführung kirchlicher Bildungseinrichtungen ${ }^{50}$, aus grundrechtlicher Sicht ermöglicht sie eine weltanschaulich geprägte Alternative zur neutralitätsverpflichteten staatlichen Schule ${ }^{51}$. In dieser grundrechtsfördernden Funktion ${ }^{52}$ liegt die eigentliche Legitimation der Privatschule, aber auch die Gefahr, daß sie ein Mittel gesellschaftlicher Desintegration wird ${ }^{53}$. Sie darf jedenfalls nicht zur Alternative werden, wohin man seine Kinder schickt, wenn in einer Klasse der öffentlichen Schule „zu viele" türkische Kinder sind.

${ }^{47}$ Dazu Lerke Osterlob, in diesem Band. Zur notwendigen Rolle des Staates im Bildungswesen vgl. auch den Tagungsbericht von Ulrich Benstz, Internationales Symposium „Recht und Bildung“, RdJB 41 (1993), S. 288 ff., 291; zum Problem Schule und Markt ebd. S. 297.

${ }^{48}$ Vgl. dazu Michael Bothe, Die Entwicklung des Föderalismus in den angelsächsischen Staaten, JöR 31 (1982), S. 109 ff., 119; zu neueren Entwicklungen Benstz, a. a. O. (Fn. 47), S. 297.

49 Vgl. auch A. v. Campenbausen, a. a. O. (Fn. 44), S. 56 f.; Hans Heckel/ Hermann Avenarius, Schulrechtskunde, 6. Aufl. 1986, S. 24 f.

so Evers, a. a. O. (Fn. 2); vgl. dazu auch Lothar Theodor Lemper, Privatschulfreiheit, Diss. Köln 1984, S. 85 f.

${ }^{51}$ BVerfGE 88, 40, 46 f.; vgl. Klaus Blau, Bedeutung und Probleme der Privatschulfreiheit, JA 1984, S. 463 ff.

52 Christian Starck, Freiheitlicher Staat und staatliche Schulhoheit, in: Essener Gespräche zum Thema Staat und Kirche 9 (1975), S. 9 ff., 32 f.; vgl. auch BVerwGE 27, $360,362 \mathrm{ff}$.

${ }^{53}$ Pieroth, a. a. O. (Fn. 40), S. 951. 
Dafür, daß es dazu nicht in größerem Umfang kommt, sind auch Anstrengungen des staatlichen Schulwesens notwendig.

Der Erziehungsauftrag des Grundgesetzes ist nicht schon erfüllt, wenn es überhaupt ein öffentliches Schulwesen gibt, er ist vielmehr auf ein leistungsfäbiges Schulwesen gerichtet. Daraus ergeben sich, wie von vielen Landesverfassungen anerkannt, Finanzierungs- und Förderungspllichten $^{54}$. Ob angesichts der Benachteilung junger Deutscher am internationalen Arbeitsmarkt, die auch durch längere Ausbildungszeiten in der Schule bedingt ist, heute auch eine Verkürzung der Schulzeit verfassungsrechtlich legitimiert oder gar gefordert sein könnte, sei hier nur als Erwägung in den Raum gestellt.

Der staatliche Erziehungsauftrag stellt eine objektive staatliche Verpflichtung dar. Wie weit dieser subjektive Rechte von Eltern oder Kindern entsprechen, ist nach wie vor umstritten. Allerdings ist die Ableitung subjektiver Berechtigungen aus dem Sozialstaatsprinzip jedenfalls in Verbindung mit grundrechtlichen Schutzpflichten, wenn auch in beschränktem Maße, anerkannt ${ }^{55}$. Die Formulierung eines "Rechts" auf Bildung ${ }^{56}$ in verschiedenen Landesverfassungen ${ }^{57}$ legt für den Bereich des Landesverfassungsrechts die Annahme eines subjektiven Rechtes nahe. Auch viele neuere europäische Verfassungen ${ }^{58}$ und, im Gefolge der Allgemeinen Erklärung der Menschenrechte, völkerrechtliche Verträge ${ }^{59}$ formulieren ein „Recht auf Bildung" oder "auf Erziehung". Das ist unproblematisch, wenn und soweit man dieses nur als Recht auf freien $\mathrm{Zu}$ gang zu vorhandenen Bildungseinrichtungen versteht. Jedoch haben die

${ }^{54}$ LV Brandenburg, Art. 30 Abs. 5, NRW Art. 8 Abs. 3.

55 Vgl. Friedrich E. Schnapp, in: Ingo v. Münch / Philipp Kunig (Hrsg.), Grundgesetz-Kommentar, Bd. 1, 4. Aufl. 1992, Rdn. 19 f. zu Art. 20; Michael Kittner, Art. 20 Abs. 1-3 IV (Sozialstaatsprinzip), Rdn. 62 f., in: AKGG, 2. Aufl. 1989.

${ }^{56}$ Dazu Klaus-Dieter Heymann / Ekkehart Stein, Das Recht auf Bildung, AöR 97, 1972, S. 185.

${ }^{57}$ Brandenburg, Art. 29; NRW, Art. 8 Abs. 1. Dazu eingehend Jörg Dieter Kübne, in: Gregor Geller / Kurt Kleinrahm (Hrsg.), Die Verfassung des Landes NRW, 3. Aufl., Art. 8, Fn. 2 a) bb).

${ }_{58}$ Art. 73 der portugiesischen, Art. 27 Abs. 1 der spanischen, Art. 37 der estnischen, Art. 38 der lettischen Verfassung; im Sinne einer staatlichen Förderungspflicht Art. 16 der griechischen, Art. 23 der niederländischen und Kap. 1 Art. 2 der schwedischen, Art. 16 der ungarischen, Art. 23 der bulgarischen Verfassung, für die berufliche Bildung auch Art. 29 der estnischen Verfassung. Eine Garantie kostenfreier staatlicher Erziehung findet sich in Art. 40 der litauischen Verfassung.

${ }^{59}$ Art. 13 Internationaler Pakt über wirtschaftliche, soziale und kulturelle Rechte; Art. 22 Konvention über die Rechte des Kindes; Art. 21 . Zusatzprotokoll zur EMRK. 
Gerichte aus solchen Vorschriften einen begrenzten, aber klagbaren Anspruch auf Kapazitätserweiterung abgeleitet ${ }^{60}$.

Der prinzipielle Gleichrang ${ }^{61}$ von staatlichem (schulischem) Erziehungsauftrag und elterlichem Erziehungsrecht kann nicht an der typischen Familie mit traditioneller Rollenverteilung festgemacht werden ${ }^{62}$. Deshalb ändern die dargestellten Entwicklungen einer Vielfalt unterschiedlicher Formen familiären oder familienähnlichen Zusammenlebens, in denen heute Kinder großgezogen werden können, nichts daran, daß elterliches Erziehungsrecht und staatliche Schulhoheit gleichgeordnet sind und zu einem schonenden Ausgleich gebracht werden müssen, was auch bedeutet, daß der Staat elterliche Auswahlentscheidungen hinsichtlich der schulischen Erziehung respektieren, ja ermöglichen muß ${ }^{63}$. In den eigenen Bereich der Erziehung in der Familie darf sich der Staat nur unter den engen Voraussetzungen des Art. 6 Abs. 3 GG einschalten ${ }^{64}$. $\mathrm{Daß}$ Familien mit der Erziehung der Kinder in Schwierigkeiten geraten, ist ein Phänomen, das nicht oder jedenfalls nicht allein diesen neuen Entwicklungen zugeschrieben werden kann. Hier muß der Staat helfend eingreifen, insbesondere zur Erleichterung des schwierigen Loses Alleinerziehender ${ }^{65}$.

\section{Erziehungsmaßstäbe}

Unter Erziehungsmaßstäben werden im folgenden Regeln allgemeiner Art verstanden, die Inhalt oder angestrebtes Ergebnis der staatlichen $\mathrm{Er}$ ziehung im Bereich der Schulen bestimmen. Die Regeln über angestrebte

60 OVGNRW, OVGE 34, 211, 213; zum Recht auf Erziehung nach der spanischen Verfassung als ein Recht auf eine gewisse Mindestqualität der Ausbildung vgl. die Entscheidung des spanischen Verfassungsgerichts vom 13. 2. 1981, Boletín de Jurisprudencia Constitucional 1981-I, S. 23 ff., 39.

61 BVerfGE 34, 165; 47, 72; 59, 376; VGH Baden-Württemberg, DVBl. 1975, S. 438 ff., 440; Ingo Richter, in: AK-GG, 2. Aufl., Art. 7, Rdn. 27 ff.; Ulfried Hemmrich, in: I. v. Münch / P. Kunig (Hrsg.), Grundgesetz-Kommentar, 4. Aufl. 1992, Art. 7, Rdn. 14, 52; C. Starck, a. a. O. (Fn. 52), S. 25; differenzierend Arnulf Schmitt-Kammler, Elternrecht und schulisches Erziehungsrecht nach dem Grundgesetz, 1983, S. 50 ff.; für einen Vorrang des Elternrechts hingegen Fritz Ossenbübl, Das elterliche Erziehungsrecht im Sinne des Grundgesetzes, 1981, S. $110 \mathrm{ff}$.

${ }^{62}$ Eva Marie v. Münch, Art. 6 Rdn. 32, in: I. v. Münch / P. Kunig (Hrsg.), a. a. O.; vgl. auch I. Richter, in: AK-GG, 2. Aufl., Art. 6 Rdn. 11a ff.; insbes. 15a für den Begriff der Familie in Art. 6.

${ }^{63} \mathrm{Vgl}$. Schmitt-Kammler, a. a. O. (Fn. 61), S. 32 f.

${ }^{64}$ Dazu E. M. v. Münch, a. a. O. (Fn. 62), Art. 6 Rdn. 45 ff.

65 Dieser Gedanke ist zutreffend formuliert in Art. 27 Abs. 3 LV Brandenburg. 
Erziehungsergebnisse werden auch (und plastischer) als Erziehungsziele bezeichnet.

\subsection{Sinn und Unsinn rechtlich festgelegter Erziehungsmaßstäbe und-ziele}

Möglichkeit und Sinn der rechtlichen Festlegung von Erziehungsmaßstäben sind streitig. Von Sinn und Möglichkeit rechtlicher Zielvorgaben für den Erziehungsprozeß geht eine weit verbreitete Verfassungspraxis aus, so Art. 148 der WRV, ebenso die frühen Landesverfassungen in der Bundesrepublik ${ }^{66}$ und nunmehr wieder die Verfassungen der neuen Bundesländer ${ }^{67}$. Gelegentlich hat der Verfassungsgeber insofern auch nachgebessert, so etwa in NRW 1986 bei der Einfügung der „Verantwortung für die Erhaltung der natürlichen Lebensgrundlagen" in die Liste der verfassungsgeforderten Erziehungsziele ${ }^{68}$. Die Gemeinschaft der Verfassungsinterpreten hat darüber hinaus aus Grundprinzipien der Verfassung und den Grundrechten Erziehungsziele, aber auch Verbote von Erziehungszielen abgeleitet.

Auch die Verfassungen anderer Staaten enthalten Erziehungsziele. Dies gilt vor allem für die Staaten Südeuropas, die sich im Zuge ihre Redemokratisierung neue Verfassungen gaben ${ }^{69}$. Auch im außereuropäischen Bereich sind solche Bestimmungen häufig anzutreffen ${ }^{70}$. Allerdings gibt es auch neuere europäische Verfassungen, die zwar einen staatlichen Schulauftrag, nicht aber ausdrückliche Erziehungsziele enthal$\operatorname{ten}^{71}$.

Ferner geben völkerrechtliche Verträge und internationale Erklärungen, insbesondere im Bereich der Menschenrechte, Erziehungsziele vor.

Wie der Menschenrechtsschutz allgemein, geht auch die Formulierung von menschenrechtlichen Erziehungszielen aus von der Allgemeinen Erklärung der Menschenrechte ${ }^{72}$, deren Text fast wörtlich in Art. 13 Abs. 1

66 Übersicht bei Evers, a. a. O. (Fn. 2), S. 37 f.

${ }^{67}$ Jörg-Detlef Kübne, Neue Länder - neue Erziehungsziele?, RdJB 1994, S. $39 \mathrm{ff}$.

${ }_{68}$ Kühne, a. a. O., (Fn. 57), Art. 7 Fn. 5 a) cc).

${ }^{69}$ Art. 16 Abs. 2 der griechischen Verfassung 1975; Art. 73 Abs. 2 der portugiesischen Verfassung 1976; Art. 27 Abs. 2 der spanischen Verfassung 1978.

${ }^{70} \mathrm{Sehr}$ ausführlich ideologisch ausgeprägt und an herausgehobener Stelle: Art. 3 der mexikanischen Verfassung von 1917; vgl. ferner Art. 205 der brasilianischen Verfassung von 1988; Art. 80 der venezolanischen Verfassung.

7 Art. 23 der niederländischen Verfassung von 1983, ebenso die meisten neuen osteuropäischen Verfassungen.

${ }^{72}$ Art. 26 Abs. 2 Abdruck der Texte der im folgenden zit. Verträge bei Christian Tomuschat (Hrsg.), Menschenrechte, 1992. 
Satz 2 und 3 des Internationalen Paktes über soziale, wirtschaftliche und kulturelle Rechte übernommen wird:

„(Die Vertragsstaaten) stimmen überein, daß die Bildung auf die volle Entfaltung der menschlichen Persönlichkeit und des Bewußtseins ihrer Würde gerichtet sein und die Achtung vor den Menschenrechten und Grundfreiheiten stärken muß. Sie stimmen ferner überein, daß die Bildung es jedermann ermöglichen muß, eine nützliche Rolle in einer freien Gesellschaft zu spielen, daß sie Verständnis, Toleranz und Freundschaft unter allen Völkern und allen rassischen, ethnischen und religiösen Gruppen fördern sowie die Tätigkeit der Vereinten Nationen zur Erhaltung des Friedens unterstützen muß“.

Dieser Text findet sich mit Variationen wieder in den Anti-Diskriminierungs-Konventionen, insbesondere der Konvention zur Bekämpfung der Rassendiskriminierung ${ }^{73}$ und dem Übereinkommen gegen Diskriminierung im Unterrichtswesen ${ }^{74}$. Spezifisch gleichheitsbezogen sind die Erziehungsziele in der Konvention zur Beseitigung der Diskriminierung der $\mathrm{Frau}^{75}$, ausführlicher in der Konvention über die Rechte des Kindes ${ }^{76}$. Menschenrechtserziehung ist ein wesentlicher Teil des Arbeitsprogrammes der UNESCO ${ }^{77}$.

Ein besonders wichtiges internationales Anliegen ist die Umwelterziehung. Entsprechende Zielbestimmungen finden sich in den Erklärungen der Umweltkonferenz von Stockholm $1972^{78}$ und Rio $1992^{79}$, der Weltcharta der Natur von $1982^{80}$ und in der Erklärung der von UNESCO und UNEP gemeinsam organisierten Konferenz von Tiflis über Umwelterziehung ${ }^{81}$.

Diese Formulierung von Erziehungszielen auf allen Ebenen, in unterschiedlichen Staaten und im internationalen Bereich sollte allen jenen

73 Art. 7.

74 Art. 5 Abs. 1 (a); BGBl. 1968 II, S. 385, 402.

75 Art. 5 Abs. 2, 10 (c); BGBl. 1985 II, S. 648.

76 Art. 29; BGBl. 1992 II, S. 122.

77 Daniel G. Partan, United Nations Educational, Scientific and Cultural Organization, in: Rudolf Bernhardt (Hrsg.), EPIL Lfg. 5 (1983), S. 314 ff., 317 f.; Stephen P. Marks, Human Rights Activities of Universal Organizations, ebd. Lfg. 8 (1985),

S. $274 \mathrm{ff} ., 279 \mathrm{f}$.

78 Prinzip 19.

79 Prinzip 21.

${ }^{80}$ Resolution der Generalversammlung der Vereinten Nationen vom 28. 10. 1982, Ziff. 15.

81 Vgl. dazu Michael Bothe / Lothar Gündling, Tendenzen des Umweltrechts im internationalen Vergleich, 1978, S. $111 \mathrm{f}$. 
doch zu denken geben, die ein solches Unterfangen für sinnlos halten. Allerdings - die Tatsache, daß es eine bestimmte normative Übung gibt, daß offenbar ein weit verbreiteter Glaube daran besteht, das Recht sei zur Steuerung des Verhaltens der in der Erziehung Tätigen sinnvoll in der Lage, ist zwar ein Indiz, beweist aber noch nicht hinreichend, daß diese Steuerungsfähigkeit auch wirklich vorhanden ist.

Soweit es um die Erziehungsmaßstäbe der Verfassung geht, beruht ein Teil des Streits wohl darauf, daß zwei unterschiedliche Dimensionen von Verfassungswirkung nicht immer hinreichend unterschieden werden, nämlich einmal eine „rein“ juristische, zum anderen eine affektive, erzieherische, gemeinschaftsbildende, ethische Komponente. Häberle hat das die kulturwissenschaftliche Seite der Verfassung genannt ${ }^{82}$. Es gibt auch andere Umschreibungen, etwa Symbolwirkung, Integrationswirkung, Verfassungspatriotismus. Dieser Aspekt der Verfassungswirkung ist eine gesellschaftlich-politische Notwendigkeit und auch Realität. Daß diese Symbolwirkung gerade für die Erziehung wesentlich ist, liegt auf der Hand. Sie geht allerdings häufig von Bestimmungen aus, deren rein juristische Wirkungen mitunter etwas problematisch, ja indirekt sind. Hier sind wir auch bei dem Streit um die Staatszielbestimmungen ${ }^{83}$. Trotz dieser rechtlichen Problematik hat die WRV, haben die frühen Landesverfassungen nach 1945 und die Verfassungen der neuen Bundesländer auf solche Bestimmungen nicht verzichten wollen. Die Mütter und Väter des Grundgesetzes waren jedoch offenbar von der Weimarer Erfahrung geschreckt, daß der symbolische Gehalt der WRV schließlich zu einer Abqualifizierung des juristischen geführt hat - also eine Art Programmsatzneurose. Dies ist aber nicht der einzige Grund für die Abstinenz des Grundgesetzes auf diesem Gebiet. Die Mütter und Väter des Grundgesetzes wollten angesichts der nicht zu vollziehenden Einheit Deutschlands ein Provisorium schaffen und verzichteten deshalb auf den Namen „Verfassung" und konsequenterweise auch auf vieles Dekor, das den Symbolwert einer Verfassung ausmacht. Um so unverständlicher ist es, daß die Gemeinsame Verfassungskommission die Gelegenheit hat verstreichen lassen, dieses Defizit des Grundgesetzes nachzubessern und unsere Verfassung in Einklang zu bringen mit dem Stil der Verfassungsgebung, wie er nicht nur in den Bundesländern, sondern auch in neuen Verfassungen im Norden, Westen, Süden und jetzt auch im Osten Euro-

${ }^{82}$ Peter Häberle, Verfassungsprinzipien als Erziehungsziele, FS Hans Huber, S. $211 \mathrm{ff} ., 228 \mathrm{f}$.

${ }^{83} \mathrm{Vgl}$. dazu aus der neueren Literatur zu der weit verbreiteten ablehnenden Grundhaltung Detlef Mertens, Die Staatszieldebatte, in: Eckart Klein (Hrsg.), Verfassungsentwicklung in Deutschland nach der Wiedervereinigung, 1994, S. $65 \mathrm{ff}$. 
$\operatorname{pas}^{84} \mathrm{zu}$ finden ist. Die wertorientierte Rechtsprechung des Bundesverfassungsgerichts und auch die Bemühungen der Verfassungsinterpreten, verfassungrechtliche Grundentscheidungen als gesellschaftliche Orientierungswerte zu deuten ${ }^{85}$, sind ein schwacher Ersatz für den Symbolwert des ausdrücklichen Verfassungstextes. Der Pädagoge bedarf so erst des Nachhilfeunterrichts durch den Juristen, d. h. meist den richtlinienverfassenden Schulbürokraten, ehe sich ihm oder ihr die ganze Fülle des kulturwissenschaftlichen Gehalts der dürren Worte des Grundgesetzes erschließt.

Doch wenden wir uns nunmehr dem "rein“ juristischen Aspekt der Erziehungsziele zu. Bei der Frage nach Sinn und Möglichkeit solcher rechtlichen Vorgaben kann der deutsche Jurist nicht an der Rechtsprechung des Bundesverfassungsgerichts zu Wesentlichkeitstheorie und Gesetzesvorbehalt $^{86}$ vorbeigehen. Danach müssen wesentliche Bestimmungen über den Inhalt der Lehre, da sie grundrechtsrelevant sind, auf einer Entscheidung des Gesetzgebers beruhen. Damit ist aber zugleich das Gebot einer Verrechtlichung ausgesprochen. Das BVerfG geht mit anderen Worten von einer Steuerung schulischer Bildung und Ausbildung durch Recht aus ${ }^{87}$. An dieser Verrechtlichung ${ }^{88}$ ist von juristischer ${ }^{89}$ und sozialwissenschaftlicher ${ }^{90}$ Seite erhebliche Kritik geäußert worden. Die Rechtsprechung des Verfassungsgerichts enthebt uns nicht der Frage, ob das Recht hier als Steuerungsmittel nicht überfordert ist, ob hier nicht nur eine Scheinsteuerung vorliegt ${ }^{\text {911}}$. Ja noch mehr: der Versuch einer rechtlichen Steuerung, der die Eigengesetzlichkeiten der Prozesse personaler

${ }^{84}$ Die Aufnahme von Staatszielbestimmungen und sozialen Grundrechten in die neueren europäischen Verfassungen kann hier nicht im einzelnen dargestellt werden. Vgl. dazu etwa Jörg Polakiewicz, Soziale Grundrechte und Staatszielbestimmungen in den Verfassungsordnungen Italiens, Portugals und Spaniens, ZaöRV 54 (1994), S. 340 ff.; zur niederländischen Verfassung vgl. C. A. J. M. Kortmann, Das niederländische Grundgesetz vom 17. 2. 1983, JöR 33 (1984), S. 175, 180 ff. (einschlägig Art. 18-23).

${ }^{85}$ Häberle, a. a. O. (Fn. 2), insbes. S. $87 \mathrm{ff}$.

${ }^{86}$ Grundlegend für das Schulrecht BVerfGE 34, 165.

87 Reuter, a. a. O. (Fn. 5), S. 119 f., 125 ff.

${ }^{88}$ Dabei ist zu unterscheiden zwischen Vergesetzlichung oder Parlamentarisierung, Justitialisierung und Bürokratisierung.

${ }_{89}$ Mit ganz unterschiedlichen Ansätzen, Gerd Roellecke, Erziehungsziele und der Auftrag der Staatsschule, FS Faller, 1984, S. 187 ff.; und Frankenberg, a. a. O. (Fn. 3), S. $218 \mathrm{ff}$.

90 Grundlegend J. Habermas, Theorie des kommunikativen Handelns, Bd. 2, 1982, S. $541 \mathrm{ff}$.

${ }_{91}$ Dieter Grimm, Der Wandel der Staatsaufgaben und die Krise des Rechtsstaates, in: D. Grimm (Hrsg.), Wachsende Staatsaufgaben - sinkende Steuerungsfähigkeit des Rechts, 1990, S. 291 ff., 300. 
Interaktion in Lehren und Lernen, der die „kommunikativen Strukturen ${ }^{\text {"92 }}$ der pädagogischen Tätigkeit nicht respektiert, droht zu Funktionsstörungen zu führen ${ }^{93}$. Aber dieser Prozeß von Lehren und Lernen vollzieht sich eben im Rahmen einer rechtlich geordneten Institution. Deshalb müssen im Rechtsstaat bestimmte Verhaltensweisen der in dieser Institution Tätigen rechtlich gesteuert werden. So kann dem Erzieher rechtlich vorgegeben werden, welche Inhalte er zum Gegenstand seines Unterrichts macht. Das Curriculum kann nicht allein in das Belieben erzieherischer Kreativität gestellt werden. Bei Erziehungszielen handelt es sich freilich um rechtliche Vorgaben besonderer Art. „Duldsamkeit und Achtung vor der Überzeugung des Andern“, „Verantwortung für den Erhalt der natürlichen Lebensgrundlagen“, „Liebe zu Volk und Heimat“, „Friedensgesinnung" sind Idealvorstellungen einer Persönlichkeit, einer psychologischen Disposition, die als Ergebnis des Erziehungsprozesses erwünscht ist ${ }^{94}$. Wird dem Erzieher rechtlich vorgeschrieben, auf das Erreichen dieser Idealvorstellung hinzuwirken, so bedeutet dies rechtliche Steuerung nicht, jedenfalls nicht primär, durch ein Konditionalprogramm, sondern durch ein Finalprogramm ${ }^{95}$. Dieses gewährt anders als das Konditionalprogramm Freiräume der Ausführung. Ein Finalprogramm wirft aber stets die Verfahrensfrage der Zuständigkeit für die Ausführung, für die Konkretisierung auf. Weil es um die Formung der Persönlichkeit des zu Erziehenden geht, ist Inhalt und Richtung der erzieherischen Einwirkung wesentlich für dessen Persönlichkeitsrecht und auch für das Erziehungsrecht der Eltern. Deshalb muß der Gesetzgeber inhaltliche Grundsatzentscheidungen über die Richtung dieser Einwirkung treffen. Er muß, so das Bundesverfassungsgericht, die "Groblernziele" festlegen. Damit ist dieser Bereich einer Festlegung durch Verwaltungsvorschriften insoweit entzogen. Die Vergesetzlichung stellt eine gewisse Sicherung pädagogischer Freiheit gegenüber der Kultusbürokratie dar ${ }^{96}$. Will der Gesetzgeber allerdings diese Aufgabe sachgerecht erfüllen, so muß er die Sachgesetzlichkeiten seines Gegenstandes beachten, $\mathrm{d}$. h. insbesondere die Begrenzung der rechtlichen Steuerbarkeit des Erziehungsvorgangs. Dieser Vorgang bedarf eines erzieherischen Freiraums ${ }^{97}$.

92 Habermas, a. a. O., S. 543.

${ }^{93}$ Eingehend Frankenberg, a. a. O. (Fn. 3), S. $218 \mathrm{ff}$.

${ }_{94}$ Evers, a. a. O. (Fn. 2), S. 120 ff.; Brezinka, a. a. O. (Fn. 8), S. $562 \mathrm{ff}$.

${ }^{95}$ Grimm, a. a. O.

${ }^{96}$ Kommission Schulrecbt des Deutschen Juristentages, a. a. O. (Fn. 2), S. 36. Aus diesem Grunde bewertet auch Frankenberg, a. a. O. (Fn. 3), S. 238 diese Rechtsprechung als positiv; vgl. auch Reuter, a. a. O. (Fn. 5), S. 126 f.; Raimund Wimmer, Die rechtliche Legitimation von Curricula, ZfParl. 24 (1978), S. 241 ff., insbes. S. 250 f. 
Rechtliche Übersteuerung lähmt ihn. Überregulierung ist darum ungeeignet zum Erreichen legitimer, vom Gemeinwohl geforderter Erziehungsziele und bedeutet eine unverhältnismäßige Beeinträchtigung von Grundrechtspositionen der am Erziehungsprozeß Beteiligten ${ }^{98}$. Dies gilt nicht nur für den Schulgesetzgeber, sondern auch für die Verfasser von Richtlinien.

Ist es also (mit diesem Vorbehalt) Aufgabe des Gesetzgebers, Ziele und Gegenstände des Lehrens und Lernens zu regeln, so stellt sich natürlich die Frage, welchen weiteren Vorgaben der Gesetzgeber hierbei unterliegt. Es ist die normale Aufgabe der Verfassung, dem Gesetzgeber Pflichten aufzuerlegen und Grenzen zu setzen ${ }^{99}$. Ferner hat der Gesetzgeber die Vorgaben übergeordneter Rechtsordnungen (EG-Recht, Völkerrecht) zu beachten. Diese Vorgaben sind auch bei Vollzug und Auslegung des Gesetzes zu beachten.

Bei der gebotenen genaueren Betrachtung ergibt sich, daß zwei unterschiedliche Funktionen rechtlich gesetzter Erziehungsziele zu unterscheiden sind, die beide ihre besonderen Probleme aufwerfen ${ }^{100}$. Zum einen haben sie eine negative, ausgrenzende Funktion. Bestimmte unerwünschte Erziehungsziele, etwa Erziehung gegen Völkerverständigung oder zum Rassenhaß, werden verboten. Eine solche Norm ist einfach zu operationalisieren, sie ist unmittelbarer Anwendung fähig. In dieser Funktion wird das Finalprogramm zum Konditionalprogramm: Wenn verbotene Ziele verfolgt werden, können Sanktionen gegenüber dem Erzieher ergriffen werden. Dann stellt sich aber die Frage, ob denn allgemeine Zielvorgaben der Verfassung wirklich geeignet sind, in dieser Weise zu Konditionalprogrammen umgestaltet zu werden. Unbestimmtheit der Norm auf der einen, Furcht vor Sanktion auf der anderen Seite können die kommunikativen Strukturen des Erziehungsprozesses durchaus sachwidrig belasten ${ }^{101}$.

97 So auch BVerfGE 47, 46 (83).

${ }^{98}$ Hier scheint mir der wesentliche Kern von Frankenbergs Schulrechtskritik zu liegen, vgl. a. a. O. (Fn. 3) S. 218 ff.

99 In diesem Sinne $\$ 2$ Satz 3 EDJT (1. Alternative): „Das Grundgesetz ... und die Verfassung des Landes ... bilden hierfür Richtlinie und Rahmen.“

100 Vgl. etwa Kübne, a. a. O. (Fn. 57), Fn. 2a zu Art. 7 NRWV; B. Pieroth, a. a. O. (Fn. 40), S. 952; zur ähnlich gelagerten Problematik im spanischen Recht, Alfonso Fernández-Miranda y Compoamor, in: Oscar Alzaga Villaamil (Hrsg.), Comentarios a las Leyes Políticas. Constitución Española de 1978, tomo III, 1983, S. 130.

${ }^{101}$ Dies ist wesentliche Ansatz der Kritik von Frankenberg und Habermas, a. a. O. 
Zum anderen haben Erziehungsziele eine positive, anleitende Funktion $^{102}$. Sie sollen erreichen, daß die Erziehung in ihrem Sinne stattfindet. In dieser Funktion ist die Norm auf Ausfüllung ausgelegt. Das ist für Normen des Völker- und Verfassungsrechts nichts Ungewöhnliches. Hier stellen sich aber zwei Probleme. Das Erziehungswesen stellt ein gesellschaftliches selbstreferentielles Subsystem dar, das für eine rechtliche Steuerung nicht ohne weiteres empfänglich ist ${ }^{103}$. Insbesondere wenn und soweit das Recht auf seine hauseigenen Durchsetzungsmittel der Sanktionen verzichten muß, stellt sich die Frage der Aufnahme der systemfremden Steuerungssignale des Rechts in dem selbstreferentiellen Subsystem des Erziehungswesens, d. h. die Notwendigkeit einer Übersetzung in das System ${ }^{104}$. Eine solche Übersetzung muß erfolgen, sollen gesetzliche, verfassungs-, europa- und völkerrechtliche Erziehungsziele Erzieher wirklich anleiten oder inspirieren. Diese Anleitung ist in den Fällen noch relativ einfach, in denen sich das Ziel aus einem geschriebenen Text ergibt. Ist das Ziel aber erst aus einer Interpretation zu erschließen, wie dies für die aus dem Grundgesetz abzuleitenden Erziehungsziele der Fall ist, so kann eine Aufnahme dieser Ziele im Erziehungswesen nur erfolgen, wenn und soweit der Erzieher an die Gemeinschaft der Verfassungsinterpreten angeschlossen wird. Sieht man zur Lösung dieses Kommunikationsproblems die Kultusbürokratie als den angemessenen Transponder an, so gelangt man schließlich doch wieder zu einer Einschränkung erzieherischer Freiheit durch bürokratisches Regelwerk, die zu Recht kritisiert wird. In der Übertragung rechtlicher Erziehungsziele in die Welt der Erzieher liegt ein wesentliches Problem, das es „unbürokratisch“ zu lösen gilt. Wege dazu gibt es, etwa in der Lehrerfortbildung, in der sich die Gemeinschaft der Verfassungsinterpreten ja durchaus engagiert und weiter engagieren sollte.

Neben dieser anleitenden Funktion haben Erziehungsziele eine legitimierende Wirkung. Sie vermögen auch Erziehungsinhalte gegen rechtliche Angriffe abzusichern. Dies könnte für Erzieher einen zusätzlichen Anreiz darstellen, Erziehungsziele der Verfassung aufzugreifen und sich auf diese zu berufen.

Die Tatsache, daß Erziehungsziele auf unterschiedlichen rechtlichen Ebenen vorgegeben werden, führt auch zu Rangfragen und zur Frage

102 Vgl. dazu das Urteil des spanischen Tribunal Constitucional vom 13. 2. 1981, Boletín de Jurisprudencia Constitucional 1981 - I, S. 23 ff., 33 f., s. a. das Sondervotum Tomás y Valiente, ebd. S. 44.

${ }^{103} \mathrm{Vgl}$. Gunnar Folke Schuppert, Grenzen und Alternativen von Steuerung durch Recht, in: D. Grimm (Hrsg.), a. a. O. (Fn. 91), S. 217 ff., 223 ff.

104 Schuppert, a. a. O., S. 228. 
nach der Vereinbarkeit bestimmter Erziehungsziele mit höherrangigem Recht, insbesondere der Vereinbarkeit von Erziehungszielen der Landesverfassungen mit Bundesrecht. Einzelne geschlechtsspezifische Erziehungsziele älterer Landesverfassungen ${ }^{105}$ sind kaum noch mit dem Gleichheitsgebot des Grundgesetzes und auch nicht mit völkerrechtlichen Normen zur Beseitigung der Diskriminierung der Frau zu vereinbaren.

In der bereits erwähnten Debatte der 70er Jahre wurden die in der Verfassung wirklich oder angeblich angelegten Erziehungsziele in beiden $\mathrm{Be}$ deutungsvarianten als Kampfinstrumente für oder gegen Bildungsreformen eingesetzt ${ }^{106}$. Dieser Vorgang lädt auch zu der Frage ein, ob heute geforderte Erziehungsziele, von denen bereits die Rede war, aus der Verfassung abgeleitet werden können. Er hat aber auch ein Grundproblem der Festlegung von Erziehungszielen im pluralistischen Staat aufgezeigt, nämlich das Spannungsverhältnis zwischen verfassungsrechtlich gebotener Offenheit, Nichtidentifikation oder Neutralität auf der einen und verfassungsrechtlich legitimierter, ja geforderter materialer Wertfixierung auf der anderen Seite.

\subsection{Erziehungsziele im pluralistischen Staat}

Eine Grenze der Befugnis des Staates, Erziehungsziele festzulegen, liegt, das ist im Prinzip unbestritten, im Verfassungsprinzip des Pluralismus. Dieser erfordert eine gewisse Offenheit des Erziehungsprozesses. Doch wo verläuft diese Grenze?

Im Hinblick auf schulische Erziehungsziele ist ein erster, älterer Ansatz E. Steins zur Begründung des Pluralismus-Gebots das Persönlichkeitsrecht des Kindes, Art. 2 Abs. 1 i. V. m. der Menschenwürde-Garantie des Art. ${ }^{107}$. Das Recht des Kindes auf freie Entfaltung fordere es, dem Kinde „einen ausgewogenen Querschnitt, eine repräsentative Auslese von Gedanken der wichtigsten geistigen Strömungen “ zu bieten. Es stehe der Vermittlung „einseitiger Ansichten und von tendenziös ausgewähltem Wissen" entgegen. Hier trifft sich Stein mit erziehungswissenschaft-

\footnotetext{
105 Art. 131 Abs. 4 LV Bayern; Rheinland-Pfalz hat die geschlechtsspezifischen Erziehungsvorgaben des Art. 32 LV kürzlich gestrichen.

106 Eine Übersicht über diese Entwicklung gibt Stock, a. a. O. (Fn. 10), S. 212, 215 ff.; I. Richter, Bildungsverfassungsrecht, 1973, zusammenfassend S. 303 ff.; vgl. auch Reuter, a. a. O. (Fn. 5), S. 126 f.

107 So vor allem Ekkehart Stein, Das Recht des Kindes auf Selbstentfaltung in der Schule, 1967, S. $42 \mathrm{ff}$.
} 
lichen Lehren der pädagogischen Autonomie ${ }^{108}$. Diese Thesen Steins sind in der bildungsrechtlichen Diskussion der 70er Jahre, etwa von Oppermann und Evers, im Grunde akzeptiert, aber um weitere Gesichtspunkte erweitert worden ${ }^{109}$.

Für den weltanschaulich-religiösen Bereich ist dies die Glaubensfreiheit. Art. 4 ist - darauf ist noch zurückzukommen - eine wesentliche Grenze erzieherischer Gestaltungsfreiheit in der Schule, zugleich aber auch positive Leitlinie im Sinne religiöser Toleranz.

Für den gesellschaftlich-politischen Bereich ist dies das Demokratieprinzip, das eine gewisse liberale Grundlage der Schule und Freiheit des Schülers vor einseitiger politischer Indoktrinierung fordert, sowie das Grundrecht der Meinungsfreiheit, das staatsfreie Meinungsbildung ermöglichen will, womit eine einseitige politische Beeinflussung des Schülers nicht vereinbar ist. Aus alledem ist eine ideologische Toleranz als objektive Verpflichtung der Schule, aber auch ein Grundrecht auf eine ideologisch tolerante Schule abzuleiten ${ }^{110}$. Der elternrechtliche Aspekt dieses Befundes stützt sich auf Art. 6 Abs. $2^{111}$.

Diese Ableitung des Pluralismus-Gebotes führt zu zwei Schlüssen. Das Gebot verbietet es nicht, bestimmte wichtige Gemeinschaftswerte zu Erziehungszielen zu erheben. Die Verfassungsnormen, die das Gebot begründen, können und müssen mit anderen Verfassungsnormen gemäß dem Grundsatz der Einheit der Verfassung ${ }^{112}$ im Wege praktischer Konkordanz zum Ausgleich gebracht werden. „Das Toleranzgebot bedarf ... seinerseits einer gleichsam toleranten Anwendung "113. Es ist nicht Sinn des Pluralismus-Gebotes, die Orientierung der Erziehung an bestimmten Verfassungszielen zu verhindern ${ }^{114}$. Weltanschauliche Neutralität bedeutet nicht Wertneutralität, die verfassungsrechtlich gebotene Beschei-

108 Nachw. bei Stock, a. a. O. (Fn. 10), S. 212 ff.

109 Oppermann, Gutachten DJT, insbes. S. C $36 \mathrm{ff}$., $81 \mathrm{ff}$., $92 \mathrm{ff}$.; Evers, a. a. O., insbes. S. 58 ff., 82 ff.; Günter Püttner, DÖV 1974, S. 656 ff.; vgl. ferner Huber, a. a. O. (Fn. 3), S. $553 \mathrm{f}$.

110 BVerwGE 79, 298.

111 Zur Begründung eines Indoktrinierungsverbots im Zusammenhang mit Sexualkunde-Unterricht vgl. Eibe Riedel, Bundesverfassungsgericht und Europäischer Gerichtshof für Menschenrechte zur Frage der Sexualkunde an öffentlichen Schulen, EuGRZ 1978, S. 264 ff. (Art. 6 Abs. 2 GG, Art. 2 Satz 2 1. Zusatzprotokoll zur EMRK).

112 So zutreffend Oppermann, Gutachten DJT, S. C $94 \mathrm{f}$.

113 BVerwGE 79, 298, 307.

114 So ausdrücklich im Hinblick auf die Erziehungsziele der Landesverfassungen BVerfG NVwZ 1990, S. 54; einschränkender Schmitt-Kammler, a. a. O. (Fn. 61), S. $35 \mathrm{ff}$. 
dung in Wertfragen bedeutet keinen Wertrelativismus ${ }^{115}$. Allerdings verhindert das Pluralismus-Gebot eine verabsolutierende Darstellung bestimmter Werte. Ein harter Kern des Verbotsgehalts des PluralismusPrinzips liegt in der vom Grundgesetz vorbehaltlos garantierten Glaubensfreiheit. Insoweit ergeben sich gewisse Probleme aus der Rangordnung der Normen, die Erziehungsziele festlegen. Die religiös gefärbten Erziehungsziele der älteren Landesverfassungen (Erziehung zur „Ehrfurcht vor Gott" oder zur "Gottesfurcht ${ }^{\text {") }}$ sind im Hinblick auf die grundgesetzliche Garantie der Glaubensfreiheit und auf entsprechende völkerrechtliche Normen nicht völlig problemfrei ${ }^{116}$. Die Verfassungen der neuen Bundesländer vermeiden solches ${ }^{117}$. Hier liegt im übrigen auch ein schwieriges Problem neuerer europäischer Verfassungsgebung ${ }^{118}$.

Positiv folgt aus dem Gesagten aber, daß das Pluralismus-Prinzip nicht allein als Verhinderungsgrundsatz verstanden werden darf. Aus ihm ergibt sich vielmehr ein Gebot der Erziehung zu Toleranz und Achtung der Meinung anderer. Ein so verstandenes Toleranzgebot ergibt sich im übrigen auch aus den völkerrechtlichen Vorgaben.

\subsection{Einzelne Erziehungsziele}

Auf der Grundlage des bisher Erörterten sollen nunmehr Existenz und Tragweite einzelner Erziehungsziele untersucht werden. Dabei kann es nicht um eine Gesamtübersicht gehen. Vielmehr seien einige mögliche Erziehungsziele herausgegriffen, die für die eingangs dargestellten gesellschaftlichen Entwicklungen von besonderer Bedeutung sein können:

Es sind dies die Problemkomplexe Selbstverwirklichung und Gemeinschaftsethos, Bindungskrise, Bewährung in der Arbeitswelt und Indu-

115 v. Campenbausen, a. a. O. (Fn. 12), S. 193 ff.; Amdt, a. a. O. (Fn. 4), S. 215.

116 Vgl. dazu J.-D. Kühne, Ehrfurchtsgebot und säkularer Staat, NWVBl 5 (1991), S. 253 ff.; Art. 12 Abs. 1 LV Baden-Württemberg, Art. 131 Abs. 2 LV Bayern, Art. 33 LV Rheinland-Pfalz, Art. 7 Abs. 1 LV NRW.

117 Kübne, a. a. O., (Fn. 67), S. 42.

118 Die portugiesische Verfassung (Art. 43 Abs. 2) schreibt strikte konfessionell weltanschauliche Neutralität staatlicher Erziehung vor, während die spanische Verfassung das Eltern-Recht auf religiöse oder moralische Erziehung gemäß ihrer Überzeugung garantiert (Art. 27 Abs. 3); zu dem damit verbundenen Spannungsverhältnis vgl. Tribunal Constitucional vom 13. 2. 1981, Boletín de Jurisprudencia Constitucional 1981-I, S. 23, 27. Die griechische Verfassung sieht hingegen die Entwicklung einer religiösen Gesinnung noch als Erziehungsziel an (Art. 16 Abs. 2). Angesichts der Tatsache, daß die griechische Verfassung nicht in gleicher Weise Staat und Kirche trennt (vgl. Art. 3) wie dies im übrigen Europa Verfassungspraxis ist, ist ein solches Erziehungsziel konsequent. 
striegesellschaft, Multikulturalismus sowie Frieden und Völkerverständigung.

Der Blick ist dabei auf die besonderen Erziehungsziele der Landesverfassungen, auf Staatszielbestimmungen des Grundgesetzes sowie der Landesverfassungen und schließlich auf sonstige wertsetzende Normen beider Verfassungsebenen gerichtet. Dies ist durch einen Blick auf die Ebenen des EG-Rechts und des Völkerrechts zu ergänzen. Dabei muß unsere Suche offen sein, $d$. h. wir dürfen die rechtliche Landschaft nicht nur auf der Suche nach eventuell als richtig erkannten Lösungen durchstreifen. Wir müssen auch offen sein für die Beobachtung etwaiger gegenläufiger Direktiven. Es könnte ja sein, daß wir bei unserem Streifzug auch einige Verfassungsdefizite aufdecken.

\subsubsection{Erziehungsziel: kritische, verantwortliche und gemeinschafts- orientierte Selbstverwirklichung}

Die Verfassungsentwicklung in Deutschland spiegelt durchaus den Wandel von Pflicht- und Akzeptanz- zu Selbstentfaltungswerten. Blickt man auf die symbolisch-programmatischen Bestimmungen der Verfassungen der neuen Bundesländer, so fällt im Gegensatz zur WRV und zu den älteren Landesverfassungen die Abwesenheit von Pflichtenbestimmungen auf ${ }^{119}$, mit Ausnahme des Bereichs des Umweltschutzes und des klassischen "Eigentum verpflichtet". Im übrigen wird bestimmt, was der Staat alles zu fördern und zu schützen hat. Nur ganz gelegentlich klingt auch der Gedanke von Pflichten an, wenn etwa gesagt wird, daß Kinder den Schutz von Staat und Gesellschaft genießen, was ja wohl jedes einzelne Mitglied der Gesellschaft in die Pflicht nimmt. Insgesamt stimmt das programmatische Bild der neuen Verfassungen etwas nachdenklich. Es entsteht das Bild des netten Staates, der die Selbstverwirklichung seiner Bürger in Arbeit und Kultur fördert. Das ist angesichts der schwierigen historischen Situation, in der diese Verfassungen entstanden sind, verständlich. Insbesondere mußten sich diese Verfassungen absetzen von der Kollektivisierung der vergangenen Epoche. Von daher konnte eine Betonung von Grundpflichten, von Gemeinschaftsgebundenheit als Wiederbelebung eines gerade überwundenen Systems mißverstanden werden ${ }^{120}$.

Auch bei den Erziehungszielen ist die Betonung von Pflicht- und Gemeinsinnwerten in frühen Länderverfassungen stärker als in den neuen.

119 Darauf weist zutreffend hin $P$. Häberle, Die Verfassungsbewegung in den fünf neuen Bundesländern Deutschlands, 1991 bis 1992, JöR 42 (1994), S. 149 ff., 176 f.

$120 \mathrm{Vgl}$. Häberle, a. a. O. (Fn. 119), Kübne, a. a. O., (Fn. 67), S. $41 \mathrm{f}$. 
Art. 148 WRV ist sehr stark von solchen Werten geprägt. Auch in den alten Landesverfassungen überwiegt die Betonung von Pflicht, Tüchtigkeit und Gemeinsinn ${ }^{121}$. Lediglich die bremische Verfassung postuliert daneben so etwas wie einen Selbstentfaltungswert: „die Erziehung zum eigenen Denken, zur Achtung vor der Wahrheit, zum Mut, sie zu bekennen und das als richtig und notwendig Erkannte zu tun." Hingegen betonen die Erziehungsziele der Verfassungen der neuen Bundesländer (mit Ausnahme Sachsens) durchweg Selbstentfaltungswerte ${ }^{122}$ : „Erziehung zu eigenem Denken“, „Entwicklung der freien Persönlichkeit" ${ }^{123}$.

Freilich bleibt diese Selbstentfaltung gemeinschaftsorientiert. Die Landesverfassungen Sachsen-Anhalt ${ }^{124}$ und Mecklenburg-Vorpommern ${ }^{125}$ fordern etwa gleichlautend „die Persönlichkeit, die bereit ist, Verantwortung für die Gemeinschaft mit anderen Menschen und Völkern zu tragen.“ Die Landesverfassung Sachsens ${ }^{126}$ fordert „Erziehung zu sittlichem und politischem Verantwortungsbewußtsein“ und zu „sozialem Handeln". Bei den Erziehungszielen der Verfassungen Thüringens und Brandenburgs findet sich freilich nichts in diese Richtung Deutendes, wenn man von der „Verantwortung für Natur und Umwelt" absieht ${ }^{127}$.

Betont werden als Erziehungsziele auch die Toleranz, die Achtung vor der Würde, dem Glauben und den Überzeugungen anderer, ferner Anerkennung der Demokratie, der Freiheit, Wille zu sozialer Gerechtigkeit oder Solidarität sowie Friedfertigkeit.

Hinsichtlich des Grundgesetzes (und auch hinsichtlich der Verfassungen der alten Bundesländer) ist man für Selbstentfaltung als Erziehungsziel auf die Kunst der Verfassungsinterpreten angewiesen. Den Grundrechten, allen voran Art. 2 Abs. 1, ist ein starkes Bekenntnis zur Selbstverwirklichung eigen, allerdings nie zu einer schrankenlosen, sondern zu einer gemeinschaftsgebundenen Selbstverwirklichung.

121 Art. 12 LV Baden-Württemberg; Art. 131 LV Bayern; Art. 26 LV Bremen; Art. 51 LV Hessen; Art. 7 LV NRW; Art. 33 LV Rheinland-Pfalz.

${ }_{122}$ So Kühne, a. a. O. (Fn. 67), S. 41 f. Deshalb stehe ich Kühnes Versuch, die Verfassungen der neuen Bundesländer ganz in gemeindeutsche Verfassungstradition zu stellen, skeptisch gegenüber.

${ }^{123}$ Art. 28 LV Brandenburg; Art. 15 Abs. 4 LV Mecklenburg-Vorpommern; Art. 27 Abs. 1 LV Sachsen-Anhalt; Art. 22 LV Thüringen.

124 Art. 27.

125 Art. 15.

126 Art. 101.

127 Art. 28 LV Brandenburg. 
Mit „Verantwortung für die Gemeinschaft", Anerkennung der Demokratie $^{128}$, Erziehung zu freiheitlicher demokratischer Haltung ${ }^{129}$ formulieren die neuen Bundesländer Demokratie ausdrücklich als Erziehungsziel. Aber auch das Demokratieprinzip des Grundgesetzes ist als Erziehungsziel zu verstehen. Es fordert Partizipation und Bereitschaft zur Übernahme von politischer Verantwortung in vielen Bereichen - im Kleinen wie im Großen. Zum Demokratieprinzip (in Verbindung mit der Garantie der Meinungsfreiheit) gehört auch die Entwicklung von Kritikfähigkeit im Umgang mit Informationen. Dieses Erziehungsziel wird deutlicher formuliert in den Verfassungsbestimmungen, die Erziehung zu selbständigem Denken und Handeln fordern. Schließlich sind eine wesentliche Anleitung zu gemeinschaftsorientiertem Handeln die Be-

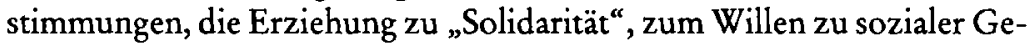
rechtigkeit fordern. Dieses Erziehungsziel ist auch im Sozialstaatsprinzip angelegt.

Erziehung zu verantwortlicher Selbstentfaltung bedeutet auch eine $\mathrm{Er}$ ziehung, die den zu Erziehenden dazu befähigt, sich in dieser Gesellschaft, so wie sie ist und sich entwickelt, zu bewähren, ohne über persönliche Probleme zu neurotischen Frustreaktionen zu gelangen. Entwicklung einer "freien Persönlichkeit" bedeutet eben auch dies. Das heißt, daß die Schule Erfahrung der Selbstverwirklichung ${ }^{130}$, aber auch Sinn für Voraussetzungen und Grenzen solcher Selbstverwirklichung vermitteln muß. Sie soll und muß dem Schüler und der Schülerin helfen, selbständig und ohne traditionsvermittelte Sicherheit einen eigenen sinnvollen Lebensentwurf zu finden. So sollten die ausdrücklichen und impliziten Erziehungsziele unserer Verfassungen verstanden und entfaltet werden.

Dazu gehört auch eine Vorbereitung auf Rollenfindung im persönlichen Leben, die nicht auf traditionelle geschlechtsspezifische Rollen fixiert ist. Der neue Art. 3 Abs. 2 GG und die Gleichberechtigungsvorschriften der neuen Landesverfassungen verpflichten den Staat, die Gleichstellung von Frauen und Männern in allen Lebensbereichen zu fördern. Dies muß auch eine Erziehung bedeuten, die die Bereitschaft und Fähigkeit entwickelt, im privaten und gesellschaftlichen Bereich Gleichberechtigung der Geschlechter zu praktizieren.

${ }^{128}$ LV Brandenburg, Art. 28; LV Thüringen, Art. 22.

129 LV Sachsen, Art. 101.

$130 \mathrm{Vgl}$. Klages, a. a. O. (Fn. 8), S. $36 \mathrm{ff}$. 


\subsubsection{Erziebungsziel: moderne Industrie- und Informationsgesellschaft}

Die Erziehung zur Bewährung in der modernen Arbeitswelt war ein wichtiges Element in der WRV. Auch die frühen Länderverfassungen sehen berufliche Tüchtigkeit oder Fähigkeit ${ }^{131}$ als wichtiges Erziehungsziel an, die bremische Verfassung darüber hinaus die „Erziehung zu einem Arbeitswillen, der sich dem allgemeinen Wohl unterordnet“. In den Verfassungen der neuen Bundesländer ist dieser Aspekt ausgeblen$\operatorname{det}^{132}$. Allein Sachsen fordert u. a. eine Erziehung zu „beruflichem Können“. Im übrigen taucht die Arbeit regelmäßig in dem Zusammenhang eines Rechtes auf Arbeit und des staatlichen Kampfes gegen Arbeitslosigkeit auf. Dessen Wichtigkeit wird niemand bestreiten, aber im $\mathrm{Zu}-$ sammenhang einer umfassenderen Programmatik von Staats- und Erziehungszielen ist dies wohl etwas zu kurz gegriffen.

In Zusammenhang mit dem Arbeitsleben, ja mit wirtschaftlicher Betätigung im allgemeinen ist ein weiteres Erziehungsziel wichtig, nämlich das der sozialen Verantwortung wirtschaftlicher Tätigkeit. Hier leisten die Verfassungen der neuen Bundesländer einen positiven Beitrag, wenn sie Erziehung zu sozialem Handeln (Sachsen), Willen zu sozialer Gerechtigkeit (Brandenburg und Thüringen) als Erziehungsziele angehen.

Wesentliche Aufgabe in der modernen Industriegesellschaft ist die Erhaltung der natürlichen Umwelt als Existenzgrundlage für zukünftige Generationen, ist tragfähiges Wachstum. Dies muß ein wesentliches Erziehungsziel sein. Dies haben schon einige Verfassungen der alten Bundesländer durch Verfassungsänderungen in den 80 er Jahren anerkannt ${ }^{133}$. Die neuen Bundesländer sind sich bei diesem Erziehungsziel der „Verantwortung gegenüber künftigen Generationen ${ }^{134}$, "Verantwortung für

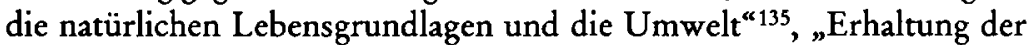
Umwelt $^{\alpha 136}$ einig. Ergänzt wird dies durch ausführliche Staatszielbestimmungen zum Umweltschutz in alten und neuen Bundesländern, die auch Umweltschutzpflichten des einzelnen zum Gegenstand haben ${ }^{137}$, sowie durch das Bekenntnis zur sozialen und ökologischen Marktwirt-

131 Art. 12 Abs. 1 LV Baden-Württemberg; Art. 131 Abs. 1 LV Bayern; Art. 26 Nr. 2 LV Bremen; Art. 56 Abs. 4 LV Hessen; Art. 33 LV Rheinland-Pfalz.

132 Kühne, a. a. O., (Fn. 67), S. 41 f.

133 Art. 7 Abs. 2 LV NRW, Änderung 1985.

134 Mecklenburg-Vorpommern, Art. 15 Abs. 4; Sachsen-Anhalt, Art. 27 Abs. 1.

135 Thüringen, Art. 22 Abs. 1, ähnlich Brandenburg Art. 28.

136 Sachsen, Art. 101 Abs. 1.

137 Brandenburg, Art. 39, Mecklenburg-Vorpommern Art. 12; Thüringen Art. 31-33; Sachsen Art. 10; Sachsen-Anhalt, Art. 25. 
schaft ${ }^{138}$, die zusätzlich als Erziehungsziele interpretierbar sind. Erziehung zur Achtung vor der Umwelt ist auch durch völkerrechtliche Verträge geboten ${ }^{139}$.

\subsubsection{Erziebung in der multikulturellen Gesellschaft}

Die Tatsache, daß unser Land, jedenfalls in seinem städtischen Bereich, sich zu einer multikulturellen Gesellschaft entwickelt hat, stellt besondere Herausforderungen an das Erziehungswesen ${ }^{140}$. Hierbei sind zwei Aspekte zu unterscheiden, nämlich einmal Multikulturalität in der Erziehung, zum anderen Erziehung zum Leben in der multikulturellen Gesellschaft. Zum ersten Aspekt ist nach den Normen zu fragen, die den Umgang der Schulen mit Kindern aus anderen Kulturen bestimmen (also nach rechtlichen Maßstäben für die Organisation der Erziehung), zum zweiten nach in den Verfassungen verankerten Werten, die eine Erziehung zum Leben in der multikulturellen Gesellschaft erfordern oder rechtfertigen (also nach Erziehungszielen im engeren Sinn). Beides ist freilich nicht völlig zu trennen.

\subsubsection{Multikulturalität in der Erziebung}

Normative Grundlagen für den ersten Fragenkreis ist das Toleranzund Pluralismusgebot des Grundgesetzes, Art. 3 Abs. 3, Art. 4 und die Minderheitenschutzregeln der Landesverfassungen. Daneben sind EGrechtliche Vorgaben zu beachten.

Oben wurde gezeigt, daß eine wesentliche Grundlage des PluralismusGebots im Erziehungswesen das durch Art. 2 Abs. 1 und Art. 1 geschützte Entfaltungsrecht des Kindes ist. Für das Kind, dessen Eltern aus einer anderen Kultur stammen, stellt sich die Frage des Entfaltungsrechts in einer besonders prekären Weise. Will es sich in Richtung auf die Erhaltung der eigenen kulturellen Identität entfalten oder in Richtung auf eine Integration, auf ein Aufgehen in der deutschen Kultur. Allerdings wäre es verhängnisvoll, die in dieser Frage angelegten Spannungen im Sinne eines „entweder-oder" lösen zu wollen. Ohne eine genaue Begrifflichkeit bieten zu können, seien nur unterschiedliche Optionen schlagwortartig bezeichnet: Assimilation - Integration - Erhaltung der Iden-

138 Brandenburg, Art. 42 Abs. 2; Thüringen, Art. 38.

139 Art. 29 Abs. 1 (e) der Konvention über die Rechte des Kindes.

140 Vgl. dazu Cobn-Bendit / T. Schmid, a. a. O. (Fn. 37), S. 301 ff.; vergleichend zur multikulturellen Erziehung Benstz, a. a. O. (Fn. 47), 298 f. 
tität - Segregation ${ }^{141}$. Jedenfalls muß eine am Pluralismus-Gebot orientierte Schule dem Kind sowohl die Chance zur Bewahrung der eigenen kulturellen Identität als auch die zur Integration bieten. Das ist um so schwieriger, als das von der Schule zu respektierende Elternrecht und der Entfaltungswille des Kindes oder Jugendlichen sehr weit voneinander abweichen können.

Zum gleichen Ergebnis muß eine sinnvolle Anwendung des Art. 3 Abs. 3 kommen, denn das Verbot der Benachteiligung wegen der Herkunft bedeutet ja nicht, daß Kinder aus anderen Kulturen schlechterdings genauso behandelt werden müssen wie deutsche, sondern daß ein angemessenes Eingehen auf ihre Eigenart durchaus zulässig ist. Das Eingehen auf den Identitätswunsch ist keine Bevorzugung gegenüber deutschen Kindern in gleicher Lage, sondern das Unterlassen einer verbotenen Benachteiligung. Denn praktisch werden Angehörige einer Minderheit dadurch benachteiligt, daß sie sich nicht gemäß ihrer Kultur verhalten dürfen, während die deutschen Kinder eben dieses können ${ }^{142}$.

Die Bemühungen, einen ausdrücklichen Minderheitenschutz zum Bestandteil des Grundgesetzes zu machen, sind kläglich gescheitert. Dabei traf der Minderheiten-Artikel, der wenigstens die Verfassungskommission noch passierte, nur teilweise das hier untersuchte Problem, da er sich auf die in der Bundesrepublik „seit längerer Zeit bestehenden“ Minderheiten ${ }^{143}$, also praktisch auf die „lokalen“ Minderheiten der Dänen, Friesen und Sorben ${ }^{144}$, dazu wohl Sinti und Roma beschränkte. Allein Sachsen hat in seiner Verfassung einen Artikel, der wohl eher das Problem unserer multikulturellen Gesellschaft betrifft, wie es sich in der Realität, nicht zuletzt in der Praxis des großstädtischen Schulalltags stellt: „Das Land achtet die Interessen ausländischer Minderheiten, deren An-

141 Vgl. dazu Thilo Maraubn, Der Status von Minderheiten im Erziehungswesen und im Medienrecht, in: Jochen Abr. Frowein / Rainer Hofmann / Stefan Oeter (Hrsg.), Das Minderheitenrecht europäischer Staaten, Teil 2, 1994, S. 410 ff., 413.

${ }_{142}$ Der Streit um sog. "reverse discrimination “, der damit zusammenhängt, kann an dieser Stelle nicht entfaltet werden.

${ }^{143} \mathrm{Vgl}$. dazu den Abschlußbericht der Gemeinsamen Verfassungskommission, BTDr. 12/6000, S. 74. Zu dem Art. 20b, der schließlich doch nicht ins Grundgesetz aufgenommen wurde, vgl. Alexander $H$. Stopp, Minderheitenschutz im reformierten Grundgesetz, Staatswissenschaften und Staatspraxis 5 (1994), S. 3 ff.; zur Vorgeschichte und zu der Frage des Anwendungsbereichs vgl. Dietrich Franke / Rainer Hofmann, Nationale Minderheiten - ein Thema für das Grundgesetz? EuGRZ 19 (1992), S. $401 \mathrm{ff}, 408 \mathrm{f}$.

144 Auf die Behandlung dieser Minderheiten im deutschen Erziehungswesen kann hier nicht näher eingegangen werden, vgl. dazu Marauhn, a. a. O. (Fn. 141), S. 424, 432. 
gehörige sich rechtmäßig im Lande aufhalten. ${ }^{\text {"145 }}$ Dies dürfte wohl auch die aus den neuen Migrationsbewegungen entstehenden Minderheiten erfassen.

Diese Bestimmung, das versteht sich von selbst, ist auf die Tätigkeit von Land und Kommunen als Schulträger anzuwenden. „Achtung der Interessen" bedeutet, daß ein Wunsch nach Erhaltung der Identität, die von der Gruppe ausgeht und respektiert werden muß. Die Spannung zwischen dem Identitätswunsch der Gruppe und dem eigenen Identitätswunsch des Kindes ist vergleichbar der Frage des Verhältnisses zwischen Schulaufsicht und Elternrecht - und entsprechend zu lösen.

All dieses gibt an sich eine Basis für eine minderheitenfreundliche $\mathrm{Ge}-$ staltung des Schulunterrichts. Dennoch hat sich in der Praxis als Hort des Minderheitenschutzes bislang allein Art. 4 erwiesen ${ }^{146}$. Das Problem hat sich in Deutschland im wesentlichen am koedukativen Sportunterricht entzündet. Das BVerw $G^{147}$ und ähnlich das schweizerische Bundesgericht $^{148}$ haben ein Recht des islamischen Mädchens auf Befreiung aus religiösen Gründen anerkannt. Der Fall zeigt allerdings auch die Grenzen der Rücksichtnahme auf Minderheiten, ebenso wie die Grenzen der Berufung auf Glaubensfreiheit. Es gibt eine Berufung auf Glaubensfreiheit und/oder kulturelle Identität, die nach der Wertordnung unseres Staates als so gemeinschaftsschädigend anzusehen ist, daß sie nicht hingenommen werden kann. Genausowenig wie Pluralismus ist Minderheitenschutz ein absoluter Wert. Er muß vielmehr mit anderen verfassungsrechtlich geschützten Gütern zu einem schonenden Ausgleich gebracht werden. Die Sportentscheidung des BVerwG liegt an der Grenze des angesichts hohen Werts der Gleichberechtigung, des gleichen Persönlichkeitsrechts von Mann und Frau noch zu Akzeptierenden. Das BVerwG hat gut daran getan, seine Entscheidung insoweit einzugrenzen, als es im nicht koedukativen Sportunterricht eine gangbare Alternative sah. Wesentlich ist auch, daß die Eltern und die Tochter gemeinsam auf der Befreiung bestanden. Eine Befreiung aufgrund des religiös motivierten

\footnotetext{
145 Art. 5 Abs. 3.

146 Vgl. dazu Johannes Hellermann, Multikulturalität und Grundrechte - am Beispiel der Religionsfreiheit, in: Christoph Grabenwarter / Stefan Hammer / Alexander Pelzl / Eva Schulev-Steindl / E. Wiederin (Hrsg.), Allgemeinheit der Grundrechte und Vielfalt der Gesellschaft, 1994, S. 129 ff., $134 \mathrm{ff}$.

147 BVerwG NVwZ 1994, S. 78 f. = DVBl. 1994, S. 163 ff.; vgl. dazu Pieroth, a. a. O. (Fn. 40), S. 959 f.; Uwe Wesel, Turnvater Jahn oder der Bart des Propheten, NJW 1994, S. 1389.

148 BGE 119 Ia 178 = Schweizerisches Zentralblatt für Staats- und Verwaltungsrecht 95 (1994), S. 24 m. krit. Anm. Hans Peter Moser.
} 
Wunsches der Eltern gegen den erklärten Willen der Tochter wäre verfassungsrechtlich ausgesprochen bedenklich ${ }^{149}$.

Das schweizerische Bundesgericht beruhigte sich damit, daß das betroffene Mädchen noch nicht 16 Jahre alt war und infolgedessen die Geltendmachung der religiösen Überzeugung dem Vater oblag. Das Gericht machte aber Vorbehalte unter dem Gesichtspunkt der Gleichstellung deutlich. Das Ergebnis des Bundesverwaltungsgerichts ist auch völkerrechtlich nicht unproblematisch, verlangt doch die Konvention zur Beseitigung jeder Form von Diskriminierung der Frau in Art. 10 die „Beseitigung jeder stereotypen Auffassung in Bezug auf die Rolle von Mann und Frau ... in allen Unterrichtsformen durch Förderung der Koeduktion. "Der französische Conseil d'Etat ${ }^{150}$ geht in ganz anderer Weise auf das Verfassungsprinzip des laizistischen Staates ein und begrenzt von daher die Ausübung von Religionsfreiheit oder von Verhalten, das durch religiöse Überzeugungen gefordert ist, in der Schule. In einer Entscheidung aus dem Jahre 1992 hat er zwar das Tragen des Tschador akzeptiert, jedoch ist damit über den Streit zwischen grundsätzlichen Wertvorstellungen des Staates, wozu eben der Laizismus gehört, und Äußerungen islamischer Identität in der Schule letztlich noch nicht entschieden. Gerade kürzlich sind neue Anläufe zur Durchsetzung des Laizismus unternommen worden.

EG-rechtliche Vorgaben für das deutsche Schulwesen betreffen vor allem die für Identität und Integration so wichtige Sprachenfrage. Sie setzen bei der Tatsache an, daß die schulische Versorgung der Kinder die in Art. 48 ff. EGV garantierte Freizügigkeit der Arbeitskräfte berührt ${ }^{151}$. Deshalb stellt die auf Art. 49 EGV gestützte Richtlinie über die schulische Betreuung von Wanderarbeitnehmern ${ }^{152}$ ein doppeltes Erfordernis auf: nämlich einmal ein kostenloser Einführungsunterricht in die Sprache und sonstigen Gegebenheiten des Aufnahmestaates, der "den spezifischen Bedürfnissen dieser Kinder angepaßt “ ist, zum andern die Förde-

${ }^{149} \mathrm{Vgl}$. auch $U$. Wesel, a. a. O.

150 C.E. 27 novembre 1989, L'actualité juridique - Droit administratif 20-1-90, S. 39; C.E. 2 novembre 1992, La Semaine juridique 1993, S. 61; vgl. dazu Françoise Monéger, Les musulmans devant le juge français, Journal de Droit International 1994, S. $345 \mathrm{ff}$.

151 Ein anderes Freizügigkeitsproblem ist die Freizügigkeit für Lehrpersonen. Diese steht staatlichen Maßnahmen zur Förderung von nationaler Identität, insbesondere Maßnahmen zur Pflege einer Nationalsprache nicht entgegen, solange diese Maßnahmen den Grundsatz der Verhältnismäßigkeit beachten, vgl. Rs. C-379/87, Slg. 1989, S. 3967 - Anita Groener gegen Minister of Education and the City of Dublin Vocational Education Committee.

${ }^{152}$ RL 77/486/EWG vom 25. 7. 1977, Abl. Nr. L 199 vom 6. August 1977, S. 32. 
rung einer Unterweisung derselben in ihrer Muttersprache und heimatlichen Landeskunde. Damit erhält die in Deutschland auch verfassungsrechtlich gebotene Gewährung der Chance für Integration im Aufnahmestaat und Bewahrung der heimatlichen Identität eine wichtige Untermauerung.

\subsubsection{Multikulturalität als Erziebungsziel}

Multikulturalität als Erziehungsziel folgt aus dem Toleranzprinzip. Dies ist insbesondere in den Formulierungen der neuen Landesverfassungen ganz deutlich zu sehen. Hier findet sich einmal mehr der Gedanke der Erziehung zur „Achtung vor der Würde des Menschen und Toleranz gegenüber der Überzeugung anderer ${ }^{\alpha 153}$, oder "Achtung vor der Würde, dem Glauben und der Überzeugung anderer ${ }^{\text {" } 154}$ sowie "Friedfertigkeit und Solidarität im Zusammenleben der Kulturen..."

Dieses Toleranzziel kann nicht seinerseits durch das Pluralismusgebot relativiert werden. Lehrinhalte, die diesem Toleranzziel entgegenstehen, sind verfassungswidrig. Allein dies entspricht auch den völkerrechtlichen Verpflichtungen Deutschlands aus den Erziehungszielen der Menschenrechtsverträge ${ }^{155}$.

Eine zusätzliche Dimension gewinnt das Erziehungsziel Multikulturalität durch das Recht der Europäischen Union. Die Ziele der Unionsverträge entfalten ihre Rechtswirkungen für alle deutschen Entscheidungsträger, also auch für die in der schulischen Erziehung verantwortlichen. Das Ziel des Zusammenführens der Völker Europas bedeutet auch ein Gebot, auf die gegenseitige Achtung und Kenntnis der Kulturen Europas im Unterricht hinzuwirken ${ }^{156}$.

\subsubsection{Erziebungsmaßstab Europa}

Dies führt uns zu einem weiteren Gesichtspunkt. Das Bekenntnis zur europäischen Integration, angelegt an der Präambel des Grundgesetzes und im neuen Art. 23, ist u. a. Erziehungsziel. Als solches wirken auch die Unionsverträge. Das muß eine Reihe von praktischen Konsequenzen haben. Unterricht in europäischen Sprachen, Austauschprogramme, Partnerschaften u. a. m. empfangen dadurch eine zusätzliche rechtliche Begründung und - im Zeichen leerer Staatskassen muß es gesagt werden

${ }^{153}$ LV Thüringen, Art. 22.

154 LV Brandenburg, Art. 28.

155 S. o.

156 Vgl. insbes. UnionsV: Präambel; EGV: Präambel, Art. 2, 3, 126-128. 
- Bestandsgarantie. Im Geschichts- und Gemeinschaftskundeunterricht muß sich die europäische Dimension auch inhaltlich niederschlagen ${ }^{157}$.

\subsubsection{Erziebung zur Frieden und Völkerverständigung}

Die Ableitung der Erziehungsziels Frieden und Völkerverständigung ist einfach. Die Präambel des Grundgesetzes gibt sie vor. Art. 25 und 26 konkretisieren dies. Ebenso klar ist das Bekenntnis der Verfassungen vieler alter und der neuen Bundesländer zu Frieden und Völkerverständigung als Erziehungsziel. Dieses Erziehungsziel ist auch durch eine Vielzahl von Verträgen für die Bundesrepublik völkerrechtlich geboten. Es wird zudem ergänzt und unterfüttert durch weitere völkerrechtliche Normen oder Normen nicht-rechtlicher Art, wie wir sie in Resolutionen und Erklärungen der Vereinten Nationen (etwa zum Verbot der Kriegspropaganda $)^{158}$, vor allem aber der UNESCO finden. Grundlegendes Dokument ist hier die Erklärung von Yamoussoukrou über „Peace in the minds of man". Friedenserziehung ist ein wesentliches Element des UNESCO-Programms, das zu fördern sich auch die Bundesrepublik jedenfalls politisch - verpflichtet hat. Sie tut dies insbesondere in den UNESCO-Schulen.

Auch dieses Erziehungsziel ist nicht durch ein Pluralismus-Gebot zu relativieren. Lehrinhalte, die mit diesem Ziel unvereinbar sind, sind verfassungswidrig. Die positive Umsetzung dieses Ziels setzt voraus, daß durch geeignete Aktivitäten in den Schulen eine verantwortliche Haltung für den Frieden in der Welt, und dazu gehört auch der Abbau der bestehenden Wohlstandsdisparitäten, trainiert wird, etwa in Projektwochen, Patenschaften u. a. m.

\subsection{Zur Bedeutung von Erziebungszielen - eine Schlußbetrachtung}

Art. 148 der Weimarer Verfassung habe Hitler nicht verhindert. Das beweise, daß Erziehungsziele in der Verfassung unnötig seien. So kann man bei einem angesehenen Mitglied unserer Vereinigung nachlesen ${ }^{159}$. Bevor ich in die erwartete Widerlegung dieser These eintrete, sei vorher noch eins draufgesetzt: Sind die Bayerinnen bessere Säuglingspflegerinnen, weil allein in der Bayerischen Verfassung die Säuglingspflege als Er-

${ }^{157}$ Zum „Europäischen Geschichtsbuch“ vgl. Dieter Offenhäußer, Wer kennt Daniel O‘Connor?, Das Europäische Geschichtsbuch: Ein Beispiel zur Entnationalisierung von Bildungsinhalten, UNESCO heute 41 (1994), S. 294 ff.

158 Art. 20 IPbpR.

159 Roellecke, FS Geiger, S. 344 f. 
ziehungsziel (nur für Mädchen!) verankert ist ${ }^{160}$ ? Die Absurdität der Fragestellung führt uns zum entscheidenden Punkt: Die Steuerungsfähigkeit rechtlicher Vorgaben für das Erziehungswesen und die Steuerungsfähigkeit des Erziehungssystems für das gesellschaftliche System sind begrenzt. Das bedeutet aber nicht, daß das Erziehungssystem für die gesellschaftliche Entwicklung und daß verfassungsrechtliche-und sonstige rechtliche Vorhaben für das Erziehungssystem irrelevant wären. Sie vermögen zwar keine gesellschaftlichen Großtrends umzukehren ${ }^{161}$, aber sie vermögen eine Feinsteuerung zu leisten. Orientierung des Erziehungswesens durch Verfassung und Orientierung der Gesellschaft durch Erziehung sind Teile eines Prozesses der fortlaufenden Entwicklung von Konsens in dieser Gesellschaft.

Darüber hinaus ist vor einer Überschätzung der Wirkungen zu warnen, die von einer Entfaltung von Erziehungszielen im Wege der Verfassungsinterpretationen ausgehen kann. Fehlt es an geeigneten Verfahren der Übersetzung in die Welt der Erzieher, ist die Mühe vergebens. Eine Perfektionierung von bürokratischen Richtlinienwerken mag ich dabei nicht fordern. Die Inhalte der Verfassung gilt es dem Lehrer in einer Weise verständlich zu machen, die nicht auf den berühmt-berüchtigten Vorrang der Verwaltungsvorschrift vor der Verfassung setzt. Bei der anleitenden Wirkung der Verfassung geht es aber nicht nur um Unterrichtsinhalte, sondern auch um Schulorganisationsmaßnahmen, auch solche mit finanziellen Folgen. Als Beispiel sei noch einmal an Austauschprogramme erinnert. Hier ist nicht nur die Kultusbürokratie, hier sind auch die Finanzminister gefordert.

Wenn all dies recht bedacht wird, dann lohnt sich wohl doch die Anstrengung, durch Verfassungsgebung und Verfassungsinterpretation Erziehungsziele zu entfalten. Der Versuch, auf diese Weise ein wenig zu den Zukunftsproblemen unserer Gesellschaft zu sagen, ist doch nicht untauglich. Oder wollen wir Juristen uns einfach nicht aus der Diskussion um diese Zukunftsaufgabe heraushalten?

160 Art. 131 Abs. 4 LV Bayern.

161 Hier liegt m. E. der richtige Kern der Thesen Helmut Schmidts in der sog. Grundwerte-Diskussion (dazu schon oben Fn. 12), der sich gegen die verfassungsrechtliche Verankerung von Grundwerten wendet. Ethos sei in der Gesellschaft vorgegeben, nicht in der Verfassung verankert: „Der Staat kann ein nicht mehr vorhandenes Ethos nicht mehr zurückholen ... Hier ist der Staat an die Grenze seiner Möglichkeiten gekommen " $(H$. Schmidt, Ethos in Staat und Gesellschaft, in: Gorschenek (Hrsg.), a. a. O. (Fn. 12), S. 13 ff., 22. 
Leitsätze des 1. Berichterstatters über:

\section{Erziehungsauftrag und Erziehungsmaßstab der Schule im freiheitlichen Verfassungsstaat}

1. Die Schule nimmt im gesellschaftlichen System eine Schlüsselfunktion ein, da sie die Schüler auf ibre Rolle in diesem System vorbereitet. Deshalb ist im Hinblick auf sich wandelnde gesellschaftliche Bedingungen immer wieder neu zu fragen, auf welche Ziele schulische Erziebung auszurichten ist und ob die Rechtsordnung, insbesondere die Verfassung diese Ausrichtung wirksam steuern kann und steuert.

2. Die gesellschaftliche Entwicklung ist durch Enttraditionalisierung und Individualisierung geprägt. Dies hat zu einer Veränderung von $\mathrm{Fa}$ milienstrukturen geführt. Die "typische " Familie mit typischer, traditionsgeprägter Rollenverteilung wurde zurückgedrängt, es entstand eine Vielfalt frei gewäblter Formen des Zusammenlebens in familienartigen Gemeinschaften.

3. Selbstentfaltung ist wertneutral. Es bestebt heute in weiten Teilen der Gesellschaft eine Selbstverwirklichung in bedonistischem Sinn, geprägt von Anspruchsdenken und Konsumverbalten. Selbstverwirklichung hat vielfach die notwendige Gemeinschaftsorientierung verloren.

4. Auch Information wird im Zeitalter der visuellen Massenmedien konsumiert und kommerzialisiert. Passivität und verminderte Urteilskraft sind die gemeinschaftsschädliche Folge.

5. Individualisierung und Enttraditionalisierung fübren zu Phänomenen der Vereinsamung und Beziehungslosigkeit, verbinderte Selbstentfaltung resultiert in Frustration. Dies alles erzeugt pathologische Reaktionen: Gewaltbereitschaft, Rechtsextremismus, Drogensucht und Flucht in falsche Geborgenheit, etwa in Jugendsekten.

6. Das Erziehungswesen kann und darf nicht die Entwicklung der Enttraditionalisierung und Individualisierung rückgängig machen. Es muß aber versuchen, den Gefabren, die unseren Gesellschaften aus diesen Entwicklungen droben, entgegenzuwirken und die zu Erziehenden in die Lage zu versetzen, sich in dieser Gesellschaft zurechtzufinden. Es ist nicht auszuschließen, daß es damit überfordert ist.

7. Geboten ist eine Erziehung zu kritischer, verantwortlicher und gemeinschaftsorientierter Selbstverwirklichung. Dazu gebört auch die Ent- 
wicklung der Fähigkeit, in einer enttraditionalisierten Gesellschaft einen sinnvollen Lebensentwurf selbständig zu finden.

8. Anforderungen an das Erziehungswesen ergeben sich aus der Notwendigkeit der Vorbereitung $z u$ Erziebender auf eine Tätigkeit in der internationalisierten, industriell-technischen Welt mit enormen Informationsfliussen (Wirtschaftsstandort Deutschland), der Tatsache, daß Deutschland ein Einwanderungsland (Erziehung in und zu Multikulturalität) und eine Weltmacht ist (Erziehung zu Frieden, Völkerverständigung und internationaler Solidarität).

9. Ein staatlicher Erziehungsauftrag, verstanden als Pflicht zum staatlichen Schulehalten, ergibt sich aus dem Sozialstaatsprinzip, aus Art. 7 GG und aus grundrechtlichen Schutzpflichten. Privatschulen baben daneben lediglich eine komplettierende Funktion, insbesondere im Bereich der weltanschaulich-religiösen Tendenzschule.

10. Der staatliche Erziehungsauftrag bedeutet eine Verpflichtung des Staates, das Schulsystem leistungsfähig zu halten, insbesondere finanziell angemessen auszustatten. Daraus können sich in sebr begrenztem Umfang individuelle Ansprüche ergeben.

11. Die Enttraditionalisierung des Rollenverbältnisses in der Familie und die Entwicklung einer Vielfalt von Formen familiären oder familienähnlichen Zusammenlebens ändern nichts an der grundsätzlichen Gleichordnung von staatlichem Erziebungsauftrag elterlichem Erziebungsrecht. Der Staat darf nicht zum Substituten der Elternerziebung werden, er muß lediglich helfend eingreifen, wenn Eltern, insbesondere Alleinerziebende, mit besonderen Schwierigkeiten in der Erziebung zu kämpfen haben.

12. Die Formulierung von Erziebungszielen entspricht einer verbreiteten Verfassungspraxis. Wir finden sie in der WRV, in den Verfassungen der alten und neuen Bundesländer sowie in einer Reibe von europäischen und außereuropäischen Verfassungen, ferner in internationalen Erklärungen und Verträgen zum Schutz der Menschenrechte.

13. Ausdrücklich formulierte Erziebungsziele sind ein wichtiges Element der Symbolwirkung von Verfassungen.

14. Wesentlichkeitstheorie und Gesetzesvorbehalt bedingen eine Verrechtlichung von Erziebungszielen. Rechtlich normierte Erziehungsziele sind grundsätzlich Finalprogramme, die Freiräume für eine Konkretisierung durch die Erzieher gewäbren müssen. Eine Übersteuerung des Erziehungsvorgangs ist ungeeignet zum Erreichen legitimer Gemeinwohlziele und stellt darum eine unverbältnismäßige Beeinträchtigung von Grundrechtspositionen der am Erziehungsproze $\beta$ Beteiligten dar.

15. Erziehungsziele haben eine negativ-ausgrenzende und eine positiv-anleitende Funktion. 
16. In der ersten Funktion wird das Erziehungsziel zum Konditionalprogramm, da die Verfolgung verbotener Erziebungsziele zu Sanktionen fübren kann. $\mathrm{Ob}$ durch allgemein formulierte Erziebungsziele die Voraussetzungen von Sanktionen mit hinreichender, rechtsstaatlich gebotener Klarheit bestimmt werden, ist zweifelhaft.

17. Die positiv-anleitende Funktion bedarf zur Wirksamkeit einer Aufnabme der rechtlichen Steuerungssignale im gesellschaftlichen Subsystem des Erziehungswesens. Vorbedingung dafïr ist eine Übersetzung, die nicht allein von der Kultusbürokratie vermittelt werden sollte, sondern durch eine „unbürokratische "Einbeziebung der Erzieber in die Gemeinschaft der Verfassungsinterpreten.

18. Die Erziehungsziele der Landesverfassungen sind am Maßstab des Grundgesetzes und völkerrechtlicher Verträge zu messen. Es bestehen Bedenken gegen die Verfassungs- und Völkerrechtmäßigkeit von geschlechtsspezifischen und religiös gefärbten Erziebungszielen älterer Landesverfassungen.

19. Das Verfassungsgebot des Pluralismus stellt eine Grenze für die Festlegung von Erziehungszielen dar, aber es verbietet nicht, bestimmte Verfassungswerte als Erziehungsziele anzuseben. Adererseits stebt es einer verabsolutierenden Darstellung einzelner Werte entgegen und gebietet eine Erziehung zu Toleranz und Achtung der Meinung anderer.

20. Ältere Verfassungen betonen Pflicht, Tüchtigkeit und Gemeinsinn als Erziebungsziele. Die neueren Verfassungen betonen eher das Ziel der Selbstverwirklichung, freilich einer gemeinschaftsverträglichen.

21. Auch die Grundrecbte legitimieren gemeinschaftsverträgliche Selbstverwirklichung als Erziehungsziel. Aus dem Demokratieprinzip folgt als Erziehungsziel der demokratiebereite Mensch. Dazu gebört Bereitschaft zur Partizipation, zur Übernabme von Verantwortung und Fähigkeit zur kritischen Urteilsbildung.

22. Die Entwicklung von Kritikfäbigkeit ist ein wesentliches Erziebungsziel der Verfassungen der neuen Bundesländer.

23. Das Sozialstaatsprinzip entbält als Erziehungsziel Bereitschaft zum solidarischen Handeln auch im gesellschaftlichen Bereich.

24. Die freie Persönlichkeit als Erziehungsziel bedeutet Entwicklung der Fähigkeit, selbständig und ohne Einordnung in Tradition seinen sinnvollen Lebensentwurf $z$ u finden.

25. Sowobl der neue Art. 3 Abs. 2 Satz 2 GG als auch die Gleichberechtigungsziele der Verfassungen der neuen Bundesländer verbieten eine Erziebung auf überkommene gescblecbtliche Rollenverteilung und fordern als Erziehungsziel die Bereitschaft und Fäbigkeit, im privaten und gesellschaftlichen Bereich Gleichberechtigung der Geschlechter zu praktizieren. Altere Bestimmungen von Landesverfassungen, die Erziebung 
$z u$ geschlechtsspezifischen Rollen anstreben, sind insoweit verfassungswidrig.

26. Arbeitsethos und berufliche Tüchtigkeit sind in den ausdrücklichen Formulierungen der Verfassungen der neuen Bundesländer unterbewertet.

27. Wesentliches neues Erziehungsziel ist das Umweltbewußtsein, die Verantwortung gegenüber künftigen Generationen.

28. Multikulturalität in der Erziehung, d. b. die erzieberische Rücksichtnabme auf Kinder aus anderen Kulturen ist durch das Toleranz- und Pluralismusgebot des Grundgesetzes, Art. 3 Abs. 3 und Art. 4 GG sowie durch Minderbeitenschutzregelungen in den Landesverfassungen geboten. Zusätzliche Grundlagen findet dieses Rücksichtnabmegebot in völkerrechtlichen Verträgen und im Recht der Europäischen Union.

29. Multikulturalität als Erziehungsziel ergibt sich aus dem Toleranzgebot und der Menschenwürde-Garantie des GG sowie aus den Erziebungszielen der neuen Landesverfassungen, die die Achtung vor der Würde und der Überzengung anderer verlangen. Eine weitere Grundlage dieses Erziehungszieles sind das Recht der Europäischen Union und völkerrechtliche Verträge.

30. Wesentliche Erziebungsziele sind die Entwicklung eines EuropaBewußtseins sowie die Bereitschaft zu Frieden und Völkerverständigung.

31. Rechtliche Zielvorgaben können die Erziehung nur begrenzt steuern. Auch sind die Einwirkungsmöglichkeiten der Erziebung auf die gesellschaftliche Entwicklung nicht zu überschätzen. Da letztere aber letztlich nicht zu leugnen ist, müssen auch erstere entfaltet und entwickelt werden. 
Erster Beratungsgegenstand:

\section{Erziehungsauftrag und Erziehungsmaßstab der Schule im freiheitlichen Verfassungsstaat}

2. Bericht von Prof. Dr. Armin Dittmann, Stuttgart-Hohenheim

\section{Inhalt}

Einführung

I. Erziehungsauftrag der Schule - auch im freiheitlichen

Verfassungsstaat

II. Grundgesetzliche Grenzen und Vorgaben ........ 53

1. Grundgesetzliche Akzeptanz eines Erziehungsauftrags der Schule ................... 53

2. Erziehungsmaßstäbe des Grundgesetzes ........ 55

a) Grundrechtlich geprägte Maßstäbe $\ldots \ldots \ldots \ldots \quad 56$

b) Weitere grundgesetzliche Maßstäbe ........ 58

III. Erziehungsauftrag und Erziehungsziele in den Ländern 60

1. Landesverfassungsrechtliche Vorgaben ......... 60

2. Aufgaben des Gesetzgebers ............... 63

3. Erziehungsauftrag und Erziehungsziele "vor Ort" Aspekte des „Vollzugs" .................. 65

IV. Die europäische Dimension ................ 68

Schlußbemerkung $\ldots \ldots \ldots \ldots \ldots \ldots \ldots \ldots \ldots \ldots, 70$ 


\section{Einführung}

Dem freiheitlichen Verfassungsstaat - so scheint es - fehlt der „Mut zur Erziehung". Dieser Eindruck drängt sich auf, wenn man kritischen Bestandsaufnahmen von Pädagogen und Bildungspolitikern folgt, die in gesellschaftlichen Fehlentwicklungen, wie z. B. zunehmender Gewaltbereitschaft und Neigung zu politischem Extremismus, eine Krise der Erziehung ausmachen und in diesem Zusammenhang gerade auch auf Erziehungsdefizite der Schule hinweisen ${ }^{1}$. Statt emanzipatorischer und einseitig-wissenschaftlicher Erziehung sollte es Aufgabe der Schule sein, wieder stärker Grundwerte zu vermitteln sowie auf eine Charakter-Erziehung und Gemütsbildung hinzuwirken. Die Schulen seien nicht bloß Dienstleistungsbetriebe zugunsten privater Interessen der Schüler an Ausbildung und Aufstieg, sie hätten zugleich auch öffentlichen Interessen zu dienen, insbesondere die Bindungen an Institutionen wie Ehe, Familie und Staat zu pflegen ${ }^{2}$. Die Vermittlung dieser Grundhaltungen sei in der bildungspolitischen Emphase der 60er und 70er Jahre mit ihren „Bildungsexperten“, „Bildungsreformen“ und „Bildungsplänen“ sträflich vernachlässigt worden ${ }^{3}$. Das Plädoyer für eine „Wiedergewinnung des Erzieherischen “4 reicht vom Bonner Forum „Mut zur Erziehung“ im Jahre 1978 bis zur Neuordnung der baden-württembergischen Lehrpläne in diesem Sommer, bei der eine Stärkung der erzieherischen Komponente des Unterrichts im Vordergrund steht ${ }^{5}$.

Mit der Aufnahme dieser Forderungen durch die Bildungspolitik und ihrer rechtlichen Umsetzung für den schulischen Unterricht ist notwendig auch der verfassungsrechtliche Diskussionsbeitrag eingefordert. Spätestens seit der lebhaften Diskussion der 70er Jahre um die ,Schule im Rechtsstaat sind Fragen der inneren und äußeren Schulangelegenheiten keine ausschließliche Domäne von Erziehungswissenschaft und Bil-

1 So etwa Wolfgang Brzinka, Krise der Kultur - Krise der Erziehung, in: ders. I Franz Petermann / Lothar Schneider (Hrsg.), Mut zur Erziehung, 1994, S. 7 ff.; Fordern statt verwöhnen? Erziehungsziele in der Diskussion, mit Beiträgen von Felix v. Cube, Albin Dannbäuser u. a., Politische Studien, Nr. 333, 1994; Werner Heldmann, Werteerziehung und Gemeinwohlbezogenheit als Auftrag schulischer Erziehung, demnächst in: Aktuelle Fragen der Politik, hrsg. von der Konrad-Adenauer-Stiftung.

2 So W. Brzinka (Fn. 1), S. 15.

${ }^{3}$ So Erich E. Geißler, in: ders. (Hrsg.), Bildung und Erziehung. Notwendige Korrekturen im Schulverständnis?, 1982, S. 12.

4 So der Titel der gleichnamigen Schrift von Hans Maier aus dem Jahre 1972.

5 Vgl. Staatsanzeiger für Baden-Württemberg, Nr. 62, v. 6. 8. 1994, S. 1. 
dungspolitik, sondern auch Rechtsfragen, die nach Maßgabe der Verfassungsordnung des freiheitlichen Verfassungsstaats zu beantworten sind, in Deutschland also vorrangig nach Maßgabe der bundesstaatlich geteilten Verfassungsordnung im Bund und in den Ländern.

Vor diesem Hintergrund ist es erstaunlich genug, daß die Grundsatzfrage nach Erziehungsauftrag und Erziehungsmaßstab der Schule - von der monographischen Behandlung durch Hans-Ulrich Evers ${ }^{7}$ und Peter Häberle ${ }^{8}$ einmal abgesehen - bisher weithin ausgeklammert blieb und erst zu Beginn der 80er Jahre am Rande der seinerzeitigen GrundwerteDiskussion vorübergehend ins Blickfeld geriet ${ }^{9}$. Es ist also verfassungsrechtlich nachzubessern.

\section{Erziehungsauftrag der Schule - auch im freiheitlichen Verfassungsstaat}

Die verfassungsrechtliche Diskussion hat sich zunächst der grundsätzlichen Frage zu stellen, $o b$ der Schule im freiheitlichen Verfassungsstaat überbaupt ein Erziehungsauftrag zukommen kann, ob es also Aufgabe des Staates sein kann, über den Bildungs- und Ausbildungsauftrag der Schule hinaus gezielt auf die allgemeinmenschliche Entwicklung der Schüler einzuwirken.

Es wäre an dieser Stelle allerdings ein hoffnungsloses Unterfangen, die Begriffe Bildung und Erziehung im einzelnen diskutieren und abgrenzen zu wollen, gehören sie doch zu den schillerndsten der Geistesgeschichte

6 Vgl. vor allem die Verhandlungen des 51. DJT im Jahre 1976 zu dem Thema „Nach welchen rechtlichen Grundsätzen sind das öffentliche Schulwesen und die Stellung der an ihm Beteiligten zu ordnen?", insbes. das in diesem Zusammenhang erstattete Gutachten C von Thomas Oppermann und den späteren Bericht der Kommission Schulrecht des DJT, Schule im Rechtsstaat, Bd. I, Entwurf für ein Landesschulgesetz, 1981.

7 Hans-Ulrich Evers, Die Befugnis des Staates zur Festlegung von Erziehungszielen in der pluralistischen Gesellschaft, 1979; ders., Verfassungsrechtliche Determinanten der inhaltlichen Gestaltung der Schule, in: Josef Krautscheidt / Heiner Marré (Hrsg.), Essener Gespräche zum Thema Staat und Kirche, Bd. 12, 1977, S. 104 ff.

${ }_{8}$ Peter Häberle, Erzichungsziele und Orientierungswerte im Verfassungsstaat, 1981; ders., Verfassungsprinzipien als Erziehungsziele, in: FS Hans Huber, 1981, S. $211 \mathrm{ff}$.

9 Von „Unsicherheiten in Grundpositionen“ spricht auch Thilo Ramm, Bildung, Erziehung und Ausbildung als Gegenstand von Grundrechten, in: FS Erwin Stein, 1983, S. 239 ff. (240). 
überhaupt $^{10}$. Für unser Thema genügt die grundsätzliche Feststellung, daß Erziehung und Bildung ein Bild des Menschen zu verwirklichen suchen und damit zwangsläufig weltanschaulichen Inhalt haben. Beide sind tendenziell auf Fremdbestimmung angelegt ${ }^{11}$, Erziehung zudem stärker auf Bindung ausgerichtet. Der Erziehung wohnt immer ein adaptives Element inne, gleichviel, ob man hierunter Anpassung an soziale Verhaltensweisen oder aber das Überzeugtsein von bestimmten Ordnungsvorstellungen versteht.

Es ist dieser Aspekt der Fremdbestimmung, der grundsätzliche Skepsis gegenüber einem Erziehungsauftrag des Staates hervorruft, sei es, daß sich diese Skepsis auf historisch negative Erfahrungen stützt ${ }^{12}$ oder auf die Vermutung der prinzipiellen Unfähigkeit des Staates zur Erziehung. Immerhin läßt es aufhorchen, daß gerade Wilhelm von Humboldt in seiner Schrift „Ideen zu einem Versuch, die Grenzen der Wirksamkeit des Staates zu bestimmen" die „öffentliche Erziehung “ verwirft ${ }^{13}$.

Der freiheitliche Verfassungsstaat teilt diese Skepsis nicht; er steht weder seiner Idee ${ }^{14}$ noch seiner Geschichte nach einem Erziehungsauftrag ablehnend gegenüber. Zumindest in Deutschland ist die Tradition staatlichen Schulehaltens fester Bestandteil des Verfassungsstaates ${ }^{15}$. Diese Tradition bezieht sich auf die äußeren und inneren Schulangelegenheiten gleichermaßen, einschließlich der normativen Festlegung von

$10 \mathrm{Vgl}$. zusammenfassend Clemens Menze, Stw. Bildung, in: Staatslexikon, 7. Aufl., Bd. 1, 1985, Sp. 783 ff. sowie Marian Heitger, Stw. Erziehung, in: Staatslexikon, 7. Aufl., Bd. 2, 1986, Sp. 387 ff. Speziell zu Bildung und Erziehung in der staatlichen Schule Frank Hennecke, Staat und Unterricht, 1972, S. 22 ff. Zum inhaltlich weitgehend synonymen Gebrauch der Begriffe „Bildung ", „Erziehung“, „Ausbildung“ und "Unterricht" in den Landesverfassungen Th. Ramm (Fn. 9), S. $242 \mathrm{ff}$.

11 Zur Fremdbestimmung als wesentlichem Element der Erziehung - im Unterschied zur Bildung - Th. Ramm, (Fn. 9), S. 247 f., 252 ff.

12 Zu Mißbrauchstatbeständen F. Hennecke, (Fn. 10), S. 48 ff.

13 Weitere Beispiele der Kritik am staatlichen Erziehungsauftrag bei $F$. Hennecke (Fn. 10), S. 91 ff. Ablehnend gegenüber einem Erziehungsauftrag des Staates, weil „der Staat in Wahrheit nicht erziehen kann ", auch Gerd Roellecke, Erziehungsziele und der Auftrag der Staatsschule, in: FS Hans Joachim Faller, 1984, S. 187 ff. (195 f.).

14 Zur Idee des Verfassungsstaates zusammenfassend etwa Klaus Stern, Das Staatsrecht der Bundesrepublik Deutschland, Bd. I, 2. Aufl. 1984, S. 80 ff.; Josef Isensee, Staat und Verfassung, in: Isensee/Kirchhof (Hrsg.), Handbuch des Staatsrechts, Bd. I, 1987, $\$ 13$ Rdn. 121 ff.

15 Zur Staatlichkeit des deutschen Schulwesens ausführlich Thomas Oppermann, Kulturverwaltungsrecht, 1969, S. 40 ff., und zum Zusammenhang von Staatsverfassung und Bildungsverfassung ausführlich Ernst Rudolf Huber, Deutsche Verfassungsgeschichte seit 1789, Bd. I, 2. Aufl. (Nachdruck) 1975, S. $261 \mathrm{ff}$. 
Erziehungsauftrag und Erziehungszielen der Schule. Kennzeichnend für das deutsche Schulwesen ist die allerorts enge Verbindung zum Staat. Schulen waren und sind - in der berühmten Formulierung des ALR ganz überwiegend „Veranstaltungen des Staates"16. Über alle verfassungsgeschichtlichen Stufen deutscher Staatlichkeit hinweg blieb die Überzeugung erhalten, daß der Staat an seinen Bürgern eine Erziehungsaufgabe zu erfüllen habe ${ }^{17}$. Die Vorstellung, daß der Staat allein das „Schulhaus" baut, auf die Hausordnung jedoch keinen Einfluß mehr nimmt, ist dem deutschen Schulwesen fremd ${ }^{18}$.

Gerade auch der freiheitliche Verfassungsstaat steht ganz in dieser Tradition. So enthielt bereits die Weimarer Verfassung detaillierte bildungsrechtliche Vorgaben sowie - in Art. 148 WRV - die verfassungsstaatliche Pionierleistung einer Definition von Erziehungszielen ${ }^{19}$. Vor allem aber die Erfahrung mit der Schule im totalitären Staat nach $1933^{20}$ sowie -

${ }^{16}$ Teil II Titel 12 ALR; ausführliche Exegese dieser Grundnorm deutscher Schulentwicklung bei Walter Landé in: Brauchitsch, Verwaltungsgesetze für Preußen, Bd. 6, 1933, S. 63 ff.

$17 \mathrm{Zu}$ dieser Entwicklung und den wechselnden inhaltlichen Zielvorstellungen zusammenfassend Th. Oppermann (Fn. 15), S. $40 \mathrm{ff}$.

18 Wer vor diesem verfassungs- und schulgeschichtlichen Hintergrund einen "staatlichen Erziehungsauftrag" zur Fiktion erklärt, verkennt die Bedeutung des historischen Arguments in der Verfassungsauslegung. So aber Erich Bärmeier in seiner politikwissenschaftlichen Dissertation „Über die Legitimität staatlichen Handelns unter dem Grundgesetz der Bundesrepublik Deutschland. Die Unvereinbarkeit staatlichen Schulehaltens mit den Verfassungsprinzipien der Staatsfreiheit und der Ver-

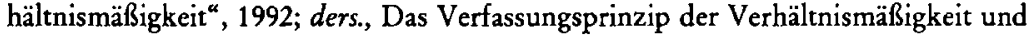
die Unverhältnismäßigkeit staatlichen Schulehaltens, RdJB 1993, S. 80 ff.

19 So P. Häberle (Fn. 8), Erziehungsziele, S. 46. Die wichtigsten Aussagen in Art. 148 lauten:

Abs. 1: „In allen Schulen ist sittliche Bildung, staatsbürgerliche Gesinnung, persönliche und berufliche Tüchtigkeit im Geiste des deutschen Volkstums und der Völkerversöhnung zu erstreben".

Abs. 2: „Beim Unterricht in öffentlichen Schulen ist Bedacht zu nehmen, daß die Empfindungen Andersdenkender nicht verletzt werden ".

Abs. 3: „Staatsbürgerkunde und Arbeitsunterricht sind Lehrfächer der Schule. Jeder Schüler erhält bei Beendigung der Schulpflicht einen Abdruck der Verfassung (...)

Zum Inhalt im einzelnen Walter Landé, Die staatsrechtlichen Grundlagen des deutschen Unterrichtswesens, in: Anschütz/Thoma (Hrsg.), Handbuch des Deutschen Staatsrechts, Bd. II, 1932, $\$ 107$.

${ }^{20}$ Dazu Th. Oppermann (Fn. 15), S. 49 f., sowie zur ideologischen Ausrichtung des schulischen Erziehungsauftrags im Nationalsozialismus die Nachw. in BVerfGE 6, S. $132 \mathrm{ff}$. (155 ff.). 
neuerdings - die Bilanz der Schule im Sozialismus ${ }^{21}$ waren für den freiheitlichen Verfassungsstaat nicht Anlaß, die Schule aus staatlicher Vormundschaft zu entlassen, sondern - ganz im Gegenteil - Grund, schulische Erziehung im Sinne des freiheitlichen Verfassungsstaates zu instrumentalisieren.

Die Landesverfassungen der Jahre 1946/47 legen darüber beredtes Zeugnis ab und dokumentieren mit der verfassungsrechtlichen Fixierung von Erziehungsauftrag und Erziehungszielen deren besondere Bedeutung und den Willen, die neue Konzeption möglichst auf Dauer zu sichern $^{22}$. Sie entsprachen damit zugleich besatzungsrechtlichen Vorgaben - vornehmlich der amerikanischen Siegermacht -, die im Rahmen ihrer "reeducation-Politik" gerade in einer Reform des deutschen Schulwesens die Voraussetzung für die Etablierung dauerhaft demokratischer Strukturen in Westdeutschland sahen ${ }^{23}$.

Auch in den Landesverfassungen und Schulgesetzen der neuen Länder wird der Erziehungsauftrag der Schule - und zwar in allen Ländern nachdrücklich hervorgehoben. Keine der neuen Landesverfassungen meidet den Begriff der Erziehung als Aufgabe der Schule ${ }^{24}-$ im Gegensatz zu den neuen Landesverfassungen in Niedersachsen und SchleswigHolstein ${ }^{25}$.

Vor dem Hintergrund von Tradition ${ }^{26}$ und normativem Anspruch läßt sich also festhalten, daß sich der freiheitliche Verfassungsstaat als legitimiert ansieht, seinen Schulen einen Erziehungsauftrag zu erteilen.

21 Art. 25 Abs. 1, 2 der Verfassung der DDR von 1968 formulierte als oberstes Ziel des Bildungswesens die "sozialistische Gemeinschaft allseitig gebildeter und harmonisch entwickelter Menschen, die vom Geist des sozialistischen Patriotismus und Internationalismus durchdrungen sind“. - Zur Entwicklung des Bildungswesens auf dem Gebiet der DDR von 1945 bis zur Wiedervereinigung vgl. die zusammenfassende Darstellung und Dokumentation von Oskar Anweiler, Hans-Joachim Fuchs u. a. (Hrsg.), Bildungspolitik in Deutschland 1945-1990, 1992.

22 Übersicht bei H.-U. Evers (Fn. 7), Erziehungsziele, S. 34 ff.

23 Einzelheiten dazu demnächst bei Armin Dittmann, Erziehung und Schule, in: Knut Wolfgang Nörr (Hrsg.), Kontinuität und Fremdbestimmung. Zum Einfluß der Besatzungsmächte auf die deutsche und japanische Rechtsordnung 1945-1950.

${ }^{24}$ Art. 28 brand. Verf.; Art. 15 Abs. 4 meckl.-vorp. Verf.; Art. 101 Abs. 1 sächs. Verf.; Art. 27 Abs. 1 sächs.-anh. Verf.; Art. 22 Abs. 1 thüring. Verf. - Zu dieser Eindeutigkeit auch Jörg-Detlef Kübne, Neue Länder - neue Erziehungsziele?, RdJB 1994, S. $39 \mathrm{ff}$.

${ }^{25}$ Landesverfassung für Niedersachsen v. 19.5. 1993 (GVBl.S. 107); Verfassung des Landes Schleswig-Holstein v. 30. 5. 1990 (GVBl. S. 391).

${ }^{26}$ Zur staatstheoretischen Tradition dieser Staatsaufgabe Nachw. bei J.-D. Kühne (Fn. 24), S. 40. 
Allein: Der Hinweis auf Tradition und landesverfassungsrechtlichen Anspruch genügt nicht, um auch für den grundgesetzlich geprägten freiheitlichen Verfassungsstaat ohne weiteres von der Legitimation eines schulischen Erziehungsauftrags ausgehen zu können. Die bundesstaatliche Typik des deutschen Schulrechts läßt die sedes materiae unseres Themas zwar eher auf der Länderebene vermuten und verleiht von daher den landesverfassungsrechtlichen Aussagen besonderes Gewicht ${ }^{27}$. - Jedoch auch diese Aussagen werden vom Grundgesetz überwölbt und eventuell mit der Radikalität des Art. 31 GG verdrängt. Es ist also zu fragen, ob das Grundgesetz einen Erziehungsauftrag der Schule akzeptiert und - gegebenenfalls - Erziehungsmaßstäbe und Erziehungsziele vorgibt.

\section{Grundgesetzliche Grenzen und Vorgaben}

\section{Grundgesetzliche Akzeptanz eines Erziehungsauftrags der Schule}

Das Grundgesetz enthält bekanntlich nur wenige Bestimmungen, die sich ausdrücklich auf das Bildungswesen beziehen. Dies gilt in gleicher Weise für Grundrechtsnormen, institutionelle Garantien und organisatorische Regelungen wie auch für die Zuweisung von Bundeszuständigkeiten im Bildungsbereich ${ }^{28}$. Für Aussagen zur schulischen Erziehung gilt dieser allgemeine Befund allemal.

Soweit in den Grundrechten ausdrücklich Fragen der Erziehung angesprochen werden, steht das Erziehungsrecht der Eltern eindeutig im Vordergrund. Hier liegt, grundgesetzlich gewollt, das Fundament der Erziehung. Pflege und Erziehung der Kinder sind das natürliche Recht der Eltern und die zuvörderst ihnen obliegende Pflicht ${ }^{29}$. Sie haben den Gesamtplan für die Erziehung des Kindes aufzustellen und seinen Bildungsweg zu bestimmen ${ }^{30}$. Der besonders erziehungsrelevante Religionsunterricht wird zwar als ordentliches Lehrfach staatlich garantiert, inhaltlich aber von den Religionsgemeinschaften gestaltet. Der Staat zieht

27 Grundlegend zu Leitprinzipien und Typik des deutschen Schulrechts unter dem Grundgesetz Th. Oppermann (Fn. 15), S. 147 ff. Zum Schulwesen als Kernbereich der Eigenstaatlichkeit der Länder BVerfGE 6, S. 309 ff. ( 353 ff.).

${ }_{28}$ Vgl. zuletzt etwa Klaus Faber / Peter Glotz, Richtlinien und Grenzen des Grundgesetzes für das Bildungswesen, in: Benda/Maihofer/Vogel (Hrsg.), Handbuch des Verfassungsrechts, 2. Aufl. 1994, $\$ 28, S .1364$.

${ }^{29}$ Art. 6 Abs. 2 S. 1 GG - Umfassend zum Elternrecht Hans F. Zacher, Elternrecht, in: Isensee/Kirchhof (Hrsg.), Handbuch des Staatsrechts, Bd VI, 1989, \$134.

${ }^{30}$ BVerfGE 34, S. 165 ff. (183 f.); 53, S. 185 ff. (195 ff.); 59, S. 360 ff. (380). 
sich auf die Rolle des Veranstalters und Kostenträgers zurück ${ }^{31}$. Erst im Zusammenhang mit den Genehmigungsvoraussetzungen für private Schulen in Art. 7 Abs. 4 GG werden "Lehrziele" öffentlicher Schulen beiläufig erwähnt.

Diese erkennbare Scheu des Grundgesetzes, sich ausdrücklich zu einem Erziehungsauftrag der Schule zu bekennen, kann durchaus als eine bereichsspezifische Ausprägung der allgemeinen Abneigung des Grundgesetzes gegen eine staatliche Bevormundung der Bürger gelten, wie sie sich vor allem in der Glaubens- und Bekenntnisfreiheit (Art. 4 Abs. 1 GG), den Kommunikationsfreiheiten (Art. 5 Abs. 1 GG) und dem Zensurverbot (Art. 5 Abs. 1 S. 3 GG) zeigt.

Eine grundgesetzliche Absage an einen Erziehungsauftrag der Schule ist darin jedoch nicht enthalten, denn die Entscheidung des Parlamentarischen Rates, sich zu diesem Thema weitgehend zu verschweigen, hat weniger inhaltliche denn entstehungsgeschichtliche und kompetenzielle Gründe.

Im Zeitpunkt seiner Beratungen waren die wesentlichen bildungspolitischen Entscheidungen - einschließlich der Definition schulischer Erziehungsziele - bereits auf Ebene der Länderverfassungen gefallen. Zudem war es weithin übereinstimmende Auffassung und besatzungsrechtliche Vorgabe zumal ${ }^{32}$, daß das Bildungswesen als Vorbehaltsgut der Länder und tragendes Element ihrer Eigenstaatlichkeit anzusehen und zu sichern sei. Nicht einmal die schwache und seinerzeit kaum ausgenutzte Grundsatzgesetzgebungskompetenz der Weimarer Reichsverfassung für das Schulwesen wurde dem Bund zugesprochen ${ }^{33}$. Das Grundgesetz war von daher nicht der rechte Ort, klare gesamtstaatliche Vorgaben für Erziehungsauftrag und Erziehungsziele der Schule zu machen ${ }^{34}$.

${ }^{31} \mathrm{Zu}$ Einzelfragen des Art. 7 Abs. 3 GG zusammenfassend etwa Alexander Hollerbach, Freiheit kirchlichen Wirkens, in: Isensee/Kirchhof (Hrsg.), Handbuch des Staatsrechts, Bd. VI, 1989, \$140 Rdn. 32 ff.

32 Das an den Parlamentarischen Rat gerichtete Memorandum der Londoner SechsMächte-Konferenz vom November 1948 brachte unmißverständlich zum Ausdruck, daß die Siegermächte die Einräumung von Kompetenzen auf dem Sektor des Erziehungswesens an eine deutsche Zentralebene nicht dulden würden; Text bei Ernst Rudolf Huber, Quellen zum Staatsrecht der Neuzeit, Bd. II (1951), S. 208 f. Näher dazu demnächst A. Dittmann (Fn. 23).

${ }^{33}$ Art. 10 Ziff. 2 WRV.

${ }^{34}$ Zum anderen wirkte auch im Parlamentarischen Rat der "Weimarer Schulkompromiß ${ }^{\star}$ nach und verhinderte von daher eine klare normative Entscheidung über das Verhältnis von Elternrecht und Staatsrecht im Schulwesen; dazu ausführlich Ingo Richter, Bildungsverfassungsrecht, 1973, S. $44 \mathrm{ff}$. 
Trotz dieser erklärlichen Zurückhaltung des Grundgesetzes, dem Staat „Mut zur Erziehung“ zu machen, ist der freiheitliche Verfassungsstaat nach dem Willen des Grundgesetzes nicht aus dem Kreis der Erziehungsberechtigten verbannt.

Bereits das grundgesetzliche Menschenbild mit seiner Vorstellung vom sozial gebundenen und verpflichteten Individuum ${ }^{35}$ nährt die Vermutung, daß dem elterlichen Erziehungsrecht ein staatliches Erziehungsrecht an die Seite gestellt werden könnte ${ }^{36}$. Für die außerschulische Erziehung ist dies mit dem "Wächteramt" der staatlichen Gemeinschaft i. S. eines subsidiären Miterziehungsrechtes ausdrücklich angesprochen ${ }^{37}$. Für den schulischen Bereich versteckt sich der staatliche Anspruch hinter der vorsichtigen und den Staat verbal in eine eher distanzierte. Rolle verweisenden Formulierung des Art. 7 Abs. 1 GG. Es ist aber anerkannt, daß die Aufsicht des Staates über das gesamte Schulwesen neben der Rechtsaufsicht über private und kommunale Schulträger kraft traditioneller Prägung auch die inhaltliche Gestaltungsmacht des Staates im Sinne eines Erziehungs- und Bildungsauftrags umfaßt, einschließlich der Befugnis, die Unterrichtsziele inhaltlich festzulegen ${ }^{38}$. Es war nicht der Wille des Parlamentarischen Rates, mit Art. 7 Abs. 1 GG die entschiedene Inanspruchnahme eines schulischen Erziehungsauftrags durch die Landesverfassungen zu Makulatur werden zu lassen. Das Grundgesetz akzeptiert einen Erziehungsauftrag der Schule.

\section{Erziebungsmaßstäbe des Grundgesetzes}

Mit dieser Grundsatzentscheidung des Art. 7 Abs. 1 GG ist jedoch noch keine Aussage darüber getroffen, ob und inwieweit dem Grundgesetz inhaltliche Vorgaben im Sinne von Erziebungsmaßstäben und Erziehungszielen der Schule zu entnehmen sind.

${ }^{35}$ BVerfGE 5, S. 85 ff. (204); 7, S. 198 ff. (205); 27, S. 1 ff. (6) und st. Rspr. seither.

${ }^{36}$ Zur zulässigen Orientierung schulischer Erziehungsziele an diesem grundgesetzlichen Menschenbild H.-U. Evers (Fn. 7), Essener Gespräche, S. $107 \mathrm{f}$.

37 Art. 6 Abs. 2 S. 2 GG. Zu diesem "Wächteramt" des Staates näher Hans F. Zacher, Elternrecht, in: Isensee/Kirchhof (Hrsg.), Handbuch des Staatsrechts, Bd. VI, 1989, \$ 134 Rdn. 93 ff.; Olaf Miehe, Erziehung unter dem Grundgesetz, in: Reinhard Mußgnug (Hrsg.), Rechtsentwicklung unter dem Bonner Grundgesetz, 1990, S. 249 ff.; Mutmaßungen zur dezenten Wortwahl ("staatliche Gemeinschaft ${ }^{\text {" statt }}$ Staat) bei Theodor Maunz, in: Maunz/Dürig (Hrsg.), Komm. z. GG, Art. 6 Rdn. 26 b.

${ }^{38}$ BVerfGE 34, S. 165 ff. (182); 47, S. 46 ff. (71 ff.). Krit. zur historischen Auslegung der staatlichen Schulaufsicht unter dem Grundgesetz zuletzt Frank-Rüdiger Jach, Schulvielfalt als Verfassungsgebot, 1991, S. 22 ff. und E. Bärmeier (Fn. 18). 
Das Grundgesetz enthält insoweit keine ausdrückliche Festlegung, ist andererseits aber auch nicht "offen" oder "neutral" im Sinne inhaltlicher Indifferenz.

\section{a) Grundrechtlich geprägte Maßstäbe}

Orientierungswerte ergeben sich vor allem aus den Grundrechten in ihrer individualrechtlichen wie objektivrechtlichen Funktion einer Wertordnung, an der sich alle staatliche Tätigkeit auszurichten hat ${ }^{39}$.

Die besonders nachdrückliche Betonung von Elternrecht, konfessionell gebundenem Religionsunterricht und Privatschulfreiheit in Art. 6 und 7 GG verbietet die Festschreibung eines umfassenden staatlichen Monopols bei der Definition von Erziehungsauftrag und Erziehungszielen der Schule. Das Grundgesetz geht von einer Pluralität der Erziehungsmächte aus ${ }^{40}$.

Während die Einflußsphären von Staat und Religionsgesellschaften bei der Gestaltung des Religionsunterrichts durch Art. 7 GG exakt umschrieben werden, ist das Verhältnis von staatlichem und elterlichem Erziehungsrecht im schulischen Bereich grundgesetzlich nicht eindeutig geklärt. In der Formulierung des Bundesverfassungsgerichts bedeutet dies, $\mathrm{da} ß$ die gemeinsame Erziehungsaufgabe von Eltern und Schule ein sinnvoll aufeinander bezogenes Zusammenwirken der beiden Erziehungsträger verlangt ${ }^{41}$. Damit ist allerdings aus naheliegenden Gründen praktischer Unterrichtsgestaltung nicht die individuelle oder kollektive Elternmitbestimmung in der Schule gefordert ${ }^{42}$, sondern die Verpflichtung des Staates, bei der Definition seiner Erziehungsziele die Vielfalt der Anschauungen in Erziehungsfragen im Sinne größtmöglicher Toleranz zu

${ }^{39} \mathrm{Zu}$ diesem objektiv-rechtlichen Gehalt der Grundrechte und den umfassenden Konsequenzen für die gesamte Rechtsordnung zusammenfassend etwa Klaus Stern, Das Staatsrecht der Bundesrepublik Deutschland, Bd. III/1, 1988 ff.; ders., Idee und Elemente eines Systems der Grundrechte, in: Isensee/Kirchhof(Hrsg.), Handbuch des Staatsrechts, Bd. V, 1992, \$109 Rdn. $50 \mathrm{ff}$.

40 "Vorbildlich“ insoweit die Formulierung in Art. 12 Abs. 2 b.-w. Verf.: „Verantwortliche Träger der Erziehung sind in ihren Bereichen die Eltern, der Staat, die Religionsgemeinschaften, die Gemeinden und die in ihren Bünden gegliederte Jugend.“

41 BVerfGE 34, S. 165 ff. (182 f.); 47, S. 46 ff. (74). - Zu den weiteren, insbes. schulorganisatorischen Konsequenzen dieser gemeinsamen Verantwortung vgl. näher etwa Th. Oppermann (Fn. 6), S. 98 ff.; Faber/Glotz (Fn. 28), S. 1376 ff.

$42 \mathrm{Zu}$ diesen unterrichtspraktischen Aspekten ausdrücklich BVerfGE 47, S. 46 ff. (76). 
berücksichtigen, soweit es sich mit einem geordneten staatlichen Schulsystem verträgt ${ }^{43}$.

Inhaltliche Grundsatznorm für die Definition schulischer Erziehungsziele ist das Grundrecht auf die freie Entfaltung der Persönlichkeit (Art. 2 Abs. 1 GG), das - seit Ekkehard Stein - die Selbstentfaltung des Kindes einschließt ${ }^{44}$. Als verfassungsrechtlich vorgegebene Orientierungslinie kann hierbei das grundgesetzliche Menschenbild von der eigenverantwortlichen Persönlichkeit dienen, die sich innerhalb der sozialen Gemeinschaft frei entfaltet ${ }^{45}$. Hieraus fließt die Pflicht des Staates, seine Bildungs- und Erziehungsbemühungen so zu gestalten, daß Schüler die Möglichkeit erhalten, zur kritischen und selbstbestimmten Person heranzureifen ${ }^{46}$. Art. 2 Abs. 1 GG schlägt die verfassungsrechtliche Brücke zur pädagogischen Grundvorstellung eines Pestalozzi und Humboldt, die Bildung als einen Teil der Menschwerdung des einzelnen Menschen begreift ${ }^{47}$.

Über Art. 3 Abs. 1 GG wird der Gedanke der freien Entfaltung der Persönlichkeit mit der Forderung nach individueller Chancengleichheit verbunden. Schulische Erziehung darf nicht nur darauf bedacht sein, Benachteiligungen beim Bildungserwerb abzubauen, sondern hat auch Sonderbegabungen Raum zur Entfaltung zu geben ${ }^{48}$. Umgekehrt zieht Art. 3 Abs. 2 GG geschlechtsspezifisch differenzierenden Erziehungszielen enge Grenzen.

Insgesamt legen diese erziehungsrelevanten „Fundamentalnormen “ des Grundgesetzes dem schulischen Erziehungsauftrag eine das Elternrecht ergänzende und dienende Funktion bei, hat sich Schule in den Dienst der Eltern und - mit zunehmender Mündigkeit - auch des Schülers selbst zu stellen, um sein individuelles „Recht auf Selbstentfaltung" zu unterstützen".

43 BVerfGE 34, S. 165 ff. (183); 47, S. 46 ff. (75).

${ }^{44}$ Ekkehart Stein, Das Recht des Kindes auf Selbstentfaltung in der Schule, 1967.

45 Vgl. Fn. 35.

46 Thomas Oppermann, Schule und berufliche Ausbildung, in: Isensee/Kirchhof (Hrsg.), Handbuch des Staatsrechts, Bd. VI, 1989, \$135 Rdn. 35.

47 Vgl. dazu etwa Herwig Blankertz, Die Geschichte der Pädagogik. Von der Aufklärung bis zur Gegenwart, 1982, S. $101 \mathrm{ff}$.

48 Näher Th. Oppermann (Fn. 46), Rdn. 38 ff.

$49 \mathrm{Zu}$ dieser "unterstützenden" und "fördernden“ Aufgabe des schulischen Erziehungsauftrages ausdrücklich BVerfGE 34, S. 165 ff. (182). Zu einem im Text des Grundgesetzes nicht, in einigen Landesverfassungen hingegen ausdrücklich erwähnten "Recht auf Bildung" zusammenfassend etwa Klaus-Dieter Heymann / Ekkehart Stein, Das Recht auf Bildung, AÖR 97 (1972), S. 185 ff. 


\section{b) Weitere grundgesetzliche Maßstäbe}

Der freiheitliche Verfassungsstaat ist in seinem schulischen Erziehungsauftrag durch das Grundgesetz aber nicht einseitig auf diese dienende Funktion festgelegt. Über das grundgesetzliche Menschenbild von der ,in der Gemeinschaft stehenden und ihr vielfältig verpflichteten Persönlichkeit ${ }^{\alpha}$ eröffnen sich Möglichkeiten, Erziehungsauftrag und Erziehungsziele im Rahmen der grundgesetzlichen Wertordnung auch „überindividuell“ zu definieren. Die "Einheit der Verfassung "50 gebietet, neben den grundrechtlichen auch andere Wertentscheidungen des Grundgesetzes einzubeziehen, das Visier also weit zu öffnen und nicht von vornherein ideologisch zu verengen ${ }^{51}$. Eine Erziehung zur Demokratie, zu umweltbewußter Lebensweise, aber auch die Orientierung schulischer Erziehungsziele am Beschäftigungssystem und an den Anforderungen der Industriegesellschaft sind grundgesetzlich nicht untersagt, denn die ökonomische Leistungsfähigkeit des Gemeinwesens ist materielle Basis des grundgesetzlichen Steuer- und Sozialstaates ${ }^{52}$. Mit einer Erziehung zur Leistungsfähigkeit ${ }^{53}$ und zu sozialem Verhalten ${ }^{54}$ stellt sich die Schule also nicht außerhalb des grundgesetzlichen Rahmens, sondern unterstützt - im Gegenteil - die Persönlichkeitsentfaltung des Schülers und erweitert dessen individuellen Entfaltungsraum i. S. d. Art. 2 Abs. 1 GG. Pestalozzi und Fichte - „Menschenbildung“ i. S. individueller Entfaltung der Persönlichkeit und "Nationalerziehung" i. S. gemeinschaftsorientierter Erziehung - beide haben ihren Platz in der Schule des freiheitlichen Verfassungsstaats ${ }^{55}$. Es war daher eine sehr verkürzte Interpretation der grundgesetzlichen Rahmenbedingungen staatlichen Schulehaltens, wenn es im "Strukturplan für das Bildungswesen“ aus dem Jahre 1970 hieß $^{56}$ :

${ }^{50} \mathrm{Zu}$ diesem „vornehmsten Interpretationsprinzip“ BVerfGE 1, S. 14 ff. (32) und st. Rspr. seither; zusammenfassend etwa Klaus Stern, Das Staatsrecht der Bundesrepublik Deutschland, Bd. I, 2. Aufl. 1984, S. $131 \mathrm{ff}$.

51 So anschaulich H.-U. Evers (Fn. 7), Essener Gespräche, S. 106.

52 Ähnlich in diesem Sinne Th. Oppermann (Fn. 46), Rdn. $9 \mathrm{f}$.

${ }^{53}$ Zur legitimen Orientierung der Schule am Leistungsgedanken H.-U. Evers (Fn. 7), Essener Gespräche, S. 128; Th. Oppermann (Fn. 46), Rdn. $41 \mathrm{ff}$.

${ }^{54}$ Dazu positiv BVerwG, NJW 1982, S. 250 f.

${ }_{55} \mathrm{Zu}$ den Grundideen von Pestalozzi und Fichte sowie deren Rezeption in Preußen zusammenfassend E. R. Huber (Fn. 15), S. 269 ff.

${ }^{56}$ Deutscher Bildungsrat, Empfehlungen der Bildungskommission, Strukturplan für das Bildungswesen, 4. Aufl. 1972, S. 25. - Krit. dazu bereits F. Hennecke (Fn. 10), S. 36 . 
„Dem Bildungswesen fällt insbesondere die Aufgabe zu, die Voraussetzungen dafür zu schaffen, daß der einzelne das Recht auf freie Entfaltung der Persönlichkeit sowie das Recht auf freie Wahl des Berufs wahrnehmen kann."

Angesichts des vehementen Plädoyers von Herrn Häberle, im Wege einer "pädagogischen Interpretation" die erzieherische Dimension der Verfassungsprinzipien freizulegen und die darin bisher verborgenen $\mathrm{Er}$ ziehungsziele verfassungsrechtlich aufzuwerten ${ }^{57}$, ist - bei aller Zustimmung im Grundsätzlichen - folgende Klarstellung angebracht ${ }^{58}$.

Die Verfassungsprinzipien des Grundgesetzes enthalten auch aus meiner Sicht legitime Maßstäbe für die Definition schulischer Erziehungsziele. Ihr Orientierungswert beschränkt sich aber darauf, daß sie lediglich mögliche schulische Erziehungsziele ausweisen und im übrigen Prinzipien umschreiben, gegen die schulische Erziehung keineswegs gerichtet sein darf. Nur in diesem Sinne eines verfassungsrechtlichen Angebotes und einer äußersten Grenzziehung sind die grundgesetzlichen Verfassungsprinzipien für den Erziehungsauftrag der Schule fruchtbar zu machen. Eine Interpretation, die den grundgesetzlichen Verfassungsprinzipien inhaltlich verbindliche Vorgaben im Sinne obligatorischer Erziehungsziele entnähme, liefe Gefahr, die bundesstaatlich gewollte Vielfalt im Bildungswesen "von oben her" $z u$ vereinheitlichen und stünde zudem in krassem Gegensatz zur ausdrücklichen Zurückhaltung des Grundgesetzes in Fragen der inhaltlichen Festlegung des schulischen Erziehungsauftrags. Es ist Aufgabe der Länder, aus ihren jeweiligen Verfassungsprinzipien und unter Beachtung des bundesstaatlichen Homogenitätsgebotes (Art. 28 Abs. 1 S. 1 GG) Konsequenzen zu ziehen, etwa im Sinne einer Erziehung im Geiste der Demokratie oder sozialstaatlicher Solidarität.

Zusammenfassend gilt: Das Grundgesetz enthält in seinem Grundrechtsteil und in anderen verfassungsrechtlichen Grundentscheidungen Maßstäbe für die inhaltliche Orientierung des schulischen Erziehungsauftrags. Diese Maßstäbe verdichten sich jedoch nicht zu einem definitiven und normativ verbindlichen Kanon einzelner Erziehungsziele ${ }^{59}$ oder zu einer bestimmten Rangfolge der verschiedenen Erziehungsträger im

${ }^{57}$ P. Häberle (Fn. 8), in: FS Huber, S. 211 ff. Zum Begriff der „pädagogischen Verfassungsinterpretation “ insbes. S. 228.

${ }^{58}$ Distanziert auch G. Roellecke (Fn. 13), S. 189 f.

59 So auch Th. Ramm (Fn. 9), S. 253. 
schulischen Bereich $^{60}$. Das Grundgesetz steckt lediglich einen Orientierungsrahmen ab und überläßt es den Ländern, diesen Rahmen durch die Definition einzelner Erziehungsziele nach eigenen Vorstellungen auszufüllen ${ }^{61}$.

Diese Zurückhaltung des Grundgesetzes, den Ländern verbindliche Erziehungsziele vorzugeben, stärkt deren Eigenständigkeit und eröffnet Chancen pluraler und kompetitiver Vielfalt im bundesstaatlich gegliederten Bildungswesens. Sie ist daher zu Recht nie ernsthaft in Frage gestellt worden. Weder für die Enquête-Kommission Verfassungsreform des Bundestages der 7. Legislaturperiode ${ }^{62}$ noch für die Gemeinsame Verfassungskommission von Bundestag und Bundesrat ${ }^{63}$ stand eine "Anreicherung" des Grundgesetzes insoweit auf der Tagesordnung. Selbst der berühmt-berüchtigte „Mängel“-Bericht der Bundesregierung über die struktuellen Probleme des föderativen Bildungssystems aus dem Jahre $1978^{64}$ sah allenfalls in Randfragen einen moderaten Korrekturbedarf.

\section{Erziehungsauftrag und Erziehungsziele in den Ländern}

Die Länder haben diesen grundgesetzlich belassenen Freiraum in Sachen Erziehungsauftrag der Schule kraftvoll genutzt und seine nähere Ausgestaltung - mit Ausnahme der Länder Berlin, Hamburg, Niedersachsen und Schleswig-Holstein - sogar als Verfassungsfrage angesehen.

\section{Landesverfassungsrechtliche Vorgaben}

Eine Bestandsaufnahme ${ }^{65}$ der normativ fixierten Erziehungsaufträge und Erziehungsziele ergibt ein überaus buntes Bild von Festlegungen, die sich in Dichte und Offenheit, Phantasie und Prägnanz der inhaltlichen

${ }^{60}$ Zur grundsätzlichen Gleichrangigkeit von Elternrecht und Erziehungsauftrag des Staates BVerfGE 47, S. 46 ff. (72) - „Sexualkunde“ -

61 Vgl. auch BVerfGE 53, S. 185 ff. (196), mit der Anmerkung, daß sich deshalb auch das Bundesverfassungsgericht bei der verfassungsrechtlichen Beurteilung schulrechtlicher Regelungen der Bundesländer große Zurückhaltung auferlegen müsse.

62 Schlußbericht der Kommission in BT-Drucks. 7/5924.

${ }^{63}$ Bericht in BT-Drucks. 12/6000.

${ }^{64}$ BT-Drucks. 8/1551.

${ }^{65}$ Eine Synopse der verfassungsrechtlichen Erziehungsziele der alten Bundesländer bei H.-U. Evers (Fn. 7), Essener Gespräche, S. 131 f.; P. Häberle (Fn. 8), in: FS Huber, S. 213 ff. Speziell zu den neuen Ländern J.-D. Kühne (Fn. 24), S. 41 ff. 
Aussage deutlich voneinander unterscheiden und die in einem mehrfachen „sowohl-als-auch" die Problematik einer praktischen Konkordanz derart pluraler Zielvorstellungen deutlich vor Augen führen, wie etwa Art. 33 rh.-pf. Verf. beispielhaft zeigt:

„Die Schule hat die Jugend zur Gottesfurcht und Nächstenliebe, Achtung und Duldsamkeit, Rechtlichkeit und Wahrhaftigkeit, zur Liebe zu Volk und Heimat, zum Verantwortungsbewußtsein für Natur und Umwelt, zu sittlicher Haltung und beruflicher Tüchtigkeit und in freier, demokratischer Gesinnung im Geiste der Völkerversöhnung zu erziehen.“ Als Reaktion auf die Mißachtung des Menschen im Nationalsozialismus und Sozialismus sowie in teilweise ausdrücklicher Aufnahme der grundgesetzlichen Wertordnung ${ }^{66}$ mühen sich die Verfassungen und Schulgesetze bei der Formulierung ihrer Erziehungsziele, die Grundwerte menschlicher Existenz, Gemeinschaftsbezogenheit, Völkerversöhnung und zunehmend auch die Verantwortung für die Umwelt und künftige Generationen zu aktualisieren ${ }^{67}$. Oberstes Erziehungsziel ist - bei weltanschaulich unterschiedlich grundierter Formulierung ${ }^{68}$ - die Entwicklung des Schülers zu einer sittlichen Persönlichkeit, die durch einen Katalog von Tugenden und Bürgertugenden bestimmt und in das Gemeinschaftsleben von Staat und Gesellschaft eingebunden ist ${ }^{69}$.

Andere Normen sprechen eher das pädagogische Ethos und das Schulklima an, wie etwa die leicht mystifizierende Formulierung in Art. 17 bad.-württ. Verf.: „In allen Schulen waltet der Geist der Duldsamkeit und der sozialen Ethik."

Gewiß: Die teilweise unzulängliche Systematik, das Nebeneinander von Belangvollem und (scheinbar) Zweitrangigem sowie die oftmals entwaffnende Generalität der Formulierungen provoziert den Vorwurf der Leerformel ${ }^{70}$. Dieser Befund ändert aber nichts an der verfassungsrechtlichen Verbindlichkeit dieser normativen Vorgaben. Interpretatorische

${ }^{66}$ Z. B. $\$ 1$ bad.-württ. SchulG; $\$ 2$ Abs. 2 hess. SchulG; Präambel des ersten Schulreformgesetzes des Landes Mecklenburg-Vorpommern; $₫ 2$ Abs. 1 nds. SchulG; $\$ 1$ Abs. 1 sächs.-anh. Schulgesetz; $\mathbb{1} 1$ Abs. 2 sächs. SchulG; $\mathbb{} 2$ Vorl. BildungsG Thüringen.

67 Für die alten Bundesländer H.-U. Evers (Fn. 7), Essener Gespräche, S. 113.

${ }^{68} \mathrm{Vgl}$. etwa die stark christlich geprägte Formulierung in Art. 131 bay. Verf. einerseits, die säkularisiert-nüchterne Formulierung in Art. 28 brand. Verf. andererseits.

69 So H.-U. Evers (Fn. 7), Essener Gespräche, S. 114.

$70 \mathrm{Zu}$ derartigen Vorwürfen bereits H.-U. Evers (Fn. 7), Essener Gespräche, S. 107; w. Nachw. bei J.-D. Kühne (Fn. 24), S. 45 f. Äußerst skeptisch zu Auslegung und Justitiabilität von Erziehungszielen G. Roellecke (Fn. 13), S. 191 ff. 
Schwierigkeiten beruhen auf der vergleichsweise hohen philosopischpädagogischen Aufladung der Begriffe, dürften aber - wie in anderen Fällen interdisziplinär geprägter Verfassungsbegriffe - hermeneutisch zu bewältigen $\operatorname{sein}^{71}$. Überdies sollten scheinbar altväterlich klingende Erziehungsziele, wie z. B. die immer wieder gern zitierte „Liebe zur bayerischen Heimat ${ }^{\text {"72 }}$ gerade in einem dezidiert föderalistisch geprägten Staat nicht der Lächerlichkeit preisgegeben, sondern als Ausdruck landsmannschaftlicher Vielfalt und Eigenart akzeptiert werden.

Neben einem breiten, auf gemeinsamer kultureller Tradition und Geschichte beruhenden Fundament "gemeindeutscher" Erziehungsziele, wie etwa dem Ziel, zu eigenverantwortlicher und schöpferischer Tätigkeit zu befähigen oder die Bereitschaft zu sozialem Handeln und zu politischer Verantwortung zu wecken ${ }^{73}$, setzen einige Landesverfassungen auch eigene Akzente, wie etwa Bremen mit der Erziehung zur Zivilcou$\mathrm{rage}^{74}$. Zumal die neuen Bundesländer haben es nicht bei einer Kopie westdeutscher Vorbilder belassen, sondern aus der Erfahrung einer sozialistischen Vergangenheit ${ }^{75}$ neben überkommenen auch neue Erziehungsziele formuliert und zeitnah fortgeschrieben ${ }^{76}$, vor allem die Verantwortung für Natur und Umwelt in den Kanon aufgenommen ${ }^{77}$. Eigenes Profil zeigen die neuen Länder schließlich auch insoweit, als keines

${ }^{71}$ So J.-D. Kühne (Fn. 24), S. 45 f. unter Hinw. auf die Schwierigkeiten bei der grundgesetzlichen Menschenwürdeauslegung. $\mathrm{Vgl}$. auch das Beispiel des „Thüringer Schulgebets" bei H.-U. Evers (Fn. 7), Essener Gespräche, S. 108 f.

72 Art. 131 Abs. 3 bay. Verf.

${ }^{73}$ Zum länderübergreifend gemeinsamen Nenner von Erziehungszielen vgl. die Erklärung der Ständigen Konferenz der Kultusminister der Länder vom 25. 5. 1973 „Zur Stellung des Schülers in der Schule“, in: Handbuch für die Kultusministerkonferenz, 1977, S. $106 \mathrm{ff}$.

74 Art. 26 Ziff. 3: „Erziehung zum eigenen Denken, zur Achtung vor der Wahrheit, zum Mut, sie zu bekennen und als richtig und notwendig Erkanntes zu tun."

${ }^{75}$ J.-D. Kübne (Fn. 24), S. 41.

${ }^{76} \mathrm{Zu}$ den Erziehungszielen in den neuen Ländern vgl. etwa Frank-Rüdiger Jach, Die Entstehung des Bildungsverfassungsrechts in den neuen Bundesländern, RdJB 1992, S. 268 ff. (272 ff.); Hans-Peter Bull, Die Verfassungen der neuen Länder zwischen östlicher Selbstbestimmung und westlichen Vorgaben, in: FS W. Thieme, 1993, S. 305 ff. (322); Peter Häberle, Die Verfassungsbewegung in den fünf neuen Bundesländern Deutschlands 1991 bis 1992, JÖR 42 (1994), S. 149 ff. (169 ff.); J.-D. Kübne (Fn. 24).

77 Vgl. etwa - mit unterschiedlichen Formulierungen - Art. 28 brand. Verf.; Art. 15 meckl.-vorp. Verf.; Art. 101 sächs. Verf.; Art. 22 thür. Verf. Schon zuvor Art. 131 Abs. 2 bay Verf.; Art. 33 rh.-pf. Verf. 
von ihnen ausdrücklich christliche Erziehungsziele formuliert ${ }^{78}$. Allerdings sind Erziehungsziele wie „Ehrfurcht vor allem Lebendigen“ und „Nächstenliebe“ unverkennbar sprachlich und inhaltlich von einem übergreifend-abendländisch geprägten Verständnis der Welt und eines sinnerfüllten Lebens getragen ${ }^{79}$.

Ungeachtet solcher besonderen Akzentuierungen lassen sich die Erziehungsziele auch der neuen Länder dem gemeindeutschen Kanon zuordnen. Vor allem aber fügen sich die landesrechtlich definierten Erziehungsziele in ihrer Bandbreite zwischen individualbezogener und gemeinschaftsbezogener Orientierung in den grundgesetzlich abgesteckten Rahmen ein. Föderative Vielfalt und gesamtstaatliche Einheit bleiben gleichermaßen gewahrt.

\section{Aufgaben des Gesetzgebers}

Der weitgehende Zugriff der Landesverfassungen auf Erziehungsauftrag und Erziehungsziele der Schule hat - neben der sich darin manifestierenden staatspolitischen Bedeutung des Themas - Konsequenzen für die Rolle des Gesetzgebers in diesem Bereich.

Ohne diesen verfassungsrechtlichen Zugriff wäre es im freiheitlichen Verfassungsstaat - nach Maßgabe der sog. Wesentlichkeitstheorie ${ }^{80}-$ Aufgabe des Gesetzgebers gewesen, die unstreitig grundrechtsrelevanten Festlegungen von Erziehungsauftrag und Erziehungszielen der Schule vorzunehmen, zumal in Abgrenzung zum Erziehungsrecht der Eltern ${ }^{81}$. In den Ländern Berlin, Hamburg, Niedersachsen und Schleswig-Holstein ist das insoweit bestehende verfassungsrechtliche Vakuum entsprechend durch den einfachen Schulgesetzgeber gefüllt worden ${ }^{82}$. Die in der

${ }^{78}$ Für die alten Bundesländer vgl. demgegenüber etwa Art. 12 bad.-württ. Verf. ( der Ehrfurcht vor Gott, im Geiste der christlichen Nächstenliebe“); ähnlich Art. 131 bay. Verf.; Art. 7 nordrh.-westf. Verf.; Art. 33 rh.-pf. Verf.; Art. 30 saarl. Verf.; $\$ 2$ nds. SchulG. - Zu dieser Zurückhaltung J.-D. Kübne (Fn. 24), S. 42.

79 Vgl. etwa Art. 101 sächs. Verf. und näher dazu Wilhelm Holfelder / Wolfgang Bosse, Sächsisches Schulgesetz, 3. Aufl. 1993, \$1 Erl. 8.

${ }^{80}$ Zur Wesentlichkeitstheorie zusammenfassend etwa Fritz Ossenbübl, Vorrang und Vorbehalt des Gesetzes, in: Isensee/Kirchhof (Hrsg.), Handbuch des Staatsrechts, Bd. III, 1988, \$62 Rdn. 41 ff.; speziell zur Bedeutung im Schulbereich Th. Oppermann (Fn. 6), S. 48 ff.; ders. (Fn. 46), Rdn. 15 ff.; H.-U. Evers (Fn. 7), Erziehungsziele, S. $136 \mathrm{ff}$.

${ }^{81} \mathrm{Vgl}$. BVerfGE 47, S. 46 ff. (80).

${ }^{82}$ Vgl. $\$ 1$ berl. SchulG; $\$ 2$ hamb. SchulG; $\$ 2$ nds. SchulG; $\$ 4$ schlesw.-holst. SchulG. 
Mehrzahl der Länder übliche verfassungsrechtliche Regelung, manchmal bis ins Detail ${ }^{83}$, entlastet und sperrt den einfachen Gesetzgeber zugleich. Ihm bleibt formal allein die Möglichkeit, die verfassungsrechtlichen Vorgaben deklaratorisch aufzugreifen, zu konkretisieren und aktualisierend fortzuschreiben.

Das verfassungsrechtliche Korsett dürfte jedoch i. d. R. nicht allzusehr drücken. Angesichts der häufig generalklauselartigen Weite der verfassungsrechtlichen Erziehungsziele eröffnen sich dem Gesetzgeber in der Sache erhebliche Gestaltungsmöglichkeiten, insbesondere bei Gewichtung und Akzentuierung einzelner Erziehungsziele. Der Unterschied zwischen Ländern mit und ohne verfassungsrechtlich normierten Erziehungszielen wird auf der Ebene des Gesetzgebers weithin verwischt.

Die Möglichkeiten des Gesetzgebers, verfassungsrechtliche Erziehungsziele durch spezifische Teilziele und thematische Vorgaben für den schulischen Alltag zu konkretisieren und inhaltlich einzuengen, werden allerdings maßgeblich davon beeinflußt, ob das Erziehungsziel stärker auf die individuelle Entfaltung des Schülers ausgerichtet oder eher gemeinschaftsbezogen ist. Bei Berücksichtigung des Elternrechts und des Grundrechts des Schülers auf die freie Entfaltung seiner Persönlichkeit sind die Grenzen einer inhaltlichen Programmierung des schulischen Unterrichts enger, je mehr es um die Umsetzung von Erziehungszielen vorrangig individualen Zuschnitts geht und um so weiter, je mehr das Erziehungsziel gemeinschaftsbezogen is ${ }^{84}$. Die sich daraus für den Gesetzgeber ableitenden Bindungen und Grenzen seiner Gestaltungsfreiheit sind im einzelnen nur schwer zu bestimmen. Im staatsbürgerkundlichen Unterricht dürfte ein weiter, im Deutsch- oder Ethikunterricht hingegen ein enger Gestaltungsspielraum bestehen. Allein für den Religionsunterricht hat Art. 7 GG derartige Schranken eindeutig abgesteckt und ein inhaltliches Bestimmungsrecht des Staates ausgeschlossen.

Ein Blick auf die Praxis der Landesschulgesetze zeigt einen recht unterschiedlichen Umgang mit der verbleibenden Gestaltungsfreiheit. Während etwa das bremische Schulgesetz sich mit einer generellen Ver-

${ }^{83}$ Vgl. etwa Art. 56 Abs. 5 hess. Verf. zum Inhalt des Geschichtsunterrichts.

${ }^{84}$ Ähnlich diff. Th. Ramm (Fn. 9), S. 256. - Vgl. auch BVerfGE 47, S. 46 ff. (72): „Sexualverhalten ist ein Teil des Allgemeinverhaltens. Deshalb kann dem Staat nicht verwehrt sein, Sexualerziehung als wichtigen Bestandteil der Gesamterziehung des jungen Menschen zu betrachten. Dazu gehört es auch, die Kinder vor sexuellen Gefahren zu warnen und zu bewahren." 
weisung auf die Bildungs- und Erziehungsaufgaben der Landesverfassung begnügt ${ }^{85}$, nehmen andere die verfassungsrechtlichen Vorgaben auf und erläutern die damit verbundenen Aufgaben der Schule anhand besonders hervorgehobener Teilziele ${ }^{86}$ bis hin zur ausdrücklichen Aufnahme neuzeitlicher Bedürfnisse. So wird z. B. den sächsisch-anhaltinischen Schulen die Aufgabe zugewiesen, die Schüler zu individueller Wahrnehmungs-, Urteils- und Entscheidungsfähigkeit in einer von neuen Medien und Kommunikationstechniken geprägten Informationsgesellschaft zu befähigen ${ }^{87}$.

Dennoch: Insgesamt gesehen belassen es auch die Schulgesetze bei recht allgemeinen Zielvorgaben und Aufgabenstellungen für den schulischen Unterricht. Es bleibt mithin der Exekutive vorbehalten, die Erziehungsziele curricular durch Inhalts- und Methodenanweisungen sowie die Zulassung geeigneter Schulbücher für den Schulalltag, letztlich also für die Hand des Lehrers, konkret umzusetzen ${ }^{88}$.

\section{Erziebungsauftrag und Erziehungsziele "vor Ort" - Aspekte des "Vollzugs"}

In den Niederungen des schulischen Alltags entscheidet sich, ob die hehren Vorgaben des Verfassungsrechts und der Schulgesetze die eigentlichen Adressaten erreichen und angenommen werden, entscheidet sich also die Frage von Verfassungsrecht und Verfassungswirklichkeit des schulischen Erziehungsauftrags. Ihr soll an dieser Stelle - zumindest kurz - nachgegangen werden.

Der Idealfall einer Kongruenz von Verfassungsrecht und Verfassungswirklichkeit ist bei der Umsetzung von Erziehungszielen in aller Regel kaum zu erwarten, denn gerade diese verfassungsrechtlichen Vorgaben sind in einem strengen juristischen Sinne nicht vollzugsfähig.

Die praktische Umsetzung des Erziehungsauftrags und die Verwirklichung der Erziehungsziele vor Ort ist zuvörderst eine pädagogisch/

${ }^{85} \$ 2$ Abs. 1 brem. SchulG.

86 Vgl. etwa Art. 1, 2 bay. EUG.

$87 \$ 1$ Abs. 2 Nr. 4 sächs.-anh. SchulG.

88 Der Bildungsgesamtplan 1973 (BT-Dr. S. 7/1974, S. 43) definiert das Curriculum als ein System für den Vollzug von Bildungsvorgängen im Unterricht in bezug auf definierte und operationalisierte Lernziele. Es umfaßt Lernziele, Inhalte des Unterrichts, Methoden, Situationen, Strategien und die Evaluation. - Zu Einzelheiten vgl. Hans Heckel/ Hermann Avenarius, Schulrechtskunde, 6. Aufl. 1986, S. 42 ff. 
didaktische Aufgabe, die - trotz aller partizipatorischen Beimischungen zugunsten von Eltern und Schülern ${ }^{89}$ - den Lehrkräften aufgegeben ist. Die Realisierung von Erziehungsauftrag und Erziehungszielen erfolgt in einem Bereich, der zwar der Verwaltung zuzurechnen und rechtlich strukturiert ist, dessen rechtliche Steuerung aber nicht ohne weiteres in den herkömmlichen Bahnen hierarchischer Ordnung und Weisung erfolgen kann. Der immer wieder ganz allgemein für das Verhältnis von Kultur und Recht herausgestellte Gegensatz von eigengesetzlicher Autonomie und staatlich-normativer Reglementierung des Kulturellen gilt gerade auch für den Schulbereich ${ }^{90}$. Mit der Anerkennung von Ein- und Mitwirkungsrechten der Erziehungsberechtigten sowie der bereits als grundrechtsmündig angesehenen Schüler trägt das Schulrecht dieser Besonderheit Rechnung, wandelt sich die Schule von der obrigkeitlichen Lehranstalt zur Unterrichtsgemeinschaft, wird der Befehl durch den Dia$\log$ ersetzt ${ }^{91}$. In der zum Teil normativ anerkannten „pädagogischen Freiheit ${ }^{\alpha 22}$ wird das personale Element der schulischen Erziehung ausdrücklich betont. Materiell ist es dem Lehrer anvertraut, Unterricht und Erziehung aus seiner Persönlichkeit heraus und mit seinem Beispiel ${ }^{93}$ zu gestalten. Diese Gestaltungskraft kann ihm nicht von außen vorgegeben werden, insbesondere nicht durch staatliche Rechtssätze ${ }^{94}$. Erziehung und Unterricht sind im wahrsten Sinne des Wortes ein "Humanum“. Vollzugsdefizite können nicht ausbleiben. Der freiheitliche Verfassungsstaat wird an dieser Stelle seiner Zielvorstellungen stets unvollendet bleiben. Diese Einsicht mag Trost spenden in Zeiten für fehlsam gehaltener

${ }^{89}$ Zusammenfassend zum Stand der institutionellen Beteiligung von Eltern und Schülern an den Entscheidungen der Schule Heckel/Avenarius (Fn. 88), S. 69 ff.

90 Dazu Th. Oppermann (Fn. 15), S. 6 ff. und speziell zu dieser Antinomie im Schulbereich Gerd Roellecke, Zum Verhältnis von Recht und Erziehung, in: FS Willi Geiger 1989, S. $342 \mathrm{ff}$.

${ }^{11}$ So bereits Th. Oppermann (Fn. 15), S. 157.

92 Vgl. $\$ 59$ Abs. 2 hess. SchUG; zu terminologisch anderen gesetzlichen Regelungen zusammenfassend Heckel/Avenarius (Fn. 88), S. $234 \mathrm{ff}$.

${ }^{93}$ Zur Bedeutung des Vorbildes in der Pädagogik vgl. etwa Friedrich Rast, Vorbild, in: Dieter Lenzen (Hrsg.), Pädagogische Grundbegriffe, Bd. 2, 1989, S. 1585 ff. Zur Bedeutung des gelebten Vorbildes in der schulischen Erziehung auch Bernhard Sutor, Gewissensbildung und Werterziehung als öffentlicher Bildungsauftrag, in: Politische Bildung in der Demokratie, 1990, S. 21 ff. (42).

${ }_{94}$ Zur Problematik einer Steuerung des Erziehungsprozesses durch Normen bereits H.-U. Evers (Fn. 7), Erziehungsziele, S. 120 ff.; vgl. auch Theodor Maunz, Gestaltungsfreiheit des Lehrers und Schulaufsicht des Staates, in: FS Günter Dürig, 1990, S. $269 \mathrm{ff}$. (272). 
schulrechtlicher Rahmenbedingungen ${ }^{95}$, gilt aber auch zu anderen Zei$\operatorname{ten}^{96}$.

Es ist daher keine Kapitulation vor den „Sachgesetzlichkeiten“ des Schulehaltens bzw. gar ein Plädoyer für die Anerkennung einer rechtsfreien „pädagogischen Provinz ${ }^{\text {“97 }}$, wenn ich den gegensteuernden Hinweisen auf die Verfassungstreuepflicht der beamteten Lehrer ${ }^{98}$, ihre ausdrückliche Verpflichtung auf die verfassungsrechtlich festgelegten Erziehungsziele ${ }^{99}$ und das disziplinarrechtliche Damoklesschwert nur wenige Erfolgschancen einräume, auf diesem Wege den verfassungsrechtlich vorgegebenen Erziehungszielen zum praktisch-pädagogischen Durchbruch zu verhelfen.

Die Schule ist eben auch in dem Sinne „Schule der Nation“, daß sich in ihr letztlich nur die Wertvorstellungen vermitteln lassen, die auch außerschulisch von einem gesellschaftlichen Konsens sowie der Lehrerschaft getragen werden. Diese Einsicht relativiert nicht die Legitimation des Verfassungsstaates, seine verfassungsrechtlich vorgegebenen Erziehungsziele gegebenenfalls auch gegen einen andersartigen gesellschaftlichen Trend zu behaupten und zu verfolgen. Sie stellt aber in Rechnung, daß gerade der freibeitliche Verfassungsstaat kein umfassendes Bestimmungsrecht über "seine" Schüler haben kann, sondern daß auf diese Schüler legitimerweise - und unter dem Schutz der Verfassung - andere, „außerstaatliche Mächte" erzieherisch einwirken, die nicht an die verfassungsrechtlichen Erziehungsziele gebunden sind ${ }^{100}$. So weisen zwar die im Staatsvertrag über den Rundfunk im vereinten Deutschland normier-

${ }^{5}$ Thomas Oppermann, Humane, verrechtlichte, gerechte Schule?, in: Erich E. Geißler (Hrsg.), Bildung und Erziehung. Notwendige Korrekturen im Schulverständnis?, 1982, S. $134 \mathrm{ff}$.

${ }^{6} \mathrm{Vgl}$. die Feststellung von Josef Isensee, in: Isensee/Kirchhof (Hrsg.), Handbuch des Staatsrechts, 1990, Bd. IV, $\$ 98$ Rdn. 80, daß die Länder nach 1968 ihre eigenen landesverfassungsrechtlichen Erziehungsziele durchweg ignoriert haben.

${ }^{77}$ Zur Vorstellung einer „pädagogischen Provinz“ vgl. etwa I. Richter (Fn. 34), S. $241 \mathrm{f}$.

${ }_{98} \mathrm{Vgl}$. neben der allgemeinen verfassungsrechtlichen Treuepflicht der Beamten die speziell unterrichtsbezogene Regelung in Art. 56 Abs. 5 S. 3 hess. Verf.: „Nicht zu dulden sind Auffassungen, welche die Grundlagen des demokratischen Staates gefährden.“ Nach BVerwGE 61, S. 176 ff. (179) muß ein Bewerber um eine Lehrerstelle "als Lehrer im Unterricht auch die Grundwerte und Grundentscheidungen der Verfassung glaubhaft vermitteln".

99 Vgl. etwa $\$ 38$ bad.-württ. SchulG; Art. 38 bay. EUG.

$100 \mathrm{Zu}$ diesen "Schwachstellen" bei der Realisierung verfassungsrechtlicher Erziehungsziele vgl. vor allem G. Roellecke (Fn. 13), S. 187 ff. 
ten Programmgrundsätze eine erstaunliche Parallelität zu schulischen Erziehungszielen auf ${ }^{101}$, garantieren damit aber noch keineswegs ein kongeniales Zusammenspiel mit den Bemühungen schulischer Erziehung.

Daß sich in Schulkassen mit hohem, teilweise mehrheitlichem und zudem oftmals heterogenen Ausländeranteil ${ }^{102}$ zusätzliche pädagogischpraktische Vermittlungsprobleme stellen, sei zumindest als Fußnote angemerkt. Trotz aller "Internationalisierung" durch Erziehungsziele, wie z. B. „Völkerversöhnung“, „Brüderlichkeit aller Menschen“ oder „Solidarität im Zusammenleben der Kulturen und Völker" ${ }^{103}$, werden viele Lehr- und Lerninhalte im Kern legitimerweise von nationaler Kultur und Geschichte bestimmt und sind von daher einem beträchtlichen Teil der Schüler um so schwerer zu vermitteln ${ }^{104}$.

Man sollte also erkennen, daß hier - auf der pädagogisch-praktischen Ebene des Schulalltags - aus vielerlei Gründen die Achillesferse des freiheitlichen Verfassungsstaats liegt, Erziehungsauftrag und Erziehungsziele seiner Schule in Verfassungswirklichkeit umzusetzen.

\section{Die europäische Dimension des Themas}

Unser Thema hat schließlich auch eine europäische Dimension, denn der freiheitliche Verfassungsstaat des Grundgesetzes ist auf die Europäische Integration hin angelegt und in sie eingebunden.

Es ist deshalb nicht von vornherein auszuschließen, daß über die Brücke der grundgesetzlichen Integrationsentscheidung auch Erzie-

$101 \$ 23$ Abs. 1 RfStV: „Für die Rundfunkprogramme gilt die verfassungsmäßige Ordnung. Die Rundfunkprogramme haben die Würde des Menschen sowie die sittlichen, religiösen und weltanschaulichen Überzeugungen anderer zu achten. Sie sollen die Zusammengehörigkeit im vereinten Deutschland und die internationale Verständigung fördern."

102 Der Bericht der Beauftragten der Bundesregierung für die Belange der Ausländer über die Lage der Ausländer in der Bundesrepublik Deutschland vom März 1994 weist folgende Zahlen aus: 1991 besuchten 6991500 Schülerinnen und Schüler eine allgemeinbildende Schule. Davon waren 801800 Ausländerinnen und Ausländer. Ihr Anteil betrug demnach 11,5\%. Diese verteilten sich zu 26,8 \% (214 500) auf Hauptschulen, zu 10,0\% auf Gymnasien (80 400) und zu 5,8 \% (46 400) auf Sonderschulen.

Von den 6189700 deutschen Schülerinnen und Schülern besuchten 13,5\% (840 600) eine Hauptschule, 3,4 \% (212 100) eine Sonderschule und 24,1\% ein Gymnasium. Ein Vergleich dieser Gruppen zeigt, daß Schülerinnen und Schüler mit ausländischem $\mathrm{Paß}$ überwiegend an Hauptschulen anzutreffen sind. Wie bei deutschen ist auch bei diesen allerdings ein Trend zur gymnasialen Ausbildung festzustellen.

103 So jetzt z. B. Art. 28 brand. Verf. und ähnlich Art. 22 thüring. Verf.

104 Ähnlich Th. Ramm (Fn. 9), S. 262 f. 
hungsauftrag und Erziehungsziele des Europa zugewandten freiheitlichen Verfassungsstaates beeinflußt werden.

Ich denke dabei nicht in erster Linie an die Vorgabe bestimmter Erziehungsziele durch das Europarecht. Zwar gehören seit Schaffung der Europäischen Union allgemeine und berufliche Bildung zu den enumerativ benannten Tätigkeitsbereichen der Gemeinschaft ${ }^{105}$, verbindliche Erziehungsaufträge oder Vorgaben für Erziehungsziele der Mitgliedstaaten sind damit jedoch nicht verbunden. Im Gegenteil: Die Verantwortung der Mitgliedstaaten für die Lehrinhalte wird ausdrücklich betont und die Zuständigkeit der Gemeinschaft auf lediglich unterstützende und ergänzende Maßnahmen begrenzt. Europarechtlich definierte Erziehungsaufträge und Erziehungsziele wären damit nicht vereinbar.

Eher schon bieten etwa die allgemeine Loyalitätspflicht des Art. 5 EGV und insbesondere Art. 119 EGV Ansatzmöglichkeiten ${ }^{106}$, mitgliedstaatliche Erziehungsziele im Sinne einer ökonomischen Analyse daraufhin zu befragen, ob sie die Verwirklichung gemeinschaftsrechtlicher Zielvorstellungen tendenziell behindern, $z$. B. geschlechtsspezifisch differenzierende Erziehungsziele mittelbar unterschiedlich hohe „Marktzutrittschancen" aufrichten.

Vor allem aber birgt die Unterstützungs- und Ergänzungskompetenz der Europäischen Union im Bereich von allgemeiner und beruflicher Bildung die Möglichkeit, durch finanzielle Fördermaßnahmen bestimmten Erziehungszielen besonderes Gewicht zu verleihen und damit die Pluralität der nationalen Erziehungsziele faktisch im Sinne einer Rangfolge zu ordnen. Auf seiten der Kommission ist ein entsprechender Wille zur Einflußnahme unverkennbar vorhanden. Weite Teile des Grünbuchs der Kommission zur Europäischen Dimension des Bildungswesens vom September 1993 lesen sich wie die Formulierung von Erziehungszielen.

105 Art. 126, 127 EGV; näher dazu etwa Gerbard Konow, Bildungspolitik nach Maastricht, RdJB 1992, S. 427 ff.; Rüdiger Dohms, Die Kompetenz der EG im Bereich der allgemeinen Bildung nach Art. 126 EGV, RdJB 1992, S. 451 ff.; Jörg E. Feuchtbofen / Hans-Jürgen Brackmann, Berufliche Bildung im Maastrichter Unionsvertrag, RdJB 1992, S. 468 ff.; Rudolf Lassahn / Birgit Ofenbach (Hrsg.), Bildung in Europa, 1994.

106 Näher zu den sich daraus ergebenden Unterlassungspflichten etwa Eberhard Grabitz, Art. 5 Rdn. 10, in: ders. (Hrsg.), Komm. z. EWG-Vertrag, Stand: Sept. 1992; Reinhard Junghanns, Art. 119 Rdn. 18 ff., in: Carl Otto Lenz (Hrsg.), EG-Vertrag, 1994. Vgl. in diesem Zusammenhang etwa die ausbildungsbezogenen Aspekte in der Richtlinie des Rates vom 9. 2. 1976 zur Verwirklichung des Grundsatzes der Gleichbehandlung von Männern und Frauen hinsichtlich des Zugangs zur Beschäftigung, zur Berufsbildung und zum beruflichen Aufstieg sowie in bezug auf die Arbeitsbedingungen (76/207/EWG) - Abl. Nr. 39 vom 14.2. 1976. 
So wird z. B. der Auftrag der Schule darin gesehen, Selbständigkeit, Urteils-, Kritik- und Innovationsfähigkeit zu entwickeln sowie Verantwortungsbewußtsein für die Solidargemeinschaft zu vermitteln oder - ganz direkt - eine Erziehung zur Unionsbürgerschaft zu betreiben ${ }^{107}$.

Unabhängig von diesen denkbaren europarechtlichen Einwirkungen auf Erziehungsauftrag und Erziehungsziele der Schule bleibt es den Mitgliedstaaten unbenommen, im Rahmen des nationalen Rechts das Thema "Europa" in den schulischen Erziehungsauftrag einzubinden, nicht im Sinne einer grundgesetzlich verbindlichen Vorgabe ${ }^{108}$, wohl aber als pädagogisch sinnvolle Konsequenz aus der bewußten Öffnung des grundgesetzlichen Verfassungsstaats nach Europa. Bisher haben nur Niedersachsen und Sachsen-Anhalt diese Konsequenz auch normativ gezogen $^{109}$.

\section{Schlußbemerkung}

Ich komme zum Schluß und erinnere an die eingangs geäußerte Vermutung, daß dem freiheitlichen Verfassungsstaat der „Mut zur Erziehung" fehle. Die Analyse des grundgesetzlichen Verfassungsstaats hat diese Vermutung - so meine ist - widerlegt. Zumindest seinem eigenen verfassungsrechtlichen Anspruch nach bekennt sich der grundgesetzliche Verfassungsstaat zum Erziehungsauftrag der Schule und zu konkreten Erziehungszielen, das Grundgesetz eher verdeckt, die meisten Landesverfassungen hingegen überaus dezidiert. Wie in anderen Fällen verfassungsrechtlicher Grundsätze und unbestimmter Rechtsbegriffe mindern auch hier unbestreitbare Schwierigkeiten der Auslegung und der Umsetzung in der Schule nicht die normative Verbindlichkeit, noch sind sie ein Indiz dafür, daß sich der freiheitliche Verfassungsstaat mit diesem Anspruch „ultra vires“ bewege, die staatliche Schule als Erziehungsträger nicht tauge.

Ernst Wolfgang Böckenförde hat 1967 formuliert ${ }^{110}$, der freiheitliche, säkularisierte Staat lebe von Voraussetzungen, die er selbst nicht garan-

$107 \mathrm{Vgl}$. Kommission der Europäischen Gemeinschaft, Grünbuch zur Europäischen Dimension des Bildungswesens, vom Sept. 1993 - Kom. (93) 457 endg., insbes. S. 5.

108 So aber wohl Peter Häberle, Föderalismus, Regionalismus, Kleinstaaten - in Europa, DV 1992, S. 19.

109 Die europäische Dimension findet sich als Erziehungsziel bisher lediglich in $\$ 2$ Abs. 1 nds. SchulG, $\$ 1$ Abs. 2 sachs.-anh. SchulG v. 11. 7. 1991 (GVBl. S. 165) sowie verhalten in $\$ 4$ schlesw.-holst. SchulG v. 2. 8. 1978 (GVBI. S. 255).

${ }^{110}$ Ernst-Wolfgang Böckenförde, Die Entstehung des Staates als Vorgang der Säkularisation, in: FS Ernst Forsthoff, 1967, S. 75 ff. 
tieren könne. Diese Einschätzung mag in letzter Konsequenz zutreffen. - Sie kann m. E. jedoch nicht bedeuten, daß der freiheitliche Verfassungsstaat völlig darauf verzichtet, mit den ihm adäquaten Methoden des Maßes und der Toleranz seine jungen Bürger auf diese Voraussetzungen hin zu orientieren und zu erziehen, m. a. W.: eine Pflege der Freiheitsvoraussetzungen, also Staatspflege ${ }^{111}$ im besten Sinne zu betreiben. Insoweit darf Schule durchaus "Schule der Nation" sein, darf sich die wehrhafte auch als „lehrhafte“ Demokratie ausweisen.

111 Zur existentiellen Bedeutung der „Staatspflege“ gerade für den freiheitlichen Staat und durch die Schule Herbert Krüger, Allgemeine Staatslehre, 2. Aufl. 1966, S. 214 ff. (228 f.). 
Leitsätze des 2. Berichterstatters über:

\section{Erziehungsauftrag und Erziehungsmaßstab der Schule im freiheitlichen Verfassungsstaat}

1. In der Diskussion um die "Schule im Rechtsstaat" war die Grundsatzfrage nach Erziehungsauftrag und Erziehungsmaßstab bisher kein zentrales Thema. Angesichts zunehmender Forderungen von Pädagogen und Bildungspolitikern nach einer "Wiedergewinnung des Erzieberischen" ist insoweit verfassungsrechtlich nachzubessern.

2. Erziehung (und Bildung) wirken gezielt auf die Entwicklung des Schülers ein. Beide sind tendenziell auf Fremdbestimmung angelegt, Erziebung zudem stärker auf Bindung an Werte, Ordnungsvorstellungen und soziale Verbaltensweisen ausgerichtet.

3. Der Aspekt der Fremdbestimmung weckt grundsätzliche Skepsis gegenüber einem Erziehungsauftrag des Staates. Der freibeitliche Verfassungsstaat teilt diese Skepsis nicht, er steht weder seiner Idee noch seiner Geschichte nach einem Erziehungsauftrag ablebnend gegenüber.

a) Die feste Tradition staatlichen Schulehaltens schlo $\beta$ in Deutschland stets auch die normative Festlegung von Erziebungsauftrag und Erziebungszielen der Schule ein.

b) Der freibeitliche Verfassungsstaat hat diese Tradition bewußt fortgesetzt. Die negativen Erfabrungen mit der Schule im totalitären Staat waren nicht Anlaß, die Schule aus staatlicher Vormundschaft zu entlassen, sondern - ganz im Gegenteil-Grund, schulische Erziebung im Sinne des freibeitlichen Verfassungsstaates $z u$ instrumentalisieren.

4. Der grundgesetzlich geprägte freibeitliche Verfassungsstaat sieht sich als legitimiert an, seinen Schulen einen Erziebungsauftrag zu erteilen.

a) Im Vordergrund der grundgesetzlichen Aussagen zum Thema Erziehung steht das Elternrecht. Hier soll das Fundament der Erziebung liegen.

b) Der Erziehungsauftrag der Schule ist in Art. 7 Abs. 1 GG enthalten - eher verdeckt als selbstbewußt formuliert.

c) Die erkennbare Scheu, sich ausdrücklich zu einem Erziehungsauftrag der Schule zu bekennen, hat im Kern weniger inbaltliche denn entstebungsgescbichtliche Gründe. 
5. Das Grundgesetz geht von einer Pluralität der ${ }_{n}$ Erziehungsmäcbte ${ }^{\alpha}$ aus. Die nachdrückliche Betonung von Elternrecht, konfessionell gebundenem Religionsunterricht und Privatschulfreiheit (Art. 6, 7 GG) verbietet ein staatliches Monopol bei der Definition von Erziehungsauftrag und Erziehungszielen der Schule.

6. Eine ausdrückliche Festlegung bestimmter schulischer Erziebungsmaßstäbe enthält das Grundgesetz nicht. Es stebt der inhaltlichen Ausrichtung des Erziehungsauftrages aber auch nicht indifferent gegenüber.

7. Orientierungswerte ergeben sich vor allem aus den Grundrechten.

a) Inbaltliche Grundsatznorm für die Definition schulischer Erziebungsziele ist Art. 2 Abs. 1 GG. Dem schulischen Erziehungsauftrag kommt danach vornehmlich eine auf den einzelnen Schüler bezogene dienende Funktion $\mathrm{zu}$.

b) Über das grundgesetzliche Menschenbild von der , in der Gemeinschaft stehenden und ibr vielfältig verpflichteten Persönlichkeit ${ }^{\alpha}$ sind Erziehungsauftrag und Erziehungsziele der Schule im Rabmen der grundgesetzlichen Wertordnung auch gemeinschaftsbezogen zu definieren.

8. Den Verfassungsprinzipien des Grundgesetzes lassen sich nur begrenzte Aussagen über den Inbalt des Erziehungsauftrags der Schule entnehmen. Eine „pädagogische Interpretation " (P. Häberle) der Verfassungsprinzipien ist abzulebnen.

9. Die Orientierungswerte des Grundgesetzes für die inhaltliche Ausrichtung des Erziehungsauftrags der Schule verdichten sich nicht zu einem definitiven und normativ verbindlichen Kanon bestimmter Erziebungsziele. Das Grundgesetz überläßt es den Ländern, den grundgesetzlich gezogenen Orientierungsrabmen im einzelnen auszufüllen.

10. Die Länder haben den grundgesetzlich belassenen Freiraum kraftvoll genutzt und die inhaltliche Ausgestaltung des Erziebungsauftrags überwiegend auf Verfassungsebene vorgenommen.

a) Die bunte Vielfalt landesrechtlicher Erziehungsziele fügt sich - bei unterschiedlichen Akzentuierungen im einzelnen - zu einem Kanon gemeindeutscher Vorstellungen über den Erziebungsauftrag der Schule. Daneben bleibt Raum für landesspezifische Festlegungen.

b) Die landesrechtlich definierten Erziehungsziele fügen sich in ihrer Bandbreite zwischen Individualbezug und Gemeinschaftsbezug in den grundgesetzlich gezogenen Rahmen ein. Föderative Vielfalt und gesamtstaatliche Einheit bleiben gleichermaßen gewahrt.

11. Die weitgehende Regelung von Erziehungsauftrag und Erziebungszielen in den meisten Landesverfassungen entlastet und sperrt den einfachen Gesetzgeber zugleich. Das verfassungsrechtliche Korsett beläßt dem einfachen Gesetzgeber i. d. R. einen binreichenden Gestaltungs- 
spielraum, um einzelne Erziehungsziele besonders zu gewichten und neuzeitliche Bedürfnisse aufzunebmen.

12. Die Grenzen einer inbaltlichen Programmierung des schulischen Unterrichts sind enger, je mehr es um die Umsetzung von Erziehungszielen vorrangig individualen Zuschnitts geht und um so weiter, je mehr das Erziebungsziel gemeinschaftsbezogen ist.

13. Die praktische Umsetzung des Erziehungsauftrags und die Verwirklichung der Erziehungsziele ist - wiewobl Aufgabe der "verwalteten Schule" - zuvörderst eine pädagogisch/didaktische Aufgabe, die in "pädagogischer Freibeit" wabrgenommen wird. Eine rechtliche Steuerung ist nur begrenzt möglich.

14. Der freibeitliche Verfassungsstaat wird bei der Verwirklichung seiner Erziehungsziele stets unvollendet bleiben. Die Scbule ist „Schule der Nation" auch in dem Sinne, daß sich in ibr letztlich nur die Wertvorstellungen vermitteln lassen, die auch außerschulisch von einem gesellschaftlichen Konsens getragen werden.

15. Der freiheitliche Verfassungsstaat des Grundgesetzes ist Europa zugewandt und in die Europäische Integration eingebunden. Hieraus ergeben sich Konsequenzen für die Bedeutung einzelner Erziehungsziele, derzeit eher faktisch als im Sinne europarechtlich verbindlicher Vorgaben. 


\section{Erziehungsauftrag und Erziehungsmaßstab der Schule im freiheitlichen Verfassungsstaat"}

3. Länderbericht Österreich von Prof. Dr. Wolfgang Mantl, Graz

\section{Inhalt}

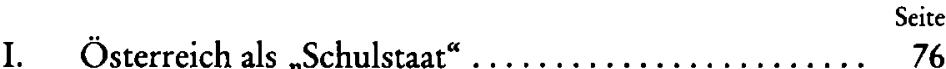

II. Die Kargheit des verfassungsrechtlichen Befundes .... 80

A. Erziehungsauftrag $\ldots \ldots \ldots \ldots \ldots \ldots \ldots \ldots, 81$

B. Erziehungsmaßstab .................. 86

III. Der Reichtum des unterverfassungsgesetzlichen

Normenmaterials ....................... 88

IV. Zukunftsaspekte $\ldots \ldots \ldots \ldots \ldots \ldots \ldots \ldots \ldots, 92$

* Für anregende Kontakte danke ich meinen Kollegen Walter Berka/Salzburg, Karl Korinek/Wien, Roman Koller/Graz und Josef Thonhauser/Salzburg, für die Mithilfe bei der Materialbeschaffung meinen Grazer Mitarbeitern Klaus Poier und Maria Ranacber. 


\section{I. Österreich als „Schulstaat“}

Der bekannte österreichische Fußballstar Hans Krankl erklärte einmal in einem Interview: "Idole wie ich haben einen Erziehungsauftrag"1. Ausdruck der Selbstüberschätzung? Indikator der Orientierungsschwäche im „Zeitenbruch"? Oder einfach ein salopper Gag? Ich bin kein Pestalozzi der Postmoderne, um hier alle pädagogischen Bedeutungsnuancen beiläufiger Beliebigkeit ausdeuten zu können. Aber die im letzten provokante Äußerung des Sportlers führt uns die Aktualität unseres Themas vor Augen, das mit aller Ernsthaftigkeit zu behandeln ist.

Auf der Kölner Tagung unserer Vereinigung im Herbst 1983 bemerkte Ernst-Wolfgang Böckenförde in der Aussprache zum Beratungsgegenstand „Kulturauftrag im staatlichen Gemeinwesen "2 nachdenklich, „daß das staatliche Schulehalten gar nicht in Blick genommen worden ist. ${ }^{\alpha 3}$ Gerade das gehöre doch auch zum staatlichen Kulturauftrag, nicht zuletzt die Festlegung der Unterrichtsprogramme und die Problematik ihrer Verbindlichkeit in der öffentlichen Schule im religiös-weltanschaulich neutralen Staat mit grundrechtlichen Freiheitsgewährleistungen als Grenze der staatlichen Aktivität. Und Böckenförde schloß mit dem Hinweis: „Ich möchte diese Frage hier nur aufwerfen, ohne jetzt weiter darauf einzugehen, aber vielleicht wäre das auch ein Thema, das wir einmal zum Gegenstand unserer Verhandlungen machen können. ${ }^{\text {" }}$ Nun wurde dieses Thema aufgegriffen. Meine Hauptaufgabe ist es, die österreichische Verfassungssituation darzustellen.

Auch Österreich mit all seinen Besonderheiten, ja Verzögerungen ist eingebunden in die neueste Geschichte, die eine Geschichte der Größe und Zerbrechlichkeit des autonomen Subjekts ist. Das robuste Postulat der "Selbstverwirklichung “ - selbst in der stummen Variante reiner Innerlichkeit - bedeutet immer auch Angewiesensein auf andere Menschen, ja oft Verfügung über sie. Auch die liberale Demokratie braucht ihre Ergänzung durch verantwortete Mitmenschlichkeit. Gemeinschaftswerte sind für das moderne Bewußtsein fast nur mehr als Zwecke und Präferenzen des Individuums denk- und lebbar. Aber selbst das Individuum unterliegt einer postmodernen Infragestellung, ja Erosion.

Ironische bis weinerliche Essays der Kulturkritiker, aber auch ernstzunehmende Analysen der Sozialwissenschafter werden nicht müde,

1 Der Standard, 24. April 1989, 18.

2 S. Bericht von Udo Steiner, Mitbericht von Dieter Grimm und Landesberichte von Norbert Wimmer (Österreich) und Thomas Fleiner-Gerster (Schweiz) sowie Aussprache und Schlußworte, in: VVDStRL, H. 42, 1984, 7-146.

${ }^{3}$ A. a. O., 110. 
diese Krisenphänomene auch auf eine Krise der Bildung und Erziebung zurückzuführen ${ }^{4}$. Welcher Bildung und Erziehung welcher Menschen? Auf der einen Seite steht auch in Österreich die empirisch feststellbare Zunahme höherer Schulabschlüsse, haben sich.Maturanten- und Akademikerzahlen vervielfacht. Auf der anderen Seite gibt es zerfallene Ehen und Familien, überforderte Schulen und überschwappende Informationen, die allesamt zunehmend zur menschlichen Abstumpfung und Vereinzelung, ja zu funktionalem Analphabetismus und moralischer Indifferenz mit wachsender Gewaltbereitschaft führen. In der Bildungs- und Erziehungsdiskussion verstummen die $Z$ weifel nicht, ob Erfahrung und Wissen ausreichend von Generation zu Generation tradiert und dabei auch schöpferisch weiter in die Zukunft hineinverwandelt werden können. Als Gründe hiefür werden angeführt:

1. die Individualisierung und Pluralisierung der Lebenswelt mit einem großen Freiheitszuwachs, dem freilich eine weitgehende "(Re)Privatisierung" des Allgemeinen und Öffentlichen, eine Schwächung des sozialmoralisch Verbindlichen gegenübersteht;

2. damit zusammenhängend ein hoher Stellenwert von nutzenorientierten, pragmatischen Aufstiegshoffnungen durch Ausbildung auf Kosten von Allgemeinbildung und Wertvermittlung;

3. die übermächtige Anziehungskraft des Fernsebens und Boulevards, wodurch der Bild- und Bildungshunger sowie die Sehnsucht nach Farbe, Bewegung und Aktion eines breiten Publikums mühelos ebenso befriedigt werden, wie eine populistische Showpolitik gefördert wird.

„Bildung ist der Verzicht auf die Anstrengung, dumm zu bleiben. ${ }^{* 5} \mathrm{Er}-$ ziehung, über die Wissensvermittlung der Bildung hinausgehend, enthält auch die moralische Aufgabe der Motivation zu sozialem und politischem Handeln. Diese Aufgabe ist schwierig, weil es in der pluralistischen Vielfalt der Moderne und gar der Postmoderne keine biederen Rezepte des Verhaltens mehr gibt. Orientierung muß sorgfältig aus einem ethischen Minimum erarbeitet werden, das als Gemeinsamkeit in einem bestimmten räumlich und zeitlich gegebenen Kulturrahmen, dessen „epochale“ Existenz immer noch optimistisch präsumiert wird, konsensfähig ist. Noch schwieriger ist es, allgemeinmenschliche Kategorien ausfindig und

${ }_{4}^{4}$ Aus der stark angeschwollenen Literatur: Wolfgang Brezinka, Erziehung in einer wertunsicheren Gesellschaft. Beiträge zu einer Praktischen Pädagogik. 2. A., 1986; Hermann Lübbe, Der Lebenssinn der Industriegesellschaft. Über die moralische Verfassung der wissenschaftlich-technischen Zivilisation, 1990; Manfred Prisching, Krisen. Eine soziologische Untersuchung, 1986.

${ }^{5}$ Odo Marquard, in: Politische Bildung. Zur Sache. Themen parlamentarischer Beratung, 16/90, 1990, 167. 
glaubhaft zu machen, wie die Menschenrechtsdiskussion, aber auch die Diskussion um die Multikulturalität zeigen, soweit sie mehr als wohlfeiler Seminar- und Erlagscheinhumanismus sind.

Die Schule ist der Zentralort des Bildungssystems und ein wichtiger, wenn auch nicht der ausschließliche Ort der Erziehung, die traditionellerweise im „Haus" und in der Familie ihren Kernbereich hat. In der Bildung als einem Vorgang geistiger Formung in Gestalt eines Lehrens durch planmäßige Vermittlung von Wissen und Fertigkeiten (Unterricht) und eines Lernens durch theoretische Einsicht überwiegen die kognitiven Elemente, in der Erziehung als umfassender Formung des Charakters durch praktische Einübung von Werten, spielen emotive/affektive und normative Elemente eine besondere Rolle, kommt die pädagogische Verantwortung in Vorbild und Beispiel zum Tragen.

Die Zahl der Erzieber ist im historischen Prozeß immer größer geworden. Sie umfaßt heute Eltern, Lehrer, Schüler und Jugendliche selbst in Gruppen und Freundeskreisen, Kirchen, mit schwindendem Einfluß Parteien und Verbände sowie mehr denn je Medien, vor allem das Fernsehen. Wenn es eine Bildungs-, Erziehungs- und Orientierungskrise gibt - und es gibt sie -, kann meiner Grundüberzeugung nach ein Remedium nicht nur bei einem dieser Erziehungsfaktoren gesucht werden, also nicht etwa - wie dies meist geschieht - die Erziehungsverantwortung von den Eltern auf die Lehrer verschoben werden, von dort vielleicht auf die Schulaufsichtsorgane, Ministerialbürokratien und schließlich Parlamente. Ein derartiger Regreß stößt auf den skeptischen Einwand, wieso denn jene Personen, die als Eltern nicht mehr ihrer Erziehungsaufgabe nachkommen, dies auf einmal gemeinwohlorientiert und solidarisch als Lehrer, Schulinspektoren, Ministerialbeamte und Parlamentarier tun sollten. Die wirkliche Schwierigkeit unseres Themas liegt ja gerade darin, daß die Schule durchaus Kondensat der Befindlichkeit ihrer Epoche ist und nicht als eine "pädagogische Provinz" paradiesisch davor bewahrt und "krisenexemt " ist.

In idealtypischer Straffung hochkomplexer historischer Entwicklungen in Europa kann man von einem weitgehenden, nicht vollständigen Übergang der Schule von der Kirche auf den Staat, also einer weitgehenden „Verstaatlichung" des Bildungssystems (Planung, Errichtung, Organisation, Erhaltung, Leitung, Aufsicht als Fach-, Dienst- und Rechtsaufsicht, Festlegung der Bildungs- und Erziehungsziele, Prüfungsund Zeugniswesen durch den Staat, allgemeine Schul-, zumindest Unterrichtspflicht) und der "Erfindung “ der Institution „öffentliche Schule ${ }^{*}$ in der Neuzeit, zumal im aufgeklärten Absolutismus, sprechen, ein Vorgang, der von heute kaum mehr vorstellbaren Konflikten begleitet war. 
In Österreich ${ }^{6}$ gilt seit Maria Theresia die Schule als ein "Politicum". Das große Ursprungsereignis war die am 6. Dezember 1774 erlassene „Allgemeine Schulordnung für die deutschen Normal-, Haupt- und Trivialschulen in sämmtlichen Kaiserlich Königlichen Erbländern“. Die schulpolitischen Auseinandersetzungen erhielten mit dem Aufstieg des kirchenskeptischen Liberalismus (Reichsvolksschulgesetz 1869) im 19. Jahrhundert und dann der Sozialdemokratie (Glöckelsche Schulreform 1919/20) jeweils neue Schärfe. Immer blieb die Schule im Mittelpunkt des kulturpolitischen Interesses und neben Ebe und Familie einer der großen Kontroverspunkte im Verhältnis von Kirche und Staat.

In Österreich erfolgten besonders intensive Konfliktstöße 1848-1874, 1918-1929, dann in den Diktaturperioden, zuerst konservativ-autoritär 1934-1938, dann totalitär gesteigert 1938-1945, bis schließlich 1962 ein großer Schulkompromiß $\beta^{7}$ zugleich als großer Kulturkompromiß erzielt wurde. Dies geschah nach mühsamen, langwierigen Verhandlungen zwischen ÖVP und SPÖ. Das durchaus nach wie vor vorhandene Mißtrauen der politischen Kräfte schlug sich nieder im auffallenden Detailreichtum der schulrechtlichen Regelungen in der Bundesverfassung (Art. 14 sowie Art. 81a und später - 1975 - für das land- und forstwirtschaftliche Schulwesen auch Art. 14a B-VG) und in einfachen Gesetzen, aber auch in der Tatsache, daß die damals noch großen politischen Parteien vom Volksparteitypus sozialer Integrationsparteien sich wechselseitig absicherten durch das Erfordernis der Zweidrittelmebrbeit für die Änderung kulturpolitisch wichtiger Bestimmungen des Schulwesens (Art. 14 Abs. 10, dann auch Art. 14a Abs. 8 B-VG). Schließlich verankerten ÖVP und SPÖ den Parteienproporz in den Kollegien der Schulbehörden des Bundes in den Ländern und Bezirken (Art. 81a und b B-VG). Das Jahr 1962 ist der Höhepunkt der österreichischen Parteienstaatlichkeit: Frucht der prekären Spätphase der ersten Großen Koalition. Gleichzeitig wurden

${ }^{6}$ Zur Gesamtentwicklung: Helmut Engelbrecht, Geschichte des österreichischen Bildungswesens. Erziehung und Unterricht auf dem Boden Österreichs. 5 Bde., 1982-1988. - Zum maria-theresianischen Reformwerk schon: Joseph Alexander Helfert, Die Gründung der österreichischen Volksschule durch Maria Theresia, 1860.

7 Zur Schulpolitik der Republik Österreich: Herbert Dachs, Schule und Politik. Die politische Erziehung an den österreichischen Schulen 1918 bis 1938, 1982; Josef Höchtl / Fritz Windhager (Hrsg.), Bildungspolitik für Österreich. Analysen, Kritik, Konzeptionen, 1983; Gerbard Schmid, Schulpolitik im Wandel. Schulreform und Schulentwicklung zum gegenwärtigen Zeitpunkt, (ungedruckte politikwissenschaftliche Diplomarbeit), 1992; Hermann Schnell, Bildungspolitik in der Zweiten Republik, 1993; Josef Thonbauser, Erziehung und Bildung, in: Wolfgang Mantl (Hrsg.), Politik in Österreich. Die Zweite Republik: Bestand und Wandel, 1992, 620-644. 
auf einfachgesetzlicher Basis Schulgesetze ${ }^{8}$ erlassen, die auch für unser Thema wichtig sind, vor allem das Schulorganisationsgesetz $v$. 25. Juli 1962, BGBl. 242 (SchOG), das inzwischen sechzehnmal novelliert wurde.

Die kompetenzrechtliche, organisatorische und finanzielle Dominanz der Gebietskörperschaft Bund ist - anders als in der Bundesrepublik Deutschland, der Schweiz und anderen vollentwickelten Bundesstaaten - im Schulwesen bis hin zur Universität unübersehbar. Es gibt ca. 6600 Schulen in Österreich mit 117000 Lehrern und deutlich über einer Million Schülern. Nur $7 \%$ sind Privatschulen (Deutschland: $6 \%$, Niederlande: $71 \%$, Griechenland: $3 \%)^{9}$.

\section{Die Kargheit des verfassungsrechtlichen Befundes}

In den letzten 15 Jahren wurde der österreichische Verfassungslakonismus zum Sprechen gebracht. Das ist auf den Einfluß eines Teiles der österreichischen Staatsrechtslehre, der EMRK samt der Judikatur der Straßburger Organe sowie schließlich auch und gerade der Rechtsprechung des österreichischen Verfassungsgerichtshofes zurückzuführen. Ein Rechtsverständnis gewann an Boden, „daß die Verfassung auch inhaltlich relevante Aussagen enthält; insbesondere hat man die verfassungsrechtlichen Grundrechtsgewährleistungen in ihrer die Gesetzgebung prägenden Wirkung " ${ }^{10}$ erkannt. Grundrechtliche Schutz- und Leistungspflichten des Staates wurden in historischer ${ }^{11}$ und aktueller Perspektive $^{12}$ diskutiert, wie es kurz vorher kaum möglich schien.

${ }^{8}$ Das Rechtsmaterial wird dargestellt von Jobannes Hengstschläger, Das Bildungswesen, in: Herbert Schambeck (Hrsg.), Das österreichische Bundesverfassungsgesetz und seine Entwicklung, 1980, 587-628; ders., Schulrecht, in: Herbert Schambeck (Hrsg.), Parlamentarismus und öffentliches Recht in Österreich. Entwicklung und Gegenwartsprobleme. II. Teilbd., 1993, 1045-1104; Eckart Klein, Österreich, in: Die Befugnisse des Gesamtstaates im Bildungswesen. Rechtsvergleichender Bericht, 1976, 255-301; Felix Jonak / Leo Kövesi (Hrsg.), Das österreichische Schulrecht, 3. A., 1990; Robert Walter / Heinz Mayer, Grundriß des Besonderen Verwaltungsrechts. 2. A., 1987, 122-173.

9 Der Standard, 29. September 1994, 8.

10 Karl Korinek, Entwicklungstendenzen in der Grundrechtsjudikatur des Verfassungsgerichtshofes, 1992, 5.

11 Vgl. Friedrich Lebne, Grundrechte achten und schützen? Liberales Grundrechtsverständnis 1848, in: JBl. 107 (1985), 129-136 und 216-224; ders., Grundrechte achten und schützen? 1862 und 1867, in: JBl. 108 (1986), 341-347 und 424-435.

12 Z. B. Ulrike Davy, Versammlungsschutz und Meinungsfreiheit, in: JAP 1 (1990/91), 197-205. 


\section{A. Erziebungsauftrag}

Für mich stellt sich also die verfassungsrechtliche Situation schon farbenreicher dar als für Norbert Wimmer, der 1983 in Köln den österreichischen Landesbericht über den Kulturauftrag des Staates lieferte. Dennoch geht ein nüchternes Urteil nicht fehl, das einen Erziebungsauftrag des Staates nach wie vor als eine überwiegend politische Kategorie auffaßt, die im starken „sozialen Garantismus“ der österreichischen Bevölkerung sowie ihrer Politiker und Beamten wurzelt. Verfassungsaufträge sind trotz aller materiellen Ansätze noch immer alles eher als eine normative Selbstverständlichkeit. Es gibt auch kein verfassungsrechtlich positiviertes Sozial- und kein Kulturstaatsprinzip. Auch wenn die in der Kelsenschen Tradition liegende Auffassung von der Verfassung als "Spielregel ${ }^{\alpha 13}$ nicht mehr als ausschließliche Charakterisierung gelten kann, so steht dennoch der prozedurale Spielregeltopos, wenn schon nicht im Vordergrund, so doch stets auch gewichtig im Repertoire der Verfassungsinterpretation.

Ein Blick auf die Fachliteratur ${ }^{14}$ zeigt, daß ein Kultur- bzw. Erziebungsauftrag in den Lehrbüchern und Systemen des österreichischen Verfassungsrechts nicht vorkommt, wohl aber setzen sich Spezialaufsätze ${ }^{15}$ zum Schul- und Erziehungswesen damit auseinander, vor allem Hans-Ulrich Evers ${ }^{16}$.

13 Dazu: Ludwig K. Adamovich / Bernd-Christian Funk, Österreichisches Verfassungsrecht. 3. A., 1985, 23 f.

14 Grundlegend für die wissenschaftliche Diskussion im deutschsprachigen Raum: Thomas Oppermann, Kulturverwaltungsrecht. Bildung - Wissenschaft - Kunst, 1969; für die neueste Entwicklung ist ein „Begleitaufsatz" zur Hallenser Tagung bemerkenswert: Bodo Pieroth, Erziehungsauftrag und Erziehungsmaßstab der Schule im freiheitlichen Verfassungsstaat, in: DVBl. 109 (1994), 949-961.

${ }_{15}$ Heinz Mayer, Schule und Verfassung, in: RdS (Recht der Schule, eine nur von 1979-1988 existierende Fachzeitschrift) 7 (1985), 1-6; Theo Öblinger, Kulturverfassungsrecht, in: RdS 8 (1986), 47-59; Peter Pernthaler, Kulturpolitik in Österreich. Verfassungspolitische Rahmenbedingungen, in: ders. (Hrsg.), Föderalistische Kulturpolitik, 1988, 9-27; Karl Spielbüchler, Bestand und Bedeutung der Grundrechte im Bildungsbereich in Österreich, in: EuGRZ 8 (1981), 675-686; ders., Das Grundrecht auf Bildung, in: Rudolf Macbacek / Willibald P. Pabr / Gerbard Stadler (Hrsg.), 40 Jahre EMRK. Grund- und Menschenrechte in Österreich. II. Bd.: Wesen und Werte, 1992, 149-174; Herbert Zeizinger, Das Recht auf Bildung in der österreichischen Verfassungsordnung, in: Ludwig Adamovich / Peter Pernthaler (Hrsg.), Auf dem Weg zur Menschenwürde und Gerechtigkeit. FS für Hans R. Klecatsky. II. Teilbd., 1980, 1079-1099.

${ }^{16}$ Hans-Ulrich Evers, Der Bildungs- und Erziehungsauftrag der österreichischen Schule als Rechtsproblem, in: RdS 4 (1982), 33-43; ders., Kulturverfassungsrecht und Kulturverwaltungsrecht in Österreich, in: JöR, NF 33 (1984), 189-201. - Auf die deutsche Rechtslage abstellend: ders., Die Befugnis des Staates zur Festlegung von Erziehungszielen in der pluralistischen Gesellschaft, Berlin 1979. 
Immer von neuem - nicht ein für allemal durch die Errungenschaften der letzten 200 Jahre beantwortet - stellt sich auch bezüglich der Schulen die Fragentrias: „Was soll der Staat?" "Was darf der Staat?" „Was kann der Staat?" Das Können hängt sehr stark von den finanziellen Möglichkeiten ab (Knappheit der öffentlichen Mittel, Staatsverschuldung) ${ }^{17}$. Das Dürfen hängt von den Grundrechtsschranken ab, vor allem von dem, was die Tradition der liberalen, staatsgerichteten Abwehrrechte als Raum vielgestaltiger „Privatheit" nach 1848 „freigehalten“ hat. Das Sollen bereitet uns die größten Schwierigkeiten.

Bevor wir uns den verfassungsrechtlichen Ansätzen der Verfassung zuwenden, aus denen ein inhaltlich bestimmtes Sollen des Staates, ein "Schulauftrag "im allgemeinen und ein „Erziebungsauftrag " im besonderen, abgeleitet werden können, ist es ratsam und hilfreich, kurz innezuhalten und sich der verfassungsgerichtlichen Definition des Begriffs "Schule " zu vergewissern: In seiner Judikatur seit Slg. 1505/1933 stellt der Verfassungsgerichtshof darauf ab, daß es sich bei Schulen um Einrichtungen handle, die dem Lernenden nicht nur bestimmte Kenntnisse und Fähigkeiten vermitteln oder „lediglich der Förderung des gesellschaftlichen Lebens dienen " (VfSlg. 1505/1933), wie dies die Tanz-, Fahr-, Flieger- und Schischulen tun, sondern auch eine Formung der Gesamtpersönlichkeit bezwecken, also auch "pädagogische und erzieherische Ziele“ (VfSlg. 6407/1971) verfolgen. Wenn Erziebung zum verfassungsrechtlichen Schulbegriff gehört, müssen vom Staat vorgegebene Erziehungsmaßstäbe/-ziele zumindest zulässig, ja vom Legalitätsprinzip und vom Sachlichkeitsgebot des Gleichheitsgrundsatzes her, dem großen „Wegweiser" zur inhaltlichen Anreicherung der Verfassung, auch notwendig sein, freilich im liberalen Rechtssystem grundsätzlich nur als Imperative für die öffentliche Schule, nicht für die Eltern und den "gesellschaftlichen" Bereich mit allfälligen „Privatschulen“. Dieser Grundsatz wird jedoch durch Spezialregelungen (siehe unten P. 2, dann Fn. 28 und das "Wächteramt" des Staates beim Elternrecht) relativiert.

Es bleibt freilich immer noch die Frage nach dem Sollen des Staates bezüglich der Errichtung und Erhaltung von Schulen, also der verfassungsrechtlichen Grundlegung und Verankerung der „öffentlichen Schule in einem ${ }_{n}$ Erziebungsauftrag ${ }^{\alpha}$ des Staates, zu beantworten. Verfassungsrechtsdogmatisch bieten sich verschiedene Wege an:

${ }^{17}$ Das Fehlen großen Privatkapitals ließ in Österreich nicht einmal eine Diskussion über Privatuniversitäten aufkommen. Nur bei den neugeschaffenen Fachbochschulen zeichnet sich auch die Möglichkeit privater Träger und Erhalter ab. 
1. Die öffentliche Schule wird als Selbstverständlichkeit der Moderne in der Verfassung vorausgesetzt, sie ist „im Prinzip unbestritten "18, steht "außer jedem Streit ${ }^{\text {"19 }}$ und bedarf "daher einer expliziten verfassungsrechtlichen Legitimation nicht erst" ${ }^{\text {"19 }}$. Die fast ausschließliche Beschäftigung des Verfassungsrechts und der Verfassungspraxis mit Kompetenz-, Organisations- und Finanzfragen der Schule ist nur dann sinnvoll, wenn das Schulehalten durch den Staat von der Verfassung als selbstverständlich vorausgesetzt wird.

2. Die Schulboheit (Unterrichts- und Erziehungshoheit) des Staates wird auch - ähnlich wie in der Bundesrepublik Deutschland (Art. 7 Abs. 1 GG) - aus der Leitungs- und Aufsichtsbefugnis des Staates gem. Art. 17 (5) StGG über die allgemeinen Rechte der Staatsbürger v. 21. Dezember 1967, RGBl. 142, abgeleitet: „Dem Staate steht rücksichtlich des gesamten Unterrichts- und Erziehungswesens das Recht der obersten Leitung und Aufsicht zu. ${ }^{\text {20 }}$

3. Aus dem Recht auf Bildung gem. Art. 2 Satz 1 des 1 .ZPMRK wird die Verpflichtung des Staates erschlossen, „ein Mindestmaß an öffentlichen Bildungseinrichtungen zu erhalten ${ }^{\text {"21 }}$, wobei auch immer wieder der Zusammenhang mit dem Topos des durch die Verfassung stillschweigend und selbstverständlich Vorausgesetzten (siehe P. 1) hergestellt wird.

4. Eine weitere Argumentationslinie läuft darauf hinaus, dem Art. 14 (6) Satz 1 B-VG („Öffentliche Schulen sind jene Schulen, die vom gesetzlichen Schulerhalter errichtet und erhalten werden. ") ${ }^{22}$ interpretativ eine Einrichtungsgarantie ${ }^{23}$ der öffentlichen Schulen zu entnehmen, dergemäß der Staat in seinen Gebietskörperschaften als "gesetzlicher Schul-

18 Öblinger, Kulturverfassungsrecht, 49 (Fn. 15).

19 ders., a. a. O., 51 (Fn. 15).

20 „In Reaktion auf die ehemalige kirchliche Oberaufsicht über das Schulwesen enthält die Bundesverfassung den Grundsatz der staatlichen Unterrichtshobeit (Art. 17 Abs. 5 StGG, Art. 14 und 81a B-VG), wonach Schulerrichtung und Schulbildungsinhalte primär als Staatsaufgaben qualifiziert werden." (Pernthaler, Kulturpolitik, 12/Fn. 15 - Hervorhebungen im Original).

${ }^{21}$ Evers, Bildungs- und Erziehungsauftrag, 33 (Fn. 15). - Dazu auch die in Fn. 15 angeführten Aufsätze von Spielbüchler (passim) und Zeizinger, 1090-1092.

22 Gesetzliche Schulerbalter können in komplizierter Kompetenzverteilung Bund, Land, Gemeinde oder Gemeindeverband sein (Art. 14 Abs. 6 Sätze 2 und 3 B-VG).

${ }^{23}$ Dazu Mayer, Schule, 2 (Fn. 15); Kurt Ringhofer, Die österreichische Bundesverfassung, 1977, 58; Spielbüchler, Grundrecht, 158-160 (Fn. 15). 
erhalter" in gewissem Umfang selbst Schulen errichten und betreiben müsse, woraus sich jedenfalls das Verbot einer Totalprivatisierung ergäbe $^{24}$.

5. Eine - mit Hilfe des Gleichheitsgrundsatzes freilich verallgemeinerungsfähige - über "bloße" Nichtdiskriminierung hinausgehende Sondersituation besteht für das Minderbeitenschulwesen ${ }^{25}$ zum Schutz und zur Förderung der Eigenart und Eigenständigkeit einer Volksgruppe ${ }^{26}$. Grundlegend sieht hier Art. 7 (2) des Staatsvertrages von Wien 1955 für die slowenischen und kroatischen Minderheiten einen "Anspruch auf Elementarunterricht in slowenischer oder kroatischer Sprache " und „auf eine verhältnismäßige Anzahl eigener Mittelschulen" vor.

6. Auch die Grundrechte der Freibeit der Berufswabl (Art. 18 StGG) und der Erwerbsausübung (Art. 6 Abs. 1 StGG) enthalten „Fernwirkungen auf das staatliche Bildungswesen ${ }^{\text {“27 }}$, die als zusätzliches Argument für eine staatliche Schulhoheit herangezogen werden können.

Wird mit diesen Interpretationsbemühungen um staatliche Schulhoheit und Erziehungsauftrag des Staates in der Schule das karge Verfassungsmaterial dogmatisch einigermaßen strapaziert, so fällt es leichter, das Dürfen des Staates zu bestimmen, also die (grundrechtlichen) Grenzen des - nunmehr als gegeben angenommenen - Erziehungsauftrages des Staates zu ziehen. Sie liegen im Recht auf Privatschulgründung (Art. 17 Abs. 2 StGG) ${ }^{28}$ und bäuslichen Unterricht (Art. 17 Abs. 3 StGG), im

${ }^{24}$ Die in dieser Argumentation enthaltene ,materialisierende“ Inanspruchnahme der Kompetenznorm des Art. 14 B-VG ist keine Selbstverständlichkeit, da Kompetenznormen nach wie vor überwiegend als bloße Ermächtigungsnormen verstanden werden (Adamovich/Funk, Verfassungsrecht, 185 / Fn. 13: „Die verfassungsrechtlichen Regeln über die bundesstaatliche Kompetenzverteilung sind als ermächtigende und schrankensetzende Normen zu verstehen. Sie begründen Zuständigkeiten zur Gesetzgebung und Vollziehung und stellen grundsätzlich keine Aufträge zur Erlassung von Gesetzen dar." - Hervorhebungen im Original).

${ }^{25}$ Dazu Spielbücbler, Grundrecht, 159 f. (Fn. 15).

${ }^{26}$ Vgl. VfSlg. 9224/1981.

${ }^{27}$ Spielbücbler, Grundrecht, 160, im ganzen 160-162 (Fn. 15).

${ }^{28}$ Dazu Gerhard Lebitsch, Zur Unterrichtsfreiheit der Privatschule, in: RdS 5 (1983), 33-39 und 74-78. Über die Aufsichtsbefugnis des Staates, das Recht zur Führung einer gesetzlich geregelten Schulbezeichnung, das Öffentlichkeitsrecht und die Subventionierung der Privatschulen - ganz zu schweigen vom Druck des jeweils dominierenden "Zeitgeists ${ }_{n}$ Unterordnung ${ }^{\alpha}$ ) der Privatschulen in das öffentliche Schulwesen und die staatliche Schulhoheit sowie deren Bildungs- und Erziehungsziele. 
Recht auf den Religionsunterricht (Art. 17 Abs. 4 StGG) ${ }^{29}$, überhaupt in den Grundrechten der individuellen Glaubens- und Gewissensfreibeit (Art. 14 StGG) sowie der korporativen Religions- oder Kirchenfreibeit (Art. $15 \mathrm{StGG),} \mathrm{aber} \mathrm{vor} \mathrm{allem} \mathrm{im} \mathrm{Elternrecht} \mathrm{(Art.} 2$ Satz 2 des 1. ZPMRK $)^{30}$, das in Österreich zusammen mit der EMRK seit 1964 unbestritten Verfassungsrang genießt, freilich noch so etwas wie ein „schlafender Riese“ ist, entwicklungsgeschichtlich „entrückt" in den Responscharakter nach dem Challenge der Totalitarismen rechter und linker Provenienz der Jahrhundertmitte.

Bei Zunahme von Spannungen und Wertkonflikten zwischen Staat und Eltern bzw. Elternverbänden, Kirchen, Religionsgesellschaften und sonstigen Weltanschauungsgemeinschaften könnte freilich dieser Riese „erwachen ", d. h., die Konfliktparteien würden dieses Rechtsschutzinstrumentarium mobilisieren. Die Straßburger Judikatur zum Elternrecht weist ja bereits den Weg: Indoktrinierungs- und Manipulationsverbot

29 Vgl. Alfred Rinnerthaler, Die rechtliche Normierung des Religionsunterrichts, in: RdS 2 (1980), 17-20; Hugo Schwendenwein, Religion in der Schule. Rechtsgrundlagen. Das österreichische Religionsunterrichtsrecht, 1980. Die Entropie des Religiösen im vom staatlichen Einfluß weitgehend abgeschirmten Religionsunterricht ist ein Korrelat der im übrigen zunehmenden Säkularisierung der Schule.

${ }^{30}$ Zur österreichischen Rechtslage: Adamovich/Funk, Verfassungsrecht, $418 \mathrm{f}$. (Fn. 13); Walter Berka, Konturen des Elternrechts in der Verfassungsrechtsordnung, in: RdS 4 (1982), 103-107; Gerhard Lebitsch, Das Elternrecht nach der EMRK in der österreichischen Rechtsordnung, in: RdS 9 (1987), 10-16; Mayer, Schule, 5 f. (Fn. 15); Öblinger, Kulturverfassungsrecht, 54 (Fn. 15); Spielbüchler, Grundrecht, 162-165 (Fn. 15); Otto Triffterer, $\mathrm{Zu}$ den verfassungs- und strafrechtlichen Grenzen einer Sexualerziehung in den Schulen, in: JBl. 112 (1990), 409-425; Herbert Zeizinger, Schulversuche und Elternrecht, in: JBl. 98 (1976), 473-476.

Aus der reichen deutschen Literatur im Spannungsfeld von Elternrecht und staatlichem „Wächteramt ${ }^{*}$, Hermann Avenarius / Bernd Jeand'beur, Elternwille und staatliches Bestimmungsrecht bei der Wahl der Schullaufbahn, 1992; Josef Isensee, Elternrecht, in: Staatslexikon. 7. A. II. Bd., 1986, Sp. 222-233 und 239 f.; Bernd Jeand'beur, Verfassungsrechtliche Schutzgebote zum Wohl des Kindes und staatliche Interventionspflichten aus der Garantienorm des Art. 6 Abs. 2 Satz 2 GG, 1993.

Leading Case zum Elternrecht vor dem EGMR in Straßburg: Fall Kjeldsen, Busk Madsen und Pedersen, Urteil v. 7. Dezember 1976, in: EuGRZ 3 (1976), 478-491. Dazu Kommentar und Kritik: Luzius Wildhaber, Die dänischen Sexual-ErziehungsFälle, in: EuGRZ 3 (1976), 493-496.

Öblinger (Kulturverfassungsrecht, 54/Fn. 15) spricht vom Elternrecht als „einer" ,inneren ' Grenze des staatlichen Engagements auf dem Schulsektor" und Spielbücbler (Grundrecht, 164/Fn. 15) postuliert „eine feine Abwägung“, die „der nötige Kompromiß zwischen dem staatlichen Unterrichtswesen und den Interessen der Eltern und Kinder ${ }^{*}$ erfordere. 
oder, wie man mit der Diskussion um die deutsche politische Bildung sehr anschaulich sagen könnte: Überwältigungsverbot.

"Je umfassender der Staat Erziehung und Unterricht selbst besorgt, desto großzügiger muß er letztlich private Bildungseinrichtungen oder sogar den häuslichen Unterricht als gleichwertigen Ersatz zulassen, ja unter Umständen durch eigene Beiträge sogar fördern. " 31 Aus den erwähnten Grundrechten, dem Konkordat, anderen verfassungs- und einfachgesetzlichen Bestimmungen, aber auch aus den Landesverfassungen von Tirol und Vorarlberg ist übrigens auch die besondere Pflicht zur gegenseitigen Rücksichtnabme von Staat und Kirche ableitbar, die sich immer noch in der die bisherige Geschichte der Zweiten Republik kennzeichnenden befriedeten Balance partnerschaftlicher Kooperation befinden, die nicht durch den allgemeinen Hinweis auf die Säkularität und weltanschauliche Neutralität des Staates weginterpretiert werden darf, was jedoch neuerdings von Zeit zu Zeit durch kulturpolitische Problematisierung dieses modus vivendi zwischen spiritualia und temporalia geschieht.

\section{B. Erziehungsmaßstab}

In einem zweiten Schritt ist nach der - keineswegs mühelosen - Annahme eines Erziebungsauftrages in der österreichischen Verfassung die Frage zu behandeln, ob die Verfassungsrechtsordnung auch unserer Suche nach einem Erziebungsmaßstab oder nach Erziehungszielen Erfolg schenkt. Dabei ist zweierlei zu unterscheiden:

1. die Verfassung selbst in ihrer Gänze als Erziehungsziel („Verfassungspatriotismus"), Denkkategorien dieser Art sind in Österreich politisch nur schwach und rechtlich so gut wie gar nicht entwickelt;

2. die Verfassung oder Teile von ihr als Richtschnur für Erziehungsziele einfachgesetzlicher Stufe.

Die Verfassung schenkt uns expressis verbis keine rasche Antwort. Die materiale Aufladung seit Ende der siebziger Jahre bietet Ansätze hierfür, obwohl die Bindungswirkung und die Steuerungsfäbigkeit dieser verfassungsrechtlichen Ansätze prekär bleiben und uns vor übereifrigen Erwartungen bezüglich systematisch-teleologischer Interpretationen bewahren sollten, wenn selbst explizite Positivierungen in Verfassungsrang bisweilen nur geringe normative Kraft haben: Ist Bayern mehr „Kulturstaat" als Österreich, weil dies in Art. 3 der Bayerischen Verfassung, aber nicht in der österreichischen Bundesverfassung steht? Jedenfalls ist auch

${ }^{31}$ Spielbüchler, Grundrecht, 165 (Fn. 15). 
in Österreich die Bereitschaft gestiegen, durch die Verfassung die inhaltliche Determinierung der einfachen Gesetze und der Vollziehung dichter als früher vorzunehmen, was auch zu einer gesteigerten Ingerenz des Verfassungsgerichtshofes führt. Stets bleibt das Problem der Justiziabilität, etwa die Einklagbarkeit der Verwirklichung von Erziehungszielen oder Lehrplänen ${ }^{32}$, ein Fragezeichen.

Theo Öblinger, selbst keineswegs ein Hymniker der materialen Elemente der Verfassung, registriert in seinen jüngst erschienenen Studienbüchern ${ }^{33}$ die inhaltliche Anreicherung der Verfassung in den vergangenen Jahren sehr präzise und spannt den Bogen von den Baugesetzen (Demokratie, Republik, Bundesstaat, Rechtsstaat, bei manchen Autoren auch liberales Prinzip, Gewaltenteilung etc.) über die Staatszielbestimmungen (Verbot nationalsozialistischer Tätigkeit, dauernde Neutralität, umfassende Landesverteidigung, Umweltschutz, Rundfunk als öffentliche Aufgabe, verschiedene Staatsziele bereits in der Mehrzahl der Landesverfassungen: Burgenland, Kärnten, Niederösterreich, Oberösterreich, Tirol und Vorarlberg), für die er sogar den Ausdruck „Verfassungsauftrag ${ }^{\text {"34 }}$ synonym verwendet, bis zu den Grundrechten.

Gerade die „Entwicklung zu einer stärker inhaltsbezogenen Judikatur des Verfassungsgerichtshofes ${ }^{35}$ bezüglich der Grundrechte ${ }^{36}$ zeitigte eine gravierende Praxiswirkung. Auch für Erziehungsmaßstäbe und Erziehungsziele im österreichischen Schulsystem bleibt dies nicht ohne Folgen: Neben dem liberalen Gebot der Offenheit, Pluralität und Toleranz forciert das umfassende Sachlichkeitsgebot des Gleichheitsgrundsatzes eine unverkürzte ${ }^{37}$ kognitive Struktur des schulischen Bildungsge-

32 Abl. Evers, Kulturverfassungsrecht, 204 (Fn. 16).

33 Theo Öblinger, Verfassungsrecht. 2 Bde., 1993 und 1994.

34 Öblinger, Verfassungsrecht (1993), 36 (Fn. 33).

${ }^{35}$ Korinek, Entwicklungstendenzen, 10 (Fn. 10).

${ }^{36}$ Nur beispielhaft: Ludwig Adamovich, Grundrechte heute. Eine Einführung, in: Rudolf Machacek / Willibald P. Pabr / Gerbard Stadler (Hrsg.), 70 Jahre Republik. Grund- und Menschenrechte in Österreich. I. Bd.: Grundlagen, Entwicklung und internationale Verbindungen, 1991, 7-27; Walter Berka; Der Freiheitsbegriff des „materiellen Grundrechtsverständnisses“, in: Jobannes Hengstscbläger u. a. (Hrsg.), Für Staat und Recht. FS für Herbert Schambeck, 1994, 339-347; Davy, Versammlungsschutz (Fn. 12); Felix Ermacora, Grundriß der Menschenrechte in Österreich, 1988; Bernd-Christian Funk, Ein Grundrecht auf Schutz der Gesundheit? Verfassungsrechtliche und verfassungspolitische Überlegungen, in: JRP 2 (1994), 68-78 (Diskussion: 78-83); Korinek, Entwicklungstendenzen (Fn. 10); Öblinger, Verfassungsrecht (1994) (Fn. 33).

${ }^{37}$ Demnach verbietet sich ein Geschichtsunterricht, in dem der Nationalsozialismus überhaupt nicht vorkommt, aber auch einer, der sich nur auf ihn konzentriert, weil er anderen Geschichtsstoff unsachlich vernachlässigt. 
schehens und bettet die emotiven/affektiven und normativen Elemente der Erziehungsfunktion in den zunehmend schärfer konturierten Normierungsgehalt des Verhältnismäßigkeitsprinzips, Abwägungsgebots und Übermaßverbots.

An all dem müssen einfachgesetzliche Erziehungsziele ihr Maß nehmen. Als in aller Regel weitgehend unbestimmte Gesetzesbegriffe stehen sie unter dem Damoklesschwert des Determinierungsgebots nach dem Legalitätsprinzip des Art. 18 B-VG. Dies spielte auch bei einem diesbezüglichen Verfassungsgerichtshoferkenntnis eine Rolle, wo es darum ging, in einer Verwaltungsstrafnorm des Salzburger Lichtspielgesetzes 1958 den Begriff „sittlich-religiöses Empfinden“ zu interpretieren. Der Verfassungsgerichtshof befand damals, „daß das Landesgesetz das Rechtsgut, das ihm vorgeschwebt ist, nicht in einer für eine Strafnorm unbedingt erforderlichen Deutlichkeit umschrieben hat" (VfSlg. $4037 / 1961)^{38}$. Dabei ist freilich zu berücksichtigen, daß an Normen des Verwaltungsstrafrechts "strengere Anforderungen zu stellen sind als an Zielnormen ${ }^{\text {"39 }}$ wie jene des nunmehr zu erörternden $\$ 2$ SchOG, der schulische Bildung und Erziehung im Unterrichtsgeschehen einander zuordnet.

\section{Der Reichtum des unterverfassungsgesetzlichen Normenmaterials}

War und ist der Erziehungsauftrag der Universität kaum Diskussionsgegenstand, überwiegen seit alters her die universitären Bildungsaufgaben, wenn sich auch aus dem Universitätsorganisations- und dem Studienrecht Erziehungsziele rechtlich ableiten lassen und ein faktisches Interesse am Zulauf zu den "Sinnorientierungsfächern" wie Psychologie, Pädagogik, aber auch Soziologie, Publizistik und Politikwissenschaft erkennbar ist, so war schon im alten Österreich der Bildungs- und Erziehungszweck der Schulen unbestritten, wie der $\$ 1$ des vom politischen und kulturellen Liberalismus als eine seiner größten Errungenschaften empfundenen Reichsvolksschulgesetzes v. 14. Mai 1896, RGBl. 62, zeigt:

„Die Volksschule hat zur Aufgabe, die Kinder sittlich-religiös zu erziehen, deren Geistestätigkeit zu entwickeln, sie mit den zur weiteren Ausbildung für das Leben erforderlichen Kenntnissen und Fertigkeiten auszustatten und die Grundlage für Heranbildung tüchtiger Menschen und Mitglieder des Gemeinwesens zu schaffen."

38 „Das Gebiet, das durch die vom Gesetze gebrauchten Worte abgesteckt wird, ist unübersehbar. Die Antworten, die die Strafbehörde geben kann, sind nicht vorhersehbar. " (VfSlg. 4037/1961).

39 Evers, Bildungs- und Erziehungsauftrag, $37^{45}$ (Fn. 16). 
Der 1962 erzielte schulrechtliche Kompromiß brachte auf einfachgesetzlicher Ebene mit dem Schulorganisationsgesetz (SchOG) die "geistige ${ }^{" 40}$ und die „organisatorische Einheit ${ }^{\text {"41 }}$ des Schulsystems, mit Ausnahme des land- und forstwirtschaftlichen und des Hochschulwesens, zustande. Das SchOG enthält in seinem $\$ 2$ die einheitliche Festlegung der Aufgabe der österreichischen Schule, nach der sich nicht nur der Unterricht selbst, sondern die gesamte innere Ordnung aller Schulen zu richten hat: vgl. z. B. die $\$ \$ 2,17$ (1), 43 (1), 47 (1), 58 (1) und 61 (1) Schulunterrichtsgesetz (SchUG) v. 6. Feber 1974, BGBl. 139-wiederverlautbart 1986-, in denen immer wieder expressis verbis auf \$2SchOG Bezug genommen wird, dergestalt die schulrechtliche Tradition eines Jahrhunderts fortsetzend, die freilich noch ältere, bis in die Antike reichende Wurzeln hat. Der 1. Absatz - zweigeteilt - lautet:

„Die österreichische Schule hat die Aufgabe, an der Entwicklung der Anlagen der Jugend nach den sittlichen, religiösen und sozialen Werten sowie nach den Werten des Wahren, Guten und Schönen durch einen ihrer Entwicklungsstufe und ihrem Bildungsweg entsprechenden Unterricht mitzuwirken ${ }^{42}$. Sie hat die Jugend mit dem für das Leben und den künftigen Beruf erforderlichen Wissen und Können auszustatten und zum selbsttätigen Bildungserwerb zu erziehen.

Die jungen Menschen sollen zu gesunden, arbeitstüchtigen, pflichttreuen und verantwortungsbewußten Gliedern der Gesellschaft und Bürgern der demokratischen und bundesstaatlichen Republik Österreich herangebildet werden. Sie sollen zu selbständigem Urteil und sozialem Verständnis geführt, dem politischen und weltanschaulichen Denken anderer aufgeschlossen sowie befähigt werden, am Wirtschafts- und Kulturleben Österreichs, Europas und der Welt Anteil zu nehmen und in Freiheits- und Friedensliebe an den gemeinsamen Aufgaben der Menschheit mitzuwirken."

Der sogenannte "Zielparagraph" des $₫ 2$ SchOG hat keine hohe literarische Konjunktur: Robert Walter und Heinz Mayer bezeichnen ihn als "sehr pathetisch "43, Manfried Welan attestiert ihm, „Wortmu$\operatorname{sik}^{\text {“44 }}$ zu sein. Nur das verstorbene Mitglied unserer Vereinigung HansUlrich Evers nahm den Zielparagraphen wissenschaftlich ernst und

${ }^{40}$ Ders., a. a. O., 33 (Fn. 16).

${ }^{41}$ Hengstschläger, Schulrecht, 1073 (Fn. 8): „Die einzelnen Schularten wurden in einem abgestimmten System einander zugeordnet."

${ }^{42}$ Zurückhaltend reklamiert der Staat nur eine Mitwirkung an der Erziehung für sich.

${ }^{43}$ Walter/Mayer, Grundriß, 132 (Fn. 8).

${ }^{44}$ Manfried Welan, Der Bildungsauftrag der Universität, in: Höchtl/Windhager (Hrsg.), Bildungspolitik, 326 (Fn. 7). 
widmete ihm 1982 einen inhaltsreichen, differenzierten und subtilen Aufsatz ${ }^{45}$.

\$2 SchOG legt eine gemeinsame Bildungs- und Erziehungsaufgabe für die allgemeinbildenden und berufsbildenden öffentlichen Schulen aller Stufen sowie für die Anstalten der Lehrer- und Erzieherbildung fest $(\$ 1$ SchOG): $„ \$ 2$ gliedert diese Aufgabe in die Bildungsaufgabe, die Jugend mit dem für das Leben und den Beruf erforderlichen Wissen und Können auszustatten und zum selbständigen Bildungserwerb zu erziehen (Abs. 1 Satz 2) sowie in eine individualbezogene (Abs. 1 Satz 1) und eine sozialbezogene Erziehungsaufgabe (Abs. $1 \mathrm{Satz} 3$ ). Die individualbezogenen Erziehungsaufgaben bestimmt das Gesetz als eine wertgebundene, aber wertoffene Erziehung der Jugend nach einem Kanon in der christlich-humanistischen Tradition begründeter Werte, an der die Schule mitzuwirken habe. Die sozialbezogene Erziehungsaufgabe bestimmt das Gesetz durch einen Kanon von Bürgertugenden, die bei den jungen Menschen herangebildet werden sollen, und durch die Umschreibung der Aufgaben des Menschen in der Gesellschaft, im Staat und in der Welt, auf deren verantwortliche Wahrnehmung der Schüler vorbereitet werden soll. “46 (Hervorhebungen von mir).

Der Zielparagraph mit seinen zahlreichen unbestimmten Recbtsbegriffen gehört dem Regelungstypus der finalen Programmierung an und ist deshalb rechtlich nicht leicht zu vollziehen. Bei Schulorganisation, Schulzeit etc. ist dies leichter möglich. Die Verwirklichung des Zielbündels stellt hohe Anforderungen an die Abwägungsleistung unter dem Leitstern der Sachlichkeit und Verhältnismäßigkeit, nicht zuletzt unter Rücksichtnahme auf das Elternrecht. Nicht der pädagogische Erfolg, wohl aber Verhalten, Bemühen und Streben von Lehrern und Schülern sind als Pflicht, zumal als Amtspflicht staatlicher Organwalter (Lehrer) durchsetzbar.

Es ist interessant, daß bei der Operationalisierung des Zielparagraphen in den vergangenen drei Dekaden, worüber sogleich zu handeln sein wird, ganz allgemein die Momente der Kritikfäbigkeit, aber auch der Umweltverantwortung ${ }^{47}$ immer stärker betont wurden. Auffallend ist auch das Fehlen oder die Beiläufigkeit von Hinweisen auf Subsidiarität

${ }^{45}$ Evers, Bildungs- und Erziehungsauftrag ( $F n .16$ ), dort wird auch der zum Teil vom $\$ 2$ SchOG abweichende Erziehungsauftrag der land-und forstwirtschaftlichen Schulen behandelt ( $42 \mathrm{f}$.).

46 Evers, Kulturverfassungsrecht, 202 (Fn. 16).

47 Erziehungsziel Ökologie. Umfrage über die Wünsche der Familien an die Schule, in: Der Standard, 6. Oktober 1993, 9. 
und Föderalstruktur der Lebenswelt, überhaupt die Unterbelichtung von Staat und Recht.

Eine wichtige Konkretisierungsstufe der Bildungs- und Erziehungsziele der österreichischen Schule stellen die Lebrpläne ${ }^{48}$ ( $\$ 6$ SchOG) als Verordnungen des Unterrichtsministers dar, in denen die Allgemeinen Bestimmungen, das Allgemeine Bildungsziel und die Allgemeinen didaktischen Grundsätze, gefolgt von zahlreichen Detailregelungen, normiert sind.

Ich habe das explizit an $\ 2$ SchOG anknüpfende Allgemeine Bildungsziel der Allgemeinbildenden Höheren Schulen (AHS) der Lehrpläne aus dem Jahre $1984^{49}$ quantitativ-qualitativ nach den Kriterien "kognitiv", „emotiv/affektiv" und "normativ" untersucht, wobei sich folgende Verteilung der Elemente ergab:

1. kognitiv: 16

2. emotiv/affektiv: 4

3. normativ: 15.

Pragmatisch-utilitaristische Zielsetzungen schlug ich den normativen Elementen zu.

Das unterverfassungsgesetzliche Rechtsmaterial an Gesetzen, Verordnungen und Erlässen ist reich. Besondere Erwähnung verdient hiebei der Erlaß des Unterrichtsministers v. 11. April 1978 „Politische Bildung in den Schulen " ${ }^{\text {"50 }}$. Politische Bildung ${ }^{51}$, zumal als bloßes Unterrichtsprinzip mit seiner Eo ipso-Vagheit, läßt einmal die Probleme und Bruchlinien derartiger Zielvorgaben und ihres kompromissarischen Charakters aufblitzen. Bemerkenswert an diesem Erlaß ist das Fehlen des Terminus Staat, der durchwegs durch „Demokratie“ ersetzt wird.

Die finale Programmierung und die Unbestimmtheit der Erziehungsziele eröffnen dem Lebrer ${ }^{2}$ durchaus bemerkenswerte pädagogische

48 Dazu auch Diethelm Thurnber, Werterziehung als Aufgabe der Schule. Überlegungen zu dem im SchOG festgelegten Erziehungsauftrag anhand der AHS-Lehrpläne, in: Erziehung und Unterricht, 1986, 178-188.

49 Verordnung des Bundesministers für Unterricht und Kunst v. 14. November 1984, BGBl. 1985/88.

50 Zl. 33.464/6-19a/1978.

51 Allgem. zur politischen Bildung: Karl Kalcsics / Wolfgang Mantl / Klaus Poier, Herausforderung Steiermark. Eine Initiative zur politischen Bildung, 1993; Wolfgang Mantl, Die Überwindung von Ignoranz und Indifferenz. Politische Bildung als Teil der Allgemeinbildung, in: Caesar Walter Ernst / Markus Jaroschka (Hrsg.), Zukunft beginnt im Kopf. FS 75 Jahre Urania, 1994, 338-342; Elisabetb Morawek, Politische Bildung in den Schulen, in: RdS 8 (1986), 112-117.

52 Umfassend Walter Berka, Die pädagogische Freiheit des Lehrers als Rechtsproblem, in: JBl. 100 (1978), 571-587. 
Spielräume bei der Erfüllung der Aufgabe der österreichischen Schule „in eigenständiger und verantwortlicher Unterrichts- und Erziehungsarbeit ${ }^{\text {" }}$ ( $\$ 17$ Abs. 1 Satz 1 SchUG). Im Schulalltag kommt auch den Unterrichtsmitteln ( $\$ 14$ SchUG) wie Lehrbüchern, Filmen, Landkarten, Präparaten und - zunehmend umstritten - Medienkoffern besonderes Gewicht zu.

Zusammenfassend läßt sich sagen, daß der kulturpolitische Schulkompromi $\beta$ des Jahres 1962 über drei Jahrzehnte - unter wechselnden Parlamentsmehrheiten, wechselnden Regierungen und über die „68er Schwelle“ hinaus - von den politischen Kräften beibebalten wurde, wobei sich in der Praxis leichte zeitgeistkonforme Verschiebungen ergaben, ohne daß es jedoch bis jetzt zu einem Bruch der Traditionslinie gekommen wäre, die nach wie vor jüdisch-christliche Überlieferung mit neubumanistischen (Betonung der Allgemeinbildung und Relativierung eines bloß utilitaristischen Funktionalismus) und kritisch-rationalistischen (Karl Raimund Popper) Elementen zu verbinden trachtet, wobei der letztgenannte Faktor als das leise, aber offenbar allgemein akzeptierte Novum in der Entwicklungsgeschichte des $\$ 2$ SchOG erscheint.

\section{Zukunftsaspekte}

Wenn man die Gegenwartstendenzen Revue passieren läßt und vorsichtige Schätzungen möglicher Entwicklungen vornimmt, so ergibt sich folgendes Bild:

1. Die Schulreformbestrebungen, die es in Österreich derzeit gibt, verlaufen konventionell in dem Sinne, daß sie wieder hauptsächlich auf $O r$ ganisations-, Kompetenz- und Finanzierungsfragen, nicht auf Erziebungsziele abstellen. Neu, ja geradezu umwälzend ist die Tatsache, daß die Reformtexte ${ }^{53}$ erstmals in der österreichischen Schulgeschichte seit Maria Theresia das aufgeklärt-absolutistische Paradigma verlassen und als ihre Leitbegriffe Dezentralisierung, Regionalisierung, Deregulierung und Autonomie gewählt haben, was - rechtlich gesprochen - zumindest auf einen größeren Spielraum für die Landesverfassungs- und Landesgesetzgebung hinausliefe. Auch der allgemeine exogene Reformdruck durch den Beitritt Österreichs zur Europäischen Union dürfte kaum zu

53 Christian Brünner u. a., Föderalisierung, Autonomie und Ende des Parteienproporzes, o. J. (1993); Reinhard Gande/ Hans Putzer/Herbert Schwetz (Hrsg.), Schulautonomie. Ein Handbuch für die Praxis, 1994; Josef Thonhauser, Schulentwicklung durch Autonomie in den Schulen? In: VCL. Die Österreichische Höhere Schule. Organ der Vereinigung christlicher Lehrerinnen und Lehrer an höheren und mittleren Schulen, 45 (1993), H. 1, 1-5. 
einer besonderen expliziten bundesverfassungsrechtlichen ${ }^{54}$ Positivierung von Erziehungsauftrag und Erziehungsmaßstab des Staates bezüglich der Schule führen, wiewohl die Projektion von Erziehungserwartungen von der Familie auf den Staat zunehmen wird.

2. Die politischen Träger des Schulkompromisses von 1962, die sozialen Integrationsparteien vom Volksparteitypus (ÖVP und SPÖ), fielen bei den Nationalratswahlen 1994 unter die Zweidrittelmarke des Art. 14 (10) und 14a (8) B-VG: SPÖ und ÖVP erreichten zusammen bei den abgegebenen Stimmen nur mehr 62,6\% und bei allen Wahlberechtigten gar nur mehr 50,2 \%, während die sogenannte Konzentration der Stimmen und Mandate auf die beiden größten Parteien früher durch Jahre hindurch sogar über der $90 \%$-Marke lag. Die ÖVP verlor ihr "Sperrdrittel ${ }^{\alpha}$ bereits 1990. Damit ist noch nicht gesagt, daß der Scbulkompromiß notwendigerweise seine Auflösung erfährt, aber die Wahrscheinlichkeit seiner Veränderung steigt.

3. Das Abbröckeln des Parteieinflusses und die Abschwächung der Partizipationsimpulse könnte - gegenläufig zu den oben erwähnten Autonomiewünschen - geradezu eine "Rebürokratisierung " und Entparlamentarisierung des Schulwesens dergestalt zur Folge haben, daß in den Medien populistisch und charismatisch agierende Persönlichkeiten mit ihren "Chefbeamten", wie es im alten Österreich hieß, die Schule verwalten.

4. Individualisierung und Pluralisierung der Lebenswelt, zusammenschießend in einem veränderten Rollenbild der Frau, könnten zur Folge haben, daß Einzelpersonen, Eltern und Kleingruppen grundrechtliche Rechts- und damit stets auch Wertdurchsetzung in zahlreichen Auseinandersetzungen anstreben, die in dezentralisierten Wertkonflikten ausgetragen werden, die erst durch eine sich allmählich stabilisierende Judikatur und Lehre ihre Partikularität abstreifen und zu einer generellen Praxis führen können. Konsistente Gruppen, etwa Lehrer- und Elternverbände, Universitätslehrer, vor allem der Pädagogik, Personalberater, aber auch Richter, gerade der Höchstgerichte, würden hiebei eine gewichtige Rolle spielen.

5. Wir Kinder der Aufklärung unterschätzen in unserer begreiflichen Freude über den Freibeitsgewinn der letzten 200 Jahre bisweilen die soziokulturellen Modernisierungs- und Säkularisierungskosten, die keine "Verfassungsmagie ${ }^{\alpha}$ aus der Welt schaffen kann. Es stimmt schon, daß die Verfassung nicht nur Spielregel ist, sie ist aber auch keine Zauberformel für alle menschlichen, gesellschaftlichen und politischen Probleme. Der Staat und seine Schule können nicht allein und von sich aus als der

${ }^{54}$ Allenfalls sind noch landesverfassungsrechtliche Verankerungen zu erwarten. 
große Problemlöser auftreten. Die von Ralf Dabrendorf als „Böckenförde-Paradox ${ }^{\alpha 55}$ bezeichnete Einsicht lehrt uns, daß der Staat von Voraussetzungen lebt, die er selbst nicht garantieren kann, daß er viel Moral braucht, ja verbraucht, die er selbst nicht produzieren kann. Er bedarf eines ethischen Umfeldes, das bisher in verschiedenen vorstaatlichen Erziehungs- und Sozialisationseinheiten entfaltet wurde, das auszutrocknen und zu zerfallen droht, wenn Ehe, Familie und Kirchen in Krisen geraten. Wer sich nicht in den üblichen rhetorischen Optimismus eines Referatschlusses flüchten will, darf sein Auge nicht vor den vielen Fragezeichen unseres Zukunftshorizonts verschließen.

55 S. Ralf Dabrendorf, Freiheit und soziale Bindungen. Anmerkungen zur Struktur einer Argumentation, in: Krzysztof Michalski (Hrsg.), Die liberale Gesellschaft. Castelgandolfo-Gespräche 1992, 1993, 11; grundlegend Ernst-Wolfgang Böckenförde, Die Entstehung des Staates als Vorgang der Säkularisation. Zuerst 1967, jetzt in ders., Recht, Staat, Freiheit. Studien zur Rechtsphilosophie, Staatstheorie und Verfassungsgeschichte, 1991, 92-114, zumal 110-114. 
Erziehungsauftrag und Erziehungsmaßstab der Schule im freiheitlichen Verfassungsstaat

4. Länderbericht Schweiz von Prof. Dr. Yvo Hangartner, St. Gallen

$$
\text { Inhalt }
$$

Seite

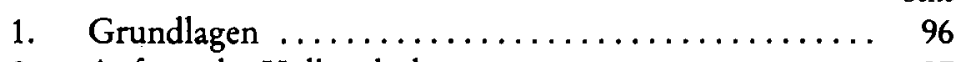

2. Auftrag der Volksschule ................... 97

3. Erziehungsziele .................... 99

4. Weltanschauliche Neutralität der öffentlichen Schule .. 101 


\section{Grundlagen}

Die Volksschule - auf die wir uns im folgenden beschränken - ist in der Schweiz Sache der Kantone ${ }^{1}$. Gemäß den Kantonsverfassungen und Schulgesetzen ist jede Gemeinde verpflichtet, eine Schule zu führen, in der die Grundschulpflicht erfüllt werden kann. In der Regel obliegt diese Aufgabe den Einwohnergemeinden; in einzelnen Kantonen bestehen besondere, ebenfalls direktdemokratisch organisierte Schulgemeinden ${ }^{2}$.

Die Bundesverfassung bestimmt im Art. 27 Abs. 2 und 3: „Die Kantone sorgen für genügenden Primarunterricht, welcher ausschließlich unter staatlicher Leitung stehen soll. Derselbe ist obligatorisch und in den öffentlichen Schulen unentgeltlich. - Die öffentlichen Schulen sollen von den Angehörigen aller Bekenntnisse ohne Beeinträchtigung ihrer Glaubens- und Gewissensfreiheit besucht werden können." Die Kantone beziehungsweise Gemeinden haben somit Volksschulen zu führen, die dem in Frankreich entwickelten Modell der école publique, gratuite, obligatoire et laïque ${ }^{3}$ entsprechen. Die Regelung wurde aufgrund des Kulturkampfes in die 1874 totalrevidierte Bundesverfassung aufgenommen ${ }^{4}$.

Die Unterrichtsfreiheit als Individualrecht wurde vom Bundesverfassungsgeber - im Gegensatz zu zahlreichen Kantonsverfassungen - bewußt nicht gewährleistet ${ }^{5}$. Kantonale Schulmonopole, wie sie früher aufgrund einengender Vorschriften zumindest faktisch vereinzelt bestanden $^{6}$, würden heute allerdings dem von der Schweiz in diesem Punkt vorbehaltlos ratifizierten Internationalen Pakt über wirtschaftliche, soziale und kulturelle Rechte widersprechen?. Privatschulen werden aber nur

1 S. Art. 27 Abs. 2 bzw. Art. 3 der Bundesverfassung der Schweizerischen Eidgenossenschaft vom 29. Mai 1874 (BV).

2 Vgl. Hans Bosshard, Die Rechtsordnung der schweizerischen Volksschule, Diss. Zürich 1955, S. 81 ff. und S. $169 \mathrm{ff}$.

${ }^{3} \mathrm{Vgl}$. André de Laubadère, Traité élémentaire de droit administratif, tôme III, 1966, S. 208.

4 Vgl. Ulrich Lampert, Das schweizerische Bundesstaatsrecht, 1918, S. 163.

${ }^{5}$ Vgl. Eduard His, Geschichte des neuern Schweizerischen Staatsrechts, Band III/2, 1938, S. 619; Walther Burckbardt, Kommentar der schweizerischen Bundesverfassung vom 29. Mai 1874, 3. Aufl., 1931, S. 200; Walter Kämpfer, Bestand und Bedeutung der Grundrechte im Bildungsbereich der Schweiz (mit bes. Berücksichtigung des Rechts auf Bildung), in EuGRZ 1981, S. 694.

${ }^{6}$ Vgl. His (Fn. 5), S. 622 f.; Kämpfer (Fn. 5), S. 694.

7 S. Art. 13 Abs. 3 des Internationalen Pakts über wirtschaftliche, soziale und kulturelle Rechte vom 16. Dezember 1966, AS 1993725 (SR 0.103.1), für die Schweiz in Kraft seit 18. September 1992. Das erste Zusatzprotokoll zur EMRK vom 20. März 1952 mit der Gewährleistung des Rechts der Eltern, Erziehung und Unterricht ent- 
zugelassen, wenn ihr Unterricht jenem an der öffentlichen Schule gleichwertig ist ${ }^{8}$.

Vor allem in den deutschsprachigen Kantonen besuchen die meisten Kinder die öffentliche Volksschule?. Deshalb kommen zum vornherein Schüler verschiedenster Herkunft in der von der Gemeinde geführten Einheitsschule zusammen. Nicht nur soziale und konfessionelle Unterschiede der Schüler prägen die öffentliche Schule, sondern angesichts des hohen Anteils von Gastarbeitern aus entfernteren Ländern zunehmend auch kulturelle Verschiedenheiten. In vielen städtischen Schulen sind die Ausländerkinder in der Mehrzahl ${ }^{10}$. Probleme gibt es allerdings weniger mit den Schülern als mit einzelnen Eltern. Nur in ganz ländlichen $\mathrm{Ge}-$ genden bestehen noch homogene Verhältnisse.

\section{Auftrag der Volksschule}

Die Volksschule hat in erster Linie die Aufgabe, den Kindern und Jugendlichen unerläßliche Grundkenntnisse weiterzugeben. Die Bundesverfassung fordert in diesem Sinn einen "genügenden Primarunterricht" (Art. 27 Abs. 2 BV). Den Schülern ist zu vermitteln, was jeder Einwohner unter den herrschenden zivilisatorischen Bedingungen wissen muß. Die Schüler sollen jene Fähigkeiten erwerben und entfalten, die notwendig sind, um einen Beruf zu erlernen und auszuüben und die Anforderungen des modernen Lebens selbständig zu meistern ${ }^{11}$. Die nähere Festlegung dieser Unterrichtsziele obliegt den Kantonen. Der Bundesverfassungsgeber hat auf eine Gesetzgebungskompetenz des Bundes zur Ausführung des bundesverfassungsrechtlichen Begriffs des genügenden Primarunterrichts verzichtet ${ }^{12}$.

sprechend ihren eigenen religiösen und weltanschaulichen Überzeugungen sicherzustellen, wurde von der Schweiz bisher nicht ratifiziert. Siehe auch Art. 29 Abs. 2 des von der Schweiz bisher ebenfalls nicht ratifizierten Übereinkommens der Vereinten Nationen vom 20. November 1989 über die Rechte des Kindes.

${ }^{8}$ S. z. B. $\$ 58$ des Aargauer Schulgesetzes vom 17. März 1981; $\$ 6$ Abs. 1 des Schulgesetzes des Kantons Basel-Landschaft vom 26. April 1979. Vgl. BGE 91 I 490; $\mathrm{Her}$ bert Plotke, Schweizerisches Schulrecht, 1979, S. 466.

9 Im Kanton St. Gallen z. B. besuchen auf der Primarschulstufe (7.-12. Altersjahr) gemäß Auskunft des Erziehungsdepartements nur 1,2\% der Kinder eine Privatschule.

${ }^{10}$ Rund ein Fünftel der Gesamtbevölkerung der Schweiz sind Ausländer.

11 Vgl. Marco Borghi, Komm. BV, N. 33 zu Art. 27; Plotke (Fn. 8), S. 46.

12 Vgl. His (Fn. 5), S. 1014 ff. Der Versuch der Bundesversammlung, durch eine institutionalisierte Bundesaufsicht über die Erfüllung der Verpflichtungen der Kantone gemäß Art. 27 Abs. 2 und 3 BV stärkeren Einfluß auf das Schulwesen zu gewinnen, scheiterte in der denkwürdigen eidgenössischen Volksabstimmung vom 26. Novem-

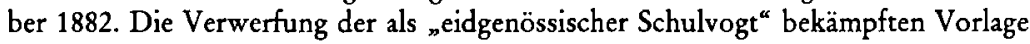


Die Volksschule soll das Kind aber auch erziehen und ihm in seiner sittlichen Entfaltung helfen ${ }^{13}$. Die Schule ist aufgrund der Schulgesetze neben den Inhabern der elterlichen Gewalt institutionalisierter Erzieher. Es ist eine wesentliche und nicht nur akzessorische Aufgabe der Schule, in Ergänzung der elterlichen Erziehung, aber gerade auch über das jeweilige Umfeld des Kindes hinaus zu erziehen und die Entwicklung der Kinder zu sittlich verantworteter Einstellung und Lebensführung zu fördern ${ }^{14}$. Die Erziehung durch die Schule dient dem Kindeswohl, gleichzeitig aber auch dem öffentlichen Interesse.

Die Schule hat aber trotz ihres eigenständigen Erziehungsauftrags zu beachten, daß die Kinder in erster Linie in der Familie erzogen werden ${ }^{15}$. Es ist - in der Sprache des Schweizerischen Zivilgesetzbuches - Aufgabe der Eltern, „das Kind ihren Verhältnissen entsprechend zu erziehen und seine körperliche, geistige und sittliche Entfaltung zu fördern und $\mathrm{zu}$ schützen" (Art. 302 Abs. 1 ZGB). Die Schule hat daher nach Harmonisierung häuslicher und schulischer Erziehung zu streben. Sie muß darauf achten, daß auch Konflikte mit Eltern, die von der Mehrheit abweichende Auffassungen und Verhaltensweisen haben, nach Möglichkeit vermieden werden. Aus diesem Grund ist zum Beispiel im Sexualkundeunterricht Zurückhaltung geboten. Ganz lassen sich Konflikte jedoch nicht ausschalten, soll die Schule ihren selbständigen Erziehungsauftrag erfüllen.

Nur über die religiöse Erziehung der Kinder bis zur religiösen Mündigkeit nach erfülltem 16. Altersjahr bestimmt gemäß ausdrücklicher Vorschrift der Bundesverfassung (abschließend) der Inhaber der elterlichen Gewalt (Art. 49 Abs. 3 BV; Art. 303 ZGB) ${ }^{16}$. Der Bereich religiöser Erziehung ist allerdings nicht leicht abzugrenzen. Schutzgut der Religionsfreiheit sind auch Verhaltensweisen, die - wie religiöse Kleider- und Speisevorschriften - unmittelbarer Ausdruck religiöser Überzeugungen sind ${ }^{17}$. Die Schule hat hierüber keine Wertungen zu äußern. Sie hat hin-

war derart wuchtig, daß das Bundesparlament nie mehr einen entsprechenden neuen Versuch unternahm. Vgl. zum historischen Streit über die bundesgesetzliche Ausführung der Verfassungsvorschriften über die Volksschule L. R. von Salis, Schweizerisches Bundesrecht, Band 5, N. 2460, S. $558 \mathrm{ff}$.

13 Vgl. Plotke (Fn. 8), S. 46 f. S. a. Art. 29 Abs. 1 des Übereinkommens der Vereinten Nationen vom 20. November 1989 über die Rechte des Kindes.

${ }^{14} \mathrm{Vgl}$. Karl Alexander Eckstein, Schule und Elternrecht, Staatliche Bildungsziele und elterliche Befugnisse im öffentlichen Schulwesen, Diss. Basel 1979, S. $226 \mathrm{f}$.

15 Vgl. Thomas Fleiner, Die Rechte der Eltern gegenüber der Schule, in AJP/PJA 1993, S. 666 ff.; Plotke (Fn. 8), S. 42 und 46 f.

${ }_{16} \mathrm{Vgl}$. Eckstein (Fn. 14), S. $247 \mathrm{f}$.

17 Vgl. BGE 119 Ia 178 E. 4c, 184 f., und Bemerkungen von Yvo Hangartner dazu in AJP/PJA 1994, S. 622 ff.; Malcolm N. Shaw, Freedom of Thought, Conscience and Religion, in: R.ST.J. Macdonald et al. (Eds.), The European System for the Protection of Human Rights, 1993, S. 458 f. 
gegen auch in den Bereichen, die über Glaubens- und Kultusfragen im engeren Sinn hinausführen, die Fähigkeiten zu vermitteln, die ein junger Mensch unbedingt erwerben mu $\beta^{18}$. So hat die Schule unter den heutigen Gegebenheiten zum Beispiel über die verschiedenen Möglichkeiten der Verhütung einer HIV-Infektion aufzuklären, auch wenn Eltern aus religiösen Gründen bestimmte Vorkehren ablehnen. Das Gebot der Rücksichtnahme auf die Entscheidungen und Erziehungsziele der Eltern gilt in solchen religiös beeinflußten Bereichen aber selbstverständlich in ganz besonderem Maße.

\section{Erziehungsziele}

Die schweizerischen Kantone formulieren die Erziehungsziele ähnlich wie die Verfassungen und die Schulgesetze der deutschen Länder ${ }^{19}$. Ein repräsentatives Beispiel ist $\ 1$ des Solothurner Volksschulgesetzes ${ }^{20}$. Er lautet wie folgt: „Die solothurnische Volksschule unterstützt die Familie in der Erziehung der Kinder zu Menschen, die sich vor Gott und gegenüber dem Nächsten verantwortlich wissen und danach handeln. Sie entfaltet die seelischen, geistigen und körperlichen Kräfte in harmonischer Weise, erzieht zu selbständigem Denken und Arbeiten und vermittelt die grundlegenden Kenntnisse zur Bewährung im Leben. - Die Volksschule respektiert die Glaubens- und Gewissensfreiheit. Sie führt die Kinder von unterschiedlicher Herkunft zur Gemeinschaft, fördert die Erziehung zur Mitverantwortung in unserem demokratischen Staatswesen und weckt die Achtung vor der heimatlichen Eigenart." Andere Kantone haben etwas andere Formulierungen gewählt ${ }^{21}$. Es würde zuweit führen, hier auf Unterschiede und Nuancen der Texte einzugehen. Die Gesetzgeber ringen zwar erfahrungsgemäß um die Formulierungen, denn diese ergehen in einem weltanschaulich und politisch sensiblen Bereich. Die Texte sind aber zu vage, als daß sie die Praxis über eine allge-

${ }^{18}$ Vgl. Eckstein (Fn. 14), S. 248 ff.; Elena Bannwart-Maurer, Das Recht auf Bildung und das Elternrecht, Art. 2 des ersten Zusatzprotokolls zur Europäischen Menschenrechtskonvention, Diss. Zürich 1975, S. $126 \mathrm{f}$.

19 Vgl. Hans-Ulrich Evers, Die Befugnis des Staates zur Festlegung von Erziehungszielen in der pluralistischen Gesellschaft, 1979, S. 34 ff.; Frank Hennecke, Staat und Unterricht, 1972, S. 51 ff.; Hans-Joachim Reeb, Bildungsauftrag der Schule, 1981, S. $200 \mathrm{ff}$.

20 Vom 14. September 1969.

${ }^{21}$ In einzelnen Kantonen finden sich die Regelungen bereits in der Verfassung; s. Art. $42 \mathrm{KV} \mathrm{BE}$, Art. $27 \mathrm{KV}$ OW, Art. 3 Abs. $3 \mathrm{KV} \mathrm{NW}$, Art. $17 \mathrm{KV}$ FR, Art. 104 Abs. 1 und $2 \mathrm{KV} \mathrm{SO}, \$ 94$ Abs. 1 und $2 \mathrm{KV}$ BL sowie Art. $32 \mathrm{KV} \mathrm{JU}$. 
meine, ohnehin akzeptierte Richtlinie hinaus beeinflussen könnten ${ }^{22}$. Einzelne Kantone haben denn auch früher ganz auf gesetzlich umschriebene Erziehungsziele verzichtet ${ }^{23}$.

Aus den allgemein formulierten Erziehungszielen läßt sich nicht mehr herauslesen als der Auftrag der Schule, in Ergänzung der elterlichen Bemühungen die Jugendlichen zu einem sittlich verantworteten Leben heranzuführen. Dabei geht es der Schule als öffentlicher Einrichtung vorab darum, die Gemeinschaftsfähigkeit der heranwachsenden Menschen zu fördern und sie zu pflichtbewußten Gliedern der Gesellschaft zu erziehen. In der Demokratie, gerade auch in der Demokratie schweizerischer Prägung mit ihren zahlreichen Volksabstimmungen über Sachfragen von zum Teil existentieller Bedeutung für die Bevölkerung, geht es wesentlich auch darum, Staatsbürger heranzuziehen, die bereit und fähig sind, die Geschicke des Gemeinwesens mitzutragen und mitzugestalten $^{24}$.

Die allgemeine Bildung des jungen Menschen vollzieht sich allerdings mehr im engern familiären und gesellschaftlichen Umfeld. Dies gilt aufgrund der Erfahrungen in der Schweiz auch für den staatsbürgerlichen Bereich ${ }^{25}$. Praktisch bedeutsamer sind daher für die Schule die immer zahlreicher werdenden besonderen Erziehungsziele, die in Lehrplänen, Richtlinien zu einzelnen Fragen und ganz einfach in der Schulpraxis konkretisiert werden.

Solche besonderen Erziehungsziele sind etwa die Erziehung zu Toleranz gegenüber Minderheiten, zum Umweltschutz, zu Disziplin im Straßenverkehr, zu Aids-Prävention und zu gesundheitsbewußter körperlicher Betätigung und Ernährung. Dabei geht es um die Vermittlung von Kenntnissen und Fähigkeiten, aber eben auch um Erziehung zu verantwortungsvollem Handeln gegenüber den Mitmenschen und sich selbst und zu Engagement im Dienste gesellschaftlicher Anliegen. Die Schule kann erzieherisch dort am fruchtbarsten wirken, wo Ausbildung und Bildung eng zusammenhängen. Auf diese Bereiche sollte sich die Diskussion über den Erziehungsauftrag der Schule konzentrieren. Hier lassen sich auch die vertiefenden Einsichten für die Erziehungsverant-

${ }^{22}$ Vgl. Gerd Roellecke, Erziehungsziele und der Auftrag der Staatsschule, in: FS Hans Joachim Faller, 1984, S. 187 ff. Peter Häberle spricht von den Erziehungszielen als "soft law" des Kulturverfassungsrechts; vgl. Erziehungsziele als Orientierungswerte im Verfassungsstaat, 1981, S. 69 ff. Noch weiter ausgreifend Peter Häberle, Verfassungsprinzipien als Erziehungsziele, in: FS Hans Huber zum 80. Geburtstag, 1981, S. $211 \mathrm{ff}$.

${ }^{23} \mathrm{Vgl}$. Eckstein (Fn. 14), S. 161.

${ }^{24}$ Vgl. Bosshard (Fn. 2), S. 48 ff.

${ }^{25}$ Vgl. Bosshard (Fn. 2), S. 50 f. und die Hinw. in Fn. 31 dazu. 
wortlichen selbst gewinnen, zum Beispiel das Wissen, daß es im Umgang mit Minderheiten nicht nur um Toleranz geht. Toleranz heißt nämlich Duldung ${ }^{26}$, Duldung von etwas, das man eigentlich verneint; das Ziel muß daher nicht bloß die Erziehung zur Toleranz, sondern die Erziehung zum Respekt des andern, zur Bejahung der pluralistischen Gesellschaft und demokratischen Vielfalt sein.

Die schweizerische Schule muß sich im besondern auch bemühen, die Jugendlichen in ein Land zu integrieren, das sprachlich-kulturell nicht eine Einheit bildet, sondern - als ein Europa im Kleinen - auf der Vielfalt seiner vier Nationalsprachen beruht. Die Kantone unterrichten die Schüler, auch die vielen Kinder fremdsprachiger Gastarbeiter, in der Sprache, die auf dem jeweiligen Territorium vorherrscht, und sie dürfen trotz grundsätzlicher Anerkennung der Sprachenfreiheit um der Integration willen auch von Privatschulen sprachlicher Minderheiten verlangen, daß die nach dem Territorialitätsprinzip maßgebende Sprache vermittelt wird ${ }^{27}$. Anderseits gehört es zu den selbstverständlichen Erziehungszielen, die Verständigung zwischen den Angehörigen der Sprachregionen zu fördern; aus diesem Grund wird die zweite Landessprache heute bereits an den Primarschulen gelehrt ${ }^{28}$.

Knaben und Mädchen sind im Interesse der Chancengleichheit in Ausbildung und Erziehung absolut gleich zu behandeln (Art. 4 Abs. $2 \mathrm{BV})^{29}$. Weil die Bundesverfassung auch die faktische Gleichstellung der Geschlechter im Alltag anstrebt ${ }^{30}$, ist die gelebte Geschlechtergleichheit wenn auch erst in jüngster Zeit - zu einem wichtigen Erziehungsziel geworden.

\section{Weltanschauliche Neutralität der öffentlichen Schule}

Die Schulfälle, die als schulrechtliche Fälle behandelt werden, betreffen vor allem die Schranken erzieherischer Betätigung der öffentlichen Schule. Sie ergeben sich aus dem Gebot weltanschaulicher und politischer Neutralität ${ }^{31}$.

${ }^{26} \mathrm{Vgl}$. die Toleranzedikte des 17. und 18. Jahrhunderts.

27 Vgl. BGE 91 I 480 E. 2, 486 ff.

28 Wobei der einzelne Kanton selbst entscheidet, welches für ihn die zweite Landessprache ist. Uri hat sich zum Beispiel nicht für die französische, sondern für die italienische Sprache entschieden.

${ }^{29}$ Vgl. Jörg Paul Müller, Die Grundrechte der schweizerischen Bundesverfassung, 1991, S. 229 f.

30 Vgl. Müller (Fn. 29), S. 231.

${ }^{31} \mathrm{Vgl}$. Ulrich Weder, Die innenpolitische Neutralität des Staates - Ihre Bedeutung für die Schweiz, Diss. Zürich 1981, S. 111 ff.; Josef Marschall, Das Prinzip der Konfessionslosigkeit der öffentlichen Schulen in der Bundesverfassung, Diss. Zürich 1948. 
Die Bundesverfassung bestimmt ausdrücklich, daß die religiöse Erziehung der Kinder dem Inhaber der elterlichen Gewalt zusteht (Art. 49 Abs. 3 BV) ${ }^{32}$. Im Einverständnis mit ihm dürfen jedoch auch Dritte Glaubensinhalte vermitteln. Aus diesem Grund ist es zulässig, wenn die Lehrpläne öffentlicher Schulen (fakultativen ${ }^{33}$ ) Religionsunterricht für Angehörige von Religionsgemeinschaften vorsehen und die Studienpläne ihnen hierfür normale Unterrichtszeiten einräumen ${ }^{34}$. Auch religiöses, nicht säkuralisiertes Brauchtum darf in der Schule gepflegt werden, sofern die Schüler der gleichen Religion oder Konfession angehören und kein Inhaber elterlicher Gewalt Einspruch erhebt. Unter den gleichen Voraussetzungen ist auch das Schulgebet zulässig ${ }^{35}$. Die Bundesverfassung fordert keine doktrinär verstandene laizistische Schule.

Hingegen verlangt die Bundesverfassung ausdrücklich, daß die öffentlichen Schulen von den Angehörigen aller Bekenntnisse ohne Beeinträchtigung ihrer Glaubens- und Gewissensfreiheit besucht werden können («sans qu'ils aient à souffrir d'aucune façon dans leur liberté de conscience ou de croyance»; Art. 27 Abs. 3 BV) ${ }^{36}$. Diese Verpflichtung besteht heute auch aufgrund der Europäischen Menschenrechtskonvention (Art. 9) ${ }^{37}$ und des Internationalen Pakts über bürgerliche und politische Rechte (Art. 18) ${ }^{38}$. In der üblichen gemischten Zusammensetzung der Klassen darf die öffentliche Schule deshalb nicht entsprechend einer bestimmten Religion, Konfession oder Weltanschauung unterrichten. Sie darf in diesem Sinn nicht indoktrinieren.

In der konfessionell gemischten Schweiz wird traditionsgemäß vor allem darauf geachtet, daß der Unterricht in der öffentlichen Schule nicht einseitig nach römisch-katholischen oder protestantischen Auffassungen

${ }^{32} \mathrm{Vgl.} \mathrm{Burckbardt}$ (Fn. 5), S. $456 \mathrm{ff}$.

33 Vgl. Burckhardt (Fn. 5), S. 200; Ulrich Häfelin, Komm. BV, N. 61 zu Art. 49; Bosshard (Fn. 2), S. 78; Schreiben der Justizabteilung vom 19. April 1938, VEB 12 (1938), Nr. 20, S. 42 f. (Zulässigkeit obligatorischen Religionsunterrichts, soweit nicht ausdrücklich darauf verzichtet wird).

${ }^{34} \mathrm{Vgl}$. Entscheid des Bundesrates vom 1. März 1938, VEB 12 (1938), Nr. 21, S. 44 f.; Werner Kurt Bräm, Religionsunterricht als Rechtsproblem im Rahmen der Ordnung von Kirche und Staat, Diss. Basel 1978, S. 48 ff.; Plotke (Fn. 8), S. 134 f.; Peter Karlen, Das Grundrecht der Religionsfreiheit in der Schweiz, Diss. Zürich 1988, S. 392.

${ }^{35} \mathrm{Zu}$ diesen Fragen liegt allerdings kein publizierter Entscheid vor. In der Literatur gehen die Meinungen auseinander; vgl. Karlen (Fn. 34), S. 395 f. Die hier vorgetragene differenzierende Lösung wird u. a. vertreten von Burckbardt (Fn. 5), S. 200 Fn. 2; Plotke (Fn. 8), S. 162; Borghi (Fn. 11), N. 79 zu Art. 27.

${ }_{36}$ Vgl. Burckbardt (Fn. 5), S. 200 ff.; Häfelin (Fn. 33), N. 55 ff. zu Art. 49; BGE 116 Ia 252 (Kruzifix-Urteil).

37 AS 19742151 (SR 0.101), für die Schweiz in Kraft seit 28. November 1974.

38 AS 1993725 (SR 0.103.1), für die Schweiz in Kraft seit 18. September 1992. 
vermittelt wird. Größere Schwierigkeiten bestehen hinsichtlich der zunehmenden Zahl von Schülern, die konfessionslos sind oder dem Islam oder einer anderen fremd- oder neuartigen Religionsgemeinschaft angehören. Ältere, aber auch neuere Kantonsverfassungen und Schulgesetze sehen ausdrücklich vor, daß die Schule den Zweck habe, die ihr anvertraute Jugend "nach christlichen Grundsätzen" heranzubilden ${ }^{39}$. Angesichts der Pflicht zur Respektierung der Glaubens- und Gewissensfreiheit aller Schüler besteht Übereinstimmung darüber, daß mit solchen Formulierungen lediglich gemeint sein kann - aber immerhin gemeint ist -, daß die Schule christlichen Grundwerten, die auch in der säkularisierten Gesellschaft der Gegenwart akzeptiert sind, verpflichtet ist ${ }^{40}$. In dieser Interpretation wurde die Formulierung von den zur Entscheidung solcher Streitigkeiten zuständigen politischen Bundesbehörden als zulässig angesehen ${ }^{41}$.

Insoweit besteht aber doch eine Schranke der Glaubens- und Gewissensfreiheit von Schülern, die weltanschaulich anders geprägt sind. Diese Einschränkung muß klar gesehen werden. Die Schule, die erzieht, kann ethischen Werten gegenüber nicht indifferent sein. Ethische Werte aber werden im Kontext der Kultur einer Gesellschaft entwickelt und konkretisiert. Die Schule, die auf das Leben in dieser Gesellschaft vorberei-

${ }^{39}$ S. z. B. Art. 1 Abs. 3 des Berner Gesetzes vom 2. Dezember 1951 über die Primarschule; Art. 27 der Obwaldner Kantonsverfassung vom 19. Mai 1968; Art. 14 Abs. 3 der Nidwaldner Kantonsverfassung vom 10. Oktober 1965; Art. 2 Abs. 1 zweiter Satz des appenzell-innerrhodischen Schulgesetzes vom 29. April 1984. Art. 17 der Freiburger Staatsverfassung vom 7. Mai 1857 verlangt die Organisation und Leitung der öffentlichen Erziehung und des öffentlichen Unterrichts , in religiösem und vaterländischem Sinne ${ }^{\alpha}$ und bestimmt, daß der Geistlichkeit ein „mitwirkender Einfluß darauf" eingeräumt wird. Diese Vorschriften sind heute freilich im Sinn der Bundesverfassung von $1874 \mathrm{zu}$ relativieren.

${ }^{40}$ Vgl. Häfelin (Fn. 33), N. 56 zu Art. 49; Karlen (Fn. 34), S. 387 f.; Dieter Kraus, Schweizerisches Staatskirchenrecht, Tübingen 1993, S. 348; Plotke (Fn. 8), S. 155 ff. Eingehend zum Thema Gerald Petitjean, Die christliche Grundlegung der Schule, Diss. Basel 1972 (ungedruckt).

${ }^{41} \mathrm{Vgl}$. Entscheid des Bundesrates vom 11. Januar 1984, VEB 51 (1987) I Nr. 7, S. 48 ff.; Entscheid der Bundesversammlung vom 14. Dezember 1984/25. September 1986, Amtliches Bulletin der Bundesversammlung, Nationalrat, 1984, S. 1894 ff., und Ständerat, 1986, S. 515 ff. Ebenso Meinungsäußerung des EJPD vom 21. Oktober 1940, wo aber wegen möglicher Mißverständnisse von der Aufnahme einer solchen Vorschrift in ein Schulgesetz abgeraten wird; vgl. VEB 14 (1940), Nr. 12, S. 25 f. - Die Bundesversammlung entscheidet in Streitigkeiten über Beschwerden wegen Verletzung von Art. 27 Abs. 2 und 3 BV als letzte Instanz aufgrund von Art. 79 in Verbindung mit Art. 73 Abs. 1 lit. a Ziff. 2 des Bundesgesetzes vom 20. Dezember 1968 über das Verwaltungsverfahren, SR 172.021. 
tet, muß allen Schülern, gerade auch den aus anderen Kulturkreisen zugezogenen Schülern, die Grundwerte der Gesellschaft vermitteln, der sie angehören ${ }^{42}$. In diesem Sinn hat das schweizerische Bundesgericht in einem Entscheid ${ }^{43}$, der den koedukativen Schwimmunterricht einer islamischen Schülerin betraf, das Mädchen zwar aufgrund einer Rechtsgüterabwägung dispensiert. Es hat aber gleichzeitig festgehalten, die von den Eltern vertretenen Glaubensansichten hätten gegenüber dem Kindeswohl hintanzustehen, wenn das Kind zum Beispiel „in seiner Entwicklung in einem Maße eingeschränkt würde, daß die Chancengleichheit - einschließlich derjenigen zwischen den Geschlechtern - nicht mehr gewahrt wäre, beziehungsweise wenn es die Lehrinhalte nicht vermittelt erhielte, die in der hiesigen Wertordnung als unverzichtbar gelten ${ }^{\alpha 44}$.

${ }^{42} \mathrm{Vgl}$. Marschall (Fn. 31), S. $103 \mathrm{ff}$.

$43 \mathrm{Vgl.} \mathrm{BGE} 119$ Ia 178.

44 BGE 119 Ia 178 E. 8a, S. 194 f. 


\section{Aussprache und Scblußworte}

\section{Erziehungsauftrag und Erziehungsmaßstab der Schule im freiheitlichen Verfassungsstaat}

Vorsitzender (Schneider): Liebe Kolleginnen und Kollegen! Ich möchte zunächst Ihnen, den beiden Referenten und den Berichterstattern zu Österreich und der Schweiz, im Namen des Vorstands noch einmal sehr herzlich für die Vorträge danken. Wir fühlen uns bereichert und angeregt zur Diskussion. Wenn man Ihre Ausführungen allesamt noch einmal Revue passieren läßt, könnte man fast den Eindruck gewinnen, daß diejenigen Länder, welche die Erziehungsziele nicht auf die Ebene des Verfassungsrechts gehoben haben, ihnen dank der einfachgesetzlichen Regelungen eine wesentlich größere Bedeutung beimessen, so daß man sich fast fragen könnte, ob sie für die Praxis nicht in Gesetzen oder Lehrplänen sehr viel besser, wirksamer uns sachnäher plaziert sind als in der Verfassung. Das wäre aber schon ein Beitrag zur Diskussion. Ich eröffne hiermit die Aussprache zum ersten Beratungsgegenstand und möchte gleich zu Beginn darum bitten, das Erziehungsziel "Nächstenliebe“ auch einmal unter uns walten zu lassen und Rücksicht auf die Nachredner zu nehmen. Dann könnte es uns trotz der Vielzahl von Wortmeldungen, die ich bereits vorliegen habe, gelingen, allen, die etwas sagen möchten, gerecht zu werden, ohne daß sie von dem, was sie zu Gehör bringen wollen, wesentliche Abstriche machen müßten. Fassen Sie sich also bitte kurz.

Häberle: Herr Vorsitzender, verehrte Kolleginnen und Kollegen, liebe Referenten: Wer in unserem Kreis die Diskussion eröffnet, hat in $O p$ permannscher Tradition die Referate zunächst wertend zu vergleichendie heutigen sind ja durchaus kontrastreich. Ich versuche sogleich einige größere Linien und Zusammenhänge herzustellen. In diesem Sinne zwei Vorbemerkungen und drei Akzente setzende Nachbemerkungen. Erstens zur Kontinuität: Das heutige Thema steht in der größeren Tradition der unverzichtbaren inhaltlichen, kulturellen Grundierung der offenen $\mathrm{Ge}$ sellschaft bzw. freiheitlichen Demokratie. Unsere Vereinigung hat sie Stück für Stück erarbeitet. Erinnert sei an die Münchner Tagung unter Herrn Zacher zum Thema „Familie“ (1986), zuvor an Konstanz und 
Köln unter der Vorstandschaft von Herrn Lerche bzw. die Themen "Grundpflichten“ sowie „Kulturauftrag im staatlichen Gemeinwesen“ (1982/83). In diesem größeren Kontext darf man das heutige Thema sehen, und einige Passagen der Referate gingen in ihrem Verweis auf die Familie darauf ein. Daran schließt meine zweite Vorbemerkung an, zur Aktualität. Ich vermag zwar nichts so Aktuelles zu bieten, wie das von Herrn Mantl wiederholte Zitat eines österreichischen Fußballstars. In der Publizistik unserer Tage findet sich aber die These, der Erziehungsauftrag sei heute praktisch von der Familie, dem Staat und den Kirchen auf die Medien, insbesondere das Fernsehen übergegangen. Wenn dem so ist, ergibt sich daraus die dogmatische Frage, ob wir um eine „Drittwirkung" der Erziehungsziele, d. h. ihre Wirkung gegenüber dem öffentlichrechtlichen, aber auch privaten Fernsehen ringen müssen, um Entartungen und Mißbräuchen, z. B. in Sachen Brutalität, „Sex and Crime“ entgegenzutreten. Ein Referent hat Rundfunkgesetze, bzw. ihre ethischen Grundwerte zitiert, die in diese Richtung deuten, doch muß das effektiv gemacht werden. -

Es folgen meine drei Nachbemerkungen, hier die erste: Welches Verständnis von „Erziehung " haben wir, was soll sie? Hier müssen wir in der ganzen Tiefe der europäischen Kulturgeschichte arbeiten. Das beginnt mit der vorklassischen Sentenz von Heraklit: Erziehung gleiche nicht dem Füllen eines Fasses, sondern dem "Entzünden eines Lichtes“. Wir sollten im Geiste Goethes und Schillers fragen nach dem Zusammenhang von Freiheit und Bindung bzw. Bildung, Erziehung und des Menschengeschlechts, Freiheit aus tradierter und offener Kultur. Es geht auch um Erziehung zu den Menschenrechten, wie dies die Menschenrechtspakte verlangen und wie der Erstreferent in seinem schönen völkerrechtlichen Exkurs nachgewiesen hat. Hier muß das reiche Erbe des deutschen Idealismus eingebracht werden, etwa Hegels Deutung der Erziehung als „zweiter Geburt" des Menschen. Vor allem ist Rousseau vom „Kopf auf die Füße" zu stellen, also nicht „Zurück zur Natur“, sondern im Sinne Arnold Geblens „Zurück zur Kultur“. Wir erleben derzeit schmerzlich in Ex-Jugoslawien, wie rasch der Mensch in den barbarischen Naturzustand zurückfallen kann. Liegt also doch ein Stück Wahrheit beim Pessimismus von T. Hobbes? - Meine zweite Nachbemerkung: Es besteht aller Grund, auch aus Reverenz vor dem genius loci von Halle, daß wir uns die schöpferische Fortschreibung der Erziehungsziele in den neuen ostdeutschen Länderverfassungen vergegenwärtigen, auch die hier zu leistende kulturelle Sozialisation zum Verfassungsstaat hin. Herr Dittmann und Herr Bothe haben dies erwähnt (LS 10 bzw. 27). Im Umbruch der so glücklichen Wende vom totalitären Staat zur freiheitlichen Demokratie erkennen wir die Funktion von Erziehung, den inneren, theoretischen 
Zusammenhang ihrer Ziele mit den substantiellen Prinzipien der Verfassung, fast im Sinne einer neuen Grundwerte-Debatte. So finden wir neu die Erziehung zum Umweltbewußtsein, auch in Verantwortung vor künftigen Generationen. Ausnahmsweise beharre ich auf dem von Herrn Koreferenten als solchen freundlich genannten „Irrtum“, d. h. auf meiner These von der "pädagogischen Verfassungsinterpretation". Bayern hat in verfassungsändernder Volksabstimmung etwa 1984 die Erziehungsziele des Art. 131 („Verantwortungsbewußtsein für Natur und Umwelt") fortgeschrieben und im gleichen Atemzug parallel zu diesem soft law des Kulturverfassungsrechts den juristischen Umweltschutz als „andere Seite“ verstärkt, durch das "hard law" der Rechts- und Abwägungsprinzipien des Art. 141. Rechthaberisch sei gegenüber Herrn Dittmann, mit dem mich ja das Schwäbische verbindet, auf der „Pädagogischen Verfassungsinterpretation" beharrt. Wenn man seinen Leitsatz 7 genau liest und prüft, wie er die Menschenbildjudikatur des BVerfG fruchtbar gemacht hat, wenn man sieht, wie Herr Bothe aus Art. 20 und dem neuen Europa-Artikel 23 GG Erziehungsziele "herausgezuselt" hat (Zitat Mantl), so bestätigt sich die Unentbehrlichkeit pädagogischer Verfassungsinterpretation. Ich sage dies nur in Bangigkeit, da man ja als erster Redner nur loben, nicht kritisieren soll. - Zuletzt die dritte Nachbemerkung, Stichwort „Mitmenschlichkeit, Gemeinsinn“. Wir alle kennen die einfach fabelhaften Ergebnisse der gemeinsamen Verfassungskommission von Bundestag und Bundesrat (1993). Sie alle wissen um die interessante Diskussion, ob und inwiefern ein neuer Art. 2 a ins deutsche Grundgesetz eingebaut werden soll. Nach meiner Auffassung gehört der Orientierungswert „Mitmenschlichkeit und Gemeinsinn“, der doch im Grunde nur eine Fortschreibung der „Brüderlichkeit“, des oft vergessenen Ideals der französischen Revolution (so Herb. Krüger) ist, in der Tat nicht in den Grundrechtsteil. Indes hat er seine ideelle Entsprechung bzw. biographische Vorstufe in den schon klassischen gemeindeutschen Erziehungszielen für den jungen Bürger, wie „Verantwortungsfreudigkeit“, "Hilfsbereitschaft“ etc. Der humanistische Orientierungswert "Mitmenschlichkeit, Gemeinsinn" nähme sich inhaltlich und systematisch in der insoweit zu ergänzenden Präambel des Grundgesetzes am besten aus. Vielen Dank.

Oppermann: Herr Vorsitzender, meine Herren Referenten, sehr verehrte Kolleginnen und Kollegen! Wir schulden dem Vorstand großen Dank, daß er dieses Thema hier in Halle, also in Ostdeutschland, gewählt hat. Ich habe mich im ersten Moment gefragt, ob unser Schulthema einen Bezug zur Wiedervereinigung hat. Wir haben uns in der Vereinigung mehrfach mit der deutschen Einheit befaßt, zweimal unter Herrn Vogel 
in Berlin 1990 und in Gießen 1991, grundsätzlich, sowie mit der Rechtsstaatlichkeit der Wiedervereinigung und dann 1992 in Bayreuth mit der finanziellen Seite - und jetzt die Kultur! Herr Schmitt Glaeser hat es gestern abend gesagt: Die Kultur, wenn ich jetzt einmal die Schule zur Kultur rechnen darf, berührt einen der wichtigsten Aspekte der Wiedervereinigung. Es geht um die Rückbesinnung auf die innere Gemeinsamkeit. Davon ist in beiden Referaten über die ostdeutschen Landesverfassungen einiges angeklungen. Ich würde dabei den Akzent nicht so sehr darauf legen, was die ostdeutschen Landesverfassungen Neues gebracht haben. Das ist alles wichtig und richtig. Aber was besonders ins Auge sticht, ist - ich darf einen Ausdruck von Herrn Dittmann aufgreifen - der gemeindeutsche Kanon in den Bildungsbestimmungen. Er ist in den ostdeutschen Landesverfassungen ebenso wie in den westdeutschen enthalten. Diese gemeindeutsche Verfassungstradition ist eine wichtige Voraussetzung für die innere Wiedervereinigung. Die Kultur ist der gründende Grund für das Übrige. Wir kennen in Europa - beide Referenten haben zu meiner Freude Europa angesprochen - das berühmte Wort von Jean Monnet: „Wenn ich es noch einmal zu tun hätte, ich würde mit der Kultur anfangen". Weshalb? Weil ohne die gemeinsame Kultur nichts Beständiges entstehen kann. Insofern greife ich gerne das Wort von Herrn Dittmann von der "Schule der Nation" auf. Herr Vorsitzender, Sie haben es ein wenig kritisch kommentiert; aber wenn man sagen würde, „Schule der Kulturnation", dann klingt es schon freundlicher. Vielleicht können wir uns auf dieser Ebene einigen. Es war einer der mehr grundsätzlichen Dissense, wenn ich es richtig gesehen habe, zwischen Ihnen, Herr Bothe, und dem Zweitreferenten, der Akzent auf der Schule der Nation einerseits und auf der Schule der Multikulturalität andererseits. Im übrigen habe ich, wenn ich die unterschiedlichen methodischen Ansätze der beiden Referate einmal beiseite lasse, gar nicht so viel Dissens entdeckt, wie es nach einigen plakativen Formulierungen zunächst den Anschein hatte. „Schule der Nation“ in diesem Sinne einer Förderung der inneren Wiedervereinigung ist meines Erachtens ein richtiges Wort am Platze. Ich habe auch nichts gegen die "Schule der Multikulturalität ${ }^{\text {" }}$, würde dieses Wort allerdings nicht so hoch aufhängen, Herr Bothe. Im wesentlichen ist damit der Toleranzgedanke angesprochen, den Sie mit Recht erwähnt haben. Die Schule bei uns in Deutschland ist zunächst einmal genau wie in Österreich, in der Schweiz, eine Schule des jeweiligen Staates oder der jeweiligen Nation. Sie sollte sich heute zu den anderen Völkern Europas öffnen, der Toleranzgedanke bringt das zum Ausdruck.

Noch etwas anderes zu den Referaten. Wenn ich mir die Titel der beiden Referate ansehe, entdecke ich eine interessante Differenz. Herr Bothe hat die Worte "der Schule“ weggelassen. Erziehungsauftrag und Erzie- 
hungsmaßstab im freiheitlichen Verfassungsstaat, heißt es bei ihm. Ich weiß nicht, ob das ein technischer Fehler war. Der vollständige Titel, wie er im Programm ausgedruckt ist, lautet: „Erziehungsauftrag und Erziehungsmaßstab der Schule im freiheitlichen Verfassungsstaat". Als ich beiden Referenten zuhörte, hatte ich das Gefühl, Referate zu hören über das Thema: „Erziehungsauftrag und Erziehungsmaßstab des Staates im freiheitlichen Verfassungsstaat ". Darin stimmten beide Referenten überein. Man hätte das Thema anders anpacken können.

Ich würde grundsätzliche Zustimmung signalisieren zum Erziehungsauftrag des Staates, insbesondere des freiheitlichen Verfassungsstaates. Wir stehen nun einmal in diesem Zusammenhang in Deutschland auf dem Boden einer alten Tradition, nämlich auf dem Boden der großartigen Leistungen des preußisch-deutschen Kulturverwaltungsstaates seit dem 19. Jahrhundert. Die Schule ist bei uns Staatsschule, $7 \%$ Privatschule in Deutschland gegenüber $71 \%$ in den Niederlanden, vielen Dank, Herr Mantl, für die wichtige Information! Da gibt es historische Unterschiedlichkeiten, während Österreich und Deutschland insoweit nahe beieinanderliegen. Ich bin mir nicht ganz sicher, wie der Prozentsatz in der Schweiz ist, Herr Hangartner, aber wenn ich mir die Schweizer Gemeindeschule ansehe, habe ich immer das Gefühl, daß hier Privates mit hineinschwingt. Wir stehen in Deutschland eben immer noch auf den Schultern des Etatismus. Bis zu den Schultern, könnte man sagen, stehen wir noch im Etatismus. Hier möchte ich meine eigentliche Frage ansetzen. Wir unterhalten uns morgen über die Privatisierung der Verwaltungsaufgaben. Da hat man manchmal das Gefühl, ob nicht auch im Kulturbereich in Deutschland Deregulierung, Privatisierung, Liberalisierung angesagt sind. Gerade wenn man die Selbstverwirklichung - beide Referenten haben Art. 2 Abs. 1 GG mit Recht hervorgehoben - auf die Fahnen schreibt, ist diese Selbstverwirklichung des Individuums etwas Privates. Stellen wir doch einmal einige zentrale Normen des Grundgesetzes nebeneinander. Zunächst die Medienfreiheit des Art. 5 Abs. 1 GG: Hier hat bekanntlich ein großer Deregulierungsprozeß mit dem Entstehen der dualen Rundfunkordnung bereits eingesetzt. Vielleicht ist die Stunde nicht fern, in der sogar das Bundesverfassungsgericht sich zu einer geläuterten Auslegung des Art. 5 Abs. 1 GG im Sinne individueller Rundfunkfreiheit durchringt. Zweitens die Privathochschulfreiheit des Art. 5 Abs. 3 GG: Herr Thieme hat ein ganzes Buch darüber geschrieben. Auch wenn Witten-Herdecke vom Staat subventioniert werden muß, ist hier manches in Bewegung gekommen. Und als Drittes: die Privathochschulfreiheit des Art. 7 Abs. 4 GG. Wenn ich die Entwicklung der Rechtsprechung zu den Waldorf-Schulen und bei anderen Privatschulen vor mir sehe, scheint mir ein allmähliches Umdenken in der Verfassungsinter- 
pretation anzuheben. Das staatliche Schulehalten im Sinne des Art. 7 Abs. 1 GG bleibt in seinem Recht stehen. Trotzdem wird das Verhältnis zwischen öffentlichem und privatem Sektor im Kulturbereich im Laufe der letzten Jahrzehnte in Deutschland verfassungsrechtlich allmählich etwas anders gewichtet, als es früher der Fall war, nämlich im Sinne prinzipieller Gleichberechtigung.

Zum Schluß noch etwas zu den Fakten. Herr Bothe, Sie haben sehr stark Fakten in Ihr Referat eingebracht. Ich halte das für richtig. Ich hätte es sonst meinerseits getan. Freilich kann man eben über diese Fakten streiten. Ist die Familie wirklich so tot, wie Sie es dargestellt haben? Da gibt es ganz andere soziologische Untersuchungen. Totgesagte leben manchmal länger. Auf jeden Fall gilt Art. 6 GG weiter; es ist vielleicht verfassungsrechtlich sogar geboten, gewissen faktischen Entwicklungen juristisch entgegenzutreten, ihnen zu widerstehen. Auf der anderen Seite stimme ich Ihnen zu, Herr Bothe, wenn Sie sagen, wir dürfen nicht nur das Erziehungsrecht sehen. Wir müssen auch die Erziehungswirklichkeit in Deutschland sehen. In ihr haben sich eine ganze Reihe von früheren Erziehungsträgern mehr oder weniger verabschiedet. Die Kirche hat sich weitgehend aus der Erziehung der Bevölkerung - ich spreche nicht nur von Ostdeutschland - verabschiedet. Von der Bundeswehr ist überhaupt keine Rede mehr gewesen! Das war früher einmal die Schule der Nation. Auch die Erziehung in der Familie ist problematisch geworden. Im Grunde sind heute nur noch zwei große Erziehungsträger übriggeblieben: Die Schule und - Herr Häberle hat es mit Recht erwähnt - das Fernsehen! Wenn Sie an den täglichen Fernsehkonsum der unter 18-Jährigen denken, wissen Sie, was ich meine. Jeder weiß, weich zweifelhafter Erziehungsträger das Fernsehen ist. Daher ist es doppelt wichtig, daß wenigstens die Schule, ob öffentlich oder privat, ihre Erziehungsaufgabe verfassungsrechtlich und tatsächlich wahrnimmt. Daß beide Referenten in diesem Punkte übereingestimmt haben, begrüße ich nachdrücklich.

Meyer: Darf ich Sie fragen Herr Oppermann, ob ich Sie richtig verstanden habe, daß Sie die harmonisierende Verbrüderung der beiden Referate mit dem Stichwort "multikultureller Nationalstaat" schaffen wollen?

Oppermann: Ich sehe mich außerstande, auf diese Frage zu antworten.

Stern: Herr Vorsitzender. Meine Damen und Herren. Es ist ja schon ein paarmal darauf hingewiesen worden, daß das Thema Schule, wenngleich in anderer Akzentuierung, nämlich als Verwaltung und Schule vor 
30 Jahren Gegenstand der Diskussion in unserer Vereinigung gewesen ist. Damals ging es vorzugsweise darum, das Verwaltungsrecht der Schule zu analysieren, heute sind wir eine Ebene höher. Es geht um das Verfassungsrecht, und zu Recht ist das Thema Schule auch als ein Thema des Verfassungsrechts erkannt. Herr Mantl hat an das schöne Zitat von Maria Theresia erinnert, die Schule als Politikum. Und weil die Schule ein Politikum ist, muß die Verfassung dazu etwas sagen.

Herr Dittmann hat in seinem Referat auf Wilhelm von Humboldt hingewiesen und seine Ideen, die Grenzen des Staates zu bestimmen. In dieser Schrift hat er gemeint, es sei nötig, die Schule aus dem Öffentlichen herauszuhalten, auf sie keinen großen öffentlichen Einfluß auszuüben. Nur muß man gleich darauf hinweisen, daß Humboldt als preußischer Kultusminister derjenige war, der sofort die Schule einschließlich der Hochschulen in die staatlichen Hände übernahm. Und das ist auch richtig so. Nicht zuletzt haben Sie, Herr Dittmann, daran erinnert, daß auch das Preußische Allgemeine Landrecht schon betont hat, daß die Schule eine Anstalt des Staates ist. Bei Ihnen, Herr Bothe, habe ich in Ihrem Referat - der dritte Redner darf ja auch das Kritische hervorheben - gefunden, daß Sie das Staatliche sehr stark ausgeblendet haben. Sie haben zwar einmal, im Leitsatz 7 war es wohl, auf das Sozialstaatsprinzip hingewiesen. Mir scheint aber die zentrale Norm Art. 7 Abs. 1 GG zu sein, der das Schulwesen, das gesamte Schulwesen, unter die Aufsicht des Staates stellt. Ich betone diesen Punkt, der in einer klaren Kontinuität steht, vom Preußischen Allgemeinen Landrecht über die Preußische Verfassung von 1850, um dem genus loci zu huldigen, und den Art. $148 \mathrm{ff}$. Weimarer Verfassung, zu den deutschen Landesverfassungen, den vorgrundgesetzlichen, dem Grundgesetz und den späteren Landesverfassungen.

Was ist darin gesagt? Man sieht in diesen Bestimmungen deutlich, daß es notwendig ist, einmal die Schule staatlicher Bestimmung zu unterwerfen; zum zweiten sind seit der Weimarer Verfassung und dann in den neueren Landesverfassungen dort auch die Erziehungsziele vom Staat bestimmt. Das ist eine ganz ganz wichtige Aussage. Daß das Grundgesetz sich bei den Erziehungszielen zurückgehalten hat, mag wohl damit zusammenhängen - wenn man die Entstehungsgeschichte richtig deutet -, daß der Weimarer Schulkompromiß ja von vorneherein auch impliziert den großen politischen Kompromiß, den man in der Weimarer Nationalversammlung geschlossen hat, einschließlich der Gefahren, die damit verbunden sind. Man wollte sich da enthalten und hat das Ganze zu Recht auf die Landesverfassungen verwiesen. Damit hat man dem Gedanken des Föderalismus Rechnung getragen und damit auch die Möglichkeit geschaffen, daß die Erziehungsziele unterschiedlich akzentuiert worden sind. 
Ein nächster Punkt: Herr Bothe, ich fand auch im übrigen den Staat zu wenig in Ihrem Referat. Das beginnt schon mit dem Leitsatz 1, wo Sie nur auf die "gesellschaftliche" Bedeutung abgestellt haben. Auch bei Ihrer Formulierung vom Lehrer als Verfassungsinterpreten sehe ich Gefahren. Was in der Wirklichkeit dabei herauskommt, da hat wohl jeder so seine Erfahrungen gemacht. Das kann sogar so weit gehen - das sind ja die neuesten Forderungen, die auf den Tisch gelegt sind -, daß man eine völlige Autonomie der Schule verlangt. Das ist in den Referaten nicht vorgekommen, aber das ist eine Forderung, die im Gegensatz zu Art. 7 GG steht und all dem, was daran aufgehängt ist; denn es geht in Art. 7 nicht nur um eine Aufsicht im technischen Sinne, sondern um die staatliche Gestaltung der Schule schlechthin.

Zum Schluß in aller Eile: Niemand kann für eine totale Verrechtlichung der Schule sein, aber bitte, Herr Bothe, erklären Sie mir einmal, was versteht man unter dieser Multikulturellität oder Multikulturalität? Wer immer den Begriff bisher gebraucht hat, hat ihn mir nicht erklären können. Toleranz, Herr Oppermann, ja, europäische Dimension ebenfalls ja, aber immerhin ist wesentlich, daß es zunächst um die Schule in Deutschland geht. Auch die Erziehungsziele sind in nationalen Verfassungen bei uns festgelegt. Ich meine, wir sollten klar erkennen, die Schule steht rechtlich in einem Koordinatensystem von Verfassung mit staatlicher Gestaltungsmacht, mit verfassungsvorgegebenen Erziehungszielen, und wiederum an 1964 angeknüpft, von Verwaltungsrecht. In dieser Hinsicht muß man das Beamtenrecht für die Lehrer erwähnen. Schließlich sollte man klar erkennen, daß die Grundrechte, vor allem Persönlichkeitsrechte der Schüler eine Rolle spielen, damit es im Schulalltag, wie Sie, Herr Dittmann, in Leitsatz 13 gesagt haben, funktioniert. Das ist eine große Aufgabe. Wenn wir als Staatsrechtslehrer hier einige Vorgaben für die Bildungsinstitutionen des Staates, für die Kultusministerien und die Schulämter geben, dann haben auch wir unseren Erziehungsauftrag erfüllt. Danke sehr.

Lerche: Herr Vorsitzender, ich glaube, es wäre sehr viel zu sagen zu dem, was in den Referaten schwerpunktmäßig nicht behandelt worden ist, aber das ist sehr schwer, in drei Minuten in dieser geschlossenen $\mathrm{Ge}-$ sellschaft von Verfassungsinterpreten darzustellen. Ich darf mich vielleicht auf eine Frage beschränken an Herrn Dittmann, der in seinem ja so abgewogenen Referat einen Leitsatz, ich glaube es ist Nr. 7a, formuliert hat, den ich eher als einen Fremdkörper empfinde. Wenn ich Sie richtig verstehe, entwickeln Sie hier aus der allgemeinen Entfaltungsfreiheit eine inhaltliche Grundsatznorm, für die Definition der schulischen Entwicklungsziele. Ist das die richtige Wertung? Schließlich ist diese Vorschrift 
primär doch eine Bekräftigung und Bestätigung der Freiheit des Privaten zur Willkür; das heißt also zu einem Verhalten, das nicht legitimierungsbedürftig ist. Dies natürlich kennt Grenzen, und es ist verständlich, daß Sie die Akzente dann auf diese näheren Grenzen legen. Aber der Substanz nach ist es nun doch einmal eine Bekräftigung privater, nicht legitimierungsbedürftiger willkürhafter Betätigung. Damit ist eine gewisse Zurückdrängung etwa von Art. 7, auf den Herr Stern vorhin hingewiesen hat und andere, verbunden. Kann man daraus eine solche Aufwertung herleiten? Wird auf diese Weise nicht auch die Perspektive in anderer Richtung, nämlich im Blick auf die eigentlichen Erziehungsziele etwa des integrativen Moments, verschoben? Das nur als eine Art Verständigungsfrage innerhalb von sicher drei Minuten.

Hans Hugo Klein: Herr Vorsitzender. Meine Damen und Herren. Ich möchte mich auf einige Fragen zu der Begrifflichkeit beschränken, die dem Referat von Herrn Kollegen Bothe zugrunde liegt, Fragen, die von kritischer Skepsis getragen sind, nicht zuletzt um darzutun, daß auch ein Mitglied dieser Vereinigung, das in den Vierziger- und Fünfzigerjahren die Schule besucht hat, eine gewisse Fähigkeit zur Kritik mitbekommen hat. Und lassen Sie mich gleich bei dem Begriff Erziehung zur Kritikfähigkeit bleiben. Ist nicht das, was damit gemeint ist oder aus meiner Sicht damit gemeint sein sollte, schlicht die Erziehung zu selbständigem Denken; in dem Sinne, wie ja das Wort Kritik in seinem griechischen Wortsinne auch eigentlich zu verstehen wäre. Aber wir können in der öffentlichen Diskussion nicht darüber hinwegsehen, daß das Wort kritisch, Kritik eine andere, überschießende Bedeutung erhalten hat, die etwa dahin zielt, alles Bestehende zunächst einmal auf seine Berechtigung zu hinterfragen. Und auf dieses Wortverständnis und auf dieses Sachverständnis führe ich nicht zuletzt das zurück, was Sie, Herr Bothe, als Enttraditionalisierung nicht zu Unrecht beschrieben haben. In einer Erziehung zu einer so verstandenen Kritikfähigkeit sehe ich die Gefahr, daß eben jene vorrechtlichen, vorverfassungsrechtlichen Voraussetzungen dahinschwinden, ohne die der Staat nicht existieren kann, die er aber selbst - um das Wort von Herrn Böckenförde noch einmal zu zitieren, nicht garantieren kann. - Meine zweite Frage, aber die stelle ich mit Rücksicht auf den Appell des Herrn Vorsitzenden zurück, zielte auch auf Ihr Verständnis des Begriffes Multikulturalität. Sie werden sicher Gelegenheit nehmen, das des näheren noch zu erläutern. - Meine dritte Frage bezieht sich auf Ihre These 6 . Die ersten acht Thesen Ihres Referats sind ja im wesentlichen und verstehen sich wohl im wesentlichen als eine Tatsachenanalyse. Aber hier in diese These 6 ist ein normatives Element eingeflossen, ich weiß nicht, ob beabsichtigt oder unbeabsichtigt, insofern 
da nämlich steht, das Erziehungswesen kann und darf nicht die Entwicklung der Enttraditionalisierung und so weiter rückgängig machen. Nun, ob die Schule in der Lage ist, sich gesellschaftlichen Tendenzen wirksam entgegenzustellen, ist eine Frage, über die sich lange streiten läßt. Daß sie es etwa von Verfassungs wegen nicht dürfen sollte, erscheint mir zweifelhaft und zwar um so mehr, als Sie selbst in Ihrem Referat in der These 20 etwa auf die herkömmlichen Erziehungsziele älterer Landesverfassungen hingewiesen haben und ja wohl nicht mit der Akzentuierung, dies sei verfassungswidrig. Wie anders im übrigen sollten hergebrachte Werte Schülern nahegebracht werden können, als durch Anknüpfung an Traditionen? An das, was Herr Oppermann mit dem Begriff der Kulturnation gemeint hat und was uns ja mit nicht zu übersehender Deutlichkeit gerade in dieser Stadt, wenn wir sie offenen Auges und offenen Sinnes durchwandern, vor Augen geführt wird. Herr Stern hat bereits Ihre These 17 angesprochen, mit der Einbeziehung der Erzieher in die Gemeinschaft der Verfassungsinterpreten. Nun kann damit etwas Selbstverständliches gemeint sein, nämlich daß natürlich auch und gerade die schulischen Pädagogen aufgerufen sind, die Verfassung in zunächst einmal ihrer Interpretation, die aber freilich ihrerseits verfassungsgeleitet sein sollte, den Schülern näher zu bringen. Das scheint mir eben so selbstverständlich wie unbedenklich. Aber ist das gemeint, wenn Sie die Erzieher zwar unbürokratisch aber vielleicht doch ein wenig institutionell in die Gemeinschaft der Verfassungsinterpreten sozusagen als selbständige Größen im Sinne eines funktionalen Kondominiums einbringen möchten? Mir schiene diese Deutung jedenfalls der Erläuterung bedürftig. - Ich komme zu einer letzten Bemerkung, die nun keine Frage, sondern eher eine These ist. Die Verfassung, das Grundgesetz, ist nicht als ganze Erziehungsauftrag der Schule. Abiturienten brauchen ja noch nicht voll ausgebildete Staatsrechtslehrer zu sein. Aber worauf ich doch gerne bestehen möchte, ist, daß die Verfassung als Erziehungsmaßstab ihre Bedeutung behält. Und das bedeutet für mich, um es an zwei Beispielen zu exemplifizieren, daß sie nicht nur die Europazugewandtheit des deutschen Staates zu betonen hat, sondern auch die deutsche Staatlichkeit in der Bedeutung, die ihr gerade in diesem Europa und in der Welt zukommt. Baut doch eben dieses Europa, wie es jedenfalls gegenwärtig noch beschaffen ist, und erst recht die Weltgemeinschaft der Staaten auf der Souveränität des Staates auf, der im wesentlichen - und außerhalb Deutschlands weithin unbestritten - ein Nationalstaat ist. Und zweites Beispiel: zur Verfassung als Maßstab gehört, das sage ich nicht etwa kritisch an die Adresse der Referenten, sondern eher kritisch an die Adresse der Erzieher als Mitglieder der Gemeinschaft der Verfassungsinterpreten, wohl auch, daß in der Erziehung das Nebeneinander von 
Wehrpflicht und Kriegsdienstverweigerungsrecht Anerkennung findet. Vielen Dank.

Isensee: Juristen neigen dazu, das Thema „Erziehungsziele“ für unjuristisch zu halten. Was ihnen dagegen an der Schule als juristisch erscheint, ist die Frage der Kompetenz. Darüber diskutieren sie seit 200 Jahren. Zunächst ging der Streit über die Kompetenzverteilung zwischen Staat und Kirche: darüber, welcher Seite die Schulaufsicht zukomme. Seit der Weimarer Republik richtete sich die Frage auf das Verhältnis zwischen Staat und Eltern: dort die nunmehr gesicherte Schulaufsicht des Staates, hier das grundrechtlich gewährleistete Elternrecht. Seit der Kulturrevolution von 1968 ist der Kompetenzkonflikt aufgebrochen zwischen Legislative und Exekutive (Stichworte: Vorbehalt des Gesetzes, Wesentlichkeitsvorbehalt), aber auch zwischen den einzelnen Lehrern der Staatsschule, die auf pädagogische Autonomie pochen und sich aus der Verwaltungshierarchie emanzipieren möchten, und der Schulverwaltung. Die Kompetenzfragen sind sämtlich auch Sachfragen. Wer die Kompetenz hat zu handeln, bestimmt über den Inhalt des Handelns. Wer kompetent ist zur schulischen Erziehung, definiert die Erziehungsziele. Das war von jeher so.

Der heutige Streit über die Erziehungsziele setzte vor 25 Jahren ein, mit der Kulturrevolution. Die Vereinigung der deutschen Staatsrechtslehrer kommt mit ihrem Tagungsthema ein Vierteljahrhundert zu spät. Aber die Staatsrechtslehrer halten es mit $\mathrm{Hegel}$ : Auch für sie beginnt die Eule der Minerva ihren Flug nicht in der Morgendämmerung.

Den Hintergrund der Referate und der Diskussionsbeiträge bildet die Lage nach der Kulturrevolution. Sie begehrte auf gegen christliche Traditionswerte und gegen bürgerliche Konventionen: sie stellte die Normen von Staat und Gesellschaft in Frage. Seither sind die hergebrachten Selbstverständlichkeiten zerbrochen. Doch deshalb ist nicht das Reich der Freiheit heraufgezogen. Vielmehr ist ein neuartiger Bedarf an Regulierung entstanden. Da die ungeschriebenen Regeln des gesellschaftlichen Zusammenlebens ausfallen, müssen nun die geschriebenen Vorschriften des Staates in die Bresche springen. Die Staatsschule, die sich herkömmlich auf Sitte und Ethos stützen konnte, bedarf jetzt der Stütze im staatlichen Gesetz. Das Erziehungsprogramm wird verrechtlicht.

Die Verrechtlichung der schulischen Erziehungsziele stößt auf Grenzen. Die Normen des Rechtsstaates können nur äußeres Verhalten anordnen, nicht aber Gesinnung, Überzeugung, Moral. Eben darauf richtet sich letztlich die Erziehung. Sie will den Menschen von innen her prägen. Darauf sind denn auch die Erziehungsziele der Landesverfassungen angelegt, so in der Verfassung Nordrhein-Westfalens Ehrfurcht vor 
Gott, Achtung vor der Würde des Menschen und Bereitschaft zu sozialem Handeln. Die Landesverfassung nennt auch „Liebe zu Volk und Heimat, zur Völkergemeinschaft". Liebe aber ist eine Sache des Gemüts. Das Gemüt läßt sich nicht regulieren. Hier zeigt sich der Rechtsstaat an der Grenze seiner Möglichkeiten. Sein Gegenstand ist die Legalität, die Ordnung des äußeren Verhaltens. Erziehung aber strebt notwendig darüber hinaus. Sie will Moralität. Das Dilemma wurde schon in der Inkubationszeit des deutschen Rechtsstaats gesehen von Carl Gottlieb Svarez. In seinen Kronprinzenvorträgen verwarf er jedweden Zwang zur Tugend. Dennoch forderte er, daß Unterrichts- und Erziehungsanstalten die moralischen Beweggründe wecken, unterhalten und stärken, also Moralität einüben sollten.

Die Moralität aber ist auch die Grundlage der rechtsstaatlichen Demokratie geblieben. Wenn sie die Herrschaft der Gesetze aufrichtet, dann ist sie angewiesen auf die Bereitschaft der Bürger zum Rechtsgehorsam. Just diese Voraussetzung aber wird seit der Kulturrevolution planmäßig durch die Schule in Frage gestellt, wenn sie - abgesunkenes Kulturgut der Frankfurter Soziologie - den Widerstand zum primären Erziehungsziel erhebt und die Befolgung des demokratischen Gesetzes der subjektiven Willkür anheimgibt. Die Schule attackiert hier die rechtsstaatliche Demokratie in ihren ethischen Voraussetzungen. Der Kampf vollzieht sich heute nicht mehr so offen und leidenschaftlich wie in den Glanzzeiten der Frankfurter Schule. Es gilt überhaupt als taktlos, daran auch nur zu erinnern.

Hier zeigt sich, daß das Grundgesetz dem Thema "Erziehungsziele“ nicht indifferent gegenübersteht, auch wenn es im Unterschied zu den Landesverfassungen nicht ausdrücklich davon handelt. Immerhin geht es um die pädagogischen Voraussetzungen der grundrechtlichen und der demokratischen Freiheit. Das heißt nicht, um mit Forsthoff zu reden, daß das Grundgesetz das „juristische Weltenei“ wäre, aus dem man, wenn man es nur lange genug interpretatorisch abklopfte, ein komplettes Erziehungsprogramm und Lebenssinn für jedermann ableiten könnte. Keineswegs. Dennoch ist der rechtliche Freiheitsentwurf der Verfassung nur realisierbar, wenn die Bürger in ihrer Gesamtheit ihre Freiheitsrechte gemeinverträglich und gemeindienlich entfalten.

Über die Erziehungsziele herrscht heute Unsicherheit in der Praxis der Staatsschule wie in der Staatsrechtslehre. Es walten Ängstlichkeit und Betulichkeit. Man weicht aus auf den Markt der Möglichkeiten und Beliebigkeiten. Das Angebot beliebiger ethischer Möglichkeiten ist aber keine Erziehung. Ein Erzieher muß wissen, was er will. Erziehung braucht klare Ziele und festen Griff, wenn sie Orientierung vermitteln soll. Die Schule, zumal die für die ersten Jahrgänge, kann nicht alles problematisieren und relativieren, ohne ihren Erziehungsauftrag preiszugeben. 
Sicheren Grund scheint das Gebot der Toleranz zu bieten. Das Prinzip findet überall Zustimmung. Aber nicht alle verstehen unter Toleranz dasselbe. Oft wird Toleranz verstanden als „Achtung vor der Überzeugung der anderen" (so eines der Erziehungsziele der Verfassung Nordrhein-Westfalens). Doch die hartnäckige Überzeugung des Schülers, daß $2+2=10$ sei, wird nicht toleriert, sondern zensiert, und das widerfährt auch Überzeugungen, die nicht so einfach zu überprüfen sind wie die Lösung einer Rechenaufgabe. In der Grundrechtsdemokratie dürfen Überzeugungen politischer und anderer Art kritisiert und bekämpft werden. Niemand ist moralisch gezwungen, Überzeugungen zu achten, die er für unmoralisch, töricht, falsch oder gefährlich hält. Toleranz wird der Person des anderen geschuldet, nicht seinen Ansichten. Toleranz ist heute ein unentbehrliches Ziel der Erziehung. Aber auf Toleranz allein läßt sich das Erziehungsprogramm der Schule nicht bauen. Im Bothe'schen Schulversuch schlägt übrigens Toleranz rasch um in Impertinenz, wenn es gilt, political correctness zu exekutieren. Auch Muslim-Mädchen und ihre Eltern bekommen hier die feministische Rute zu spüren.

Konsensfähig ist das Ziel Völkerverständigung. Es liegt auf der Hand, $\mathrm{da} ß$ sie schon in der Schule beginnen muß, seit Kinder aus unterschiedlichen Kulturkreisen in einer Schulklasse zusammenkommen. Wenn ich Herrn Kollegen Bothe richtig verstanden habe, dann sollen die deutschen Kinder in der Schule lernen, Ausländer zu akzeptieren und andere Völker zu verstehen. Eines freilich lernen sie in der Bothe-Schule nicht: was ihr eigenes Volk und seine Kultur bedeuten. Die Frankfurter Schule lehrt die Deutschen, ihrer nationalen Identität zu entfliehen. Herr Botbe bietet einige Fluchtwege an: kosmopolitsche, multikulturelle, europäische. Seltsamerweise sollen sie sich aus der Verfassung ergeben. So führt der neue Europaartikel des Grundgesetzes zwar auf die Europäische Union. Diese aber ist keine politische Einheit, keine Kultureinheit, keine Nation. Sie weist auf die Nationen zurück, die ihr angehören. Überhaupt bleibt dunkel, wie Herr Bothe aus soziologischen Überzeichnungen von empirischen Tendenzen auf normative Ziele schließen kann. Das größte Rätsel bildet sein neowilhelminisches Erziehungsziel „Deutschland als Weltmacht".

Ehe Kinder fremde Kulturen verstehen lernen, sollten sie mit der eigenen Kultur vertraut werden. Ehe sie sich mit anderen Völkern verständigen, müßten sie sich über das eigene Volk verständigt haben. Die Vermittlung nationaler Identität - im Jargon der Verfassungstheorie: die Integration - gehört zu den erzieherischen Leistungen, welche die Staatsschule der nachwachsenden Generation schuldet. Nationale Identität ist in Deutschland zugleich europäisch integrierte und weltoffene Identität. Offenheit aber setzt ein Haus voraus, das Fenster und Türen hat, die sich öffnen lassen. 
Ein unerläßliches Bildungsziel einer Schule, die zur Freiheit erzieht, ist es, Tradition zu vermitteln, literarische, politische, ethische. Bei entsprechender Reife entscheidet der Jugendliche, ob und wieweit er sich die Tradition zu eigen macht oder sich von ihr abkehrt. Aber um sich frei gegen sie entscheiden zu können, muß er sie zuvor kennen. Diese Vorleistung erbringt die Schule seit der Kulturrevolution nicht mehr. Sie folgt Zukunftsentwürfen vom politischen Reißbrett und verschließt sich der Tradition. Der normale Student kann kein Allgemeinwissen über Geschichte oder klassische Literatur mehr in sein Studium einbringen. Er kann sich auch nicht mehr von einer Überlieferung abwenden, weil er von keiner Überlieferung weiß. Das gilt vor allem für das christliche Erbe, obwohl es in seinen säkularen Brechungen und Vermittlungen auch die heutige Gesellschaft noch prägt. Es schwindet nicht nur die religiöse Energie. Es schwindet noch viel schneller das Wissen über das Christentum, damit das Wissen über die geistige Herkunft des heutigen Gemeinwesens. Hier ist die Entwicklung der DDR noch schneller gelaufen als die in Westdeutschland.

Die verfassungsrechtliche Diskussion über Erziehungsziele führt leicht in eine Sackgasse. Das erscheint dem als Unglück, der große Hoffnungen auf die erzieherische Fähigkeit der Schule setzt und der an den ethischen Einfluß der Lehrer glaubt. Aber stimmt diese Prämisse, von der die Referenten so selbstverständlich ausgegangen sind? Meine Damen und Herren, prüfen wir uns: Wenn wir meinen, daß aus uns selber etwas Leidliches geworden sei - verdanken wir das Erziehungszielen und ihrer Umsetzung? Sind wir, falls aus uns etwas geworden ist, es geworden wegen unserer Schulen oder trotz unserer Schulen?

Roellecke: Herr Dittmann hat erklärt, die Umsetzung in die Praxis sei die Achillesferse der Erziehungsziele. Das ist richtig beobachtet, aber juristisch klingt es merkwürdig. Vom normalen Verfassungsrecht würde nie jemand sagen, die Anwendung sei seine Achillesferse. Wenn man die Frage beantworten will, warum Erziehungsziele schwer umzusetzen sind, muß man anknüpfen an den Sinn von Erziehung. Den hat schon Hegel richtig beschrieben. Sinn der Erziehung sei es, den Schatz der Erfahrungen vergangener Generationen in die Gegenwart zu transportieren. Heute meint die Systemtheorie das Gleiche, wenn sie sagt, Erziehung bedeute Reproduktion der Gesellschaft. Ein Mainzer Kollege hat das paradox formuliert, als er behauptete: Erziehung nützt gar nichts, die Kinder werden doch so wie wir. Wenn Erziehung die Reproduktion der Gesellschaft ist, dann kann man Erziehungsziele beschreiben als Begriffe, mit denen Erziehung ihre gesamtgesellschaftlichen Aufgaben reflektiert. Wenn das richtig ist, dann fragt sich: Was bedeutet es, wenn sich Recht 
und Politik, also relativ kleine Ausschnitte aus der Gesamtgesellschaft, der Erziehungsziele annehmen? Bedeutet es, daß Recht und Politik die Gesellschaft dominieren? Ich meine: nein. Das zeigt sich daran, daß das Recht mit der Anwendung der Erziehungsziele offenkundig nicht fertig wird. Stichwort: Achillesferse. Das ist nicht nur eine pragmatische, sondern auch eine dogmatische Frage. Das Recht selbst steht der Anwendung von Erziehungszielen im Wege. Zwei Belege: Einmal verhindert das Recht, daß die Lehrer im Sinne der Erziehungsziele rekrutiert werden. Man kann einem Lehramtskandidaten nicht die Einstellung in den öffentlichen Dienst mit der Begründung versagen, es fehle ihm an Gottesfurcht, Heimatliebe oder Verfassungspatriotismus. Zum anderen verhindert das Recht, Schüler im Sinne der Erziehungsziele zu selektieren. Kein Schüler darf sitzenbleiben, weil es ihm an Gottesfurcht, Heimatliebe oder Verfassungspatriotismus fehlt. Erziehungsziele dürfen auch nicht geprüft werden. Was nicht geprüft wird, wird bekanntlich auch nicht gelernt. Welchen Sinn hat dann aber noch die rechtliche Positivierung von Erziehungszielen? Ich kenne die Antwort auch nicht, vermute aber, mit der Juridifizierung von Erziehungszielen lenkt sich das Recht selbst von der Erziehung ab. Es zwingt sich gleichsam, im Rahmen des Rechtes von Erziehung zu reden. Wenn es aber gleichzeitig die Umsetzung von Erziehungszielen verhindert, dann hält die Juridifizierung von Erziehungszielen Recht und Politik von der Erziehung fern.

Rauschning: Sehr verehrte Kolleginnen und Kollegen, bei uns in der Vereinigung geht es auch und wesentlich um rechtliche Vorgaben. Insofern darf ich Herrn Bothe fragen, ob die Aussagen zu den Leitsätzen 1 bis 8 sich auch rechtlich rückbinden lassen. Zu seiner These Nummer 8 und zu Herrn Dittmanns These Nr. 14 möchte ich Bemerkungen machen.

Es ist selbstverständlich, daß Respekt vor anderen und Toleranz mit Erziehungsziele unserer Schule sind. Aber es bleibt dabei, daß es auch die Schule des deutschen Staates ist; als Staatsaufgabe wird auch in der Verfassung zugrunde gelegt, daß sich der Staat selbst zu erhalten habe. Somit ist auch die Pflege der Integrationsvorgänge zum Staat hin im Sinne von Rudolf Smend ein legitimes und auch ein verfassungsrechtlich gebotenes Tun. Mein verehrter Doktorvater Herbert Krüger hat uns vor Augen gestellt, daß es das Wesen des modernen Staates sei, sich mit keinem Inhalt zu identifizieren. Auch entgegen Herbert Krüger kann aber das Identifikationsverbot mit dem eigenen Staat und mit der eigenen Nation nicht gelten. Wir haben in der Vergangenheit die Kraft der Geschichte und auch die Macht der Völker unterschätzt, und das Aufbrechen des letzten Kolonialstaats - der Sowjetunion - und die Vorgänge im östlichen Mitteleuropa und im Balkan belegen das deutlich. Wir sollten den Bereich 
der staatlichen Identifikation nicht soweit ausklammern, daß sich Mächte dessen bemächtigen, denen wir nicht folgen wollen.

Als zweites wollte ich mich gegen die Behauptung wenden, daß eine rechtliche Bindung in diesem Bereich praktisch kaum möglich sei. Auch rechtlich steht den Lehrern nicht frei, unter Berufung auf eine pädagogische Freiheit ihr persönliches Wertesystem zum Inhalt des Schulunterrichts zu machen. Die Verfassungsvorschriften sind nicht nur Recht, wenn sie gerichtlich durchsetzbar oder eben in einem Kontrollsystem erzwingbar sind. Wir sollten unterscheiden die Kontrollfunktion des Rechts, die eben mit der gerichtlichen Überprüfung in Verbindung zu bringen wäre, und die Bestimmungsfunktion. Als Walter öffentlicher Ämter können wir nicht aus unserem privaten Bereich heraus motivieren, sondern sind eben bestimmt wesentlich von den Werten, die uns ins der Verfassung vorgegeben sind. Wenn etwa im Unterricht zur Gegenwartskunde der Lehrer unter Berufung auf Wilhelm Reich erklärt, daß wir nur deshalb in der Einehe gehalten würden, damit wir die Untertänigkeit lernten und bessere Untertanen würden, obwohl doch wissenschaftlich erwiesen sei, daß die Einehe sexuell nicht befriedigen könne, dann gerät das mit der Verfassungsaussage in Konflikt: Das Grundgesetz bekennt sich in Art. 6 Abs. 1 zu den Werten von Ehe und Familie und erklärt nicht die sexuelle Befriedigung zu den obersten Werten. Ein sozusagen schulamtlicher Angriff gegen die Grundfesten der Familie ist im Rahmen eben des Schulunterrichts nicht zulässig.

Schließen möchte ich mit einer Bemerkung über einen von Herrn Bothe aufgenommenen Satz, der durchaus unsere Erziehungsaufgabe betrifft. Herr Bothe, Sie haben dieses demagogische Wort von „dem kalten Hauch der Freiheit" wiederholt. Meine Auffassung dazu ist deutlich, daß ein freiheitsverachtendes System, das auf Unsicherheit und Bespitzelung aufbaut, keineswegs die menschliche Wärme garantiert hat; ich sehe in keinem Punkt, daß die Freiheit ein menschliches Zusammensein und ein menschliches Miteinander in Frage stellen kann. Wir sollten dieses Wort wirklich als demagogisch entlarven.

Grimm: Meine Damen und Herren. Ich hätte mir die Referate in zwei Punkten etwas deutlicher vorstellen können. Der eine betrifft die Funktion von Erziehung, der andere die begrenzte Rolle, die die Verfassung dabei spielen kann. Die Funktion der Erziehung ist im wesentlichen von der individuellen Persönlichkeitsentfaltung her bestimmt worden. Zwar haben die Referenten die Persönlichkeitsentfaltung durchaus nicht individualistisch verengt, sondern auch die Bedeutung von Gemeinschaftswerten betont. $\mathrm{Zu}$ kurz gekommen ist aber der überindividuelle Bezugspunkt der gesellschaftlichen Integration. Gesellschaftliche Integration ist das Produkt von Bindungen, die eine Gesellschaft ungeachtet ihrer Mei- 
nungs- und Interessenvielfalt zusammenhalten und auf denen angesichts der begrenzten Machtressourcen auch das Funktionieren der staatlichen Ordnung beruht. Die Tradierung und Erneuerung dieser Bindungen scheint mir eine der wesentlichen Funktionen von Erziehung neben der Persönlichkeitsentfaltung zu sein. Die Grundlagen gesellschaftlicher Integration werden freilich nicht nur in der Schule gelegt. Vielmehr wirken auch andere Institutionen wie die Familie oder die Medien, vor allem das Leitmedium des Fernsehens, daran mit. Gerade die Integrationskraft dieser Institutionen, das haben auch die Referate herausgestellt, ist aber in jüngerer Zeit stark gesunken, die der Familie wegen der bekannten Auflösungstendenzen, die des Fernsehens wegen der qualitativen Vermehrung und qualitativen Veränderung der Programme. Das ist konstatierend, nicht wertend gesagt. Im selben Maß wächst freilich die Last, die die Schule zu tragen hat, mit der Folge, daß auch sie ihre Aufgabe nicht mehr zufriedenstellend erfüllen kann. Welche Rolle spielt nun die Verfassung bei der schulischen Erziehung? Die Verfassung enthält die grundsätzlichen Ordnungsvorstellungen und Konfliktlösungsregeln, auf die sich die Gesellschaft geeinigt hat und von deren Beachtung sie ihr Wohlergehen erwartet. Verfassungen gehören daher zu den wichtigsten Integrationsfaktoren der Gesellschaft neben anderen wie z. B. dem Bewußtsein gemeinsamen Erbes und Schicksals, besonderer wirtschaftlicher oder kultureller Leistungskraft etc. Integrationsfaktoren sind der Schule zur Pflege anvertraut, so auch die Verfassung, in der eine Gesellschaft ihre Einheit organisiert. Insofern sind die grundlegenden Verfassungsziele zugleich verbindliche Erziehungsziele. Ihnen gegenüber kann es daher keine pädagogische Autonomie geben. Sowohl in den Referaten als auch in der Diskussion ist aber mit einem Unterton des Bedauerns festgestellt worden, daß sich die Umsetzung der verfassungsrechtlich vorgegebenen Erziehungsziele in der pädagogischen Praxis vom Recht nicht mehr ausreichend steuern lasse. Das trifft zwar zu, verdient unter verfassungsrechtlichen Gesichtspunkten aber keine negative Bewertung. Erziehung orientiert sich nicht an rechtlichen, sondern an pädagogischen Rationalitätskriterien. Die darin begründete Eigengesetzlichkeit der Pädagogik wird von der Verfassung geschützt. Deswegen besteht für die Vermittlung der bindenden Erziehungsziele ein Freiraum der Pädagogik, den sie aufgrund ihrer professionellen Maßstäbe füllen muß. Das Recht kann hier nur diejenigen strukturellen Voraussetzungen schaffen, die eine an professionellen Standards ausgerichtete Erfüllung der Erziehungsfunktion möglichst begünstigen.

Schiedermair: Herr Vorsitzender, meine Damen und Herren! In der juristischen und vor allem der verfassungsrechtlichen Auseinandersetzung mit der Schule kommt es auf eine grundlegende Unterscheidung an, 
die sozusagen der Ausgangspunkt von allem ist. Es gilt zu unterscheiden zwischen dem Kulturauftrag, dem Bildungsauftrag und dem Erziehungsauftrag der Schule. Diese Unterscheidung will ich kurz skizzieren: Bei dem Kulturauftrag geht es um ein Problem, das sich in erster Linie der allgemeinbildenden, auf vier Jahre verpflichtenden Grundschule stellt. Die Grundschule hat die Aufgabe, im Erlernen der Grundtechniken des Lesens, Schreibens und Rechnens den, weltweit gesehen, dramatischen Kampf gegen das Analphabetentum aufzunehmen. Bei diesem Kampf geht es um die Kultur. Davon zu unterscheiden ist der Bildungsauftrag, der vor allem die weiterbildenden Schulen zu jener Vermittlung von Wissen und Können verpflichtet, auf die der Mensch in der späteren Bewältigung seines Lebens im Beruf angewiesen ist. Als drittes und ebenfalls eigenständiges Element kommt dann der Erziehungsauftrag der Schule hinzu. Hier begibt sich der Staat, und Herr Dittmann hat dankenswerterweise in seinem Referat darauf hingewiesen, in der Tat auf das weite Feld der Ethik; denn mit der Erziehung greift der Staat nach dem Charakter, der Charakterbildung und damit nach der Persönlichkeit junger Menschen. Dies ist, da es von Staats wegen geschieht, natürlich ein ganz heikles Unterfangen.

Die Landesverfassungen, die, wie wir alle wissen, schon aus kompetenziellen Gründen hier sehr viel ergiebiger sind als das Grundgesetz, unterscheiden denn auch in ihren Aufträgen an die Schule sehr genau zwischen der Kultur, der Bildung und der Erziehung. Dies ist um so mehr zu betonen, als Herrn Bothe in seinem Referat eine Verwechslung unterlaufen ist, die meines Erachtens zu durchaus fatalen Ergebnissen führt. Ich meine damit die Aussage von Herrn Bothe, daß Europa und die europäische Gesinnung zum Erziehungsauftrag der Schule gehörten. Dies kann doch wohl nicht stimmen. Immerhin verweist Europa mit dem Vertrag von Maastricht gerade im Zusammenhang mit der Bildungspolitik ausdrücklich und in absichtsvoller Betonung auf die Kultur der europäischen Nationen. Davon abgesehen, und dies ist der entscheidende Gesichtspunkt, kann es doch nicht angehen, Europa und die europäische Gesinnung dem Erziehungsziel der Schule zuzuweisen; denn in der erzieherischen Umsetzung dieses Zieles käme man nicht umhin, den europäischen Menschen schaffen zu wollen. Gerade wenn man wie Herr Bothe von multikulturellen Konzeptionen ausgeht, sollte man nicht beim europäischen Menschen stehenbleiben. Da muß man schon etwas weltbürgerlicher denken. Ganz anders aber sieht es in diesem Zusammenhang trotz des Vertrages von Maastricht mit dem Bildungsauftrag der Schule aus. Selbstverständlich gehören Europa, die europäische Gesinnung, die europäische Geschichte, der Sprachenunterricht und all das, was in der aktuellen bildungspolitischen Diskussion dazu beigetragen wird, zu die- 
sem Auftrag. So wird denn gerade auch an dieser Stelle deutlich, wie wichtig es für die zutreffende Beurteilung der Rechtslage ist, zwischen dem Bildungsauftrag und dem Erziehungsauftrag der Schule deutlich zu unterscheiden.

Bei der Frage nach dem Inhalt des Erziehungsauftrags werden wir vor allem auf die Landesverfassungen verwiesen, die mit ihrem fast lyrisch anmutenden Wortreichtum allerdings viel ergiebiger sind, als dies heute in den Referaten zum Ausdruck gekommen ist. So lassen die Landesverfassungen in kaum zu übersehender Eindeutigkeit erkennen, worum es bei dem Erziehungsauftrag der Schule gehen soll, nämlich um eine klare Absage an jede Form der Erziehungsdiktatur. Hier gab es doch eine leidvolle Lebenserfahrung. Die Mütter und Väter der Landesverfassungen hatten doch eine Jugend im Sinn und vor Augen, die in der Schule zum wehrlosen Opfer nationalsozialistischer Indoktrination gemacht worden war. Das Ergebnis dieser Indoktrination war eine Staatsjugend in Uniform. Angesichts dieses Tatbestandes liegt es doch auf der Hand, daß die Landesverfassungen unter den Bedingungen der neu gewonnenen Freiheit auch mit dem Erziehungsauftrag der Schule eine Antwort auf das geben wollten, was vorher geschehen war. Dies aber ist, meine Damen und Herren, nicht nur ein Stück Verfassungsgeschichte, sondern darüber hinaus hochaktuell. Gerade hat der deutsche Bundestag in seiner Enquete-Kommission zur „Aufarbeitung von Geschichte und Folgen der SED-Diktatur in Deutschland" das Erziehungswesen der DDR untersucht und damit ein Stück jüngster Vergangenheit aufgearbeitet. Da gab es nicht, wie Herr Mantl es in seinem Referat beschrieben hat, rot-weißrote Fähnchen zum Nationalfeiertag. Vielmehr wurden zum Tag der $\mathrm{Na}$ tionalen Volksarmee in jedem Kindergarten die dreijährigen Kinder zwangsverpflichtet, Panzer zu malen. Auch darf in diesem Zusammenhang an den Erziehungsauftrag erinnert werden, der die Universitäten gesetzlich dazu verpflichtete, die Studentinnen und Studenten zu sozialistischen Menschen zu erziehen. Dies ist unsere Vergangenheit und in ihren Folgen auch noch unsere Gegenwart. Unter diesen Umständen aber haben wir allen Anlaß, die Aussagen der Landesverfassungen zum Erziehungsauftrag der Schule ernst zu nehmen.

Entsprechendes gilt auch für den Bildungsauftrag der Schule. So verpflichtet, um nur ein Beispiel zu nennen, Art. 131 der Verfassung des Freistaates Bayern die Schulen dazu, nicht nur Wissen und Können zu vermitteln, sondern auch Herz und Charakter zu bilden. Hier hat dann das Gemüt seinen Platz, von dem Herr Kollege Isensee in der Diskussion gesprochen hat. Darüber hinaus muß man allerdings zur Kenntnis nehmen, daß Art. 131 der Bayerischen Landesverfassung mit dem Hinweis auf das Begriffspaar „Wissen und Können“ sowie mit der gleichzeitigen 
Bezugnahme auf das Wahre, Schöne und Gute (Abs. 2) durchaus philosophische Themen anspricht. Hier geht es um das Techne-Denken der Sophisten sowie um die Antwort des späten Plato (Philebos), der mit der Idee des Wahren, Schönen und Guten nicht nur ein Bekenntnis zu seiner idealistischen Philosophie ablegt, sondern gleichzeitig auch die Geburtsstunde einer Pädagogik einleitet, die seit der Aufklärung und bis heute darüber diskutiert, wie diese philosophischen Erkenntnisse in der praktischen Pädagogik umzusetzen seien. Deshalb fiel heute auch mit Recht das Stichwort Humboldt. So sind die Pädagogen in ihrer Diskussion auch heute noch nicht über die Problemvorgabe hinausgekommen, die uns Plato und die Sophisten hinterlassen haben. Ich meine allerdings, daß diese Diskussion auch von den Juristen ernst genommen werden muß, wenn sie über die Bildungsziele der Landesverfassungen und darüber reden, was sich die Mütter und Väter dieser Verfassungen mit ihren klaren bildungspolitischen Vorstellungen dabei gedacht haben.

Meine letzte Bemerkung bezieht sich auf die auch von Herrn Bothe in seinem Referat kommentierte Bestimmung des Art. 131 Abs. 4 der Bayerischen Landesverfassung. Dort geht es um ein Bildungsziel, demgemäß die Schulen dazu angehalten werden, daß die „Mädchen“ nicht nur im Geist der Gottesfurcht, der Menschenwürde und der sozialen Verantwortung zu erziehen, sondern „außerdem in der Säuglingspflege, Kindererziehung und Hauswirtschaft besonders zu unterweisen sind“. Ich habe mich über diese geradezu bezaubernde Formulierung immer besonders gefreut, zumal ich keinen Verfassungstext kenne, in dem die Konjunktion "außerdem" eine solch aparte Verwendung gefunden hat wie in der Bayerischen Landesverfassung. Abgesehen von dem ästhetischen Aspekt gibt es in diesem Zusammenhang auch einiges Aufregende. Aufregend ist, daß das Bildungsziel des Art. 131 Abs. 4 der Bayerischen Landesverfassung ebenso wie viele Bildungsziele anderer Landesverfassungen auch in der Praxis der letzten vierzig Jahre schlicht und einfach nicht mehr umgesetzt worden sind. So kann man nur mit Staunen zur Kenntnis nehmen, daß etwa in der Verfassung von Rheinland-Pfalz (Art. 38) das humanistische Gymnasium verbindlich vorgeschrieben wird, und doch denkt keiner daran, dies in die Praxis umzusetzen. Wir begegnen also an dieser Stelle dem interessanten Phänomen, daß Verfassung in der politischen Praxis nicht vollzogen wird. Darüber einmal nachzudenken, dürfte sich auch und gerade für den Verfassungsjuristen durchaus lohnen. Dies gilt im übrigen ebenso für die Unterweisung in der Säuglingspflege an den bayerischen Schulen. Dabei ist allerdings einzuräumen, daß die Unterweisung in der Säuglingspflege unter dem Gesichtspunkt der Gleichstellung heute bei manchen geradezu anstößig geworden ist. Den Freunden der Gleichstellung sei jedoch empfohlen, von 
dem Verdikt der Verfassungswidrigkeit in diesem Zusammenhang Abstand zu nehmen; denn hier honoriert die Verfassung doch nur die Tatsache, daß im Freistaat Bayern Kinder von Frauen geboren werden, und solange dieser „verfassungswidrige“ Zustand nicht beseitigt ist, kann man auch Art. 131 Abs. 4 der Bayerischen Landesverfassung nicht ernsthaft kritisieren.

Böckenförde: Herr Vorsitzender, meine Damen und Herren. Ich halte es für richtig und wichtig, daß Herr Bothe in seinem Referat zu Beginn das soziale Feld beschrieben hat, in dem schulische Erziehung heute stattzufinden hat und von dem aus sie ihre Herausforderung empfängt. Seine Beschreibung wäre vielleicht noch in mancher Hinsicht zu ergänzen. Einmal dahin, daß neben Familie und Schule, das wurde schon erwähnt, die Medienwelt ein Erziehungsfaktor ist, von dem sehr starke Wirkungen ausgehen. Auch sollte man die Kirchen als Erziehungsfaktor erwähnen, ungeachtet, daß ihre Wirkungskraft wohl im Abnehmen ist. Eine zweite Ergänzung: Erziehung der heranwachsenden Menschen im Sinne einer Prägung ihrer Persönlichkeit und der Vermittlung von Lebenseinstellungen, die als verbindlich genommen werden, findet immer statt. Nimmt eine Erziehungskraft ab, drängt eine andere vor, es bleibt keine Leerstelle, der freigegebene Platz wird sogleich besetzt.

Sehen wir uns im Hinblick darauf die gegenwärtige Wirklichkeit an, ist es in der Tat so, daß die Erziehungskraft der Familie, wie festgestellt wurde, abnimmt und ebenso die der Kirchen; die der Medienwelt wächst, auch wenn sie nicht integrierend wirkt, und die der Schule ist prekär. Was ist bei dieser Situation die Herausforderung für den Erziehungsauftrag der Schule? Angesichts der Individualisierung der Gesellschaft, von der Herr Bothe, wie ich meine, mit Recht gesprochen hat, und der abnehmenden Erziehungskraft von Familien und Kirchen kommt der schulischen Erziehung eine gesteigerte Bedeutung zu. Aber die schulische Erziehung kann nicht allein - da unterscheide ich mich von Herrn Botbe darauf orientiert sein, daß junge Menschen sich in dieser Gesellschaft zurechtfinden und daß ihre individuelle Selbstverwirklichung gestützt wird; sie hat, Herr Grimm hat das deutlich gesagt und ich bin da ganz seiner Auffassung, eine integrative Aufgabe, um das zu vermitteln, was die Gemeinsamkeit, die tragende Grundlage und die von innen her regulierende Kraft für das Zusammenleben der Gesellschaft und in der Gesellschaft ausmacht. Je ausgeprägter auf der einen Seite der Pluralismus sich entfaltet, desto notwendiger ist als Komplement diese integrative Erziehungsaufgabe. Nur wenn diese Erziehungsaufgabe einigermaßen gelingt, erhält sich die Gesellschaft auch als Gemeinwesen, das aus gewissen Grundüberzeugungen und einer gewissen Grundeinigkeit heraus lebt. 
$\mathrm{Da} ß$ dies gelingt, einigermaßen gelingt, ist notwendig einmal aus Gründen der Demokratie - das ist ja lange diskutiert worden im Hinblick auf den Grundkonsens in einer demokratischen Gesellschaft, der wichtig ist. Es ist ebenso notwendig aus rechtsstaatlichen Gründen. Herr Isensee hat von der moralischen Bereitschaft zum Gesetzesgehorsam gesprochen, man kann dies auch noch ergänzen um die moralischen Regulierungskräfte für die weit erstreckte Freiheit, die der Rechtsstaat gewährt und nur gewähren kann, wenn solche moralischen Regulierungskräfte im Freiheitsgebrauch wirksam werden.

Wie aber ist integrative Erziehung, die der Schule in besonderer Weise zufällt, möglich? Wir müssen hier, so scheint mir, etwas deutlicher als die Referate es getan haben, Erziehung von Bildung und Ausbildung abgrenzen. Erziehung ist mehr als ein nur kognitiver Vorgang, obwohl kognitive Elemente darin enthalten sind. Erziehung, Herr Mantl hat es angesprochen auch unter Rückgriff auf alte Zitate, hat auch eine charakterbildende, eine ethosbegründende und ethosvermittelnde Funktion. Insofern ist sie normativ ausgerichtet. Sie soll Lebenshaltungen und Handlungseinstellungen vermitteln und bewirken, daß sie von den Zöglingen angenommen werden. Eine solche ethosbegründende Erziehung kann aber, wenn ich recht sehe, nur aus einer Verbindlichkeit heraus erfolgen, $d$. h. einer Richtigkeitsüberzeugung, nicht daraus, daß verschiedene mögliche Angebote vorgestellt werden, die vielleicht verbindlich sein könnten, wenn man sie als für sich verbindlich ansieht. Hier liegt das zentrale Problem.

Woher kann die schulische Erziehung im freiheitlichen und religiösweltanschaulichen neutralen Staat diese Verbindlichkeit nehmen und gewinnen? Ist solche Verbindlichkeit unabhängig von Religion und unabhängig von gültigen ethischen Orientierungen zu gewinnen? Oder kann allein das kulturelle Erbe den Grund dafür abgeben? Aber woher hat das kulturelle Erbe seine Verbindlichkeit und wie wird es davor bewahrt, daß es sich in der Abfolge von ein oder zwei Generationen aufzehrt? Den Juristen liegt dafür der Rückgriff auf die Verfassung nahe, und zwar in dem Sinne, daß in Verfassungen - wie in zahlreichen Landesverfassungen geschehen - bestimmte Erziehungsziele formuliert und festgelegt werden. Ich möchte aber davor warnen, jetzt die Verfassung insgesamt sozusagen als kollektives Erziehungsziel zu proklamieren und aus Bestimmungen, die einen ganz anderen Sinn und eine andere Funktion haben, nun Erziehungsziele abzuleiten. Das richtet sich nicht gegen die Auffassung von Herrn Klein, daß zur Erziehung auch gehört, Achtung vor der Verfassung und die Anerkennung der Verfassungsprinzipien zu vermitteln. Werden aber bestimmte Erziehungsziele ausdrücklich normiert, stellt sich das Problem ihrer Vermittlung mit den Freiheitsgarantien der Ver- 
fassung. Art. 4 Abs. 1 u. 2 GG gewährleistet Religion und Weltanschauung als einen Bereich, der staatlicher Ingerenz vorausliegt. Wenn dies auch für die staatlich getragene Schule gilt, anderseits in der Verfassung - wie in mehreren Länderverfassungen - Erziehungsziele verbindlich festgelegt sind, die sich auf christliche oder allgemeine religiöse Gehalte beziehen, wie kann das zueinandergeführt werden? Übrigens gilt das entsprechend für verbindliche Erziehungsziele humanistischer oder moralisch-sozialer Art. Erweisen sich solche Erziehungsziele in dem Moment als nicht mehr vollziehbare normative Illusion, in dem ihre allgemeine Anerkennung brüchig wird und sie gerade deshalb gefordert wären? Oder kommt dem Staat gleichwohl - und auf welcher Grundlage - eine Regelungs- und Entscheidungskompetenz zu? Daraus resultieren die Probleme, die an Beispielen näher erläutert worden sind. Ich erwähne das, um zu zeigen, daß hier Herausforderungen liegen, über die man näher nachdenken muß.

Bull: Herr Vorsitzender, meine Damen und Herren. Ich möchte über das Verhältnis von Erziehung und Indoktrination sprechen oder - anders angesetzt - über das Verhältnis der Meinungsfreiheit, der pädagogischen Freiheit des Lehrers und der Lehrerin zu dem hier immer wieder mit Recht beschworenen Toleranzgebot und zu dem Gebot, Erziehung überparteilich, unparteilich vorzunehmen. Der Lehrer, die Lehrerin ist die Schlüsselfigur bei der Umsetzung all der Ziele, über die wir hier heute sprechen. Seine und ihre pädagogische Freiheit ist rechtlich und faktisch groß. Die Kontrolle über den einzelnen Lehrer, die einzelne Lehrerin in seinem und ihrem Unterricht ist schwer durchzuführen. Herr Dittmann hat in seiner These 13 mit Recht bemerkt: Eine rechtliche Steuerung ist nur begrenzt möglich. Ich nehme an, daß das sich auch auf diesen $\mathrm{Zu}-$ sammenhang bezieht. Auf der anderen Seite aber besteht doch in der Tat die Gefahr, daß einzelne Angehörige der Lehrerschaft indoktrinieren nicht nur jene, die Herr Isensee als Überbleibsel der Kulturrevolution bezeichnet, die frustrierten ehemaligen Achtundsechsziger, die vielleicht immer noch einen Linksdrall in unziemlicher Weise in den Unterricht hineinbringen, sondern natürlich auch manche auf der rechten Seite des politischen Spektrums. Wer die Zeitung aufmerksam gelesen hat, weiß ja, daß wir Fälle erleben, wo Lehrer ihre Stellung dazu nutzen, Schülerinnen und Schülern ein sehr einseitig verzerrtes, historisch falsches Bild etwa von der deutschen Geschichte zu vermitteln oder in sonstiger Weise ihre jeweiligen (auch parteipolitisch gefärbten) Urteile und Vorurteile aufzudrängen.

Herr Mantl hat vom „Überwältigungsverbot" gesprochen. Das würde hier genauso entgegenstehen wie anders ausgedrückt das Toleranzgebot. 
Disziplinarverfahren greifen hier in aller Regel nicht oder erst sehr spät - dafür muß schon sehr viel geschehen, z. B. die Grenze zu strafrechtlichen Tatbeständen überschritten sein, zu Volksverhetzung und ähnlichem. Die Schulaufsichten wissen ein Lied davon zu singen, wie schwer es ist, solche Tatbestände nachzuweisen - oft gegen einen Korpsgeist innerhalb der einzelnen Schule oder gegen die Angst von betroffenen Schülerinnen und Schülern, solche Dinge anzuzeigen.

Natürlich habe kein Rezept zur Überwindung dieses Dilemmas; ich fürchte, kaum jemand hat ein wirklich greifendes Rezept. Aber vielleicht gibt es doch einen weiterführenden Ansatz, der auf der Ebene dessen liegen würde, was wir hier über Erziehungsziele gesprochen haben, nämlich das Gebot an die Lehrenden, ihre Meinung offenzulegen, im Sinne eines richtig verstandenen Pluralismus sich dazu zu bekennen und dann die Diskussion, die Bearbeitung und Verarbeitung auch der subjektiven Meinungen in der Schule zu beginnen, anzustoßen, ganz bewußt einen Prozeß der Aufarbeitung von Positionen in Gang zu setzen und nicht etwa den anderen Weg zu wählen, die verschiedenen Positionen zu vermengen oder zu verunklaren zu einer Linie des Mittleren, des Kompromisses, der dann keine klaren Konturen mehr hätte.

Ein letztes Wort: Wie ist es eigentlich, wenn Schüler und Schülerinnen von den Lehrerinnen und Lehrern instrumentiert werden? Das kommt ja neuerdings auch vor. Wenn etwa eine Landesregierung Stellenkürzungen im Bildungsbereich ankündigen muß, aus der allseits bekannten $\mathrm{Fi}$ nanznot heraus - das kann jeder Landesregierung passieren! - oder wenn sie die Klassenfrequenzen heraufsetzen muß oder wenn bestimmte andere einschneidende Maßnahmen im Bildungsbereich vorbereiten muß oder Parlamente dies beschließen, dann kommt es vor, daß die Lehrerschaft oder die Gewerkschaften aufrufen zu Protestdemonstrationen vor dem Parlamentsgebäude oder vor dem Sitz des Kultusministeriums. Dann entsteht ja wohl die Situation, daß hier die Erziehung zum mündigen Staatsbürger in die Nähe einer Erziehung zum Widerstand gerät, jedenfalls gegen die Regierung oder das Parlament, oder wenn man es sehr dramatisch zuspitzt: zu einem Angriff auf die Demokratie, etatistischer gedacht: auf den Staat. Ich denke, die Regierungen werden auch damit im Zweifel fertig werden, aber das Problem stellt sich, die Grundsatzfrage ist aufgeworfen, und für unseren Kreis hier wäre es vielleicht eine Überlegung wert, auch darauf nach einer Antwort zu suchen: Wohin führt die Erziehung zu einer grundlegend selbständigen, konstruktiv kritischen Verhaltensweise in der Wendung gegen die Regierungen und Parlamente?

Hufen: Herr Vorsitzender. Meine Damen und Herren. Das Thema unseres heutigen Tages verbindet in sehr glücklicher Weise die Elemente 
Schule und Erziehung einerseits sowie Verfassungsstaat und Verfassungsauftrag andererseits. Ich begreife dieses Thema also als Anlaß, über Verfassungstheorie und damit über die grundsätzliche Funktion der Verfassung nachzudenken. Die von Herrn Bothe eingangs sehr eindrücklich beschriebene gesellschaftliche Realität der Familien und auch der Schule zeigt, daß sich die Frage der Funktion des Grundgesetzes derzeit in Erziehung und Schule wie in einem Brennspiegel bündelt. Die beiden Referenten haben in dankenswerter Weise die Frage aufgegriffen, ob und wie die Verfassung in diesem "modernen“ Sinne gesellschaftliche Realität beeinflussen kann. Herr Bothe kam dabei etwas mehr von der Empirie her; Herr Dittmann hat eine eher normative und auch eher vorsichtige Position bezogen. Keiner der beiden Referenten aber hat im traditionellen Sinne die Verfassung auf ein Staatsorganisationsstatut oder die Grundrechte auf reine Abwehrrechte reduziert. Auch hier ist der schöne Satz von Herrn Böckenförde schon zitiert worden, wonach der moderne Staat von geistigen Voraussetzungen lebt, die er nicht selbst gewährleisten kann. Wenn ich diesen Satz einmal aufgreifen und sozusagen umdrehen darf, dann ist die Schule doch wohl ein zentrales Instrument, mit dessen Hilfe der Staat dann doch Voraussetzungen beeinflussen kann, von denen er lebt. Die Schule ist vielleicht die einzige Institution, wo diese lebenswichtigen geistigen Grundlagen des Gemeinwesens geschaffen, zumindest aber beeinflußt werden können - mit welchem Erfolg auch immer. Das bildet auch den Ausgangspunkt für die verfassungstheoretische Frage nach dem Einfluß des Grundgesetzes auf die schulischen Erziehungsziele. Es ist hier gesagt worden, die Verfassung enthalte nur höchst abstrakte Aussagen in dieser Richtung. Dem kann ich nicht beipflichten. So hatte etwa die Schulrechtskommission des Deutschen Juristentages unter Mitwirkung des - hier gleichfalls bereits mehrfach zitierten - verstorbenen Kollegen Evers keine Schwierigkeiten, die Erziehungsziele ihres Mustergesetzentwurfes auf die materiellen Aussagen der Verfassung zurückzuführen. Auch ich sehe hier kein Problem - ganz im Sinne von Scheuner, der gesagt hat, die Grundrechte seien nicht nur Abwehrrechte, sonder auch Richtlinie und Rahmen der Staatstätigkeit mithin auch der Staatstätigkeit in der Schule. So kann man Respekt vor der Identität des in- oder ausländischen Mitschülers ohne Schwierigkeiten mit der Menschenwürde in Verbindung bringen. Auch andere Ziele wie Demokratie, Gleichheit und Toleranz sind schulische Erziehungsziele und materiale Verfassungsgebote. Demokratie bedeutet, auf die Schule bezogen, Verfahren zur rationalen Konfliktaustragung. Damit ist ein Stichwort gefallen, an dem wir mit unserem Thema gegenwärtig wohl nicht vorbeikommen. Ich meine den realen Zustand der Schule in der Gegenwart, über den wir viel Negatives - um nicht zu sagen: Nieder- 
schmetterndes - erfahren. Ich weiß nicht, ob es richtig ist, hier insgesamt von einer großen Krise zu sprechen, jedenfalls zeigen uns die Zahlen über Gewalt in der Schule, fehlende Zufriedenheit der Eltern und vor allem die Resignation eines großen Teiles der Lehrer, daß sich einiges ändern muß, wenn die Schule ihre elementare Funktion für diese Gesellschaft noch erfüllen soll. Statt dessen scheint sich die Demotivation in der Gesellschaft in der Schule in besonderem Maße niederzuschlagen. Einer der Ansätze, hier Abhilfe zu schaffen, ist der Versuch, zu mehr Binnenpluralität im Schulwesen zu gelangen. Dieses Problem wurde in beiden Referaten nur knapp angesprochen und wurde in der bisherigen Diskussion nur abwertend und negativ genannt. Ich kann mir aber nicht vorstellen, daß der vorsichtige Versuch verfassungswidrig sein soll, Schüler, Eltern und Lehrer zu einer Schulgemeinschaft zu formen, in der mehr eigene Identität und Profil entfaltet werden können und etwas mehr Spielraum in bezug auf Unterrichtsgegenstände und Gestaltung der Schule gegeben ist. Wo sollen denn die Schüler demokratisches Verhalten und Konfliktaustragung lernen, wenn die Schule als Anstalt im Sinne vergangener Jahrhunderte zentralstaatlich geführt wird? Im übrigen wissen wir doch längst, daß Schule durch die Verwaltung nicht bis in die Zehenspitzen zu steuern ist - Erziehung schon gar nicht. Etwas mehr Selbstbestimmung der Schulgemeinschaft, etwas mehr Betonung der je eigenen Identität, Entscheidungen in kleinen Einheiten und Berücksichtigung der Motivation "vor Ort" sollten daher nicht sogleich auf verfassungsrechtliche Gegenargumente stoßen. Mit „Basisdemokratie“ und - in der Tat verfassungsrechtlich problematischer - "Autonomisierung der Schule" hat das alles nichts zu tun. Fazit: Unsere Diskussion kommt mitnichten $25 \mathrm{Jahre}$ zu spät; sie kommt vielmehr exakt im richtigen Zeitpunkt. Wir müssen nur aufpassen, daß wir diese Diskussion nicht mit Argumenten von vor 25 Jahren führen. Vielen Dank.

Schachtschneider: Herr Vorsitzender! Jedes Gemeinwesen hat ein politisches Paradigma, und das Erziehungswesen dieses Gemeinwesens kann und darf sich gegen dieses Paradigma nicht durchsetzen, weil letzteres dadurch in Frage gestellt würde. Unser Paradigma ist das der Menschenwürde oder der Freiheit. Art. 2 Abs. 1 GG definiert Freiheit als freie Entfaltung der Persönlichkeit. Darauf hat Herr Dittmann wesentlich abgestellt. Also muß das Erziehungswesen eine bestmögliche freie Entfaltung der Persönlichkeit fördern. Es ist nicht richtig, wenn die Freiheit zu einem Prinzip der Selbstverwirklichung heruntergespielt wird, so daß sie trefflich angreifbar ist. Freiheit im Sinne des Grundgesetzes ist, wie es Herr Isensee der Sache nach angesprochen hat, durch das Sittengesetz definiert. Herr Häberle hat angeregt, den zu Recht und zum Glück nicht in 
das Grundgesetz aufgenommenen Entwurf eines Art. 20 a in die Präambel einzubinden. Die Verpflichtung zum Gemeinsinn und zur Mitmenschlichkeit als Prinzip bürgerlicher Freiheit steht schon als freiheitliches Ethos im Grundgesetz, als das Sittengesetz Kants klassisch formuliert. In diesem Sinne anerkennt unsere Verfassung jeden einzelnen als Person, die wesentlich frei ist. Diese Freiheit ist formal, d. h. anerkennt, daß jeder sich zu einer, seiner Persönlichkeit entfalten kann. Dieser Formalität, die untrennbar mit der Pflicht zur Sittlichkeit verbunden ist, muß die Erziehung bestmögliche Entfaltungschancen geben. Jeder einzelne muß nach Möglichkeit seine eigene Vollkommenheit erreichen können, auch um fremder Glückseligkeit dienen zu können. Die freiheitliche $\mathrm{Er}$ ziehung muß auf die Freiheit des anderen, auf die Mitmenschlichkeit, auf die Nächstenliebe ausgerichtet sein. Wie leistet man das? Die kulturellen Grundfertigkeiten müssen erneut in den Mittelpunkt gerückt werden. In der Schule muß man lesen, schreiben und rechnen lernen, aber auch alte und neue Sprachen. Die Geschichte, das Land und die Welt, die Natur, die Religionen müssen den Schülern bekannt gemacht werden. Die Grundlagen für die spätere Ausbildung oder für ein späteres Studium müssen gelegt werden. Der Staat aber bleibt auch in seinem Erziehungswesen der Krügerschen Nichtidentifikation verpflichtet. Wie die Schule unter einer aufklärerischen Verfassung zur Multikulturalität erziehen soll, ist mir nicht recht nachvollziehbar. Auch eine Erziehung zur Demokratie würde eine Verfassungsentscheidung für die Demokratie voraussetzen. Das Grundgesetz verfaßt aber eine Republik und zugleich einen demokratischen und sozialen Bundesstaat. Eine Republik ist durch die allgemeine Freiheit definiert. Das Wort Demokratie soll das vielleicht umfassen, ist aber nicht der Ausdruck, der unsere Verfassung hinreichend kennzeichnet. Herr Schiedermair hat zu Recht die Erziehung zu einem Europabewußtsein kritisiert. Warum sollten wir die Schüler nicht zum National- oder zum Weltbewußtsein erziehen. Die Erziehung eines Bewußtseins halte ich ohnehin für fragwürdig. Besser ist eine Erziehung zur menschenwürdigen, $d$. h. freiheitlichen Bewältigung des gemeinsamen Lebens. Das erfordert eine Erziehung zur Aufgeklärtheit. Aufklärung ist das entscheidende Wort unseres Gemeinwesens. Gemeint ist die Aufklärung im Sinne des sapere aude, Kants „Wage Dich Deines eigenen Verstandes zu bedienen. "Das erfordert viel Übung. Eine letzte Bemerkung zur Erziehung zur Moralität, die Herr Isensee eingefordert hat. Kann der Staat das leisten? Brauchen wir dazu nicht die Kirchen, die wir verloren haben? Dankeschön.

Vorsitzender: Wir wollen jetzt zu einem Zwischenwort der Referenten kommen. Ich würde vorschlagen in umgekehrter Reihenfolge. Ich 
möchte zunächst Ihnen, Herr Dittmann, das Wort geben, danach Herrn Bothe und bei Bedarf auch noch unseren beiden Berichterstattern aus Österreich und der Schweiz.

Dittmann: Vielen Dank, Herr Vorsitzender. Ich möchte die an mich herangetragenen Fragen in chronologischer Reihenfolge beantworten. Herr Häberle, Sie haben einen bunten Strauß verschiedenster Anregungen vorgetragen, von denen ich insbesondere zwei Aspekte herausgreifen möchte. Sie haben zum einen die interessante Frage aufgeworfen, ob man nicht die Erziehungsziele im Sinne einer Drittwirkung für die elektronischen Medien fruchtbar machen könnte. Das wirkt - auf den ersten Blick - bestechend; aber ich hege doch Vorbehalte. Zum einen habe ich in meinem Referat bereits darauf hingewiesen, daß sich im Rundfunkstaatsvertrag mit den sogenannten Programmgrundsätzen eine ganze Reihe von Zielvorstellungen finden, die sich mit Erziehungszielen der Landesverfassungen und Schulgesetze weithin decken. Was Sie, Herr Häberle, mit der Drittwirkung erreichen wollen, ist also bereits auf normativer Ebene weithin geschehen. Allerdings besteht auch hier das bisher nur unbefriedigend gelöste Problem ihrer tatbestandlichen Präzisierung und Sanktionierung dann, wenn gegen sie verstoßen wird. Von einer zusätzlichen Herübernahme der ebenfalls so schwer zu vollziehenden Erziehungsziele als Maßstab einer rundfunkrechtlichen Kontrolle verspreche ich mir daher herzlich wenig. Des weiteren haben Sie die Zurückhaltung des Grundgesetzes in Fragen von Erziehungsauftrag und Erziehungszielen der Schule beklagt und erneut angeregt, die hinter den Staatszielen verdeckten Erziehungsziele im Wege einer pädagogischen Verfassungsinterpretation fruchtbar zu machen. Auch insoweit bleibe ich bei meinen Vorbehalten und betone noch einmal, daß das Grundgesetz nicht nur aus entstehungsgeschichtlichen, sondern auch aus guten Gründen der Rücksichtnahme auf die bundesstaatliche Vielfalt gerade im Bildungswesen sich in der Frage gesamtstaatlicher Erziehungsziele zurückgehalten und dadurch der bundesstaatlichen Vielfalt und der Eigenständigkeit der Länder Raum gegeben hat. - Herr Oppermann, Sie haben mein Stichwort von der "Schule der Nation" aufgegriffen und um Präzisierung gebeten. Ich will es noch einmal deutlich sagen: Zum einen hat die Schule als "Schule der Nation" die eigene, die deutsche Nation zu akzeptieren und im Sinne der Integration positiv zu umhegen. Vor allem aber will ich mit dem Begriff von der "Schule der Nation“ sagen, daß die Schule nicht nur die Aufgabe hat, die individuelle Entfaltung der Persönlichkeit zu fördern und schulisch zu begleiten, sondern daß Schule auch die Aufgabe hat, diejenigen Einstellungen und Orientierungen zu vermitteln, die - polizeirechtlich formuliert - für ein gedeihliches $\mathrm{Zu}$ - 
sammenleben in der Gemeinschaft und im Staat unentbehrlich sind. Sie haben weiterhin nachgefragt, ob es um einen Erziehungsauftrag des Staates oder einen Erziehungsauftrag der Schule gehe. Ich sehe da keinen Unterschied. Nach Absprache mit dem Vorstand war das Thema so zu verstehen, daß es allein um die öffentliche und damit in Deutschland in erster Linie um die staatliche Schule geht, der schulische Erziehungsauftrag mithin staatlich bestimmt ist. Schließlich haben Sie, Herr Oppermann, im Hinblick auf das morgige Thema angeregt, auch im Schulbereich stärker über Entstaatlichung, Privatisierung und Deregulierung nachzudenken. Immerhin reicht Art. 7 Abs. IV GG dazu ja ausdrücklich die Hand. Aber schon Herr Stern hat in seinem Diskussionsbeitrag mit dem Hinweis auf Wilhelm von Humboldt zu Recht auf das damit verbundene Dilemma aufmerksam gemacht. Auch bei einer stärkeren Privatisierung des Schulwesens wird der Staat schon allein über die Frage der Finanzierung nicht vor der Tür bleiben, so daß ich in einer stärkeren Privatisierung des Schulwesens insgesamt nur eine graduelle Entstaatlichung sehe. Herrn Stern habe ich mit dieser Antwort indirekt auch schon bedacht. - Herr Lerche, Sie haben meinen Leitsatz 7a herausgegriffen und danach gefragt, inwieweit es eigentlich angehen kann, Art. 2 Abs. I GG als Fundamentalnorm im schulischen Bereich zu benennen, also eine Grundrechtsnorm, die zufolge ihres ausgesprochen weiten Schutzbereichs kaum geeignet erscheint, dem schulischen Erziehungsauftrag inhaltliche Konturen zu verleihen. Diese Skepsis ist m. E. unangebracht. In Art. 2 Abs. I GG ist - mit den Worten von Ekkehart Stein zu sprechen - das Grundrecht des Kindes auf Entfaltung seiner Persönlichkeit mitangelegt. Soweit nun für die Entfaltung der Persönlichkeit des Kindes z. B. die Schulwahl und die Fächerwahl eine Rolle spielt, ist es Aufgabe des Staates, diese von Art. 2 Abs. I GG mitumfaßte individuelle Entscheidung in der Schule zu fördern und zu umhegen. Insofern sehe ich aus Art. 2 Abs. I GG einen schulischen Auftrag legitimiert, derartige schulbezogene Entscheidungen des Individuums zu schützen. Das hindert aber nicht, neben dieser an Art. 2 Abs. I GG orientierten, dienenden Funktion der Schule, ihr auch überindividuelle Aufgaben i. S. e. Integrationsaufgabe zuzuweisen. - Herr Isensee, Sie haben noch einmal ihre Skepsis gegenüber ethisch orientierten Erziehungszielen zum Ausdruck gebracht und dabei vor allem die Nächstenliebe zitiert. Gerade dieses Erziehungsziel erscheint mir aber am wenigsten unter Vollzugsdefiziten in der Schule leiden zu müssen, denn es gibt in den einzelnen Fächern hinreichende Möglichkeiten vom Sportunterricht bis zu stärker leistungsorientierten Fächern -, den Gedanken der Nächstenliebe in vielfältiger Weise in der Klassengemeinschaft einzuüben - durch Hilfestellung und Rücksichtnahme des begabten auf den weniger begabten Schüler. - Herr Roellecke, Sie sehen die 
Achillesferse der Erziehungsziele darin, daß man sie nicht lernen und abprüfen könne. Richtig, aber darum geht es auch gar nicht. Erziehungsziele sind in erster Linie vielfach Vorgaben, die das schulische Umfeld bestimmen sollen, in dem das Lernen stattfindet, die das pädagogische Ethos ansprechen und das Schulklima prägen sollen. Sie sind gerade keine Lernziele und damit auch nicht prüfungsrelevant. Das Maß ihrer Akzep$\operatorname{tanz}$ durch den Schüler kann sich allenfalls in den sog. Kopfnoten oder in den Besonderen Anmerkungen des Zeugnisses niederschlagen. - Herr Rauschning, mein Hinweis auf die Staatspflege ist in der Tat an Herbert Krüger orientiert gewesen, das räume ich gerne und freimütig ein. - Herr $B u l l$, Sie haben noch einmal auf die Schwierigkeiten hingewiesen, gegebenenfalls unter Verwendung des Disziplinarrechtes die Erziehungsziele vollzugsfähig zu machen. Diese Skepsis teile ich und verweise in diesem Zusammenhang auf eine Fußnote in dem Begleitaufsatz von Herrn Pieroth, in der sich der Hinweis findet, daß derzeit lediglich drei gerichtliche Entscheidungen auszumachen sind, in denen disziplinarrechtliche Maßnahmen gegen Lehrer auf die Verletzung von Erziehungszielen gestützt werden. Das bestätigt nur noch einmal von dieser Seite her die Schwierigkeit, auf die Sie hingewiesen haben. - Schließlich Herr Hufen, Sie haben angeregt, durch identitätsstiftende Maßnahmen eine Art Schulgemeinschaft von Lehrern und Eltern dadurch zu beleben, daß der Gedanke der Partizipation aller am Schulleben Beteiligten stärker aktiviert wird, um damit auch die gemeinsame Verantwortung aller Erziehungsträger zu unterstreichen. Die Instrumente dafür wären ja vorhanden und wer selbst als Elternvertreter tätig gewesen ist, weiß, daß die Schulen immer wieder den Gedanken einer Schulgemeinschaft beschwören. Ihrem Ansatz gehört meine ganze Sympathie. Aber - Herr Hufen zurückhaltendes Desinteresse der meisten Eltern und eine vielfach resignative Haltung der Lehrer außerdienstlichen Aktivitäten gegenüber bestimmen derzeit die Realität. Mit anderen Worten: Ich bezweifle, daß über die Spielwiese partizipatorischer Elemente die Schule zur Erziehungsgemeinschaft werden kann. - Vielen Dank.

Bothe: Vielen Dank, Herr Vorsitzender! Die Diskussion hat vieles angesprochen, was mich in der Zeit der Vorbereitung des Referates umgetrieben hat. Ich will versuchen, das zu gruppieren, wobei ich natürlich Gefahr laufe, einzelne Fragen und Herausforderungen nicht aufzugreifen.

Zunächst zu dem Bereich Staat und Gesellschaft. Mir ist vorgeworfen worden, ich hätte den Staat unterbetont. Da bin ich mir keiner Schuld bewußt. In dem Referat steckt freilich manches, was die Rolle des Staates etwas bescheidener sieht, vielleicht in dem Sinne - gestatten Sie mir die 
Paraphrase - daß der Staat der erste Diener der Gesellschaft ist. Angst habe ich vor einem Konzept, daß den Staat zu sehr zu einem Selbstzweck jenseits seines Wohlfahrtszwecks für die Bürger macht. Aber in dieser Funktion als Diener der Gesellschaft habe ich den Staat, so glaube ich, nicht unterbetont. Ich möchte dabei insbesondere auf das hinweisen, was ich zur Privatschule gesagt habe. Ich gebe dem Staat schon, was des Staates ist.

Nun zur Frage Staat und Nation. Der moderne Staat ist vielleicht $\mathrm{Na}$ tionalstaat, er ist ganz bestimmt Territorialstaat. $\mathrm{Ob}$ und inwieweit er Nationalstaat ist, das hängt davon ab, was man unter der Nation versteht. Selbstverständlich ist der Staat für sein Funktionieren auf eine gewisse historisch gewordene Kohäsion angewiesen. Wir sehen heute in vielen Fällen, in der Nähe und in der Ferne, wie Staaten, denen das nation building aus irgendeinem Grund nicht gelungen ist, nicht oder schlecht funktionieren. Ich will also dieses als Nation zu bezeichnende Element einer geschichtlich gewordenen Integration nicht leugnen. Es ist eine Funktionsbedingung des Staates, wenn er seine Rolle als Diener einer auf einem bestimmten Territorium befindlichen Gesellschaft wirklich wirksam erfüllen will. Aber bei dieser Funktionalität sollte es sein Bewenden haben. Ich habe großes Mißtrauen gegen alle Formulierungen, die darüber hinausgehen. Da halte ich es lieber mit einem Frankfurter, nicht aus der Frankfurter Scbule, aber mit jemand, der in Frankfurt geboren ist, nämlich Goethe, der im Westöstlichen Diwan geschrieben hat:

„Zur Nation Euch zu bilden, Deutsche, Ihr hofft es vergebens. Bildet darum, Ihr könnt es, freier zum Menschen Euch aus.“

Soviel zur Nation.

Der nächste Punkt, der mich sehr umgetrieben hat, ist das Spannungsverhältnis zwischen Offenheit für eigene individuelle Optionen, die sich entfalten können müssen, auf der einen Seite und Integration in eine Gesellschaft auf der anderen. Hier sind Akzente unterschiedlich gesetzt worden. Darüber muß man sicherlich noch weiter nachdenken, oder darüber kann man eigentlich nie aufhören, nachzudenken. Beides ist in ein richtiges Verhältnis zueinander zu setzen. Demokratie ist, so meine ich, in der Herausbildung von Wertüberzeugungen eben doch dezentral angelegt. Auch Wertüberzeugungen bilden sich in der Demokratie auf dem Marktplatz der Meinungen. Dieser offene Prozeß soll nicht durch Fixierungen präjudiziert werden. Das zu sagen, daran lag mir. Dem liegt die Überzeugung zugrunde, daß eine gesellschaftliche Integration in diesem offenen Prozeß möglich ist.

Eine letzte Frage, bei der ich mich vielleicht deutlicher ausdrücken sollte, hat mich umgetrieben, nämlich die Möglichkeit der Umsetzung 
von Verfassungszielen im Bildungs-, Ausbildungs- und Erziehungsauftrag der Schule. Der Einbezug der Lehrer in die Gemeinschaft der Verfassungsinterpreten ist als Stichwort in diesem Zusammenhang gefallen. Darauf lege ich Wert. Die Vermittlung von verfassungsgebotenen Erziehungszielen kann nur gelingen, wenn die Lehrer, die Pädagogen in den Prozeß der Entfaltung der Verfassung irgendwie eingebunden werden. Dies ist auch eine Herausforderung an uns, die Verfassung in einer Weise zu entfalten, die auch von der Lehrerschaft aufgenommen werden kann. Ich habe die Lehrerfortbildung in diesem Zusammenhang erwähnt. Hier muß einfach Kommunikation stattfinden. Das bedeutet nicht, daß wir Verfassungsinterpretation den Lehrern überlassen, sondern, daß zwischen unserem Fach und den Lehrern Kommunikation stattfindet. Das Scharnier einer ministerialen Verwaltungsrichtlinie will mir hierfür nicht genügen.

Soviel zunächst, die Multikulturalität möchte ich mir für das Schlußwort aufheben.

Mantl: Der Lebrer ist eine Zentralfigur in den Auseinandersetzungen, die uns heute umtreiben. Die sogenannte Unterrichtsfreiheit des Lehrers wird im österreichischen Schulunterrichtsgesetz unter dem Titel „Unterrichtsarbeit" ganz kurz umschrieben: Der Lehrer hat in eigenständiger und verantwortlicher Unterrichts- und Erziehungsarbeit, also kognitiv, emotiv und normativ, die Aufgabe der österreichischen Schule, das sind die Erziehungsziele des $\$ 2$ Schulorganisationsgesetz, von denen ich in meinem Referat gesprochen habe, zu erfüllen. Das ist in der Praxis sehr schwer. Ich habe jahrelang Lehrerfortbildung in politischer Bildung und Staatsbürgerkunde betrieben. Zum Teil wollte mein Publikum ganz einfach nur wissensmäßig den Stoff der alten Staatsbürgerkunde kennenlernen: Es hat Hauptschullehrer gegeben, die ihre Schüler die Kompetenzen der österreichischen Bundesversammlung, zu denen auch heute noch das Recht der Kriegserklärung zählt, auswendig lernen ließen. Aber das sind nur Schmankerln, das wirklich Dramatische dabei - das hat Friedhelm Hufen schon angedeutet - war und ist die tiefe anarchische Grundsehnsucht der Lehrer, die ich sonst nur noch bei Künstlern gefunden habe, das Gefühl der völligen Schrankenlosigkeit bei der pädagogischen Arbeit. Zugleich sind, das ist auch empirisch erwiesen, die Lehrer die mit ihrem Beruf unzufriedenste Gruppe der öffentlichen Bediensteten. Das äußert sich in zahlreichen Krankheitsfällen und Frühpensionen. Angesichts dieses bestürzenden Faktums einer im Grunde desolaten Lehrerschaft bin ich gegenüber den die Enttraditionalisierung nahezu positiv akzeptierenden Thesen 6, auch 7 und 24 Michael Bothes skeptisch, weil dies die Schule überfordert. Es gibt den für die Herstellung der "neuen Welt“ 
notwendigen Lehrer doch nicht, und es wird ihn auf absehbare Zeit wohl auch nicht geben.

Noch zwei kleine Kritikpunkte in diesem Zusammenhang: Bothe postuliert für den Schüler, in entwickelter Mündigkeit einen sinnvollen Lebensentwurf selbständig zu finden. Auch darin liegt eine Überforderung. Auf dem Weg zum selbständig erarbeiteten, sinnvollen Lebensentwurf ist doch immer wieder - auch über die rechtliche Mündigkeit hinaus - das Vorbild notwendig, das Beispiel von "Angesicht zu Angesicht" (übrigens ein Pestalozzi-Wort). Dieser Aspekt ist bei Bothe unterbelichtet. Schließlich wende ich mich noch einmal gegen den von Bothe gleichsam verordneten Antitraditionalismus, den ich rechtlich und pädagogisch für äußest problematisch halte. Gerade die sozialintegrative Funktion der Tradition dürfte nicht übersehen werden, jene soziale Integration, die Dieter Grimm so nachdrücklich gefordert hat, immer vor der ernsten Folie der Böckenfördeschen Frage, wie dieses Ethos zu erarbeiten sei. Dies wird immer schwieriger, weil es immer weniger Alltagsselbstverständlichkeiten gibt, weil auch die Traditionsbestände dünner werden, aber gerade deswegen will ich sie nicht gleich hinauswerfen, sondern sorgsam pflegen. Wir können niemals $100 \%$ unserer Werte tradieren, das wäre eine schreckliche Welt. Wir müssen sie modifiziert, adaptiert an die nächste Generation weitergeben. Das ist überaus mühsam.

Robert Musil hat einmal im "Mann ohne Eigenschaften“ gesagt, das wahre Österreich sei die ganze Welt. Das kann sehr weltläufig verstanden werden, aber auch sehr provinziell, etwa dergestallt, daß man nichts außerhalb der eigenen Grenzen suche und brauche. Wir wissen ja, wie schwer es ist, das Partikulare in eine universalistische Menschheitsmoral zu übertragen. Und das alles sollte der Lehrer können, wenn wir es nicht zustande bringen?

Vogel: Wir sind uns wohl einig darüber, daß verfassungsrechtliche Erziehungsprinzipien die Wirklichkeit nur sehr begrenzt steuern können. Unter diesem Vorbehalt möchte ich ein paar Worte zu den Kollisionen unter solchen Erziehungsprinzipien und zu ihrer Rangordnung sagen. Herr Botbe hat den Fall der moslemischen Schülerin genannt, bei der das Gebot der Gleichberechtigung mit der Religionsfreiheit kollidieren könne. Er hat, wenn ich ihn recht verstanden habe, der Gleichberechtigung den Vorrang gegeben; ich würde ihm darin zustimmen. Hier wird erstens, meine ich, eine Grenze des „Multikulturalismus“ deutlich; das möchte ich jetzt aber nicht vertiefen, wahrscheinlich werden das andere tun. Und zweitens wird mit diesem Beispiel die Frage aufgeworfen nach der Rangordnung der Verfassungswerte, auf die hin Erziehung ausgerichtet sein muß. Dazu eine These oder auch nur Hypothese: ich denke, 
vor allen Einzelzielen rangieren hier die Grundentscheidungen der Art. 1 und 20 Grundgesetz, dazu der Art. 3 und der Kern des Art. 2 Abs. 1. Mit anderen Worten: der Verfassungsstaat, der, wie heute schon mehrfach erwähnt worden ist, seine eigenen Voraussetzungen nicht gewährleisten kann, muß gerade deshalb Wert darauf legen, daß jedenfalls der Versuch unternommen wird, diese seine Voraussetzungen im Wege der Erziehung in seinen zukünftigen Staatsbürgern zu verankern. Das Wort von der Schule als Schule der Nation, mit Verlaub Herr Vorsitzender, stammt aus der ersten Regierungserklärung Brandt-Scheel, und ich bin mir sicher, daß es damals im Sinne von Herrn Dittmann als Erziehung $z u r$ Nation gemeint gewesen ist, in einem Sinn, den auch Herr Hangartner sehr schön umschrieben hat (freilich nicht der Nation, die Goethe und Herr Botbe abgelehnt haben).

Noch ein Wort zur „Ehrfurcht vor Gott“, Herr Bothe. Solange unser Grundgesetz sich auf die Verantwortung unseres Volkes vor Gott und den Menschen beruft, werden Sie mich nicht davon überzeugen können, daß die Erziehung zur Ehrfurcht vor Gott verfassungswidrig sei. Im säkularen Staat kann sie zwar nicht Erziehung zu einer bestimmten Religion bedeuten und nicht einmal Erziehung zur Religion überhaupt. Aber sofern wir uns darüber einig sind, daß die Ethik, zu der wir erziehen sollten, nur transzendental begründet werden kann, traue ich mir zu, auch mit einem Atheisten ein Einverständnis über eine Auslegung jener Worte zu finden.

Starck: Meine Damen und Herren. Ich möchte etwas zur Verbindlichkeit der Erziehungsziele sagen, was bisher noch nicht zur Sprache gekommen ist. Die Erziehung zum Staatsbürger, und zwar die Erziehung des Erwachsenen zum Staatsbürger, ist, wie wir wissen, nicht Aufgabe des Staates; er muß hier auf Vorgegebenheiten zurückgreifen können, die anderweitig geleistet werden. Der Staat kann allenfalls mittelbar durch die Gesetzesgestaltung den Bürger dazu bewegen, sich gemeinverträglich zu verhalten. Über den Titel „Schulehalten“ hat der Staat allerdings die Möglichkeit und die Pflicht, den werdenden Bürger zu staatsbürgerlicher Gesinnung zu erziehen unter Einschluß all der staatsbürgerlichen Tüchtigkeiten, wie sie in den zumeist landesverfassungsrechtlich normierten Erziehungszielen stehen. Nun geschieht das auf dem Wege, daß die Erziehungsziele nicht den Schülern, sondern den Lehrern zur Pflicht gemacht werden. Insoweit haben wir es mit verfassungsrechtlichen Grundpflichten zu tun, die die Lehrer erfüllen müssen, wenn sie in der Schule unterrichten. Wie läßt sich die Frage der Verbindlichkeit beantworten? Wie läßt sie sich juristisch-technisch durchsetzen? Ich knüpfe an die These 15 von Herrn Bothe an, der meines Erachtens sehr plausibel un- 
terschieden hat zwischen positiv-anleitender Funktion und negativ-ausgrenzender Funktion der Erziehungsziele; er hat zur negativen Ausgrenzung auch ein Beispiel gebracht, das ich nicht wiederholen will. Vielmehr möchte ich zur anderen politischen Seite hin ein Beispiel bringen: Die Vermittlung einer anarchisch-utopischen Gesellschaftstheorie wird durch die Erziehungsziele ausgegrenzt, $d$. h. verboten. Ich glaube, daß wir in der Operationalisierung der Erziehungsziele im allgemeinen weiter kommen, wenn wir Anleihen im Planungsrecht machen, das durch intensive juristische Beschäftigung steuernde Wirkung entfaltet. Auch da gibt es Finalsteuerungen, wie sie die Erziehungsziele beabsichtigen. Das hätte man vielleicht etwas vertiefen können.

Die Frage, wie es eigentlich um die Realität der Erziehungsziele steht, verweist über die Schule und die dort tätigen Pädagogen hinaus auf die Pädagogiker in den Lehrerbildungsanstalten. Ich habe mich in den Siebzigerjahren mit dieser Frage beschäftigt und die Pädagogikliteratur durchgeschaut und dabei festgestellt, daß die Erziehungsziele entweder ignoriert oder als Ausdruck vergangener Zeiten ridikülisiert worden sind. Man hat gesagt, so etwas altertümlich Daherkommendes, was da in Landesverfassungen steht, sei völlig unbrauchbar; deshalb müsse man ganz auf die Pädagogik setzen: also die Pädagogik gegen die verfassungsrechtlichen Erziehungsziele. Nun haben sich beide Referenten mit der Umsetzung der Erziehungsziele beschäftigt und haben immer nur von der Umsetzung in der Schule gesprochen. Ich meine, daß wir hier auch in den Blick nehmen müssen, daß die Umsetzung in der Schule vorbereitet wird in der Lehrerausbildung. Die Lehrerausbildung gehört unabdingbar zum Thema "verfassungsrechtliche Erziehungsziele“. Hier gibt es gewiß Schwierigkeiten, da die Professoren in den lehrerbildenden Anstalten die Lehrfreiheit für sich geltend machen. Auch in den juristischen Fakultäten haben wir Lehrfreiheit. Aber wir wissen, daß wir bei der wissenschaftlichen Ausbildung der jungen Juristen das geltende Recht zu lehren haben und die junge Generation mit den Rechtsgrundsätzen vertraut zu machen haben. Und das muß in einer sicher abgeschwächten und anderen Weise auch an den Bildungsanstalten für die Lehrer geschehen.

Huber: Herr Vorsitzender. Ich möchte zunächst zur These Nr. 5 von Herrn Dittmann eine Frage stellen. Dort hat er festgestellt, daß ein staatliches Schulmonopol verboten sei. Ich bin mir nicht sicher, ob man so pauschal sagen kann, der Staat oder das Grundgesetz verbieten ein staatliches Schulmonopol. Ich bin mir insbesondere nicht sicher, ob man nicht $z$ wischen den unterschiedlichen Phasen der schulischen Erziehung differenzieren muß. Schon der Art. 7 unterscheidet ja zwischen der Volksschulerzieung und der sonstigen schulischen Erziehung, und gerade im 
Bereich der Volksschulerziehung kommt die Regelung einem staatlichen Erziehungsmonopol doch ziemlich nahe. Dieses Monopol ist nicht um seiner selbst willen, wir haben es ja mehrfach gehört, im Art. 7 Abs. 1 der staatlichen Schule aufgegeben, sondern zu dem Zweck, Grundkonsens, Integration oder die vorrechtlichen Voraussetzungen im Sinne von Herrn Böckenförde zu schaffen oder zumindest zu ermöglichen. Insofern hätte ich sowohl gegen die Deregulierung, die Herr Oppermann hier zu bedenken gegeben hat, als auch zu der Binnenpluralitätsvorstellung von Herrn Hufen Einwände. Auch im übrigen scheint mir der staatliche Erziehungsauftrag bei der Interpretation der Privatschulfreiheit manchmal ein bißchen zu kurz kommen, nicht zuletzt in der Rechtsprechung. Was nun die Erziehungsmaßstäbe angeht, Herr Dittmann, ist meine weitere Frage: habe ich Sie richtig verstanden, daß Sie die grundgesetzlichen Wertentscheidungen, Staatszielbestimmungen und Ähnliches lediglich als Ermächtigung verstehen, aber sozusagen nicht als bindende Vorgaben? Wenn dies so sein sollte, dann dürfte hier ein gewisser Systembruch zur sonstigen Bindungswirkung liegen, die man grundrechtlichen Wertentscheidungen im übrigen ja zuspricht; diese gelten für alle staatliche Gewalt strikt und nicht lediglich als Option; sie binden damit auch die Landesstaatsgewalt in vollem Umfang. Im Hinblick auf Art. 2 Abs. 1, bei dem Sie ja von einer "gemeindeutschen Basis" gesprochen haben, haben Sie das der Sache nach - so glaube ich - auch bejaht. Und in der Tat: sollte denn in Niedersachsen, wo die Erziehung zur Selbstverantwortung und Selbstentfaltung nicht in der Verfassung steht, diese Erziehung nicht geboten sein? Das Grundgesetz setzt den Landesverfassungen einen breiten Rahmen; dieser läßt den Ländern Raum zur Akzentuierung, wie es Herr Stern genannt hat, aber dieser Rahmen gilt natürlich mit der Wirkung des Art. 31. Letztes Wort zu den Erziehungsmaßstäben, die in Art. 7 Abs. 1 oder über Art. 7 Abs. 1 in den staatlichen Erziehungsauftrag einfließen: Sie gelten, so verstehe ich es, gleichrangig neben anderen Grundentscheidungen der Verfassung, der Religionsfreiheit - die islamische Schülerin ist ja mehrfach angesprochen worden - der Meinungsäußerungsfreiheit und anderen Wertentscheidungen. Hier, Herr Bothe, ist Raum für den „Multikulturalismus“, sozusagen als Ergebnis praktischer Konkordanz oder Toleranz zwischen staatlichem Erziehungsauftrag und seinen Maßstäben einerseits und kollidierenden Verfassungsentscheidungen auf der anderen Seite. Jedoch, und das ist mir in Ihrem Referat nicht ganz deutlich geworden, darf man doch nicht vergessen, daß der Erziehungsauftrag und seine Maßstäbe von ihrem integrativen Zweck her gedacht werden müssen; dann taucht die "Multikulturalität“ jedoch lediglich als Schranke auf und nicht als primäre Zielsetzung von Erziehungsauftrag und-maßstab. Insofern, Herr Vorsitzender, gebietet 
das Grundgesetz in der Tat auch die Erziehung zur Nation, allerdings zu einer Nation im republikanischen und in dem von Goethe gerade nicht gemeinten Sinne.

Frowein: Herr Vorsitzender, meine Damen und Herren. Wir alle sind zur Schule gegangen und die meisten von uns haben Kinder, die in die Schule gehen oder gegangen sind, und deswegen meinen wir, daß wir mehr oder weniger wissen, worüber wir reden, und das mag auch ein bißchen dazu führen, daß die Beziehung zum Recht mir manchmal etwas undeutlich zu werden scheint und wir über einen Erziehungsauftrag sprechen, bei dem wir nicht mehr ganz klar sehen, wieweit er eigentlich wirklich rechtlich determiniert ist. Ich möchte gerne zu vier Punkten, wo ich rechtliche Konfliktzonen sehe, kurze Andeutungen machen und die Referenten vielleicht auch bitten, dazu noch etwas im Schlußwort zu sagen, wenn es sich ergeben sollte. Die erste Frage Schulzwang und Problematik der Privatschulen. Hinsichtlich des Schulzwanges sollten wir uns klar sein, daß es wohl in Europa kaum ein Land gibt, das einen so scharfen Schulzwang, wie wir in Deutschland ihn haben, kennt. Das hat neulich in einem interessanten Verfahren eine Rolle gespielt, wo eine deutsche Schulwiderständlerin bis nach Straßburg kam, dort natürlich auch abgewiesen wurde. Aber der Fall hat mir doch zu denken gegeben. Die Frau ist mit ihrem Kind nach England gegangen, wo sie ihre Art der Erziehung unproblematisch verwirklichen kann. Es ist ein Punkt, über den wir nachdenken sollten. Ebenso sollten wir über das Problem Aufsicht über Privatschulen an den wirklich verfassungsfesten Maßstäben nachdenken, während die Aufsicht in der Praxis sehr weitgehend eine Gängelungsaufsicht ist, die weit über das hinausgeht, was diese Maßstäbe sind. Zweiter Punkt: Schulgliederung. Ich meine, daß eine unmittelbare Beziehung zwischen Schulgliederung und Erziehungsauftrag besteht. Früher pflegte man das ja zum Teil mit der Formel zu umschreiben, Erziehung durch klassische Bildung, das klassische deutsche humanistische Gymnasium. Das kann man nicht ganz ausblenden, wenn man über unser Problem spricht, und muß sich auch erinnern an die Rechtsprechung des Bundesverfassungsgerichts, die sehr klar in einer streitigen Phase die Einheitsschule im weitesten Sinne verworfen hat und bestimmte Auswahlmöglichkeiten garantiert hat. Das ist in unserem Zusammenhang auch zu bedenken. In diesem Zusammenhang ein Wort zum Ganztagsschulproblem, das meines Erachtens ein eminent rechtliches Problem ist, wo wir uns fragen müssen, ob nicht die deutschen Schulträger in stärkerem Umfang für Familien und Alleinerziehende Ganztagsschulen vorhalten müssen, was außer im deutschsprachigen Raum fast überall die Regel ist. Dritte Bemerkung: inhaltliche Konflikte. Wir erinnern uns alle an die Se- 
xualkunderichtliniendiskussionen und an die politischen Richtliniendiskussionen der Sechziger- und Siebzigerjahre. In einem neuen Gewand taucht das Problem wieder auf. Über Multikulturalität und Islamvorstellungen ist diskutiert worden. Ich glaube, daß da die Sache nicht so einfach ist wie bei dem Schwimmunterricht. Ich würde persönlich meinen, daß in der Tat die wesentlichen Grundlagen dieser Erziehung geleistet werden müssen, auch wenn Probleme auftauchen mit Grundvorstellungen anderer Religionen und Kulturen. Aber das ist ein sehr schwieriges Konfliktfeld, das angesprochen werden sollte. Letzte Bemerkung: Es ist von Herrn Hufen und vorher schon über das Problem der inneren Schulorganisation gesprochen worden. Ich will einmal mit der Gefahr der Mißverständlichkeit sagen: es gibt wirklich so etwas wie demokratische Organisation in der Schule. Nicht etwa basisdemokratisch, wie das eben erwähnt worden ist. Aber die Beziehung zwischen Gewährleistung dieser Ziele und Einbindung von Eltern, aber auch Schülern in bestimmtem Umfang ist etwas, was größerer Beachtung bedarf. Vielen Dank.

Wallerath: Herr Vorsitzender, meine Damen und Herren. In den Referaten wie in der Diskussion klang mehrfach die begrenzte Steuerungsfähigkeit von Recht für schulische Erziehungsprozesse an. Dem folgt auf instrumenteller Ebene, wiederzufinden in der These 14 von Herrn Bothe, daß die normative Steuerung hier in Form einer finalen Programmierung erfolgt. Beide Referenten verknüpfen diese Erkenntnis auf der Umsetzungsebene mit der Kategorie pädagogischer Freiheit. Diese Kategorie kann natürlich nicht ein Recht des Lehrers auf Erziehung dem Schüler gegenüber bedeuten - das Recht auf Erziehung steht nur dem Staat und nicht dem einzelnen Lehrer zu, es definiert also einen besonderen Freiraum des Lehrers im Verhältnis zur Schulaufsicht. Herkömmlich wird dieses Prinzip als objektiv-rechtliches Prinzip einer optimalen Gestaltung von Unterricht verstanden. Wenn Herr Bothe den Grundsatz pädagogischer Freiheit, wie ich meine: zu Recht, mit dem Grundsatz der Verhältnismäßigkeit verbindet, so setzt er damit stillschweigend die subjektiv-rechtliche Verstärkung des Prinzips pädagogischer Freiheit voraus. Dies läßt sich sicherlich nicht, jedenfalls nach herkömmlichem Verständnis, auf Art. 5 Abs. III GG, wohl aber auf Art. 2 Abs. I in Verbindung mit 5 Abs. I GG zurückführen. Die Berenzung dieser Freiheit ergibt sich aus Art. 7 GG einerseits wie auch aus den beamtenrechtlichen Vorschriften und - was nicht immer recht beachtet wird - den besonderen schulrechtlichen Bestimmungen, die die Weisungsfreiheit begrenzen, andererseits. Der Grundsatz der Verhältnismäßigkeit ist in der Tat hier als "Schranken-Schranke" zu mobilisieren: Wenn sich die dialogische Struktur von Unterricht einer strikten Programmierung von außen 
widersetzt, so ist lediglich ein „limitiertes Weisungsrecht“ geeignet, der personalen Ausfüllung des Beziehungsgeflechts zwischen Lehrer und Schüler Rechnung zu tragen. Insofern sperrt sich der Grundsatz der pädagogischen Freiheit natürlich nicht gegen die Vorgabe von Erziehungszielen - Herr Mantl hat das eben sehr schön mit eingebracht. Ich denke, damit sind auch die Bedenken von Herrn Bull zerstreut - selbstverständlich hat der einzelne Lehrer kein Widerstandsrecht gegen vorformulierte Erziehungsziele des Parlaments oder der Kultusbürokratie, soweit sie sich im Rahmen des Wesentlichkeitsvorbehalts bewegen. Wohl aber bietet der Grundsatz pädagogischer Freiheit etwa ein Reservat für methodische Freiheit, auch für didaktische Freiheit. Und hier mag das, was Herr Hufen soeben anklingen ließ, durchaus Geltung gewinnen, und hier mag auch das, was Herr Dittmann mit "Achillesferse“ bezeichnete, in der Tat eine gewisse Bestätigung finden. Vielen Dank.

Morlok: Herr Vorsitzender. Meine Damen und Herren. Unser Gegenstand Erziehungsauftrag und Erziehungsmaßstab ist gekennzeichnet durch ein Trilemma. Auf der einen Seite haben wir die Direktiven für einen staatlichen Erziehungsauftrag. Der Staat darf, soll, ja er muß Erziehungsziele setzen, wenn er die Voraussetzungen für einen freiheitlichen Verfassungsstaat erhalten will. Auf der zweiten Seite stehen demgegenüber Schranken für die staatliche Erziehungstätigkeit, insbesondere die Grundrechte von Eltern und Kind begrenzen den Staat, wehren Indoktrinierung ab, schaffen die Freiheit, eigene Vorstellungen der Bürger zur Entfaltung zu bringen. Die Herstellung praktischer Konkordanz $z$ wischen diesen beiden rechtlichen Imperativen ist ein konventionelles Geschäft der Juristen. Hierbei gibt es Verschiedenes zu betrachten, was wiederholt angesprochen wurde. Bei unserem Problem kommt aber, glaube ich, stärker als bei anderen Problemen eine dritte Seite hinzu. Und das ist eben die nur begrenzte Steuerungsfähigkeit des Bildungswesens durch das Recht. Das muß man mit systematischer Konsequenz verfolgen. Herr Bothe hat darauf zunächst einmal in einer Makroperspektive hingewiesen, indem er hervorgehoben hat, daß das Bildungssystem ein ausdifferenziertes Gesellschaftssystem ist, das nur begrenzt transparent ist für den Blick von außen und eben auch nur begrenzt steuerbar ist. Herr Dittmann hat den gleichen Gesichtspunkt von der pädagogischen Situation her betont und sodann mit dem schönen Ausdruck gesagt, Erziehung, vor allen Dingen dann, wenn es um die Vermittlung von Werten geht, funktioniere nicht per Befehl, sondern per Dialog. In der Tat, ich möchte mit meinem Kollegen Gröschner formulieren: Das dialogische Prinzip muß Leitprinzip der Erziehung sein. Daraus folgt aber, daß ich mich in der pädagogischen Situation einlassen muß auf den Zögling. 
Der Lehrer muß suchen, wo der Schüler ist, auch wo er geistig ist. Das ist nicht vorherprogrammierbar. Die pädagogische Freiheit des Lehrers ist alles andere als ein Rechtstitel, das ist eine faktische Notwendigkeit.

Angesichts dieses Befundes - der nur begrenzten rechtlichen Steuerbarkeit der Erziehungsziele - fragt sich, was zu tun ist. Herr Roellecke hat den kühlen soziologischen Blick gewählt und gesagt, das rechtliche Gerede um Erziehung solle nur ablenken, da komme sowieso nichts raus, das schaffe den Pädagogen faktische Freiheit. Da mag viel dran sein, aber das ist für uns Verfassungsrechtler, die wir eben normativ verpflichtet sind, unbefriedigend. Eine zweite Antwort hat Herr Bothe gegeben in seinem Hinweis auf die symbolische Dimension der Wirkungen des Rechts. Das ist wichtig und sollte nicht unterschätzt werden. Aber darüber hinaus haben wir doch ein Interesse daran, wie wir die normative Kraft der Verfassung umsetzen können. Im Hinblick hierauf muß man eben ganz konkret sich einlassen auf die Realisierungsbedingungen in der Schule. Ohne den Lehrer, ohne das Klassenzimmer läuft nichts. Die Stichpunkte sind jetzt alle schon genannt worden. Das erste ist Lehrerbildung, Herr Starck hat das ja gerade schon gesagt. Wer sich um Erziehungsziele wirklich kümmert, ein Interesse an der Implementation von Erziehungszielen hat, muß sich darum kümmern. Und das zweite ist, Herr Hufen hat das vor allen Dingen angesprochen, das ist ein Interesse für die Schulorganisation. Hier muß ich in der Tat eben auch den Dialog beginnen zwischen den staatlichen Instanzen und nicht nur den Schülern, sondern auch den Eltern. Das ist nötig; vielleicht sollte man ein bißchen Interesse von der Diskussion um die letzte Ziselierung der Erziehungsziele abziehen und verwenden auf diese praktischen Übersetzungsschritte.

Knies: Herr Vorsitzender, ich wollte an sich nicht zum Thema "Lehrerbildung" sprechen, obwohl dies ein Punkt war, bei dem ich vorhin einen der Herren Kollegen sehr nachhaltig unterstützt habe. Die Lehrerbildung und vor allen Dingen - angesichts der von Herrn Stark ja nicht zu Unrecht kritisierten und keineswegs karikierten Form der akademischen Lehrerbildung an unseren Hochschulen - die praxisorientierte Lehrerfortbildung sind außerordentlich wichtig zur Realisierung auch der verfassungsgeprägten Bildungs- und Erziehungsziele.

Ich wollte vielmehr zu einem Thema einige Sätze sagen, das Sie zwar in Ihrer Aufzählung der jetzt zu erörternden Fragen nicht hatten, das aber von zwei der Herren Kollegen breits aufgegriffen worden ist. Ich hatte nicht den Eindruck, daß unsere beiden Herren Hauptreferenten einen Mangel an Etatismus haben erkennen lassen. Ich würde eher sagen: Das war kräftig etatistisch, jedenfalls was das Verhältnis staatliche Schule 
- Privatschule anging. Geradezu angstvoll - so war mein Eindruck - hat Herr Bothe gesagt: Die Privatschule darf für die öffentliche Schule keine Konkurrenzschule werden! Ich glaube, man braucht sich um die staatliche Schulhoheit und die Dominanz der staatlichen Schule keine Sorgen zu machen. Wir werden den Gang der Geschichte auch in diesem Punkte nicht umkehren. Aber das sollte uns nicht veranlassen, die knappe Lebensluft, die bei uns die Privatschule aufgrund dieser Tradition und der Mentalität der Deutschen ohnedies nur hat, noch weiter abzuschnüren. Eher umgekehrt möchte ich sagen (wenn auch nicht im Sinne der Maximen, die vielleicht morgen die Debatte über die Privatisierung öffentlicher Aufgaben bestimmen werden): Ein wenig mehr Privatschulfreundlichkeit kann uns nicht schaden. Sie könnte gerade der öffentlichen Schule und der staatlichen Schulpolitik zum Vorteil gereichen. Dazu zwei Gesichtspunkte. Zunächst stimme ich Herrn Frowein ganz zu: Wir haben in vielen Schulverwaltungen die Vorstellung, die Privatschule müsse eine Blaupause der öffentlichen Schule sein, und wo sie auch nur um ein Geringes von dieser abweiche, habe die staatliche Schulaufsicht einzugreifen. Es gibt viel gewichtigere Probleme der Privatschulen, bei denen die staatliche Schulaufsicht wirklich gefordert wäre, aber dort nicht in Erscheinung tritt, weil dazu einiger Mut erforderlich wäre. Natürlich darf die private Schule - wie das Grundgesetz sagt - in ihren Lehrzielen und Einrichtungen nicht hinter den öffentlichen Schulen zurückstehen. Aber sie braucht deshalb doch nicht unter privaten Vorzeichen die Fortsetzung der Staatsschule mit anderen Mitteln zu sein; sie darf etwas anderes sein. Nur wenn sie etwas anderes ist, nimmt sie auch von der öffentlichen Schule einigen Druck weg. Was hätten wir uns - beispielsweise - in Deutschland Schulkämpfe erspart, wenn wir ein stärker ausgebildetes und eingebürgertes privates Schulwesen hätten! Dann hätten sich nämlich die Schulreformbewegungen der Sechziger-, Siebziger und Anfang der Achtzigerjahre zunächst einmal in experimentierenden Privatschulen abspielen können und nicht im Zwangsapparat der staatlichen Schule, wo das Problem für die widerstrebenden Eltern sich ja daran entzündet, daß es keine Ausweichmöglichkeiten gibt, so daß sie also ihre Kinder auf eine von ihnen abgelehnte Reformschule zu schicken genötigt sind, vor der es kein Entrinnen gibt.

Eine zweite Entlastung der öffentlichen Schule durch die private bitte ich in Erwägung zu ziehen: ein wenig Entlastung von der weitgehenden erzieherichen Ratlosigkeit. Selbst die privaten Schulen haben ja ihre Schwierigkeiten mit dem, was von den öffentlichen so lauthals und wohlfeil gefordert wird: die „Rückgewinnung des Erzieherischen“. Wie stellen wir uns das eigentlich vor? Wir selbst sind in den Familien nicht in der Lage oder nicht willens, den erzieherischen Aufgaben voll nachzu- 
kommen. Das Fernsehgerät als „beruhigender" Miterzieher ist auch in unseren Kreisen nicht unbekannt. Und dann erwarten wir, daß diese erzieherischen Defizite von der Schule, dazu der staatlichen Schule, ausgeglichen und behoben werden! Dort sind aber Lehrer, die sich - wen darf es eigentlich wundern? - wie andere Zeitgenossen auch jene hedonistischen und individualistischen Lebensziele und Lebensplanungen zu eigen gemacht haben, die hier und heute schon mehrfach festgestellt und beklagt worden sind. Darüber könnte ich ein schönes und langes Lied singen. Und von diesen Lehrern erwarten wir dann, daß sie gemeinschaftsorientierte Charakterschulung betreiben. Machen wir uns bitte keine falschen Vorstellungen, und hegen wir keine übertriebenen Erwartungen; aber gehen wir vielleicht, wo dies möglich ist, einen kleinen Schritt in Richtung auf die Verstärkung schulischer Erziehung durch Stärkung privater Schulen.

Herr Bull hat mich mit seinem Beitrag zu einer letzten Bemerkung verlockt. Herr $B u l l$, jetzt rächen sich alte Sünden! Ich kann mich beispielsweise sehr gut daran erinnern, daß in einem deutschen Land der Staatssekretär des Kultusministeriums zusammen mit Gewerkschaften und anderen Verbänden die Schulen, Schüler und Lehrer dazu aufgerufen hat, während der Schulzeit zu einer politischen Kundgebung nach Bonn zu fahren, wobei zugleich die Vergebung aller Sünden verkündet wurde: Schule schwänzen war für Lehrer und Schüler erlaubt und folgenlos, sagen wir es deutsch. Denn das politische Ziel der Kundgebung war der Landesregierung genehm; deswegen wurden die Sünden als läßliche angesehen. Jetzt ist eine politische Situation da, wo die unter Verletzung von Schul- und Dienstpflichten in Anspruch genommene Demonstrationsfreiheit sich gegen die Landesregierung selbst richtet - und nun ist man plötzlich erstaunt. Seien Sie nicht erstaunt, sondern kehren Sie zu einem strengen Amts- und Pflichtenverständnis für die Lehrer zurück. Unterscheiden Sie die Wahrnehmung der Amtspflichten von der privaten Grundrechtsausübung; die muß bei der Schule am Nachmittag stattfinden und nicht vormittags während der Schulzeit!

Würtenberger: Die beiden Referenten waren sich in einem Punkt einig: Mit der Veränderung der Gesellschaft und ihren Leitideen verändern sich zugleich auch die Erziehungsziele. Dies ist sicherlich richtig. Wenn man nämlich dem Wandel des Zeitgeistes nachgeht, finden sich im Wandel der Erziehungsziele die besten Anzeichen für einen Wandel im Zeitgeist. Gleichwohl möchte ich die kritische Frage stellen: Sind die Erziehungsziele nur Spiegel des gesellschaftlichen Zustandes oder sind Erziehungsziele nicht auch auf gesellschaftliche Stabilisierung oder auf Veränderung der Gesellschaft gerichtet? Bei der Betrachtung der Erzie- 
hungsziele ist eines zu beachten: Jede Generation baut durch die Erziehung der Nachkommenden das geistige Gehäuse der folgenden Generation. Schon daher geht es bei der Erziehung nicht um ein Sich-Treibenlassen durch den möglicherweise problematischen Gang der gesellschaftlichen Entwicklung. Deswegen sollte die Realanalyse der Gesellschaft auch kritisch bewertet werden. Mit Erziehungszielen ist gesellschaftlichen Fehlentwicklungen gegebenenfalls entgegenzusteuern. Bei den Erziehungszielen geht es immer um ein Tradieren dessen, von dem man meint, es als richtig erkannt zu haben. Dabei geht es auch um ein Lernen aus verfehlten Erziehungszielen. Ich erinnere nur an den Schulbuchstreit Ende der 70er Jahre. In diesem Zusammenhang möchte ich eine Frage an Herrn Bothe richten: Votieren Sie nach Ihrer Realanalyse für eine Erziehung zur Enttraditionalisierung? Geht es nicht auch um die Tradition der bewährten Werte, die Gegenstand der Erziehung sein muß? Muß in der Erziehung nicht auch vermittelt werden, was zur Tradition eines Kulturkreises gehört? Wenn man kulturelle Identität für bewahrenswert hält, muß man Prozesse und Phänomene der Enttraditionalisierung kritisch reflektieren. Dies führt zu einer weiteren Frage an Herrn Dittmann. In Ihrer These 8 haben Sie eine pädagogische Interpretation der Verfassungsprinzipien, wie sie von Peter Häberle vorgeschlagen ist, abgelehnt und im Zwischenwort haben Sie daran nochmals festgehalten. Diese These scheint mir im Blick auf die neuen Bundesländer besonders fragwürdig. Denn hier sollte sich die Erziehung der jungen Generation an den Verfassungsprinzipien und am Pluralismus des westlichen Verfassungsstaates orientieren. Trotz aller Buntheit der dortigen Landesverfassungen sollte die Ethik des Pluralismus vermittelt werden, also die Verfassungsethik, die dem Grundgesetz und seiner Interpretation zugrunde liegt. In diesem Zusammenhang eine letzte Bemerkung: Zum Ethikunterricht ist von beiden Referenten nichts vorgetragen worden. Hier ist für die Gestaltung der Lehrpläne großer Bedarf. Gerade im pluralistischen Staat muß man sich vergewissern, was Gegenstand eines Ethikunterrichts sein darf. Dürfen dem Agnostiker die Werte der Aufklärung oder gar des christlichen Abendlandes nähergebracht werden? Oder muß der Ethikunterricht frei sein von ethischen Wertungen, die diese Gesellschaft prägen?

Mußgnug: Ich habe begrüßt, daß Herr Dittmann in seiner vorletzten These betont hat, daß der Auftrag, das Grundgesetz an die Schulen, auch die Pflicht einschließt, das Grundgesetz selbst zum Gegenstand des Unterrichts zu erheben. Noch glücklicher wäre ich gewesen, wenn er diese zentrale wichtige These deutlicher in den Vordergrund seiner Überlegungen gerückt hätte, und wenn auch Herr Bothe auf sie eingegangen 
wäre. Sie berührt den Punkt, der uns Verfassungsrechtler allem voran interessieren muß, wenn von der Schule und ihrem Bildungsauftrag die Rede ist. Wir dürfen das Lehrfach „Staatsbürgerkunde“ nicht ganz den Bildungsplanern und Erziehungswissenschaftlern überlassen. Wir müssen ihnen vielmehr erklären, worauf es aus unserer Sicht der Dinge beim Staatsbürgerkunde-Unterricht ankommt. Daß bei ihm einiges im argen liegt, wird klar, wenn man sich vor Augen hält, daß unsere Kinder zwar mit 18 Jahren wahlmündig werden, daß aber die wenigsten von ihnen in der Schule lernen, was es mit der "Zweitstimme“ wirklich auf sich hat, und deshalb allzu leicht auf die politischen Roßtäuscher hereinfallen, die ihnen weismachen, die Zweitstimme sei eine Art politisches Almosen, mit dem man Splitterparteien glücklich machen und Minderheitenforderung betreiben könne, ohne den Parteien, die man wirklich wählen möchte, etwas vorzuenthalten. Diesen und die vielen anderen bei den jungen Wählern grassierenden Irrtümer und Fehlvorstellungen zurechtzurücken, halte ich für sehr viel dringlicher als die von Herrn Bothe beschworene Einübung multikultureller Lebensformen, an denen es ja an unseren Gymnasien nicht gerade fehlt, solange sie noch einen ordentlichen Englisch- und Französischunterricht erteilen.

Für noch wichtiger als unser Mitwirken bei der Definition dessen, was im Staatsbürgerkunde-Unterricht gelehrt werden muß, halte ich allerdings, daß die Staatsrechtslehre den staatsbürgerkundlichen Bildungsund Erziehungsauftrag der Schule verfassungstheoretisch gründlicher untermauert, als sie das bislang getan hat. Denn mit der staatsbürgerlichen Bildung der Jugend stehen und fallen die Demokratie und das Prinzip der Volkssouveränität. Die Monarchie beschäftigte Prinzenerzieher, um dem Souverän beizubringen, wie mit der Staatsgewalt umzugehen ist. Mit dem Übergang der Staatsgewalt vom Monarchen auf das Volk ist die Einübung des Souveräns in den Umgang mit ihr vom Prinzenerzieher auf die Volksschule übergegangen. Ich fürchte nur, die Volksschule hat das noch nicht gemerkt. Drum liegt es bei unserer Vereinigung, sie unablässig darauf hinzuweisen, daß das demokratische Volk in seinen Schulen neben Schreiben, Lesen und Rechnen auch lernen muß, wie der Staat funktioniert, dessen Souverän es ist. Ich hätte mir gewünscht, daß davon in den beiden Referaten mehr die Rede gewesen wäre. Denn es geht bei unseren Schülern und Abiturienten zu viel staatsbürgerlicher Unverstand um. Wie dem abzuhelfen ist, mag das Thema der Erziehungswissenschaftler sein. $D a \beta$ dem abgeholfen werden muß, und daß vor allen Dingen dies der eigentliche Auftrag der Verfassung an die Schulen ist, bleibt unser Thema. Wir machen uns einer Unterlassungssünde schuldig, wenn wir uns dazu verschweigen. 
Eckart Klein: Ich möchte anknüpfen an einen Begriff, der in den Referaten, auch in den Thesen von Herrn Bothe häufiger vorkam, den Begriff der Enttraditionalisierung. Wenn das ein beschreibender Begriff ist, ein Begriff eines faktisch existierenden, „real existierenden "Phänomens, dann ist dem sicher nichts entgegenzusetzen. Ich frage mich nur, ob aus dieser Beobachtung wirklich die weitgehenden Konsequenzen gezogen werden müssen, die Herr Bothe gezogen hat in seiner These 6, wo er sagt, daß das Erziehungswesen nicht kann und nicht darf die Entwicklung der Enttraditionalisierung und Individualisierung rückgängig machen. In ähnlicher Weise vielleicht hat auch Herr Dittmann in seiner These 14 gemeint, daß die Schule letztlich nur die Wertvorstellungen vermitteln kann, die auch außerschulisch von einem gesellschaftlichen Konsens getragen werden. Ich frage mich, ob diese Betrachtungsweise nicht zu resignativ ist. Wozu brauchen wir, um das einmal zugespitzt zu formulieren, eine Schule, die nur das reproduziert, was außerschulisch schon da ist. Ich meine, auch von den verfassungsrechtlichen Vorgaben her, sollte die Schule doch gerade die Möglichkeit darstellen, gewissen Tendenzen gegenzusteuern, außerschulischen Entwicklungen gegenzusteuern, die zu erkannt negativen Folgen führen. Herr Bothe hat sie in seiner These 5 ausdrücklich benannt. Aber dann genügt es doch nicht, sich einfach mit diesem Befund zufriedenzugeben und vielleicht an Symptomen zu kurieren statt die Sache selbst wieder in das Zentrum zu rücken, aus der diese negativen Folgen entstanden sind. Gerade gegen den Zeitgeist zu erziehen, bringt ja dazu, daß den Schülern Zivilcourage beigebracht werden kann. Also nicht dem, was ohnehin in der Gesellschaft gang und gäbe ist, einfach nachzujagen. Lassen Sie mich nur an drei kleinen Beispielen sagen, wie aus meiner Sicht es wichtig gewesen wäre, in der Vergangenheit oder auch gegenwärtig dem Zeitgeist etwas entgegenzutreten. Als es zur Wiedervereinigung kam, waren unsere Schüler überhaupt nicht auf diese Entwicklung vorbereitet. Nicht nur die Schüler übrigens, sondern viele andere auch. Für die Schüler war dieser Teil Deutschlands ein unbeschriebenes Blatt. Ich hätte einmal den Abiturienten fragen wollen, ob er wisse, wo Chemnitz liegt oder was Mecklenburg-Vorpommern ist; da war nichts da. Hier wäre es sinnvoll gewesen, gegen den Zeitgeist in den Schulen zu steuern, aber es war natürlich viel einfacher, mit dem Zeitgeist zu rennen. Oder auch zweitens, wenn ich aus den Schulen höre, von meinen Kindern habe ich das erfahren, daß dort in dem Unterricht zur Kriegsdienstverweigerung aufgefordert wird, anstatt deutlich zu machen, was zunächst einmal die primäre Grundpflicht ist, dann frage ich mich auch, ob es hier nicht wichtiger wäre, gegen den Zeitgeist vorzugehen, wobei ich allerdings angesichts der neueren Rechtsprechung des Bundesverfassungsgerichts zur möglichen Qualifizierung des Soldaten- 
berufs zugebe, daß es Lehrern schwergemacht wird, hierzu ein positives Wort zu finden. Und darüber hinaus sollte in den Schulen insgesamt Verantwortung und Verantwortungsbereitschaft geweckt werden. Individualismus, der wird in der Gesellschaft ohnehin gepredigt und liegt sozusagen zutage. Aber daß man privat Konsequenzen aus irgendwelchen verantwortungsvollen Positionen zieht, das wird eigentlich nicht vermittelt. Ich frage mich, was wir mit diesem nichtverarbeiteten Befund der Enttraditionalisierung gerade etwa auch den neuen Ländern zum Aufbau ihres Schul- und Erziehungswesens bieten können. Es mag ja sein, daß es hier pädagogisch-praktische Schwierigkeiten gibt, Herr Dittmann hat dieses Wort geprägt, aber ich meine, Schwierigkeiten sind eigentlich dazu $\mathrm{da}$, überwunden zu werden.

Ein letztes Wort noch oder eine Frage zur Multikulturalität. Herr Bothe, Sie haben die Grundlage benannt in Toleranz, Pluralismus, Menschenwürde, Europabewußtsein, Völkerverständigung. Ist Multikulturalität nur die Synthese alles dessen, was Sie hier benannt haben? Dann würde ich eher raten, diesen Begriff zu vermeiden, weil es ja nun doch ein Reizwort ist, dann reichen die anderen Begriffe völlig aus. Wenn er aber etwas anderes sein soll, etwas darüber Hinausreichendes, dann ist er nicht definiert worden. Dankeschön.

Fromont: Herr Vorsitzender, meine Damen und Herren, ich möchte zuerst eine kurze Bemerkung zur Juridifizierung der Erziehungsziele machen, ich frage mich, ob detaillierte Bestimmungen zur Kultur und Erziehung in die Verfassung eingebracht werden können: aus juristischer Sicht haben solche Verfassungsbestimmungen in der Regel nur programmatische und keine bindende Kraft. In Frankreich zum Beispiel hat das Gesetz vom 25. Juni 1992 in den Artikel 2 der Verfassung die folgende Bestimmung eingefügt: „Die Sprache der Republik ist die französische Sprache“. Mit Recht, meines Erachtens, haben die Franzosen diese Verfassungsergänzung nicht ernst genommen, weil sie zu keiner konkreten Rechtsänderung führen konnte. Gerade wurden vielen Bestimmungen des neuen Gesetzes zur Benutzung der französischen Sprache durch den Conseil constitutionell am 29. 7. 1994 als verfassungswidrig erklärt, soweit sie gegen die Kommunikationsfreiheit im allgemeinen und die Freiheit auf dem Gebiet der Forschung und Lehre im besonderen verstoßen. Im Deutschland kann man teilweise dieselbe Erscheinung beobachten. Die Referenten haben festgestellt, daß die Verfassungen der Bundesländer die Erziehungsziele ganz verschieden festgesetzt haben. In dieser Hinsicht gibt es drei Arten von Verfassungen: diejenigen, die überhaupt darüber schweigen, diejenigen, die der Erziehung eine eindeutig christliche Richtung vorzeigen, und diejenigen, die eine etwas neutrale Färbung 
haben. Nun stelle ich den Referenten folgende Frage: entsprechen den verschiedenartigen Verfassungsbestimmungen effektiv Unterschiede in der Gesetzgebung und der Praxis? An der Wirkung von Verfassungsvorschriften auf die juristische Gestaltung der Erziehung hege ich persönlich Zweifel.

Nun komme ich zur zweiten Bemerkung: sie betrifft die multikulturelle Gesellschaft. Wie Herr Referent Bothe schon gesagt hat, haben die Franzosen mit dem sogenannten islamischen Kopftuch viele Sorgen, weil mehrere Prinzipien gegeneinander stoßen, nämlich der Laïismus (Art. 2 der Verfassung) gegen die Meinungsfreiheit (Art. 9 der Menschenrechtserklärung) der Eltern und der Kinder. Aber dahinter stellt sich ein noch schwierigeres Problem, auf das schon hingewiesen wurde, nämlich die integrative Funktion der Schule. Die Schule hat die nationale Kultur zu übermitteln, insbesondere die Beachtung der Gleichheit von Mann und Frau. Nun ist das Tragen des islamischen Kopftuchs das eindeutige Zeichen der Ungleichheit zwischen Mann und Frau. Wenn es in den französischen Schulen toleriert wird, dann wird die ungleiche Behandlung von Mädchen und Jungen in vielen Familien, deren Mitglieder oft die französische Staatsangehörigkeit haben, toleriert. So besteht ein Konflikt zwischen der Erziehungsaufgabe des Staates und der Meinungsfreiheit der Familie. Hinzu kommt, daß die betroffenen Familien oft zerstritten sind: öfters will das Mädchen kein Tuch tragen, aber der Vater will es erzwingen. Eine Lösung zu finden ist nicht einfach. Der Conseil d'Etat hat am 2. 11.1992 sehr vorsichtig entschieden, daß die Rechtmäßigkeit des Verbots des Tragens des Kopftuchs von den lokalen und zeitlichen Bedingungen abhängt. Diese Entscheidung ist richtig: Das ist kein rein juristisches Problem, das der Richter lösen kann; es ist auch ein politisches Problem, das vom Gesetzgeber und von der Exekutive zu lösen ist.

Kühne: Zunächst noch außerhalb der Redezeitbeschränkung die Frage an die Veranstalter, ob es nicht bei diesem spezifischen Thema angezeigt gewesen wäre, die hiesige Saalgalerie für die Teilnehmerinnen des Beiprogramms freizugeben. Sie erziehen doch kräftig mit und im Zweifel mehr als wir. - Dann zu Herrn Botbes These 13 betr. Symbolwirkung der Erziehungsziele. Das war m. E. etwas zu wenig; hier wäre etwas tiefer auszuholen gewesen. Bei vollem Griff über Art. 148 WRV hinaus in den verfassungsgeschichtlichen Hintergrund zeigen sich die Erziehungsziele in der Traditionslinie republikanischer Tugendlehren, die am Beginn des Verfassungsstaates im angelsächsischen Bereich vorhanden sind. Sie sind sozusagen Geschäftsgrundlage für den modernen Verfassungsstaat. Wenn derartige Ziele bei uns anders als in den USA oder in England verfassungsnormiert sind, so zeigt das weiter, daß die hiesigen Verfassungs- 
geber keineswegs von Selbstverständlichkeit ausgingen. Es ist mit anderen Worten ein Stück Verzweiflung über den Untergang der Weimarer Verfassung, ein Stück nach haltigen Durchsetzenwollens darin, d. h. mehr als lediglich Symbolwirkung. - Im übrigen stellt sich vor diesem Hintergrund auch die Frage, wie die in beiden Referaten wenig angesprochene Adressatenfrage abzuklären ist. Extensiv werden die Medien mit erfaßt, restriktiv bezieht sich das nur auf Schule und Schüler und darüber hinaus ist Schluß bzw. greift die Selbsterziehung. Insoweit war es eine gute Begriffsbildung, die sicher Konjunktur machen wird, daß Sie, Herr Dittmann, neben die, wehrhafte Demokratie' auch die ,lehrhafte Demokratie 'gestellt haben. Denn es geht hier in der Tat um so etwas wie eine von den Verfassunggebern intendierte stete Verfassungsentstehungssicherung.

Herr Bothe, hinsichtlich Ihrer These 28 betr. multikulturelle Erziehung haben Sie sich nicht weiter zur Sprachenfrage geäußert. In den Verfassungen der neuen Bundesländer werden zum Teil bereits der Schutz der Kulturen genannt und mit der gescheiterten Grundgesetzergänzung durch Art. $20 \mathrm{~b}$ war ebenfalls eine Minderheitenschutzbestimmung angedacht. Wie soll diese kulturensichernde, minderheitensichernde Schule aussehen? Ich meine, es geht nur nach dem Schweizer Modell, das Herr Harngartner dankenswerterweise nutzbringend aufgezeigt hat. Die Staatssprache muß führen und daneben kann auch die Sprache der jeweiligen Kultur gebraucht werden, alles andere ist kaum administrierbar. Die Schweiz ist uns da nicht nur aufgrund ihrer besonderen sprachlichen $\mathrm{Ge}-$ fügtheit voraus, sondern auch aufgrund höheren Ausländeranteils. So hat die Züricher Kultusadministration beispielsweise eine dortige Schule mit 100 Schweizer und 300 Ausländer-Kindern aus 90 Nationen mangels externer Regelbarkeit praktisch zur autonomen Schule erklärt.

Dann zur These 4 b von Herrn Dittmann. Zwar hält sich das Grundgesetz, wie Sie mit Recht sagen, hinsichtlich des Erziehungsauftrags zurück. Doch hätte als ein Element dieses Auftrags die gemäßigte Einheitsschule (zuletzt BVerwGE 89, 368/377) stärker herausgestellt werden können. Dieser Aspekt betrifft unter sozialem Vorzeichen einmal die Zusammenfassung aller Schichten in einer Schule; insofern wäre etwa Skepsis gegenüber Privatschulausweitungen angezeigt, weil dort statistisch weniger ausländische und Unterschicht-Kinder unterrichtet werden. Im übrigen wäre der gemäßigte Einheitsschulgedanke auch unter politischem Vorzeichen stärker entfaltbar gewesen. - Schließlich zu ihrer These 5, d. h. Gottesbezug und Religionsunterricht, was auch den multikulturellen Bereich berührt. Dazu nur soviel, daß sich am Beginn des modernen Verfassungsstaats der Gottesbezug sowohl in der amerikanischen Unabhängigkeitserklärung als dortiger Vorverfassung findet wie in 
der französischen Menschen- und Bürgerrechtserklärung mit der freilich sehr deistischen Formel des ,Etre suprème ${ }^{c}$ - Zum Religionsunterricht konkret die Frage, wie wir uns auf Dauer zu verhalten haben bei zunehmender religiöser Pluralisierung. In den Landesschulgesetzen gibt es bereits den Religionsunterricht für Minderheiten, aber noch ist er großkirchlich bestimmt. Was aber, wenn islamische, buddhistische und sektenangehörige Kinder weiter zunehmen, könnten wir dann den Religionsunterricht in der Schule noch durchhalten? Vielen Dank.

Fiedler: Herr Vorsitzender, angesichts der fortgeschrittenen Zeit nur eine kurze Bemerkung und Frage an Herrn Bothe. Ich war zunächst außerordentlich erfreut über das weite Öffnen der Tür unseres Diskussionsfeldes zu dem gesamten internationalen Bereich, und nicht nur Europa spielt eine Rolle. Aber es stellte sich alsbald heraus, daß an diesem Punkte der Freude sofort die Fragen beginnen. Nämlich die Frage, wie Begriffe des internationalen Rechts in einen Verfassungszusammenhang überführt werden können, der zu einer praktikablen, umsetzbaren verfassungsrechtlichen Lösung führen kann. Und hier beginnen in der Tat die Probleme, insbesondere wenn ich Ihre Thesen 8 und 30 betrachte. In These 8 taucht zum Beispiel das Erziehungsziel „Erziehung zum Frieden“ auf und dasselbe in der These 30: „Bereitschaft zum Frieden“. Ich habe mich unwillkürlich gefragt, welcher Friedensbegriff dies eigentlich sei. Ist es ein allgemein politischer Begriff oder ein mehr theologisch-moralischer oder gar ein juristischer Begriff. Wenn es ein juristischer Begriff ist, könnte es der Friedensbegriff sein, den wir etwa aus der Satzung der Vereinten Nationen oder aus vergleichbaren Bereichen kennen. Ist überhaupt ein rechtlich durchgestalteter Begriff gemeint? Wenn wir aber rechtlich so weit gehen, taucht auch das Problem des Selbstverteidigungsrechtes und der Selbsterhaltung auf. Umgesetzt auf unser Problem könnte man fragen, wo Toleranz und Aufgeschlossenheit möglicherweise eine Grenze haben. Etwa zur Verteidigung gerade Ihres pluralistischen Systems gegen aggressiv-fundamentalistische missionarische Tätigkeiten in verschiedenen Variationen. Diese Fragen wären jedenfalls dann zu stellen, wenn es überhaupt um einen irgendwie rechtlich gemeinten Begriff ginge. Wenn aber kein rechtlich gemeinter Begriff vorliegt, dann fragt man sich, was er eigentlich soll. Das gleiche gilt für die Formulierung der internationalen Solidarität, die Sie in der These 8 erwähnt haben. Was sind dies für Begriffe? Ich meine, sie zeichnen sich, so allgemein verwendet, durch eine große Multifunktionalität aus. Denn sie sind für verschiedene Inhalte ein sehr naheliegendes Etikett, und deshalb sollte man Begriffe, die aus dem internationalen Bereich stammen, nur mit einer entsprechenden Präzisierung verwenden, weil sonst die verfas- 
sungsrechtliche Umsetzung nicht möglich ist. Man muß auch wissen, was "Friedenserziehung" ist, denn man könnte auf die Idee kommen, es sei so etwas wie ein „Rotlichtkurs“ der früheren DDR im Sinne einer staatlichen Pflichtveranstaltung gemeint. An eine solche Veranstaltung war natürlich nicht gedacht. Aber, wie gesagt, die Verfassung ist angewiesen auf klare Begriffsinhalte, wenn sie denn funktionieren soll. Vielen Dank.

Selmer: Angesichts des Verlustes meiner Meldekarte, Herr Vorsitzender, hinke ich etwa hinterher und wiederhole wohl auch das eine oder andere. Aber auch Wiederholungen sind ja geeignet, die Konturen zu schärfen, die die Diskussion zwischenzeitlich gewonnen hat. Herr Bothe, Sie haben der Schule eine Schlüsselfunktion im gesellschaftlichen System zugewiesen. Das trifft gewiß zu. Entsprechendes auch von der tatsächlichen schulischen Erziehung zu sagen, erschiene indes unrichtig. Überzogen gesprochen: Eine Erziehung findet in weiten Bereichen des Schulwesens nicht statt. Ganz andere Kräfte, dies ist auch hier gelegentlich zum Ausdruck gekommen, wie Massenmedien, allgemeiner Zeitgeist und persönliches Umfeld sind es, die prägend auf die Jugend einwirken. Hinter diese Kräfte tritt die Schule deutlich in den Hintergrund, wenn sie nicht sogar zur Stätte ungewollter Verstärkung jener Kräfte wird. Nimmt man dies alles, so sind wir hier gelegentlich von einer Geisterdiskussion nicht weit entfernt. Das ändert freilich nichts an der Berechtigung der Themenwahl. Der reale Befund der schulischen Erziehung darf uns gewiß nicht davon abhalten, die Verfassung auf ihre Aussagekraft für den schulischen Erziehungsauftrag abzuklopfen. Hier nun, Herr Bothe, vermag ich Ihrer These nicht beizupflichten, das staatliche Erziehungswesen könne und dürfe nicht die von Ihnen mit Recht registrierte Individualisierung und Enttraditionalisierung - wofür man wohl auch „Entfamiliarisierung“ setzen könnte - rückgängig machen. Und ähnliches, Herr Dittmann, kommt auch, wenngleich sehr viel behutsamer, bei Ihnen zum Ausdruck, wenn Sie davon sprechen, daß sich in der Schule nur die Wertvorstellungen vermitteln lassen, die auch außerschulisch von einem gesellschaftlichen Konsens getragen werden. Natürlich kann die Schule das Rad einer breiten tatsächlichen Entwicklung nicht zurückdrehen. Aber sollte sie dies nicht dort jedenfalls versuchen, wo die Entwicklung mit guten Gründen für fatal gehalten wird? Auch Sie, Herr Bothe, tun dies nachdrücklich, wie Ihrem Leitsatz $5 \mathrm{zu}$ entnehmen ist, ziehen aber hieraus nachfolgend keinerlei Schlußfolgerungen, sondern geben insoweit resignierend der gesellschaftlichen Entwicklung das letzte Wort. Ihr zusammenfassender Satz vom Staat als erstem Diener der Gesellschaft war nicht eben dazu angetan, das daraus resultierende Unbehagen zu mildern, versteht man ihn so, daß der schulische Erziehungsauftrag stets der tatsäch- 
lichen gesellschaftlichen Entwicklung zu folgen habe. Er steht zudem in einem gewissen Widerspruch zu Ihrer eigenen These 9, die den staatlichen Erziehungsauftrag mit Recht u. a. auch aus grundrechtlichen Schutzpflichten ableitet, damit aber doch wohl auch aus Art. 6 I G. Der Schutz der Familie als Positivposten des staatlichen Eriehungsauftrags tritt indes in Ihrem Bericht, Herr Bothe, in substantieller Weise nicht in Erscheinung. Das gilt in abgemildeter Form auch für Sie, Herr Dittmann. Denn wohl gestehen Sie den Verfassungsprinzipien des Grundgesetzes den Stellenwert legitimer möglicher Maßstäbe für den Erziehungsauftrag zu. Nicht nur verweigern Sie ihnen aber - und so also auch dem besonderen Schutz der Familie - verbindliche Aussagekraft für diesen Auftrag. Sie relativieren sie ferner dadurch, daß Sie die Orientierungswerte des Grundgesetzes zur ausfüllenden Disposition der Länder stellen, womit im Ergebnis auch die von Ihnen registrierte gleichmäßige Wahrung von föderativer Vielfalt und gesamtstaatlicher Einheit der Erziehungsziele schwerlich noch als gesichert erscheint.

Küchenhoff: An ihre Zeitvorgabe, Herr Vorsitzender, werde ich mich nicht halten, weil ich die allererste Wortmeldung abgegeben habe und jetzt erst drankomme. Aber dafür bedanke ich mich andererseits auch wieder, weil ich auf diese Weise zum Beispiel auf meinen Vorvorredner Bezug nehmen und ihn fragen kann, ob er denn bei seiner Plazierung des Friedensbegriffs nur im internationalen Recht diesen Begriff in Art. 1 und 9 und der Präambel des Grundgesetzes übersehen hat. Dann wollte ich etwas sagen zur Multikulturalität und Einwanderung: nur ein Hinweis auf den Deutschen Juristentag 1980 Ausländerrechtliche Abteilung unter dem Thema „Die Bundesrepublik ein Einwanderungsland?“. Der damalige Referent, Herr Kollege Schwerdtfeger, fragte den Vorsitzenden $\mathrm{Hel}-$ mut Simon: das Fragezeichen ist doch wohl nur rhetorisch gemeint? Das weitere dazu dann Gesagte ist nachzulesen in dem ja glücklicherweise ebenso wie bei uns Wortprotokoll. Meine Hauptmeldung aber betraf das, was Herr Häberle dann aufgenommen hat, als seinen wichtigsten Beitrag wie ich meine, nämlich diese Gedanken eines neuen Staats- und Erziehungsziels Mitmenschlichkeit und Gemeinsinn. Ich kann dazu etwas beitragen aus der Entstehungsgeschichte in der Gemeinsamen Verfassungskommission, aber auch den ergänzenden Hinweis, daß das, was Herr $H \ddot{a}-$ berle vorgeschlagen hat, doch statt eines Art. 2 a oder 20 a die Präambel als Ort einer solchen Regelung vorzusehen, schon geschehen ist: in den Beratungen der Empfehlungen der Gemeinsamen Verfassungskommission im Bundestag hat es verschiedene Plazierungsvorschläge gegeben, die dann im Ergebnis alle abgelehnt worden sind. Nur: Das Wichtigste, was die Gewichtigkeit dieses Vorschlages unterstreicht, ist, daß das nicht 
etwa eine Initiative war einer der politischen Kräfte, die das politische Leben bestimmen und auch die Zusammensetzung der Gemeinsamen Verfassungskommission, sondern es war die ganz persönliche Initiative eines einzelnen, nämlich des Ostberliner Bundestagsabgeordneten Pfarrer Konrad Elmer, die schließlich von fast zwei Dritteln der GVK interfraktionell unterschrieben worden ist. Diese Initiative entstand aus denselben elementaren Empfindungen über Defizite in der Verwirklichung des verfassungsrechtlichen Grundkonsenses von 1789, des Konsenses auch über Brüderlichkeit, selbständig neben Freiheit und Gleichheit, nicht, Herr Schachtschneider, über das Sittengesetz bloß als Grenze für die Freiheiten, sondern als selbständiger Wert neben Freiheit und Gleichheit. Sie entstand aus denselben Empfindungen, die ich herausgehört habe aus dem, was uns gestern der Rektor mit seinem Stichwort vom kalten Hauch der Freiheit sagen wollte und was der Oberbürgermeister zu den dazugehörenden Belegen in Gestalt der Defizite an sozialer Gerechtigkeit, also an Sozialstaatlichkeit, dann uns gesagt hat. Insbesondere in den Bereichen Arbeitslosigkeit und Wohnungsnot mit aller unmenschlichen Rücksichtslosigkeit, die hier die soziale Wirklichkeit und damit die Verfassungswirklichkeit bestimmt. Meine Information ist aber auch noch erforderlich darüber, wie es nun zu diesen Ausdrücken gekommen ist. Das ist ja nirgends nachzulesen: Mitmenschlichkeit an die Stelle des Originals Brüderlichkeit sollte nun vermeiden, etwa geschlechtsübergreifend modernisiert von Geschwisterlichkeit zu reden. Die Aufnahme von Gemeinsinn war, das halte ich nun für eine auch politisch, Herr Vorsitzender, unbedingt wichtige Information, der Vorschlag "Gemeinsinn“ war die Unterschriftsbedingung des Vorsitzenden des Rechtsausschusses Heymann und als das Ganze scheiterte, dann obwohl fast zwei Drittel unterschrieben hatten, am Nichterreichen der Zweidrittelmehrheit, wurde es im Vermittlungsausschuß am 1. September nochmals aufgegriffen, und zwar auf Initiative des früheren Rechtsausschußvorsitzenden Helmrich jetzt Justizminister von Mecklenburg-Vorpommern, ich wollte nur diese Interfraktionalität des Anliegens nochmals besonders hier bekanntgeben. Danke.

Pitschas: Herr Vorsitzender, meine Damen und Herren. Der Schulpraxis werden wir heute Steine statt Brot gegeben haben. Ich bin überzeugt davon, daß weder ein Lehrer noch ein Sozialarbeiter in einem Jugendfreizeitheim oder ein Erzieher in einer anderen Einrichtung mit den Ausführungen der Referenten etwas anfangen können werden. Drei Fragen sollen deshalb näher zur Problematik führen. Die erste Frage ist, ob wir eigentlich eine zutreffende Konfliktanalyse vorliegen haben. Zwei Feststellungen dazu: 
Sehen wir zunächst und mit vergleichendem empirischen Blick auf die amerikanischen Schulkonflikte, so müssen wir feststellen, daß wir eigentlich die reale Lage, die tatsächliche Situation der Akteure in den deutschen Schulen heute nicht mit der empirischen Analyse in den Referaten erfaßt haben. Eine zweite Bemerkung: Blicken wir auf die vielen Familien, die in äußerster Anstrengung ihrer Erziehungsauftrag wahrnehmen, dann irritierten in den Referaten, vor allem bei Herrn Bothe, die ausschließlichen Katastrophenmeldungen. Einer differenzierteren empirischen Schulanalyse könnten wir entnehmen, daß viele Familien bemüht sind, eigene Erziehungsansätze gegen oder mit den Schulen durchzusetzen und nicht nur Horrorszenarien existieren.

Eine zweite Frage oder Bemerkung sei sogleich angefügt. Haben wir unsere Erziehungsmaßstäbe daraufhin ausreichend geprüft, wie im Wechselspiel mit der Schule andere Institutionen eigene Leitbilder der Erziehung setzen und deren Maßstäbe verändern? Dem Sozialrechtler ist klar, was damit gemeint ist, nämlich der maßstabsetzende Einfluß der Erziehung im institutionellen Bereich des Kinder- und Jugendhilferechts. Die Arbeit in den Heimen oder in der Jugendhilfe schlechthin, der Jugendarbeiter oder Sozialarbeiter dort steht in einem Wechselverhältnis mit den schulischen Konfliktlagen und deren Bearbeitung durch die Lehrer. Aus diesem Wechselverhältnis ersprießen genuine Maßstäbe für die Schule.

Wie nun werden diese Maßstäbe angewandt? Wer etwa auf eine Großstadt wie Berlin guckt und sieht, wie etwa die Schulen in Kreuzberg bei multikulturellen Konflikten mit den Jugendinstitutionen zusammenarbeiten, gewinnt erst ein Bild davon, wie Verfassungsrecht plastisch (und praxisnah) entfaltet werden müßte. Herr Dittmann hat in seiner These 14 diese Frage unter dem Gesichtspunkt des „Konsenses“ aufgegriffen. Ich meine dazu, wir dürfen bei ihr nicht stehenbleiben, sondern wir müssen in der Antwort weitergehen und sagen, wie wir uns Konsensverwirklichung und dann soziale Integration mit einer verteilten Integrationsverantwortung von Schule, Eltern und anderen Erziehern vorstellen. Auf wessen Schultern lastet sie? Und dann müssen wir aus der wirklichkeitsbezogenen Konfliktanalyse erstens zur Kenntnis nehmen, daß die Eltern, die Integrationsprobleme nicht ertragen können oder wollen, ihren $\mathrm{Er}$ ziehungsauftrag behindert sehen, aus den staatlichen Schulen ausziehen. Sie wechseln mit ihren Kindern auf Privatschulen mit der Konsequenz, daß wir ein segregiertes staatliches Schulwesen bekommen. Von hier aus, so denke ich, müßten wir eigentlich - und zweitens - eine verfassungskonkretisierende Dogmatik entwickeln. Sie hätte Lösungen anzubieten zur konfliktsteuernden Binnenorganisation der Schule, zu Verfahren der Konfliktschlichtung, zum Umgang mit den aus der Glaubensverschie- 
denheit vieler Schüler (Islam!) hervorgehenden Alltagsproblemen. Deren konkrete Bereinigung wird drittens und letztlich dann der Richter zu entscheiden haben - ein Vorgang, den wir heute auch nicht näher diskutiert haben.

Stettner: Meine Damen und Herren. Wer so spät drankommt wie ich und andere Kollegen, steht unter einem doppelten Zwang: nämlich einmal etwas Neues sagen zu müssen und das noch, wie der Herr Vorsitzende formuliert, in der "gebotenen Kürze“. Ich hoffe, daß ich beidem gerecht werden kann. Ich darf nochmals Herrn Mantl, unter Umständen heute zum letzten Mal, zitieren mit dem Wort von der Verfassungslakonie oder dem Verfassungslakonismus. Das Problem ist doch: Wie bekomme ich die Verfassung zum Sprechen, und die offene Gesellschaft der Verfassungsinterpreten, die heute auch schon einige Male angesprochen wurde, wird hier berufen. Hier darf ich Sie auf folgendes hinweisen, meine Damen und Herren. Ich bin erstaunt, daß es bisher nicht geschehen ist. Wir haben Verfassungen, wir haben Erziehungsziele in den Verfassungen, wir haben Erziehungsgesetze, die diese realisieren sollen, und damit kommen wir in den Bereich der Verwaltung. Wir haben auch die pädagogische Provinz der erziehungswissenschaftlichen Fakultäten angesprochen, aber was vergessen wurde, sind doch die Ministerialbürokratien und die über diese sich realisierenden politischen Einflüsse. Und ich möchte mir an dieser Stelle doch eine kleine Bosheit dem Herrn Erstreferenten gegenüber nicht verkneifen, der ja aus Hessen kommt, und ihn darauf hinweisen, daß die Hessischen Rahmenrichtlinien der Siebzigerjahre immerhin die Erziehung zum bewußten Konflikt institutionalisiert haben. Als Erziehung zur Zivilcourage lasse ich mir das noch eingehen ich würde das dann aber auch anders nennen - aber wenn damit der $\mathrm{Wi}_{\mathrm{i}}$ derstand gegen eine legitimierte Staatsgewalt gemeint gewesen sein sollte, dann ist das absolut unzulässig. Also die Ministerialbürokratien, die Politik, wir dürfen sie nicht vergessen als Staatsrechtslehrer, diese Einflüsse aus diesem Bereich. Weiterhin glaube ich, muß man noch darauf hinweisen, daß sich die Realisierung der Erziehungsziele durch die schulischen Instanzen - wobei der Schulleiter, die Schulkonferenz heute auch nicht angesprochen wurden -, in einem Wechselspiel mit den zum Teil gegenläufigen Vorstellungen der Eltern, die auch institutionalisierte und nichtinstitutionalisierte Mitsprachemöglichkeiten haben, vollzieht und darüber hinaus natürlich auch im Dialog mit den Schülern, die heute auch sehr wenig drangekommen sind. Also hier, glaube ich, gibt es noch einige Dinge, die zu hinterfragen wären. Eines noch, Herr Bothe: als bayrischer Professor muß ich die Säuglingspflege auch kurz erwähnen; ohne sie gelernt zu haben, habe ich sie praktiziert. Nur soviel sei aber gesagt: wenn 
dieses Erziehungsziel im Jahre 1946 in eine Verfassung hineingeschrieben wurde, dann ist das im Einklang mit der damals praktizierten Rollenverteilung in der Gesellschaft geschehen, und man wird doch vom Staat nicht verlangen wollen, daß er die gesellschaftlichen Vorstellungen umbaut, radikalisiert. Es mag sein, daß im Verlauf der Entwicklung das gesellschaftliche Substrat entfallen ist. Dann haben wir aber einen Fall des Verfassungswandels vor uns und nicht eine Verfassungswidrigkeit ab origine. Vielen Dank.

Gröschner: $\mathrm{Da}$ die Zeit drängt, nur zwei wirklich kurze Bemerkungen. Zunähst zu den Leitsätzen 7 und 24 von Herrn Bothe. Dort ist nach meinem Eindruck der Grundbegriff des gesamten Referates enthalten, nämlich der Begriff des „sinnvollen Lebensentwurfs“. Wenn das rhetorisch kein Pleonasmus sein soll, logisch keine Tautologie - denn jeder Entwurf ist subjektiv ja sinnvoll -, dann muß das Adjektiv sinnvoll die objektive Eigenschaft eines je eigenen Entwurfs bezeichnen. Nach der Menschenwürdekonzeption des Grundgesetzes ist aber die Antwort auf die Sinnfrage des Lebens eine unentrinnbar subjektive Aufgabe. Deshalb ist mir das Verhältnis der beiden Bestandteile des Begriffs „sinnvoller Lebensentwurf" nicht klargeworden. Die zweite Bemerkung betrifft Herrn Dittmanns Hinweis auf die - ich darf zitieren - „hohe pädagogische und philosophische Aufladung der Begriffe" im Bereich unseres Themas. In dem Zusammenhang wurde als Philosoph im engeren Sinne nur Fichte genannt. Gerade als Neujenenser möchte ich hier zu großer philosophischer Sorgfalt, aber auch Vorsicht mahnen. Fichtes Nationalismus ist nicht nur pädagogisch und politisch gefährlich, sondern philosophisch auch so schwach begründet, daß wir uns nicht darauf berufen sollten; jedenfalls nicht ohne Kommentar. Danke.

Engel: Beide Referenten haben die Privatschulfreiheit des Art. 7 IV GG sehr restriktiv ausgelegt. Ich frage mich, ob dazu Anlaß besteht. Diese Zurückhaltung könnte erforderlich sein, weil zwei Besorgnisse im Raum stehen. Das erste Besorgnis ist, daß die vom Staat legitimerweise verfolgten Erziehungsziele gefährdet würden, wenn Privatschulen größeren Raum hätten. Im ersten Zugriff scheint dieses Bedenken schnell auszuräumen, denn Art. 7 I GG gestattet dem Staat ja, sowohl die Lehrinhalte wie die Lehrmittel festzulegen. Nun haben wir aber heute immer wieder und völlig zu Recht gehört, daß es Umsetzungsdefizite gibt, daß es also sehr schwer ist, diese Ziele juristisch so dingfest zu machen, daß sie hinterher auch in der Schulpraxis ankommen. Ist also vielleicht dieses Umsetzungsdefizit ein ausreichender Grund dafür, die Schulen im wesentlichen vom Staat veranstalten zu lassen? Man kann auf zwei Weisen 
reagieren. Die eine Möglichkeit ist, daß man nicht an der einzelnen Erziehungshandlung ansetzt, sondern an den Personen, die erziehen. Insoweit ist aber bei Privatschulen die Einwirkungsmöglichkeit genau so groß wie bei offentlichen Schulen: Wir haben eine staatlich regulierte Lehrerausbildung, wir prüfen ihren Erfolg in einem Staatsexamen ab und wir können bei den Privatschulen verlangen, daß sie nur solche Lehrer beschäftigen, die in dieser Weise examiniert sind. Es bleibt aber ein zweiter Gesichtspunkt, der auf den ersten Blick überzeugend scheint. $\mathrm{Zu}$ den Grundeinsichten der Regulierungstheorie gehört, daß man dort, wo die Steuerungsfähligkeit des Außenrechts defizitär ist, statt dessen auf die Steuerung durch Organisation setzen muß. Wir müssen also Strukturen schaffen, in denen sich das Steuerungsziel gleichsam von selbst verwirklicht. Wenn wir nun aber auf die Wirklichkeit der öffentlichen Schulen schauen, so sehe ich nicht, wie diese Schulen in irgendeiner Weise imstande wären, Erziehungsziele, die der Staat abstrakt vorgibt, besser zu verwirklichen, als das in einer mit Regulierung versehenen privaten Schule der Fall sein könnte.

Der zweite Grund, weshalb man für öffentliche und gegen private Schulen plädieren könnte, ist die auch in der Verfassung niedergelegte Besorgnis, daß die soziale Schichtung der Schüler nach dem Einkommen der Eltern gefördert werden könnte. Zunächst ist das aber auch heute schon im staatlichen Schulwesen offensichtlich kein vorrangiges Ziel. Eltern, die die türkischen Klassenkameraden ihrer Kinder vermeiden wollen, schaffen das auch heute schon: Entweder, indem sie vom gegliederten Schulsystem Gebrauch manchen und ihr Kind eben aufs humanistische Gymnasium schicken, oder indem sie sich auf das Wohnsitzprinzip verlassen. Denn natürlich sind die Wohnorte der Kinder nicht zufällig, sondern setzen sich wiederum sozial zusammen. Um auch die letzten Bedenken auszuräumen, möchte ich einen Gegenvorschlag machen: Sollten wir nicht das viele Geld, das wir in die kostenlose staatliche Schulausbildung investieren, so einsetzen, daß nicht mehr die Schule als Institution das Geld bekommt, sondern daß jeder Schüler einen den abstrakten Kosten entsprechenden Betrag zur freien Verfügung bekommt und damit nach Wahl seiner Eltern sei es zur Privatschule oder zur öffentlichen Schule gehen kann. Dann ist auch das Problem der sozialen Schichtung beseitigt - und die Maßnahme ist sogar kostenneutral.

Bothe: Herr Vorsitzender! Angesichts der Kürze der verbleibenden Zeit kann ich nicht in der Weise auf die Diskussion eingehen, wie das eigentlich notwendig wäre. Darum nur einige wenige Punkte.

Ob die Lehrer den Anspruch, verfassungsgebotene Erziehungsziele zu vermitteln, verwirklichen können, ist in der Tat ein ganz wesentliches 
Problem. Die Motivationslage der Lehrerschaft ist nicht immer die beste, denn selbstverständlich sind auch die Lehrer Bestandteil dieser Gesellschaft, die unter den beschriebenen Krisenphänomenen leidet. Dafür gibt es kein Patentrezept. Ansätze bei der Lehrerbildung, das möchte ich nochmal betonen, sind wichtig. Ein Schulorganisationsmodell, das eine stärkere Kooperation ermöglicht, mag auch helfen. Aber da bleibt mehr offen, als mir selber lieb ist.

Ich komme jetzt zu meiner These 6, offensichtlich die These, die sich in der Diskussion der größten „Beliebtheit" erfreut hat: Schule und Enttraditionalisierung. Persönlich bin ich kein Antitraditionalist. Doch zwei Bemerkungen dazu: einmal muß die Schule die Enttraditionalisierung zur Kenntnis nehmen. Sie kann nicht so tun, als gäbe es sie nicht. Insofern glaube ich eine weitgehende Einigkeit festgestellt zu haben. Was ist in dieser Situation zu tun? Ich hoffte klar gesagt zu haben, daß die Schule den Gefahren, die aus dieser Situation dieser Enttraditionalisierung und Individualisierung entstehen, irgendwie wehren muß. Wenn sie dies wirksam tun will, dann kann sie es und darf sie es nicht tun, indem sie einfach versucht, das Rad zurückzudrehen. Das "darf“ ist in diesem Zusammenhang nicht normativ gemeint, es ist einfach eine Feststellung: Wenn die Schule ihre Aufgabe erfüllen will, dann darf sie nicht so tun, als gäbe es die beschriebenen Phänomene nicht. Sie darf nicht einfach versuchen, die gute alte Zeit wiederherzustellen. So habe ich das gemeint. Also nicht eine Erziehung zur Enttraditionalisierung, aber eine Erziehung, die befähigt in einer Gesellschaft, die nun einmal enttraditionalisiert ist, zu leben. Damit hängt auch der sinnvolle Lebensentwurf zusammen. Allenthalben sehen wir die Gefahr, daß kein Sinn in Lebensentwürfen mehr gefunden wird. Auch um Anleitung zur Sinnfindung ist es mir gegangen.

Das führt mich ganz zwanglos zu dem Problem der Erziehung „zur Ehrfurcht vor Gott“. Es gibt zwei Möglichkeiten, mit diesem Verfassungsziel umzugehen. Beide finden Sie in der Literatur. Versteht man es als einen streng christlichen Erziehungsansatz, dann ist dieses Erziehungsziel verfassungswidrig. Oder man kann das Erziehungsziel sozusagen säkularisieren, was in der Tat auch vorgeschlagen wird. Das wäre ein Grundgedanke, wie wir ihn etwa bei Camus in der "Pest" finden, wo im Grunde der Priester und der agnostische Arzt für ihren Dienst an den Kranken aus unterschiedlichen Quellen, aber letztendlich in gleicher Weise motiviert werden.

Noch ein Wort zu Begriffen. Wenn die Verfassung wirklich nur lauter klare Begriffe hätte, weiß ich nicht, wie sie aussehen würde. Wir jedenfalls könnten dann nach Hause gehen. Das gilt auch und gerade für den Friedensbegriff, es gilt auch für die Solidarität. Darf ich mir dazu eine Kommentierung zu Art. 26 GG vorbehalten, die zu schreiben ich versprochen habe. 
Ich komme zur Multikulturalität. Wo ist sie rechtlich festzumachen? Es gibt für sie keinen einheitlichen rechtlichen Angelpunkt, wir finden immer nur Teilaspekte. Ich habe den Versuch unternommen, diese Teilaspekte zusammenzufügen. Multikulturalität ist meiner Meinung nach mehr als Toleranz, es ist ein positiver Umgang mit einem gesellschaftlichen Faktum, mit einer Lebenswirklichkeit, die wir gerade in unseren Städten vorfinden. Mit ihr müssen wir umgehen, und das ist schwierig. Sicher können wir nicht für einen einzelnen Maori, der zufällig in einer kleineren Stadt lebt (so etwas soll es geben, die Geschichte spielt manchmal merkwürdig mit Lebensschicksalen), einen eigenen Sprachunterricht geben. Dafür fehlen schlicht und einfach die Mittel. Ich habe auch gesagt, daß das Eingehen auf unterschiedliche Überzeugungen, auf unterschiedliche Lebensweisen und auf unterschiedliche Traditionen seine Grenzen hat. Es gibt ein Spannungsfeld zwischen notwendiger Einordnung und Respekt vor andersartigen Traditionen. Mein Eindruck aus dem Stand der Diskussion, auch der öffentlichen Diskussion in unserem Lande, geht aber dahin, daß wir die Buntheit, die die Multikulturalität uns bietet, zu negativ beurteilen. Dagegen wollte ich einige Pfähle einschlagen. Wir dürfen das Spannungsverhältnis zwischen Fragmentierung und Integration, das besteht und das wir aushalten müssen, nicht einfach zugunsten der Integration lösen. Darum geht es mir. Das bringt mich auch zu Schulzwang und zur Privatschule. Auch die Privatschule kann ein Instrument der Fragmentierung sein. Unter grundrechtlichen Gesichtspunkten bietet sie die Chance, ein Anderssein auch in der Erziehung zu vermitteln. Wenn dies aber zu weit geht, habe ich auch große Sorge um die Gesellschaft. Auch hier also wieder ein Spannungsverhältnis. Den Vorschlag von Herrn Engel in bezug auf die Privatschule kann ich hier nicht in extenso diskutieren. $\mathrm{Ob}$ er sich kostenneutral verwirklichen läßt, bezweifele ich. Die Privatschule als eine Alternative nur für begüterte Eltern sollte man jedenfalls nicht wollen.

Ich bedauere, daß ich Zustimmung und Widerspruch zu vielem, was in der Diskussion gesagt wurde, nicht differenzierter ausbreiten kann. Vielen Dank!

Dittmann: Angesichts der mir vom Vorsitzenden aus Zeitgründen nahegelegten Selbstbeschränkung sehe ich mich legitimiert, im Wege des "Rosinenpickens" vorzugehen und nur einige Aspekte aufzugreifen, die in der Diskussion angesprochen worden sind. - Herr Huber, Sie haben mich zunächst auf das Stichwort "staatliches Schulmonopol “ in Leitsatz 5 angesprochen. Ein staatliches Schulmonopol existiert in der Tat nicht. Dazu gehört der Hinweis auf Art. 7 GG mit seiner Garantie der Privatschulfreiheit und der Verantwortung der Konfessionen für den Inhalt des 
Religionsunterrichts. Zudem ist auf Art. 6 GG zu verweisen, der das Elternrecht nicht auf den außerschulischen Bereich beschränkt, sondern in den schulischen Bereich hineinwirkt und insoweit das Bestimmungsrecht des Staates relativiert. Ich denke, da sind wir uns einig. Sie haben dann eine gewisse Inkonsequenz darin gesehen, zwar aus den Grundrechten Orientierungswerte für den schulischen Erziehungsauftrag zu entnehmen, nicht aber auch aus anderen Verfassungsentscheidungen. Ich sehe hierin keine "Systemwidrigkeit" und keinen Verstoß gegen den Gedanken von der Einheit der Verfassung, sondern halte den Rückgriff allein auf die Grundrechte deshalb für geboten, weil mir nur hier - und nicht bei anderen grundgesetzlichen Positionen - eine Erziehungsrelevanz gegeben zu sein scheint. Ich verweise in diesem Zusammenhang noch einmal auf meine Einwände gegen die von Herrn Häberle vorgeschlagene pädagogische Verfassungsinterpretation. - Herr Frowein, Sie haben auf den inneren Zusammenhang zwischen Erziehungsauftrag und Schulgliederung hingewiesen. Das unterstreiche ich voll und ganz. Ich sehe sogar eine verfassungsrechtliche Notwendigkeit, diesen Zusammenhang herzustellen, weil das verfassungsrechtlich gebotene Miterziehungsrecht und Mitbestimmungsrecht der Eltern bei der Definition von Erziehungszielen der Schule nicht individuell, sondern am ehesten über ein staatlich vorgehaltenes, gegliedertes und den Elternwünschen insoweit entsprechendes Schulangebot verwirklicht werden kann. - Die Fragen von Herrn Klein und von Herrn Selmer kann ich zum Teil gemeinsam beantworten. Mein Leitsatz 14 wäre gründlich mißverstanden, wenn Sie darin ein Plädoyer für die nacheilende Anpassung des schulischen Auftrages an einen gesellschaftlichen Trend sähen. Nichts läge mir ferner. Ich habe in meinem Referat ausdrücklich hervorgehoben, daß der Staat durchaus legitimiert ist, gegenzusteuern und auch gegen den Strom zu schwimmen. Mein Leitsatz 14 drückt lediglich die Prognose aus, daß die Schule allerdings nicht auf Dauer gegen den Strom schwimmen kann, wenn in bestimmten Fragen der Konsens aller Erziehungsträger verlorengegangen ist. Dann kann auch die Schule nicht Rettungsanker sein. Schließlich, Herr Selmer, zu Ihnen allein. Es hätte mich schon geschmerzt, wenn Sie bei mir eine Minimalisierung des Elternrechts herausgehört haben sollten, denn ich habe gleich zu Anfang meiner grundrechtlichen Überlegungen bewußt auf Art. 6 GG hingewiesen und ausgeführt, daß hier, beim Elternrecht, grundgesetzlich gewollt das Fundament der Erziehung liegt. Soweit Sie, Herr Selmer, in Ihrer Intervention zusätzlich auf die verbindliche Vorgabe des Art. 6 GG für die inhaltliche Ausrichtung des schulischen Eriehungsauftrags hinweisen, stimme ich Ihnen voll und ganz zu, einschließlich der Feststellung, daß diese Vorgabe nicht zur Disposition der einzelnen Länder steht und von deren Dis- 
positionsfreiheit im übrigen nicht relativiert werden darf. Ich denke also, Herr Selmer, daß zwischen uns beiden in dieser Frage kein Dissens besteht. - Gestatten Sie mir abschließend noch eine allgemeine Schlußbemerkung. Bekanntlich gilt: „Non scholae, sed vitae discimus“. Zum Leben in einem Verfassungsstaat aber gehört - und davon bin ich nun in der Tat zutiefst überzeugt -, nicht nur die individuelle Tüchtigkeit, sondern auch der Gemeinsinn, das heißt, die Fähigkeit und die Bereitschaft, sich mit den Grundwerten dieses Gemeinwesens zu identifizieren und sich für das Gemeinwohl zu engagieren. Hierzu kann und sollte auch die Schule ihren Beitrag leisten. Vielleicht sollte die Schule diesen Beitrag sogar um so stärker leisten, je mehr die anderen Erziehungsträger - wie vielfach vermutet - heute in ihrer Bedeutung zurücktreten oder diese Funktion nicht mehr odnungsgemäß wahrnehmen. Ernst Rudolf Huber hat einmal zugespitzt formuliert, daß die Wirkungsmacht von Polizeirevieren und Finanzamt, verglichen mit der Wirkungsmacht der Schule, geradezu verblassen. Von daher mag es durchaus verständlich sein, wenn einem Erziehungsauftrag des Staates und damit einer gewissen Fremdbestimmung des Individuums vielfach mit Skepsis begegnet wird, so auch zum Teil in unserer heutigen Aussprache. Ich denke aber, daß gerade der grundgesetzlich geprägte freiheitliche Verfassungsstaat hinreichende Sicherungen grundrechtlicher, institutioneller und kompetenzieller Art bereithält, möglichen Gefahren, die aus dieser Fremdbestimmung resultieren könnten, effektiv zu begegnen. Die Schule ist heute eben keineswegs mehr eine „Insel des Absolutismus“ - wie es Gerhard Anschütz einmal formulierte - sondern, wie ich meine, Teil des staatsrechtlich kultivierten Festlandes.

Vorsitzender: Ich danke Ihnen, Herr Bothe und Herr Dittmann, für ihre Schlußworte. Meine Damen und Herren, ich darf noch einmal den Referenten und Landesberichtern sehr herzlich danken für das, was Sie heute uns dargeboten haben. Ich darf Ihnen schließlich für Ihr Interesse und die engagierten Diskussionsbeiträge danken, vor allem aber für Ihre Geduld mit den etwas hilflosen Bemühungen, Ihre Wortmeldungen zu ordnen und in der gebotenen Rücksicht auf den jeweiligen Sachzusammenhang aufzurufen. Wenn Sie also den Eindruck haben, daß Sie nicht rechtzeitig, zu früh, zu spät oder nur zu kurz zu Wort gekommen sind, halten Sie das meinem mangelnden Einfühlungsvermögen zugute. „Nobody is perfect" - Eine Einsicht, die vielleicht auch in der Erziehung etwas stärker in den Vordergrund gestellt werden könnte. Vielen Dank. 